HISTORY ? REFLCTIONS OF ENGNEERNG at Lawrence Livermore National Laboratory "The Flywheel of the Laboratory"
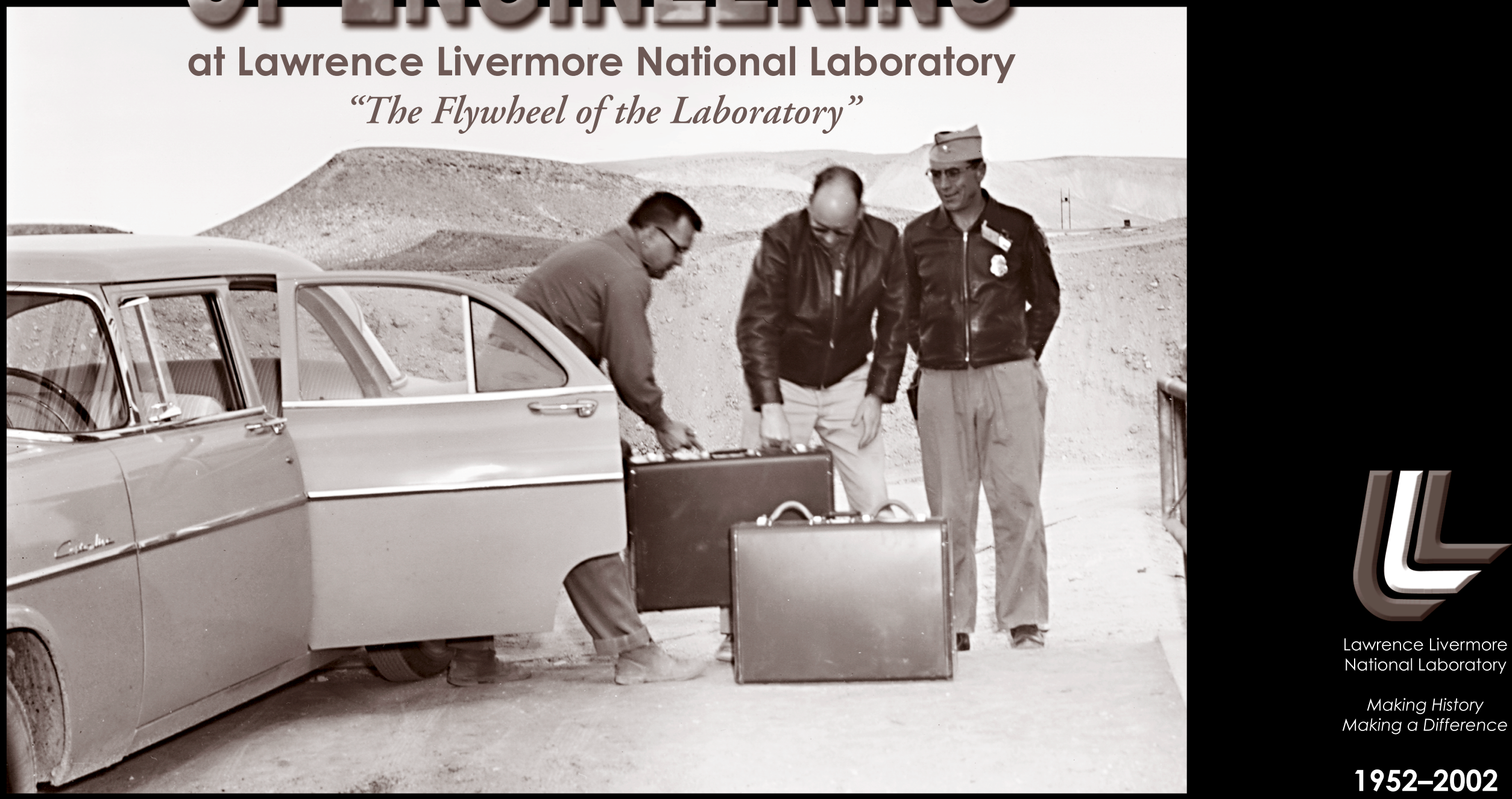

Lawrence Livermore National Laboratory

Making History Making a Difference 


\section{On the Cover:}

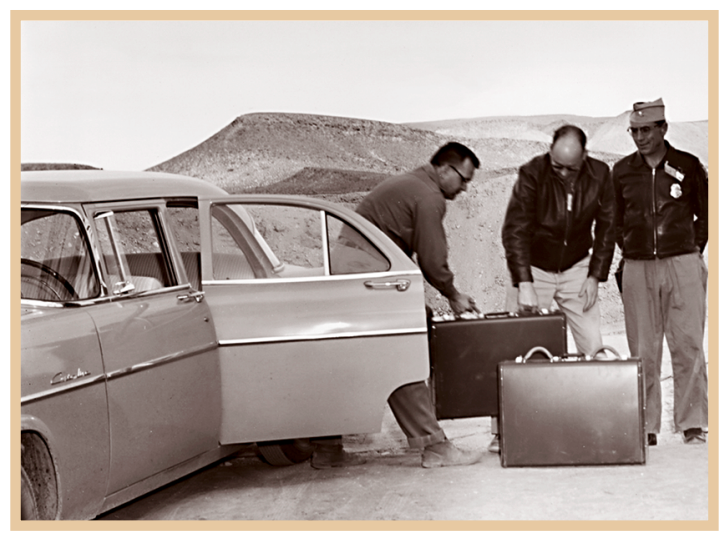

Walt Arnold, Art Werner, and an unidentified guard delivering a small device at Nevada Test Site.

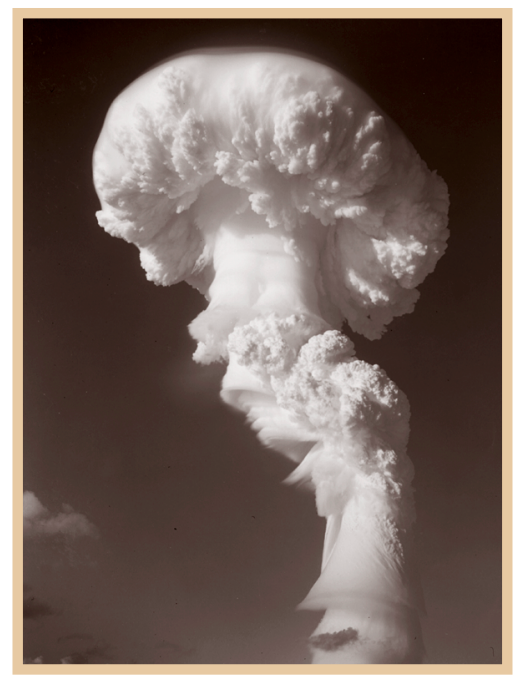

Operation Dominic, Christmas Island, 1962.

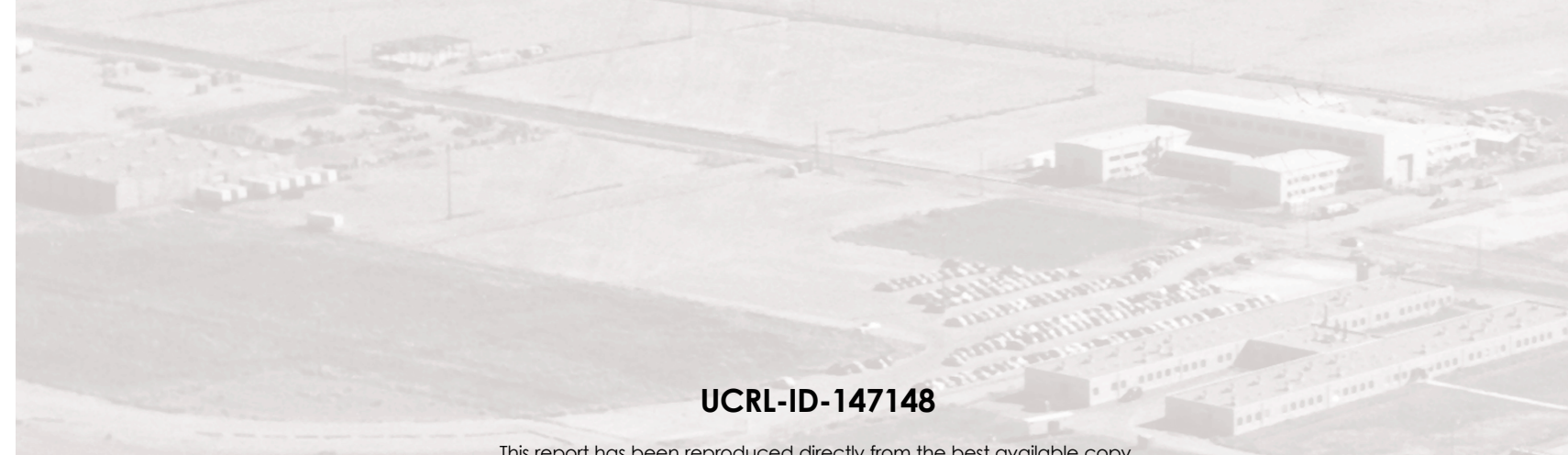

This report has been reproduced directly from the best available copy.

Available to DOE and DOE contractors from the Office of Scientific and Technical Information

P.O. Box 62, Oak Ridge, TN 37831

Prices available from (423) 576-840

http://apollo.osti.gov/bridge/

Available to the public from the

National Technical Information Senice

U.S. Department of Commerce

5285 Port Royal Rd.

Springfield, VA 22161

http://www.ntis.gov/

OR

Lawrence Livermore National Laboraton

Technical Information Department's Digital Library

http://www.Ilnl.gov/tid/Library.html

This document was prepared as an account of work sponsored by an agency of the United States Government. Neither the United States Government nor the University of California nor any of their employees makes any warranty, express or implied, or assumes any legal liability or responsibility for the accuracy, completeness, or usefulness of any information, apparatus, product, or process disclosed, or represents that its use would not infringe privately owned rights. Reference herein to any specific commercial product, process, or service by trade name, trademark, manufacturer, or otherwise, does not necessarily constitute or imply its endorsement, recommendation, or favoring by the United States Government or the University of California. The views and opinions of authors or imply its endorsement, recommendation, or favoring by the United States Government or the University of California. The views and opinions of authors
expressed herein do not necessarily state or reflect those of the United States Government or the University of California, and shall not be used for advertising or product endorsement purposes

This work was performed under the auspices of the U.S. Department of Energy by the University of California Lawrence Livermore National Laboratory under Contract W-7405-Eng-48. 

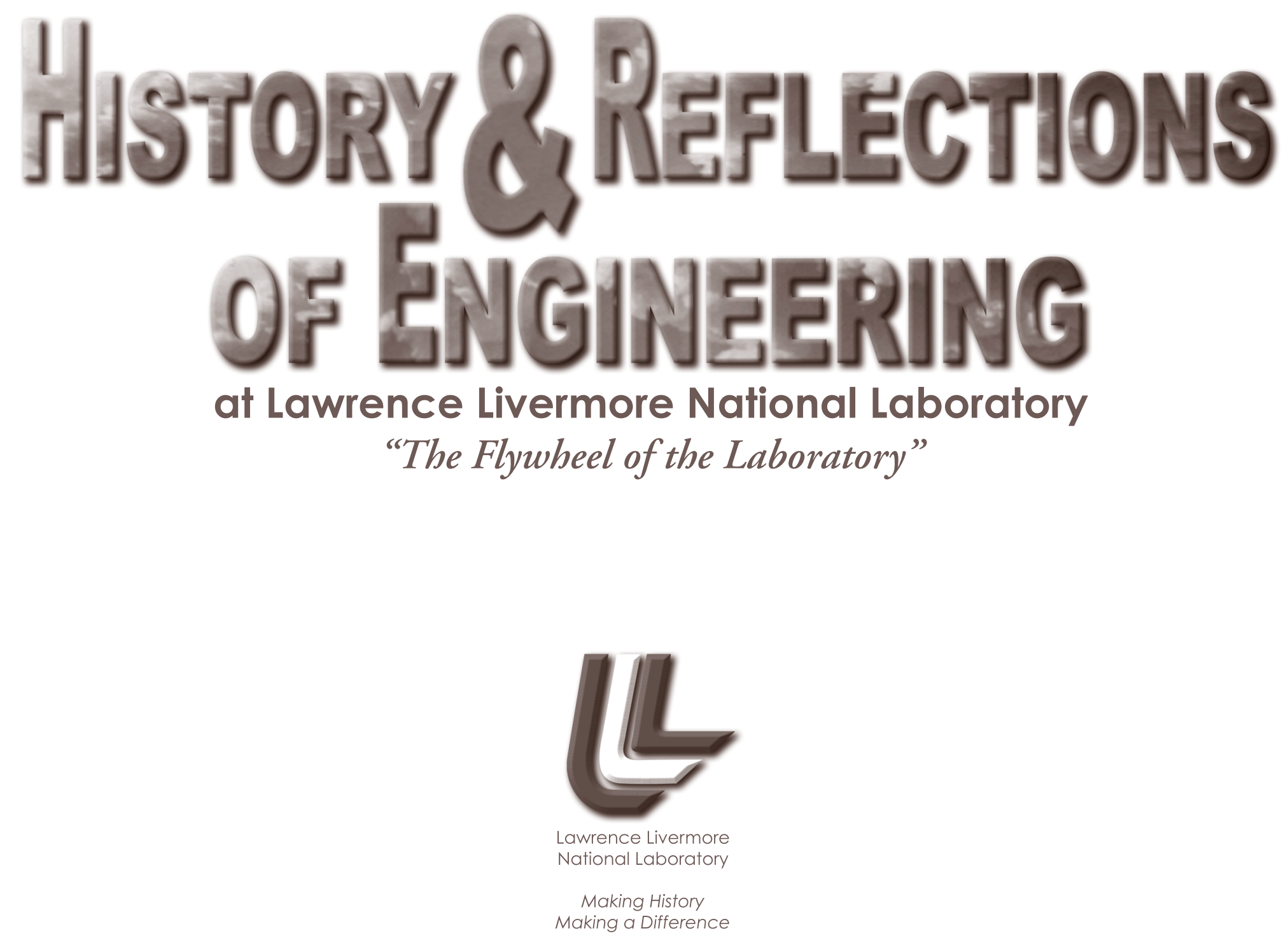

1952-2002 
The views and opinions of authors expressed herein do not necessarily state or reflect those of the United States Government or the University of California. 


\section{Contents}

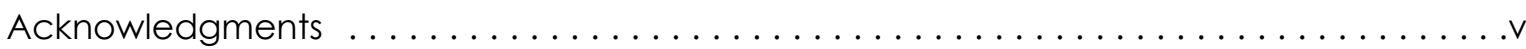

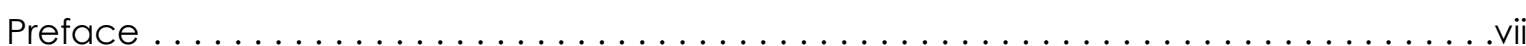

History of Engineering at Lawrence Livermore National Laboratory (Ed Lafranchi) . . . . . . . .

Engineering from 1989 to 1995 (Roger W. Werne) . . . . . . . . . . . . . . . . . . . . . . .44

Engineering in the Test Program (Gordon Longerbeam and Jim Page) . . . . . . . . . . . . . . .50

The Biomedical Program (Paul Phelps) . . . . . . . . . . . . . . . . . . . . . .72

Engineering Technology Base (Ed Lafranchi) . . . . . . . . . . . . . . . . . . . . . .80

The Engineering Research Division (L. Lynn Cleland) _ . . . . . . . . . . . . . . . . . . . . .82

From Engineering Research Division to the Microtechnology Center (Dino R. Ciarlo) . . . . .94

The Solid State Devices Group (Steve Swierkowski) . . . . . . . . . . . . . . . . . . . . .98

Electromagnetics in the Engineering Directorate (Andrew J. Poggio) . . . . . . . . . . . . . 104

The Microwave and Pulse Power Thrust Area (W. Wayne Hofer) . . . . . . . . . . . . .116

Earthquake Engineering (David B. McCallen) . . . . . . . . . . . . . . . . . . . . . . . . . 122

The Methods Development Group (Art Shapiro) . . . . . . . . . . . . . . . . . . . . . . . .124

Nondestructive Evaluation (Harry E. Martz, Jr.) . . . . . . . . . . . . . . . . . . . . . . . . . 130

Precision Engineering (Irving F. Stowers) $\ldots \ldots \ldots \ldots \ldots \ldots \ldots \ldots \ldots \ldots$

Engineering Contributions to Magnetic Fusion Energy Research (Carl Henning) . . . . . . .138 



\section{Acknowledgments}

1 any people have made contributions to this History. Some Mhave written entire sections; others have given me suggestions, offered interviews, and helped put it together.

In particular, I want to thank Jim Bell who gave me most of the early ME Weapons Program input; Chuck Hurley for his input on the early CTR Program and the ME Laser Program; Hank McDonald for his help in getting this started in the right direction, his input on the Pluto Program, and his review of the draft document; Al Hyne and Frank Inami for their contributions on the early EE weapons activities; Gordon Longerbeam and Jim Page for their work on the Nuclear Test Program sections; Dennis Fisher and Roger Werne for discussions of their years as ADs; Beverly Bull of the LLNL Archives who helped me find old material; Camille Minichino for editing and making suggestions that improved the document; and Lucy Dobson, TID, who designed this document and shepherded it through the publication process. 



\section{Preface}

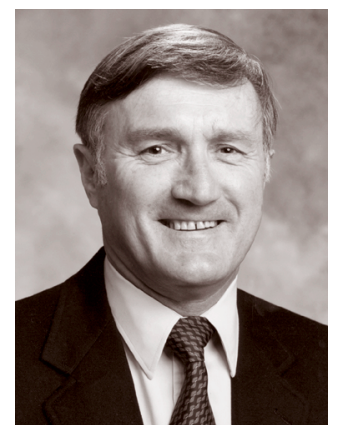

thought it was important to relate how this project began. Jens Mahler, Mechanical

Engineering Deputy Associate Director, recalls that during a discussion between him and Wally Decker, Wally suggested that he document the significant events and the organization of the Mechanical Engineering

Department since 1952, i.e., write a history of Mechanical Engineering. Jens agreed that Wally should begin this effort. Upon learning of this, Dave Pehrson, Deputy Associate Director for Engineering, suggested that the History be expanded to include Electronics Engineering and that it be called A History of Engineering. Dave asked me to join Wally on this effort and, unfortunately, Wally died shortly after I started.

In the first part of this History, I have attempted to capture the important contributions that Engineering has made to the Programs, since Engineering's primary mission is to provide "support to the Laboratory Programs."

In the later parts you will find views discussing the development and application of Engineering's technology base. While Engineering's direct programmatic support had first priority, Engineering had other responsibilities as well. Some of these were to hire and train a competent technical and leadership staff, to anticipate and develop engineering technologies for future use by the Programs, to provide support to institutional activities, to be the vehicle for internal technology transfer, to provide for the movement of personnel between Programs, to groom individuals to assume programmatic and institutional leadership positions, and to develop, operate, and maintain facilities.

Engineering developed the reputation as "the flywheel of the Laboratory." It was also known as willing to provide people for tasks broader than just primarily technical roles, such as membership on salary review committees, and members and chairs of the student policy committees and safety groups.

This History is not a compilation of facts only but a reflection by many individuals of what they viewed as important contributions during their careers at the Laboratory.

I thank them all for taking the time to write their inputs to this document.

Finally, I want to acknowledge all the former and current members of Engineering: engineers, associates, coordinators, drafters and designers, technicians, administrators and clerical, who in their own way made Engineering what it is. For after all is said and done, Engineering's primary assets were and are its people.

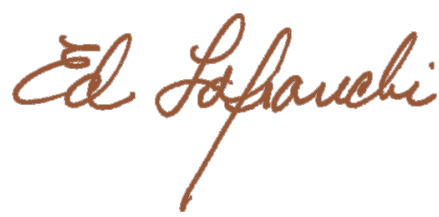




\section{History of Engineering}

at Lawrence Livermore National Laboratory

by Ed Lafranchi

\section{aris}

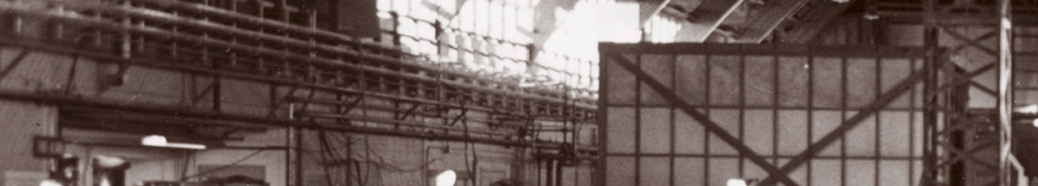
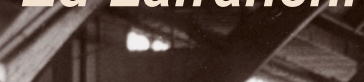
ex $\left.\sin ^{2}\right)\left(\cos \frac{2}{2}\right.$

I)

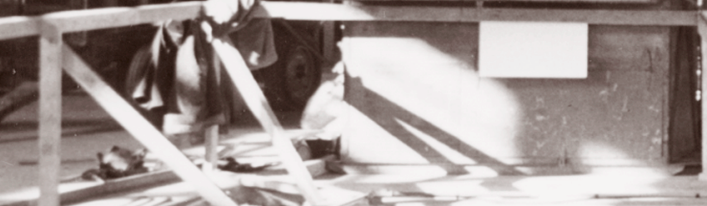

r.

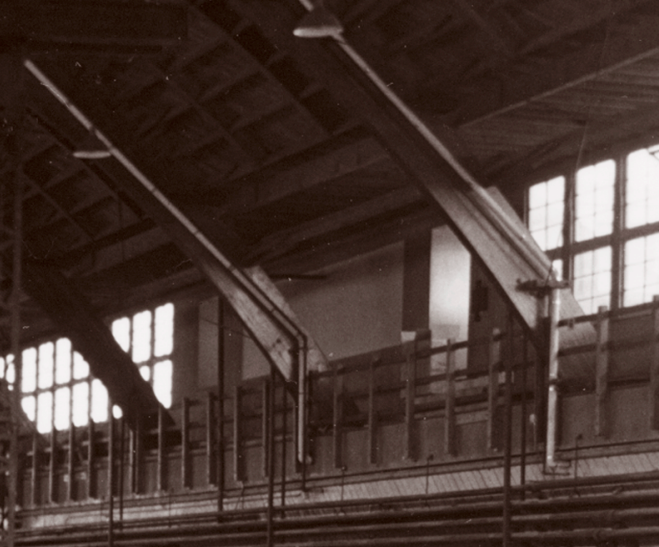

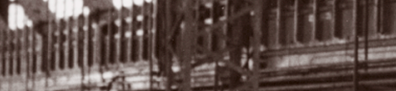

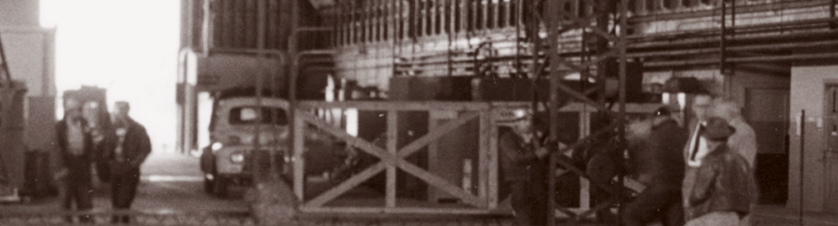

所展

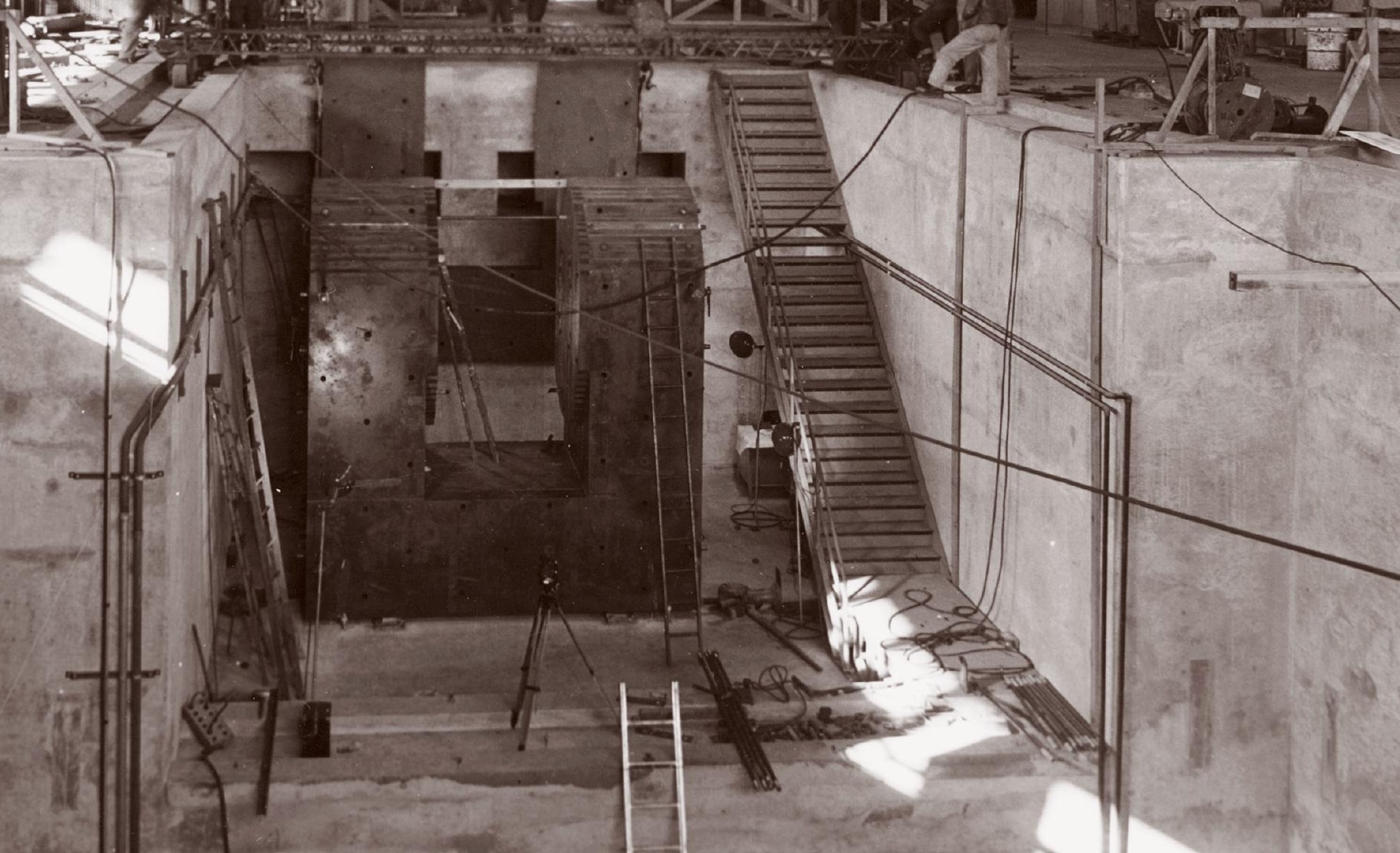




\section{The Early Laboratory and the} Berkeley Influence

The history of Engineering at Lawrence Livermore National Laboratory (LLNL) begins with the events that preceded and instigated the founding of the Laboratory.

Immediately after the entry of the United States into World War II, E. O. Lawrence accelerated the Engineering work on the development of the Berkeley-based 184-in. cyclotron, converting it to a mass spectrograph for an electromagnetic separation process for the production of uranium. Many Electronics and Mechanical Engineering personnel went to Oak Ridge, Tennessee, during World War II, to work on the production machines based on the 184-in. technology.

After the successful detonation of the Trinity event in July 1945 and the successful drops of the LANL-developed Hiroshima and Nagasaki atom bombs, on August 6 and 9 respectively, there was a long period of retrenchment of nuclear weapons research, development, and testing.

Although the effort did not go to zero, and much of the production complex remained open, there didn't seem to be a strong national interest in continuing this work. The University of California Radiation Laboratory (UCRL) had returned to developing machines for High
Energy Physics Research. Lawrence's 184-in. cyclotron was changed from a mass spectrograph to an accelerator, work was progressing on the design of the Bevatron and a 32MeV Linac was in development. However, Drs. Lawrence and Edward Teller were still advocating increased funding for weapons work. This took on a more significant role in August 1949, when the Russians detonated their first atomic device-a surprise, since many did not expect the Russians to have this capability until the mid 50 s.

After the Russian detonation there was a renewed emphasis in weapons work. Lawrence and Teller pushed for the US to begin the development of the "super" (a hydrogen bomb). Meanwhile UCRL began development of an accelerator designed by Dr. Luis Alvarez-the Materials Testing Accelerator (MTA), a prototype for a much larger machine (1.5 to $2 \mathrm{mi}$ ) to be used for the production of special nuclear material for the Weapons Program.

The prototype MTA was to be built at an abandoned Naval Air Field in Livermore, California; the prime contractor was California Research and Development

Corporation (CR\&D), a subsidiary of Standard Oil of California. CR\&D provided the functions of Architecture/Engineering and

Construction/Operation while UCRL retained

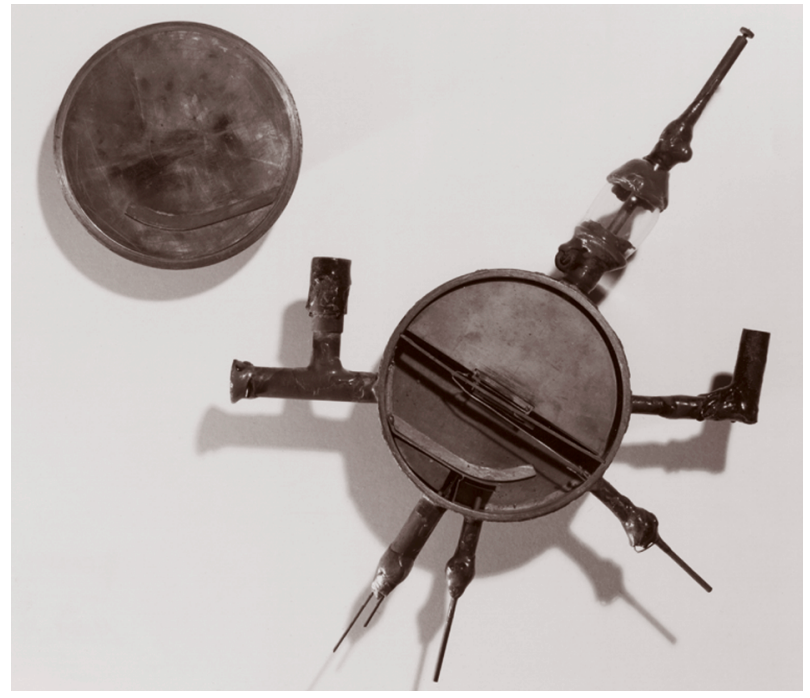

E. O. Lawrence's early cyclotron.

Left: View looking west over entire pit during yoke assembly of 90 in. cyclotron in Building 153. 
technical responsibility for the design. In 1950 Lawrence asked Duane Sewell to be liaison between CR\&D and UCRL. Sewell and James Kilpatrick, the first Electronics Engineering Department Head at Livermore, spent considerable time with CR\&D working on the MTA.

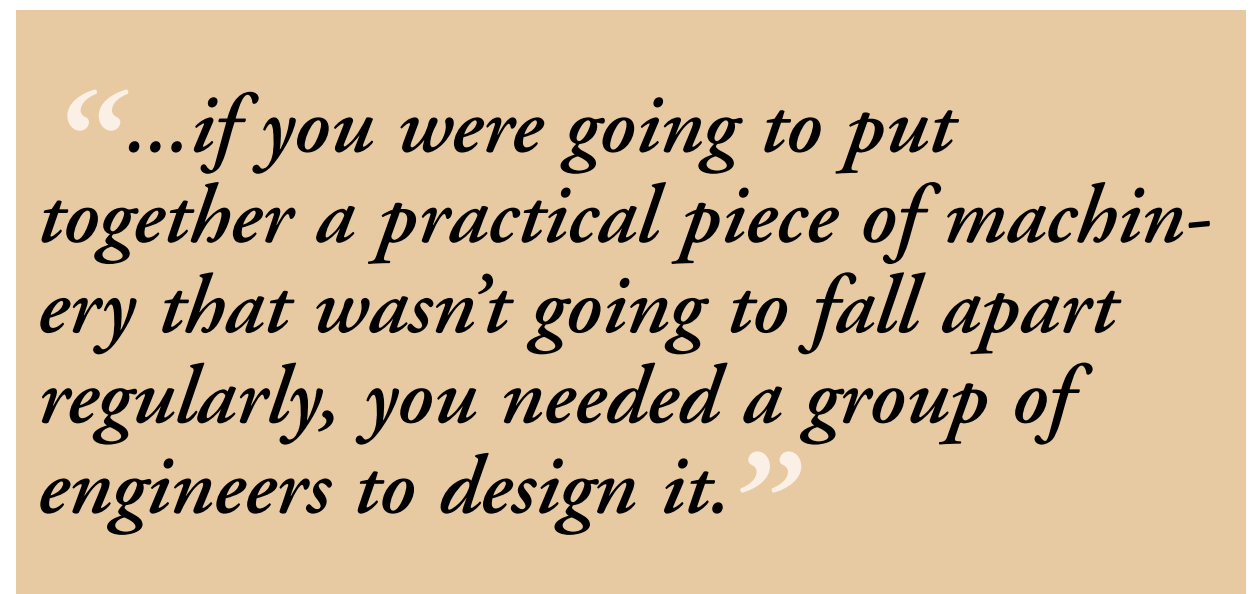

In the spring of 1952 , Bob Thornton, who was Lawrence's right-hand man at Berkeley, invited Sewell to be part of a new Laboratory, to be formed at Livermore for carrying out nuclear weapons measurements. At that time there was no discussion of weapons design work. After much thought and many family conferences, Sewell agreed.

\section{The Engineering Pioneers}

July 1, 1952 is the date the Livermore Laboratory officially came into being, but the opening move was not to take place until September 2, 1952. From July 1 until September 2, Herb York, who had been selected as the scientific leader, and Sewell, who was the engineering-technician-operations leader, put together the initial group of people that came to Livermore.

At the outset, Livermore was clearly a part of the Berkeley Laboratory. Even though York and Sewell had scientific and operational responsibilities in Livermore, and others had positions of responsibility, nearly everyone's senior manager was in Berkeley. This was more true on the engineering and support side than on the science side. At Berkeley, Thornton was in charge of Physics, William Brobeck was in charge of Mechanical Engineering, and James Norton was in charge of Electronics Engineering. The Livermore engineering people reported to Brobeck and Norton.

Early on there were discussions of how the Livermore operation should be structured. The scientists wanted the engineers assigned to them so the scientists would have direct control. The engineers believed that they should be more isolated, and be able to make more decisions on their own. Lawrence felt very strongly that the scientists should go through the creative process of coming up with new ideas, but that if you were going to put together a practical piece of machinery that wasn't going to fall apart regularly, you needed a group of engineers to design it. 
So, Lawrence ran a matrix operation in Berkeley. Livermore depended heavily on Berkeley for all administrative functions and, as a result, Livermore inherited another important concept from Berkeley: the matrix.

"This was a way of structuring and organizing an R\&D institution to better reach its technological goals," said Herb York, the first Director.

John Foster explained it this way: "The thing that impressed me about the Laboratory in the early days was the focus on national needs and technical opportunities rather than on administration. The idea that allows this approach to work is 'the matrix,' because it permits functional experts in chemistry, physics, etc., to gain an understanding of our missions and then to develop new technologies on their own."

Even though Brobeck and Norton were in charge of the Livermore engineering groups, there was always some autonomy for both Livermore groups. Brobeck was somewhat less hands-on than Norton. Both were directly involved in the hiring and selection of people who came to Livermore, but as time went on Norton stayed more involved in the hiring and selection than Brobeck. Brobeck and Norton remained directly and frequently involved with the Engineering Departments at Livermore until the early 1960s. Norton continued his involvement longer than Brobeck, but primarily with the development and acquisition of computer technology.

In the beginning, the mechanical engineering function comprised three distinct organizations: a Mechanical Engineering Design Group, headed by Jim Bell, who reported to Brobeck; a Mechanical Equipment Group, headed by Ken Copenhagen, who reported to Bill Twitchell, who reported to Wally Reynolds, the UCRL Business Manager; and a Machine Shop. The flow chart on the right shows the initial staffing of Mechanical Engineering.

In contrast to $M E$, the Electronics Department, as it was first titled, came as a single entity, organized along functional lines: design and development engineering; coordination; drafting; fabrication; installation; maintenance; and several specialty groups (computers, counting, special projects). James C. (Jim) Kilpatrick was the Department Head. Staff were added, as shown on page 4.

By December, Mechanical Design had grown to 21, Mechanical Equipment to 19, Machine Shop to 4, and Electronics to 34 people. The entire Laboratory grew from 75 in September to 144 during October and to 259

Mechanical Engineering

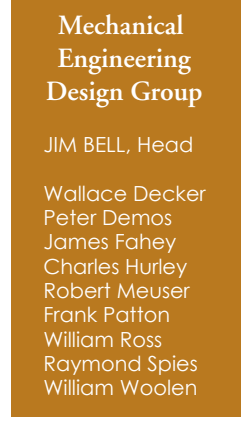

added later

October 1952:

Charles Henry

Albert Hughes

Robert Rogers

November 1952:

Edmund Burger
Alejo Guteirrez

Ethan Plat

John Turner
John Williams

Nondestructive

Testing Team:

Jack Hum

Dick Nickerso

Ellen Placas

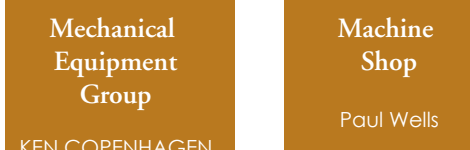

KEN COPENHAGEN

(from October 1952

Thomas McClellan

added later

October 1952:

Joseph Goglio

Richard Werner

November 1952:

Howard Appleton

Roward Appleton

William Cooper

John Currey

Daniel Murphy

Robert O'Donne

Ralph Richhold

Herman Smith

Stanley Swanso

Stan Warner added later Clyde Alexander John Kohot Ronald Laurenzo 
Electronics Department

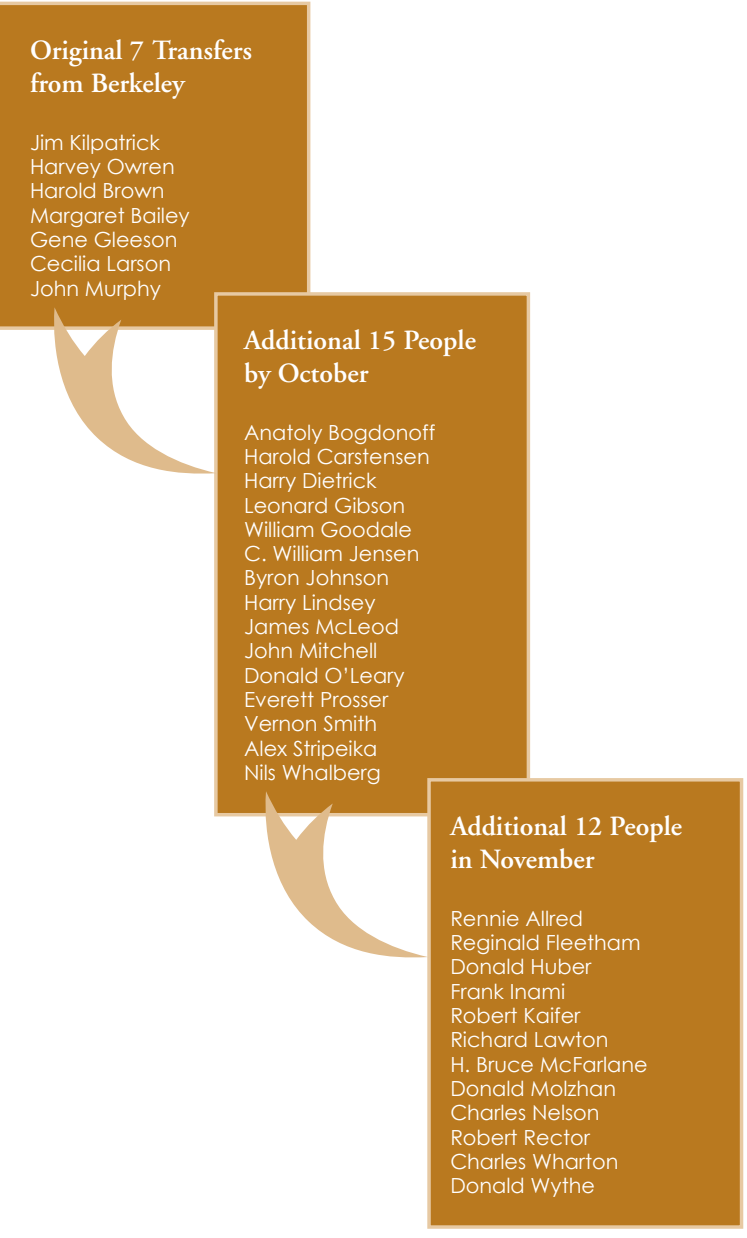

in November. By the following July the Laboratory had grown to 700 employees. Electronics was now 93; Mechanical Design had become 35; Mechanical Equipment had grown to 73, of which 40 were Accelerator Technicians; and the Machine Shop was at 17 people. The Engineering groups totaled $31 \%$ of the Laboratory work force, which was about the same percentage since the opening in September.

February 1954 documents list the responsibilities of the Engineering Departments. These responsibilities are copied below.

\section{Electronics Engineering}

- Work with physicists, chemists, mechanical engineers, etc., to determine feasibility of providing probable electronic items, which may be required to execute programs

- Design, construct, install, and maintain electronic items for approved programs

- Coordinate electronics items of other related departments to ensure accomplishment of overall functions

- Computing machine maintenance

- Provide power coordination services for all research projects
- Install and maintain all electronics equipment throughout the Laboratory

- Supervise technical aspects of electronic subcontracts

\section{Mechanical Engineering Design}

- Work with physicists, chemists, electrical engineers, etc., to preliminarily express and translate their ideas and requirements into proposed mechanical items

- Through continued coordination, translate preliminary designs into proposed mechanical items to be produced

- Upon program approval, detail general designs into production specifications

- Maintain current up-to-date drawings and incorporate all changes as they occur

- Supervise usage or installation of mechanical items produced above

- Continue general mechanical supervision over items produced during actual usage and subsequent modification

- Maintain permanent records of tracings of all mechanical drawings produced

- Employ specialists in mechanical engineering fields as required

- Operate the print room 


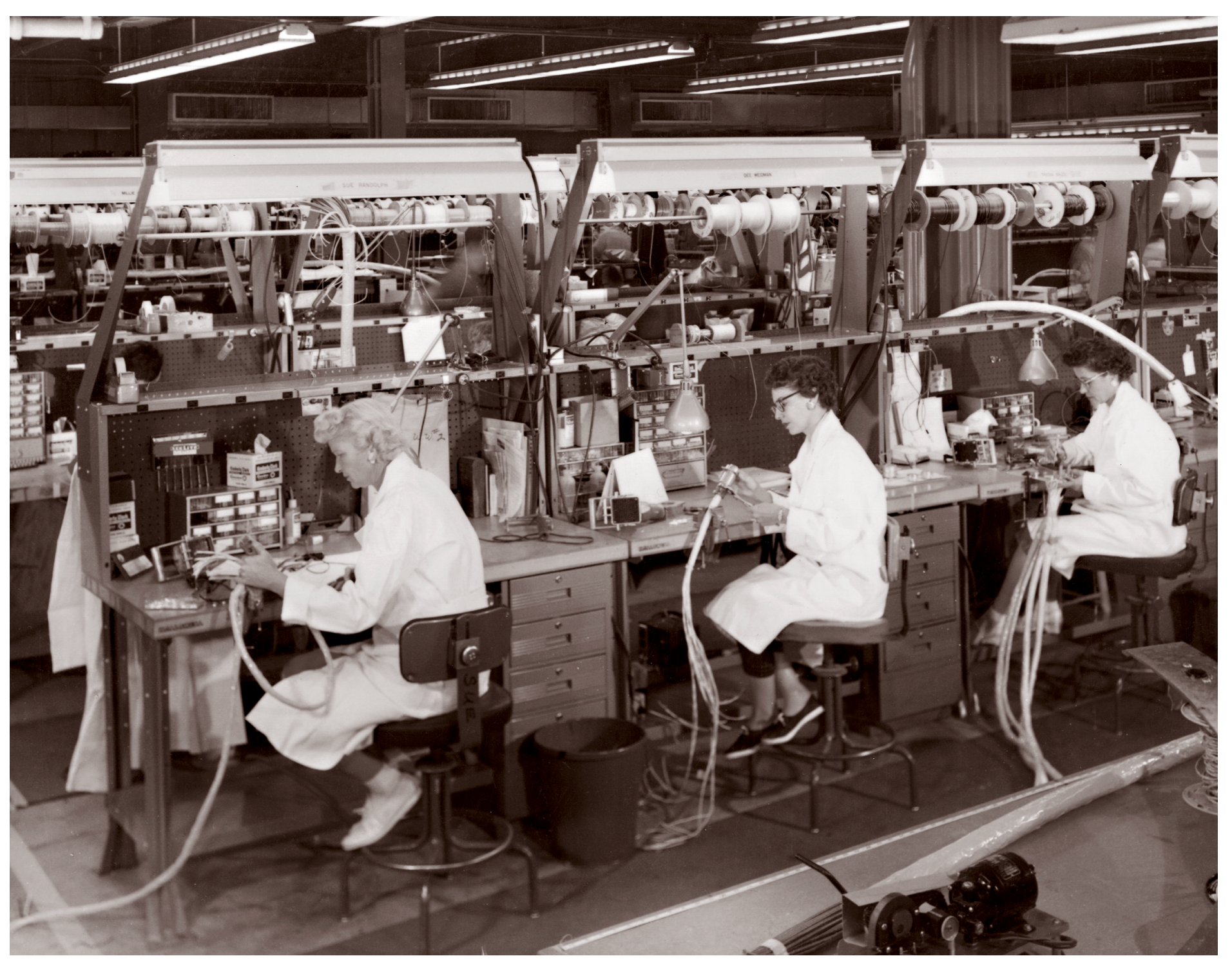

This all-women Cable Shop (part of

the Fabrication Shop) was housed in Building 131, circa 1960. 


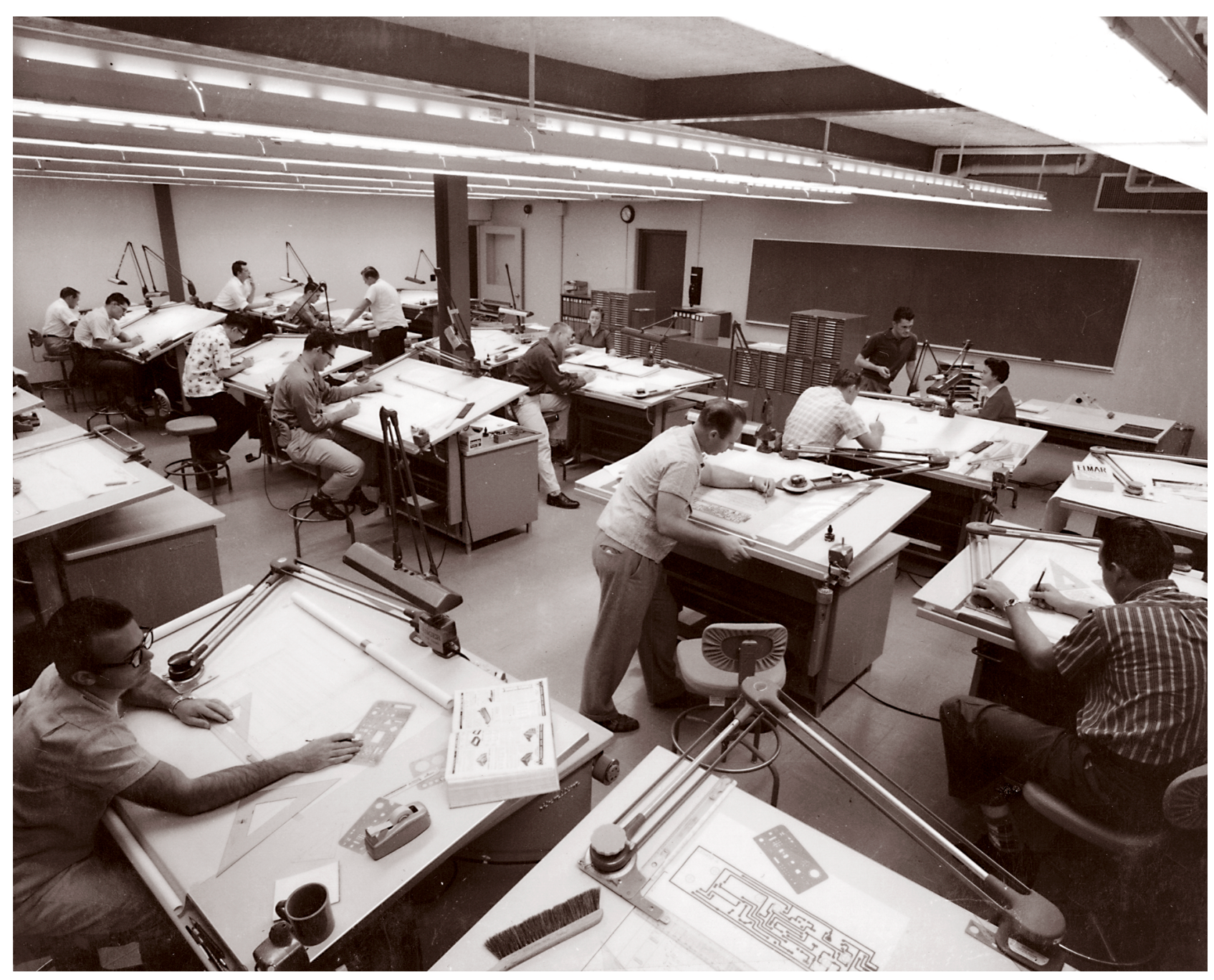

Electronics Engineering Drafting Room, circa 1960.
Mechanical Equipment

- Work with design engineers in design development

- Supervise development of design engineering job orders from drafting to completion:

a) procurement (through purchasing or special procurement)

b) fabrication

c) inspection

d) handling

e) assembly

- Provide services of accelerator technicians

- Write mechanical job orders

Accelerator Technicians

- Perform special jobs, which are not adaptable to shops or shop personnel. This includes jobs that require the services of several shops or jobs requiring a great deal of mechanical ingenuity, resourcefulness and overall mechanical or crafts knowledge.

- Perform vacuum work

- Provide similar services at test sites

Machine Shops

- Provide services of the following shops for research projects:

a) machining
1) light
2) heavy 
b) glass blowing

c) welding

- Provide basic assembly services on machined items

- Provide tool and die services

- Arrange when requested through Berkeley or CR\&D the following services:

a) sandblasting

b) painting (metal)

c) plating

\section{The Mechanical Engineering}

\section{Department}

It wasn't long after the two ME groups (Design and Equipment) reached a moderate size that they began to compete, due to encroachment onto each other's turf. The ME Equipment Group was considered a

field/construction engineering group and not a design group. However, The ME Equipment Group had a large number of mechanical engineers, and it was inevitable that they would begin doing design work. Also, the engineers in ME Design wanted to follow their designs into fabrication rather than have the ME Equipment engineers do this for them.

Consequently, these groups were merged on April 3, 1956, and became the Mechanical Engineering Department. The new ME organization is shown at right.
After the retirement of Bill Pierson on December 1, 1959, Jim Bell was appointed ME Department Head and Wally Decker Assistant Department Head. On August 1, 1962, Jim Bell was appointed Manager of Engineering, reporting to Duane Sewell. Wally Decker became ME Department Head and Walt Arnold became Assistant Department Head. On September 14, 1971, Wally officially transferred to the Director's Office as Assistant for Manpower Management reporting to the Deputy Director, Duane Sewell, after having spent the previous year with Chester Van Etta and Ted Wilson conducting a national study on employee practices in the R\&D community. Walt Arnold was appointed ME Department Head. Walt became Assistant Associate Director for Engineering in June 13, 1980, and on July 30, 1980 Bill Simecka became ME Department Head.

The Weapons Engineering Division (WED) was different from the other ME Divisions. The WED Head, Marvin Martin, was concurrently the Leader of the Weapons Engineering Program whose responsibility was to engineer and certify nuclear devices for the stockpile. So, programmatically he reported to the Laboratory Director just as did the heads of A and B Divisions. But organizationally he reported to the Head of the ME Department.
Mechanical Engineering Department Head William Pierson

> Apparatus Engineering Division Blake Meyers, Division Head William Watson, Assistant Division Head

Responsible for all mechanical engineering concerned with accelerators, reactors, and general laboratory apparatus, including diagnostics. No development work on weapons or for the Rover project will be done in this division.

$>$ Device Engineering Division Jim Bell, Division Head

Wally Decker, Assistant Division Head

Provide all mechanical engineering in connection with experimental weapons devices, with the exception of diagnostics equipment as noted above.

$>$ Rover Engineering Division Robert Meuser, Division Head

Provide all mechanical engineering required directly for Rover, with the exception of diagnostics equipment as noted above.

$>$ Weapons Engineering Division Marvin Martin, Division Head

Carry out all of UCRL's engineering responsibilities in connection with the development of production weapons.

$>$ Support Engineering Division Kenneth Copenhagen, Division Head William Humphrey, Assistant Division Head

Furnish and coordinate all general engineering support required by the other divisions. 


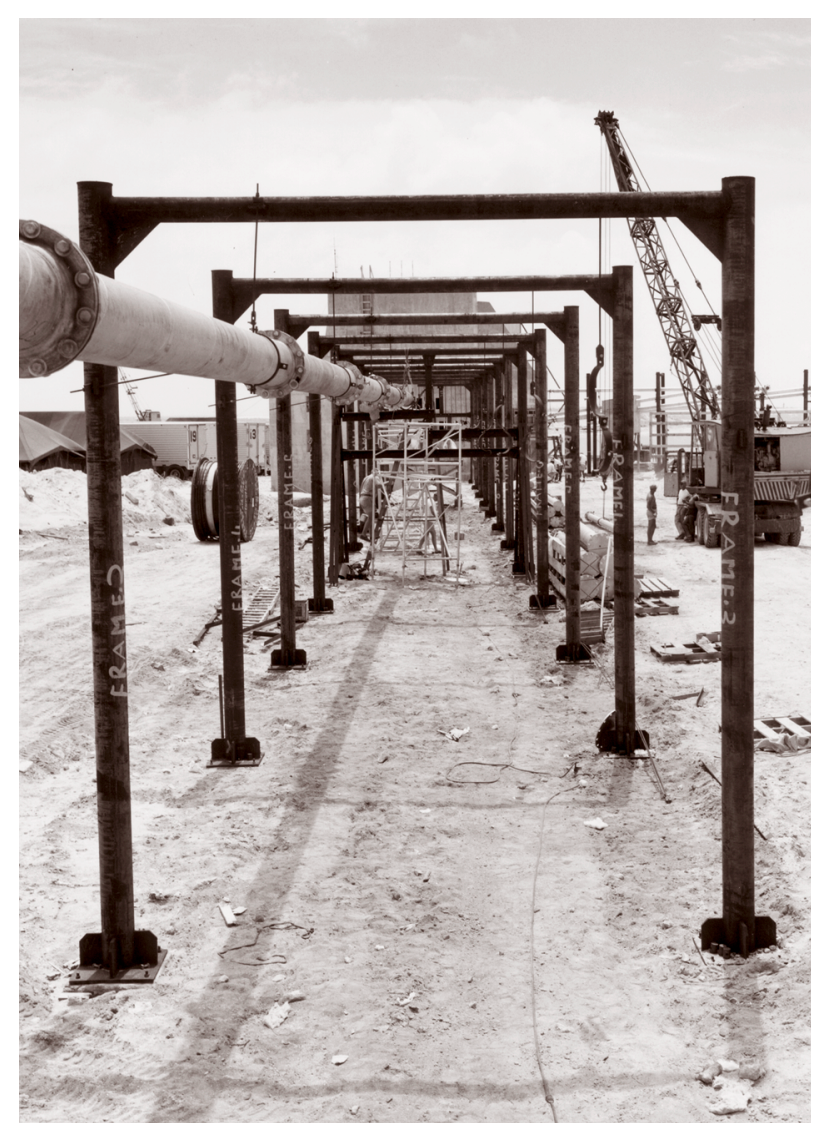

Line-of-sight pipes at Pacific Proving Grounds.
Marvin didn't like this arrangement, but York and Sewell insisted on it because WED was composed mostly of mechanical engineers, and it would need to draw on the resources of ME more than on the resources of the scientific divisions. Marvin wanted to be both Department Head and Weapons Engineering Leader, but Sewell and York believed that was not only too big a job, but also a conflict of interest. Prior to the formation of ME/WED in 1956, Marvin Martin was asked by Lawrence to set up a linear accelerator at the Nevada Test Site (NTS) to be used as a diagnostic tool. Shortly after this Marvin was asked to form a Weapons Engineering Group at Livermore. It was to initially be called "D" Division and was to have the responsibility for hydrodynamic testing at Site 300. However, Johnny Foster wanted control over this testing, so the hydro testing was moved to "B" Division and "D" did not come into being.

Also about this time the Laboratory was preparing to engineer its first weapon for the nation's stockpile. Sandia Laboratory had established a small group at Livermore to assist with their part of this development. But, many problems occurred between LLNL and Sandia-Livermore. Dissimilarities in design, philosophical differences, unresolved interface definitions, and administrative details led to the formation of the Livermore Projects
Committee (LPC), which exists today. The first representatives to LPC from LLNL were Carl Haussmann and Marvin Martin.

Wally Decker claims in his notes that he knew in August 1952 that this was going to be a Weapons Design Laboratory and not just a measurements lab because Jim Bell had assigned him to begin the design of a nuclear device. He also claims that shortly after the September move, Herb York assigned Art Biehl to be the device physicist and Decker to be the device engineer when the design work started.

This view is contradicted by Jim Bell who claims that the first ME work was diagnostic equipment development for Los Alamos, similar to the work that had been done in Berkeley for Operation Greenhouse in 1951. Bell recalls that the original ME assignment was to design the line-of-sight pipes and their associated supports for neutron time-of-flight measurements for the Castle Operation.

Perhaps the most definitive description of the Livermore Site assignment is from a reprint (source unknown) of an interview by Jim Carothers. In that interview he enumerates the original four activities on the York plan:

1) the design of thermonuclear devices 
2) diagnostic measurements on weapons experiments both for Los Alamos and for devices developed at Livermore

3) work on controlled thermonuclear reactions for potential power sources

4) basic physics research.

Carothers further states that Livermore detonated its first nuclear device at the NTS in the spring of 1953, some six months after the opening of the Livermore Laboratory. This Carothers document clearly settles the question of the initial activities assigned to Livermore. Carothers' view is corroborated by Herb York in his comments in the 30th anniversary booklet Thirty Years of Technical Excellence.

From the very beginning of the Livermore operation, ME was more directly involved with the scientific staff in the development of nuclear devices due to the basic mechanical nature of these devices. This relationship formed a very strong bond and interdependence between the Weapons Program and ME, and put ME on the "inside" of the program. ME not only provided engineering and design talent to weapons but after several years began to provide budgeting and logistical planning people as well. These latter activities placed ME in a position to have a strong influence on the allo- cation of resources, especially people, capital equipment and facilities.

All of this caused EE to believe they were a minor player in the Weapons Program and led to a feeling of frustration and resentment. EE believed that since they did not participate in the planning meetings and had no counterpart to the ME resource managers, their needs were not adequately represented and consequently ME always got whatever they wanted, with EE having to make do with what was left over.

$\mathrm{EE}$, on the other hand, was a key player in weapons diagnostics. EE's job was to provide the detectors and recording systems for collecting shot data. This required close coordination among $\mathrm{EE}, \mathrm{ME}$, and the Weapons Test Program, with the program providing the data requirements and some detector R\&D; ME providing detector housing and alignment; and EE providing detector fabrication, recording electronics, timing systems and overall general shot control systems. However, weapons diagnostics did not provide the same relationship between EE and the Weapons Test Program that existed in the weapons design activity.

These relationships between the Weapons Program and the Engineering Departments 


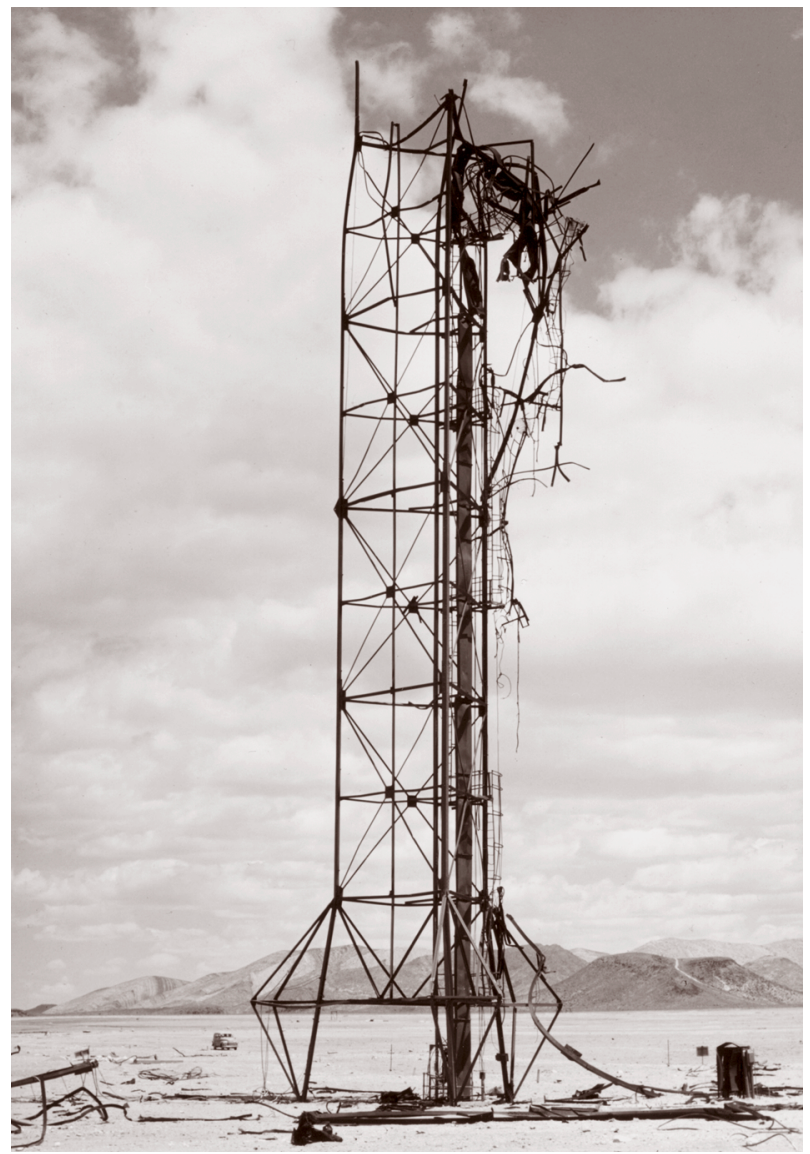

Ruth, Livermore's first nuclear test, fizzled, 1953. continued for many years and continues, but to a lesser extent, today. Since the opening of this Laboratory, its Nuclear Weapons Program has put sixteen weapons systems into the national stockpile beginning with the W-27 and concluding with the W-87. Major parts of this effort were done by Mechanical

Engineering. Significant contributions were made in the uses of new materials, the development of new processes, fabrication, assembly, and testing techniques.

\section{Preparation for the Weapon Design Mission}

ME quickly found that working on nuclear weapon designs, as opposed to particle accelerators, got them deep into the classified arena. There were practically no classified drawings at the Berkeley lab; however, as ME got into nuclear weapon design they found that a large percentage of our drawings were classified-most at the secret level.

This complicated the design and fabrication process, since they could only deal with facilities in the AEC complex set up for classified work such as Hanford, Rocky Flats, BendixKansas City, and Oak Ridge.

Wally Decker was the first ME device design engineer. In fact, he did the mechanical design of the first two nuclear devices, which were quite similar. In his memoirs he recalls that the major problem was how to fabricate the parts. Once that was solved, it was simple to make two sets. It was just necessary to add serial numbers to keep the two devices separate. Wally also recalls that it was sometimes more difficult to build the handling equipment and the detector system than the actual device. One of his early challenges in device design was how to become knowledgeable about new materials that he had never encountered in his design work at Berkeley.

Wally discusses zirconium and how difficult it was to fabricate it to the shape that was needed. In the early tests, the ME device designer also went to the field and assisted in the final assembly of the device components. He helped carry the final system materials up the towers (the first tower was $100 \mathrm{ft}$ high, with an open platform and no railing); made all the final assembly to fire the device; assisted with installation of the diagnostic system components, especially the line-of-sight pipes; and perhaps was a part of the "arming" party.

Fabrication tolerances for the early devices were not very tight and standard machine tolerances were the norm. For the early devices 
final assembly in many cases was done by using a rubber mallet to make the parts fit together. However, when Johnny Foster entered the device design scene with his "small" devices, machining tolerance became critical, and making parts of unusual shapes with tight tolerances was a great challenge. Jim Bell recalls the process that ME went through to develop the technology required.

Back in the business of the engineering of nuclear devices, early in the game, shapes were required that were not easily generated by machines, so they had to be made on a lathe that traced a shape on a template. A template is a metal pattern in the shape of the end product. The machine tools (lathes) that traced template shapes to make weapon parts were very hard on the templates. They'd chew up a steel template-and the templates were hard to come by. In production plants, templates can be filed to shape and burnished and then heat-treated and hardened, and that lets them stand up under abuse. But that wasn't possible in the early days, and still get templates out in the time scale needed by the Weapons Development Program. The use of templates was of critical importance in the early Weapons Program. They were the only technique available to the mechanical engineers and to the Machine Shop to make the required parts.
Then one of the engineers, Chuck Henry, devised a way of making a master male template, and from that making a mating female template by using a rough-sawed contour and a plastic fill to mate against the male template. Several templates could be made rapidly, because once you got the master male template you could make a dozen female templates off of it easily. In addition, if you wanted a few more male templates you could make them in reverse, going back from the female to the male with plastic again.

So the engineers looked for

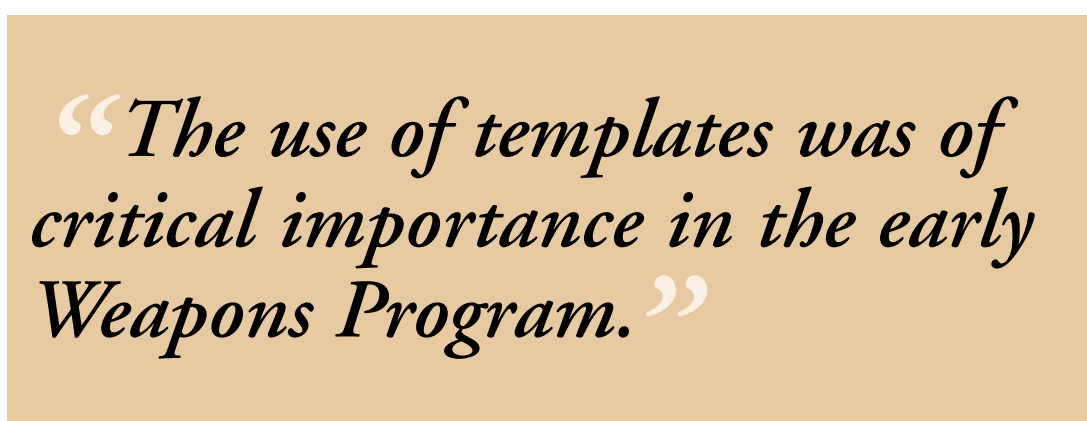
ways to make the parts bet-

ter, more rapidly, and so on, and part of it was to go to tracer lathes that had a compound tracing system and used air in the system. The sensor was an air valve, and it drove air cylinders that operated the travel of the ways on the machine. That was fairly successful, although they were very touchy. The sensitivity needed to be high, without getting them into a mode where they oscillated, because that allowed the use of templates that were more easily fabricated. Now since the lathes had very light pressures, plastic templates were good enough and did the 


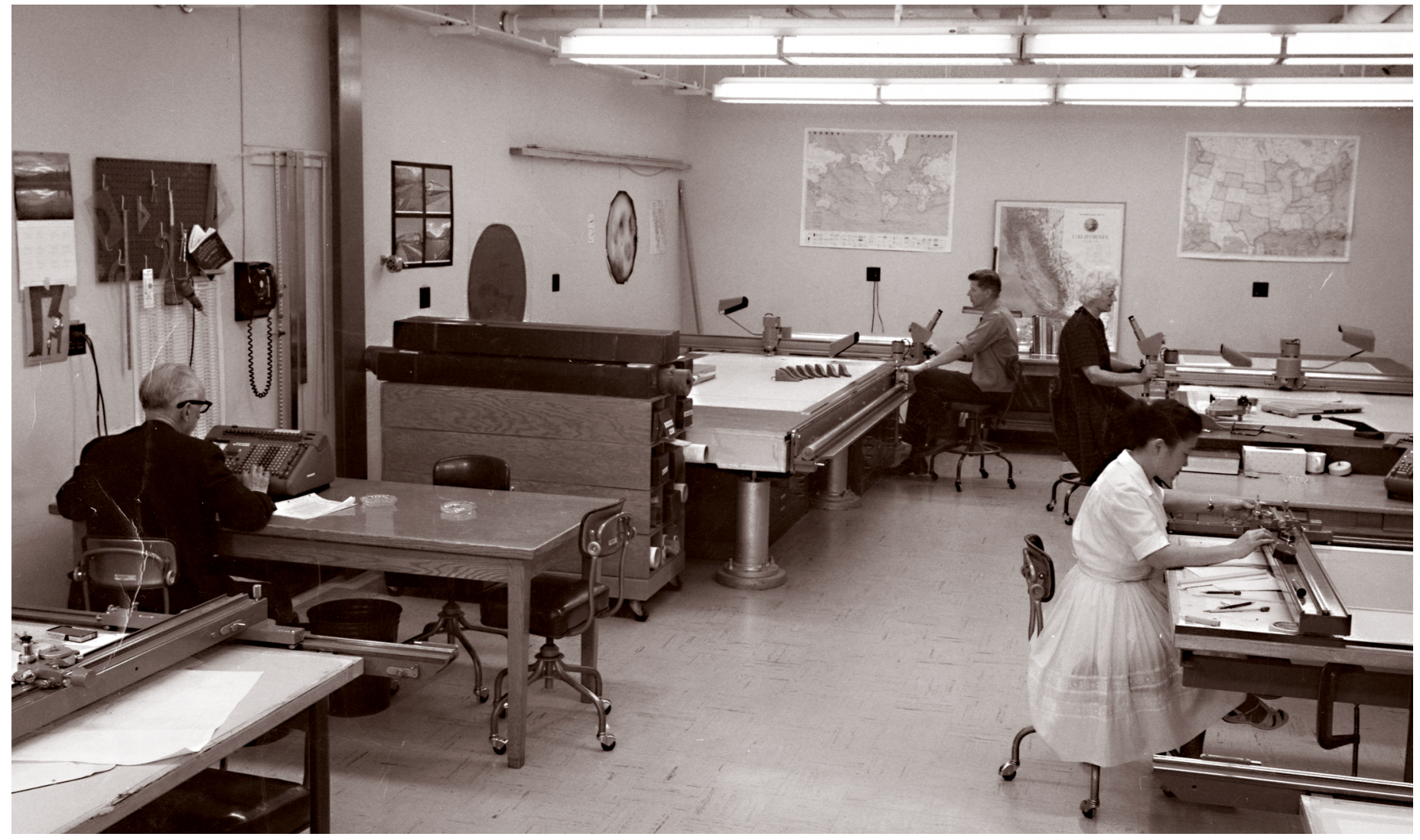

Lofting area, pre-1963. Left to right: Fletcher Pomeroy, Joe Janzen, Helen Sullivan, and Sue Kijara.

job. Eventually, there was a bay of these machines making templates.

However, the engineers wanted a machine to make a part without the need to use an accurate template, and found a company that was building a machine that worked in a very suitable way. The machine was called an index mill. It had a vertical spindle and a translating table. The table translates in both $x$ and $y$, so that you could bring the table in and advance it through; thus, you just had to rough-saw cut a template shape and then mill the inside contour or the external contour of the part.

The machine had a sensor with a valve that directed fluid to cylinders that moved the table in one of the two directions. It was fed by a lead screw system the other way. The machine was eventually driven by tapes from the big computers by replacing the hydraulic drive with synchronous motors. The computer gave data in the form of two sine waves for driving the cross-feed synchronous motors.

The controller was full of vacuum tubes, and that was a major problem. The machine shop had a maintenance department and had their own electricians who maintained the machine tools. They were maintaining electric motors and heavy-duty switches, but in this machine the electricians 
were trying to maintain a vacuum-tube type of unit. Eventually, personnel from Electronics Engineering took over the maintenance and development, which soon corrected the problems and permitted successful operation.

But in the end, the department got better systems, e.g., lathes designed and made to run directly from computer input, and that bypassed all the template problems, among other things. It was a long fight, because what would come out of physics was a series of points that defined a curve, but the machine tool had to know all of the almost infinite number of points between each of the defined points in order to have some track to follow. It became very difficult to define those areas, because they didn't drop out nicely from a physics calculation. Initially, this curve fitting was done manually in a process called "lofting." There would be variations in them if you ran it through the physics. So you had to have a smoothing program that looked at all the points and made a smooth curve out of them, and then you had to have a type of program which allowed you to compute the curve that fit in between all the points.

Engineers then had a going system that manufactured parts directly from the computer data going into the machine tool-a big step forward. Ray Spies coordinated the work among all the companies so that they all understood how to handle the data that was delivered to them. Ray did a yeoman job in getting all to work together and to produce useful parts.

Today, if you go into one of the machine shops there are computers running the machines in just about any case you come to, so it's now old-hat. But in those days that was a big step forward in the computer machining business-computer-aided machining.

\section{Advances in Metrology}

Perhaps the most significant ME activity was begun in 1955 when Bell and Decker asked James B. Bryan to investigate the formation of a

metrology effort to support the growing need in the Weapons Program for greater precision in the manufacturing and measurement of parts for nuclear devices. They instructed Bryan to take six months and find out everything he could about metrology and how to apply it to Laboratory work.

Up to this time, mechanical parts were being made to standard manufacturing accuracies of +/- .001 in., used by the automobile industry. The field of metrology was begun in 1890 with the development of the 


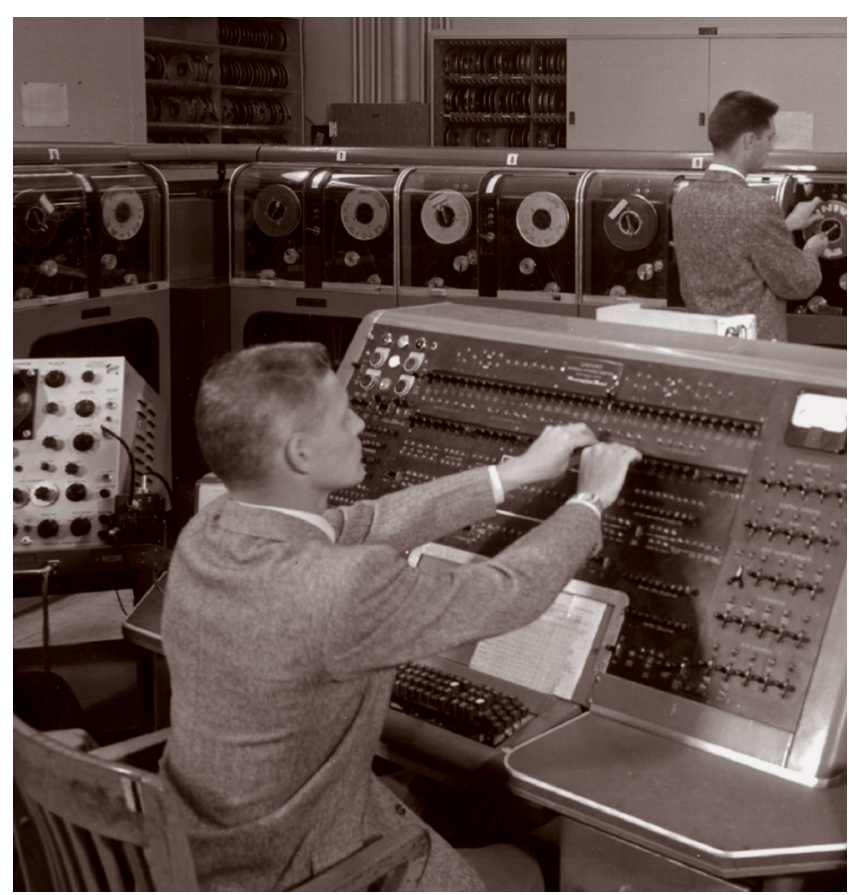

Lou Lininger at LLNL's first large computer, the UNIVAC, April 1953.
Johannson Gauge Blocks. According to Bryan, the textbook of greatest significance on the science of metrology to date (1955) was written in 1929 by F. H. Rolt, Gauges and Fine Measurements, and no significant work had been done in the field of precision measurement in many years. It is safe to say that Bryan and his coworkers reinvented metrology at Livermore. Their motto became "you can't make what you can't measure, because you can't tell when you've got it made." Their work was the foundation for the Precision Engineering Program. (See "The Precision Engineering," page 132.)

\section{The Electronics Engineering Department}

In 1952, Electronics Engineering was organized along the lines of functional activities: design and development engineering; coordination; maintenance; fabrication; installation; and drafting. In early 1953, an additional, unique group was formed to care for the Laboratory's first computer, the Univac l, built by the Echert-Mauchley Division of Remington Rand in Philadelphia, Pennsylvania.

This general EE organization remained until 1957 when two project divisions were formed: Project Engineering and Project Coordination, under the direction of Ed Hulse.
Ed was hired into EE from Westinghouse in 1955. He became EE Department Head on October 1, 1958, after Kilpatrick and Owren resigned to form a private company. There is no direct evidence that Hulse was hired to eventually become Department Head, but there is speculation that he was. The creation of the project divisions was a major change in the way that EE interacted with the program staff, providing more direct contact between the engineers and the program scientists, whereas previously, much of the detail of program needs for engineering work had been conveyed through the Coordination staff.

Throughout these early years, EE work was dominated by what could be accomplished by using the vacuum tube and the oscilloscope. These were the work-horse technologies available for high-speed diagnostics, including amplification and recording, laboratory instrumentation, and high power microwave for accelerators.

Computers were built with vacuum tubes, and consequently not highly reliable.

Reliability was a critical issue for field systems, since there was only one chance to detect and record the data from a nuclear test.

Significant effort was required to prepare the field diagnostic systems for a nuclear test. 
The bulk of diagnostic information was recorded on film that was exposed by an oscilloscope trace driven by signals from a detector. Many tens of oscilloscopes were used in each event. It was necessary that each scope be properly timed, that camera shutters opened on time, that cable delays were correct, that synchronizing signals and timing markers were operational-and that a myriad of other details were in place and working. (See "Engineering in the Test Program," page 50.)

Speed of recording was another critical issue. The data from a nuclear test was extremely fast (in the nanosecond range) and covered several orders of magnitude. Most of the commercially available oscilloscopes of that era had horizontal sweeps that were driven by signals applied to deflection plates, restricting the sweep time to about $10 \mu \mathrm{s}$. Consequently, significant EE effort went into developing sweep generators that could be connected directly to horizontal deflection plates and that produced sweeps of $5 \mathrm{~ns}$. These sweeps were produced by using high power radar tubes, most of which were made by EIMAC, Inc.

All of this equipment needed to function in environments that were less than ideal, i.e., the Pacific Proving Grounds (PPG) (Bikini and

Enewetok), and NTS. PPG was characterized by high temperature and high humidity, while NTS had high temperature and very low humidity. Both the temperature and the humidity impacted electronics systems of those days, and considering that vacuum tubes generated a lot of heat, these external environments needed to be taken into account. At both PPG and NTS, the recording bunkers-and later the recording trailers-were supplied with temperature- and humidity-controlled air by portable air conditioning units.

Only limited kinds of electronic hardware were available on the commercial market, so much effort went into the development of special instrumentation not only for field use but, equally important, for use in the laboratories. Special linear amplifiers and recording systems were developed, installed, and maintained throughout the Laboratory.

Simultaneously, high power RF and microwave modulators and electronic control systems were being developed for the 90-in. cyclotron and the accelerators in the Controlled Thermonuclear (CTR) Program.

\section{Computer Growth}
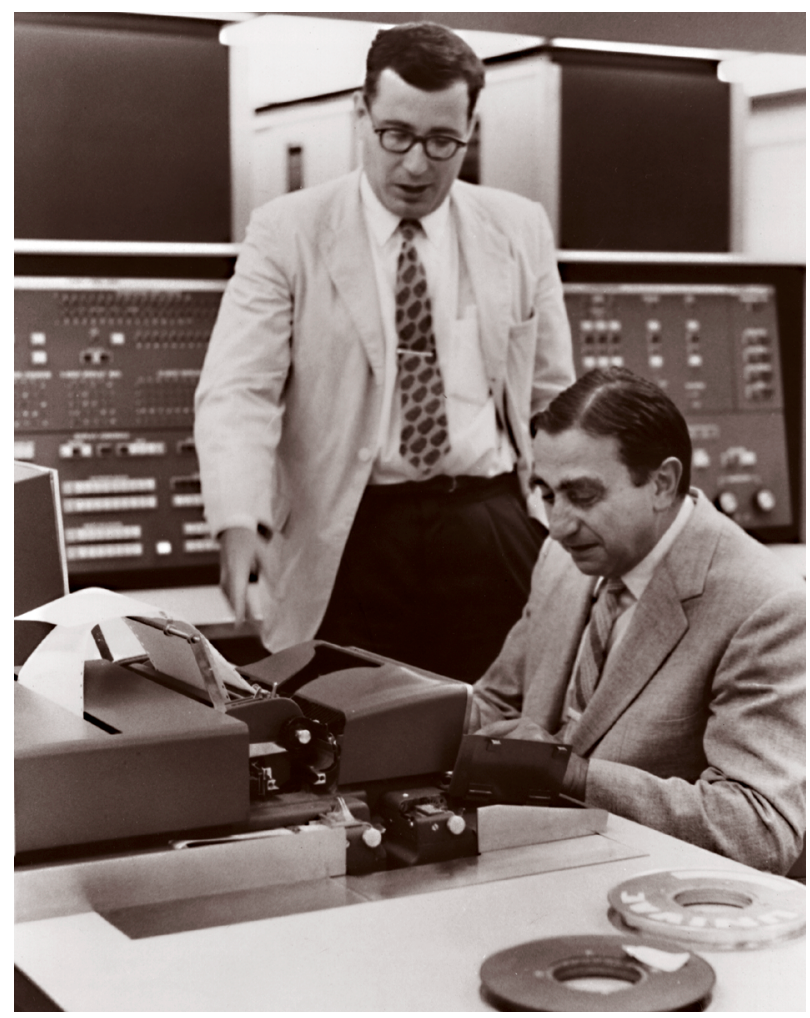

Harold Brown (I) and Edward Teller (r) at LARC console, circa 1960.
A major EE effort between 1952 and 1958 was the growth in computer resources at the Laboratory. An EE group was responsible for engineering development, maintenance, and operation for all computers and computerrelated equipment, other than that supplied by IBM. Either Computation Division or the scientific staff programmed the computers. 


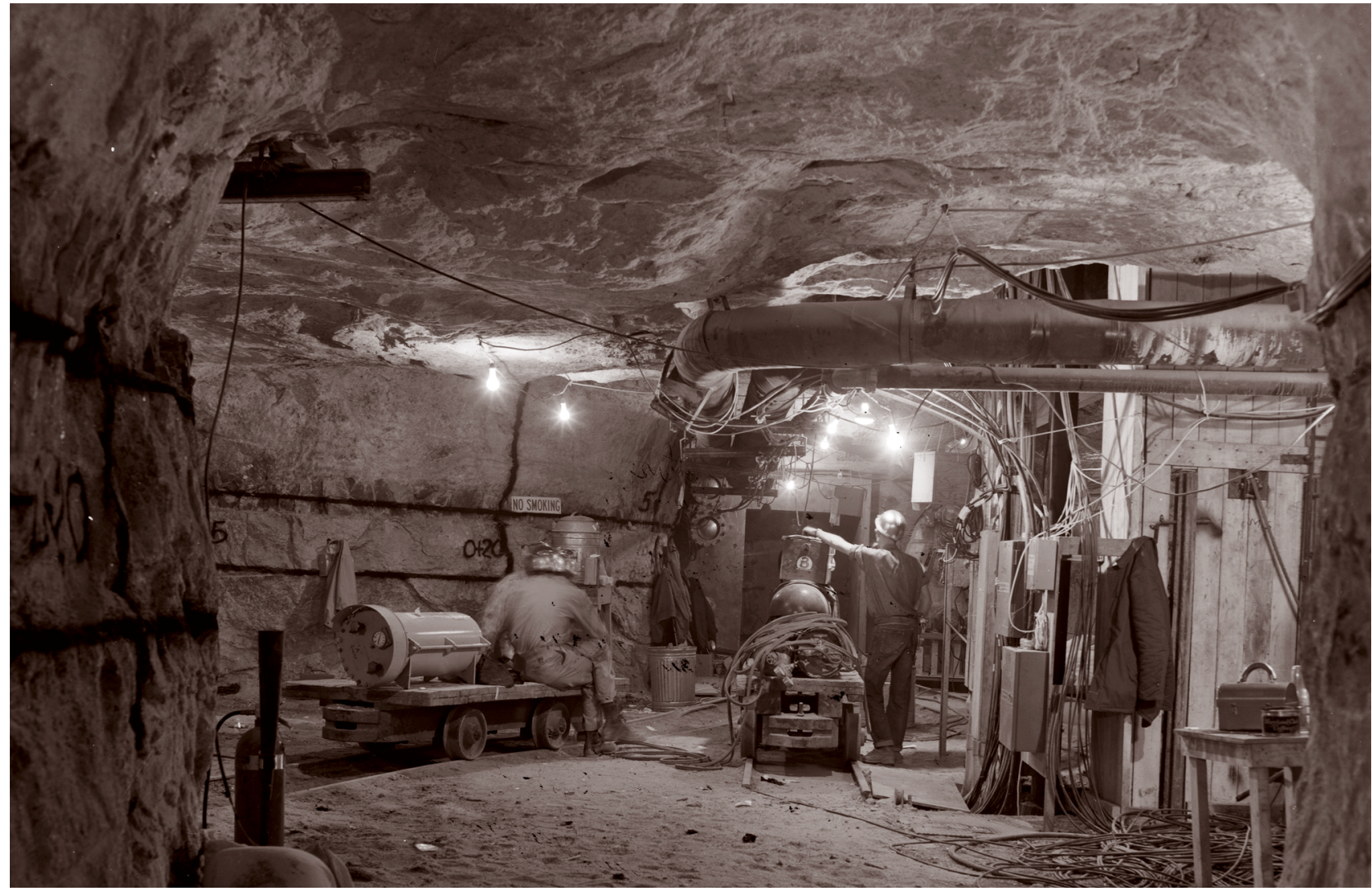

Early tunnel, Nevada Test Site.
In 1955, a joint effort between EE and Computation developed the specifications for the Livermore Advanced Research Computer (LARC), which was built by Remington Rand Univac and was the first major computer to use large numbers of transistors as the switching elements. High-power transistors were not available, so the memory and tape drive systems used vacuum tubes. Unfortunately, the LARC was about two years late in delivery, but it functioned reasonably well. A competing design was built by IBM (the IBM 7030, or Stretch) for LANL and it, too, was late in delivery. Livermore also took delivery of a Stretch about a year after LANL received theirs.

\section{Weapons Program in the 60s}

After the resumption of nuclear testing in 1962, the Weapons Program greatly expanded its underground-testing program at NTS. Initially, this testing was done in tunnels dug under Ranier Mesa. The nuclear device to be tested was placed in a side drift off the main tunnel shaft. Instrumentation and Control trailers were located atop the mesa, and cables were connected between the trailers and the device through vertical shafts.

Tunnels, which had first been used in 1958, permitted the test personnel direct access to 
both the device and the trailers. This was not much different than atmospheric testing, except that 1) it was now necessary to contain the explosion within the testing alcove, and 2) after the material used to contain the explosion was in place, no further access to the device was possible. Also, the trailers needed to be insulated from the ground shock, not only to prevent damage to trailers, but also to ensure the survival of the recording systems.

In addition to testing in tunnels, testing was started using vertical shafts drilled in Yucca Flat or on Pahute Mesa. Now new engineering problems needed to be solved. Since the device needed to be lowered several thousand feet below ground zero, special housing was required to protect the device and the instrumentation and control systems from the stemming material. Also, the integrity of the signal and control cables needed to be maintained during the downhole and stemming operation.

The MEs needed to design and field steel structures (canisters) to house the device and all its associated systems. The canister and its contents could not be too heavy since everything needed to be lowered into the test hole by a mobile crane.

A significant new problem arose for the EEs: since data signals now were required to be car- ried over long distances on coaxial cable, cable transmission parameters became very important to preserve the quality of the original signal. Significant effort went into understanding and mitigating cable dispersion. Michael Ekstrom did much of the analysis work, resulting in the development of cable equalizers.

According to Dick Neifert, L Division Leader, "Cable equalizers made it possible to take accurate time-history measurements." Cable equalizers helped take clear "snapshots of gamma rays being emitted during a nuclear explosion."

Obtaining low loss cable from manufacturers was a major effort. There were initially both basic manufacturing and quality control issues to be solved. Engineers were required to spend time with the cable manufacturers, Phelps Dodge and Andrews Corporation, to solve these problems. Eventually cable acquisition became a routine activity.

The last atmospheric tests were conducted off Christmas Island in 1962. All tests were air drops from a B52 out of Barbers Point Naval Air Station, Oahu, Hawaii. The Laboratory had people in many locations. ME had device designers and device systems people at Barbers Point, and diagnostic technicians on

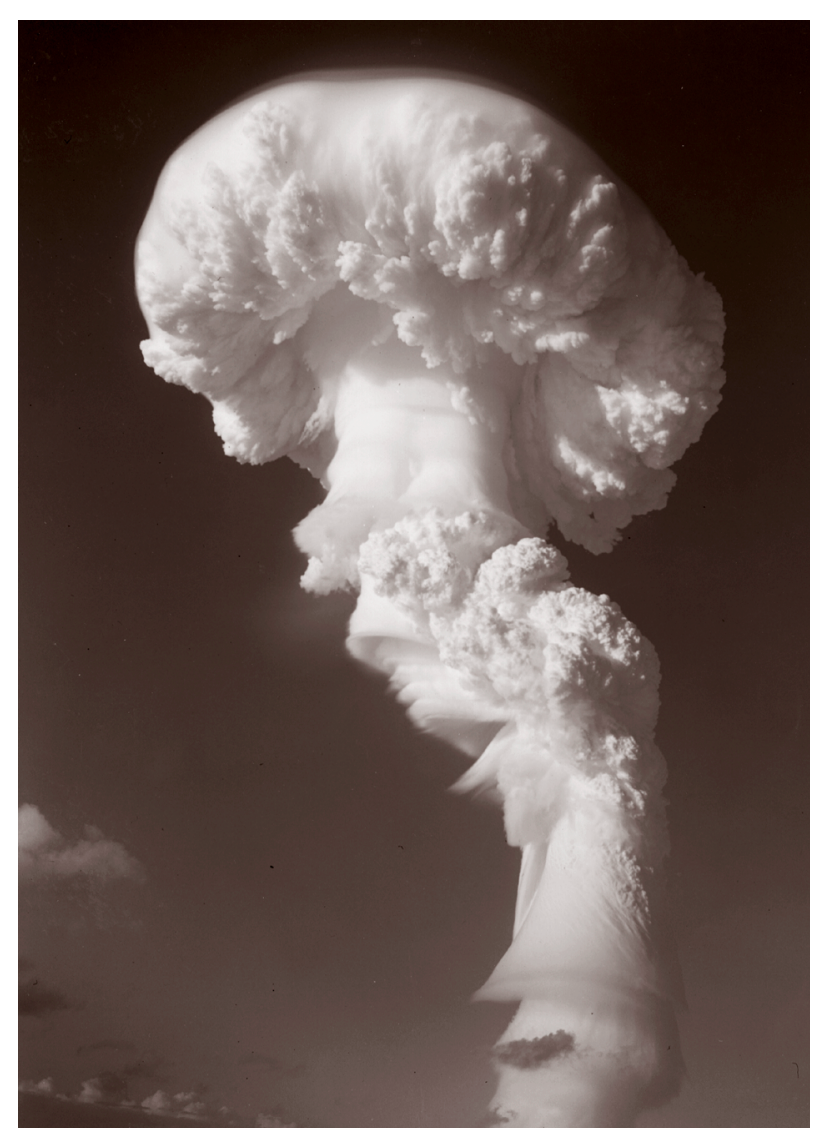

Operation Dominic, Christmas Island, 1962. 


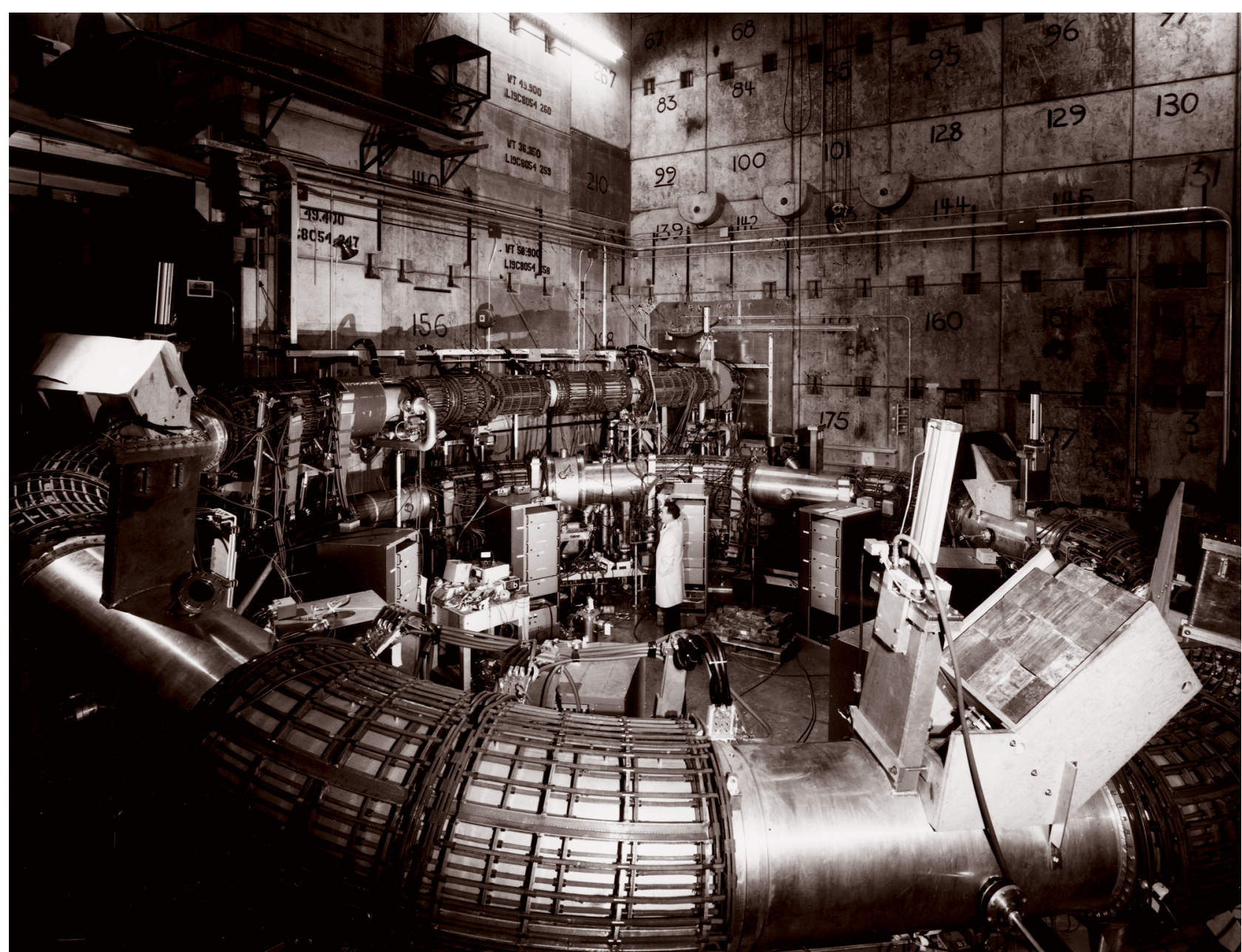

Controlled Thermonuclear Program experiment.
Christmas Island. EE had diagnostic engineers and technicians on Christmas Island and on the diagnostic $\mathrm{C} 135$ out of Hickam AFB, a few EEs at Barbers Point, some at Johnston Island and on Kauai.

It is a tribute to the Laboratory and to $\mathrm{EE}$ and ME that they were able to assemble and field the Dominic test series in addition to the ongoing NTS series in only six months' time.

\section{Non-Weapons Programs in the 50s and 60s}

In the early 60s, the Test Moratorium allowed the Laboratory to focus on the Pluto and CTR programs.

Pluto was successfully fielding two test nuclear ramjet reactors at NTS. Tory II-C was run up to full power test on May 20, 1964. The work ended on June 30, 1964, when the Air Force decided to terminate the work. Again, Engineering was asked to re-assimilate many engineers, technicians, and clerical personnel into other Laboratory areas, and did so successfully.

CTR was busy trying to develop magnetic confinement systems to control the fusion reaction to eventually generate electrical power. The engineering staff built a very large 
accelerator, Astron, for Nick Christofilos, who joined the Laboratory in 1957.

\section{The CTR Program-Charles Hurley}

Although Weapons was the dominant program in the 1950s, Engineering supported the CTR and other smaller activities.

The CTR work started in 1952 as Project Sherwood (aka Arc Research), a classified part of the Weapons Program. It was declassified in 1958.

The objective was to understand how fusion could be harnessed as a source of energy to generate electrical power for commercial uses and at commercial costs. Richard F. Post and Jack Steller did the first experiments at the Berkeley Laboratory.

When the Livermore Laboratory was opened, Herb York directed Post to assemble a team of scientists, engineers, and other technical personnel to begin an experimental program at

Livermore. The initial scientists were Post, Stellar,

Frank Ford, Fred Coensgen, Charles Damm, and Frank Eby. Robert Meuser and William Brobeck ran the Mechanical Engineering effort; Vern Smith led the Electronics Engineering work. Those early projects included Toy Top, Table Top, Tennis Court, Squash Court, Guppy, and Waldo.

Parallel to this was a research project dedicated to the "pinch approach" headed by
Stirling Colgate. What came out of all this early work was the realization that plasma containment by magnetic fields or high voltage pinch was not easy. In fact, the required vacuum pressures were far beyond existing technology. Major development programs were started, on "high field" magnets and extremely high vacuum systems and components. Another great need was the development of power supplies and capacitor banks. These engineering-intensive projects carried well into 1956. Experimental equipment was being designed at the same time.

In 1957, Nick Christofilos came up with a new idea, different from the mirror machines and pinch machines. His approach was also very different from those of Princeton, Oak Ridge, and Berkeley. Because plasma containment was the big problem, he proposed a very dense electron layer, which could achieve field reversal, and therefore form a completely closed magnetic bottle. This E-layer would be in the form of a long cylinder. Work started on the Astron Project and Charles (Chuck) Hurley became Mechanical Engineering's representative for Nick.

The engineering group, the physics group, and even the Laboratory, were never the same after Nick.

In 1958, controlled fusion (Project Sherwood) was declassified and the world 
Astron, the biggest experiment of the Sherwood Program, helped researchers learn about plasma behavior.

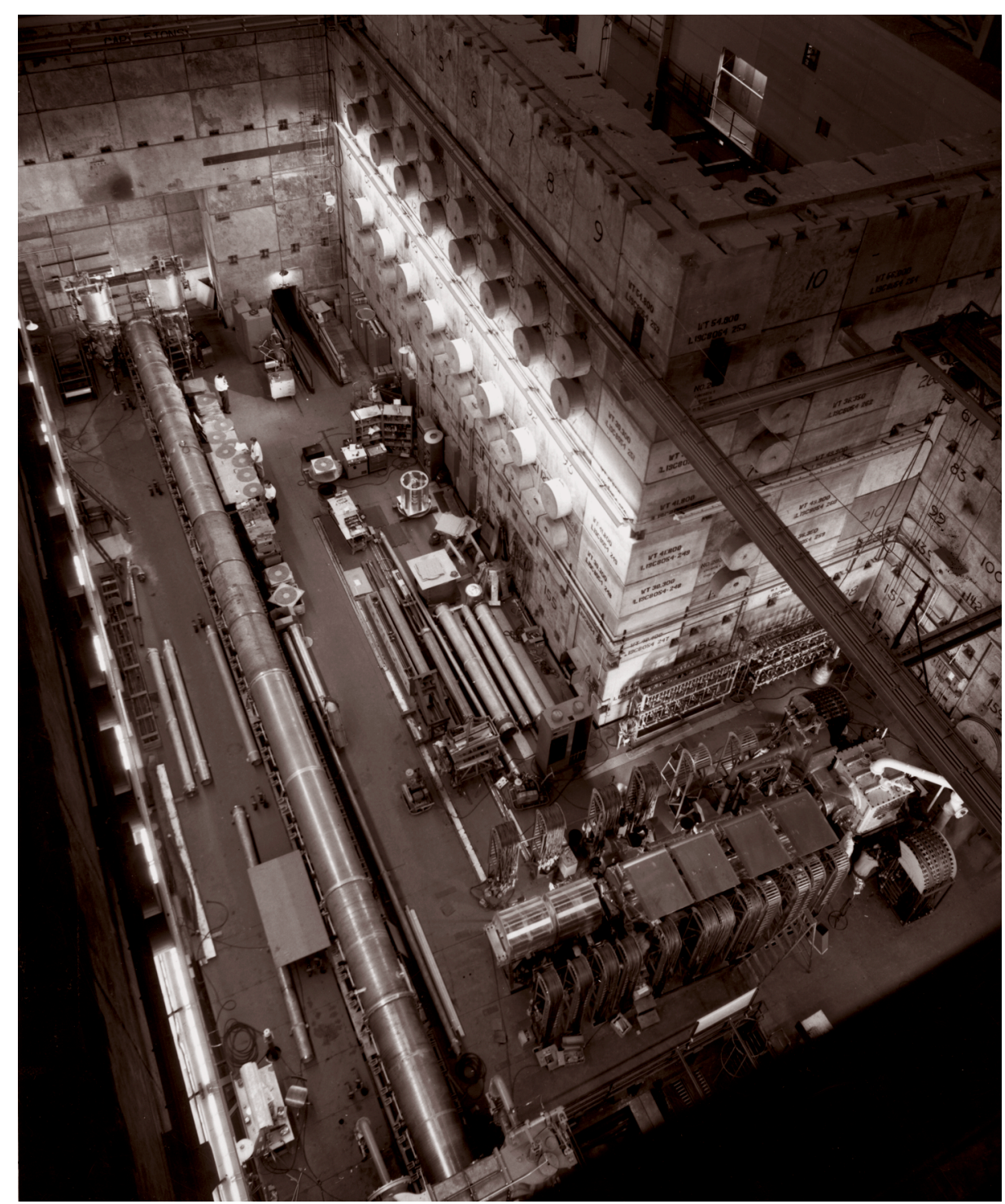

scientific community met in Geneva Switzerland, for the "Atoms for Peace" Conference.

Chuck Hurley was in charge of the design and installation of the hardware for all of the Laboratory exhibits at this conference-the first time an engineer from the Livermore Magnetic Fusion Program (and maybe the Laboratory) was sent to Europe.

This was a very important breakthrough conference. All countries (including Russia) showed up with interesting hardware. The US constructed a building on the United Nations site and every country moved in, but kept everything shrouded until the exact day of declassification. The US had a big electron gun source that everybody was excited about, and somebody (the French, I think) filed a patent on it. However, it really didn't work well.

This drove Nick Christofilos to invent the Linear Induction Accelerator. There were several models of this accelerator, each with more electron current than the preceding model, leading to major developments well into the 1960s.

The Advanced Research Project Agency (ARPA) became interested in developing charged particle beam weapons for missile 
and aircraft defense. High energy, high current beams were needed. This made part of the Astron work classified. So between 1958 and 1973 Project Seesaw was classified.

A large particle launcher and experimental tank were built (Astron) -we were in a race with the Russians. They copied the accelerator and got it wrong. They did not design a ceramic/ metal joint correctly.

The Astron/ARPA machine was the largest accelerator project in the Laboratory at the time. The Particle Beam Program continued, after Nick's death in 1973, under the direction of Dick Briggs. The Advanced Test Accelerator (ATA), an advanced clone of Astron, was built at Site 300 in 1980.

Local newspapers wanted confirmation that a Weapons Program was underway in competition with Russia. Everyone denied it.

In the timeframe of the 1958 Atoms for Peace Conference, several milestones were established which accelerated the mirror program. However, the decade following the Geneva Conference was a period of frustration. Keeping plasma instabilities free from contact with surrounding material walls seemed impossible. Many magnetic field geometries were attempted.
It took a RUssian in the USSR to come up with a workable solution, known as the Tokamak.

Meanwhile, Livermore continued its work on Table Top, then Toy Top II, and Alice. LLNL went on to new configurations, starting with

Baseball I, using coils shaped like a baseball seam, and the "yin-yang" coil.

This moved the mirror program into an era with new problems. Heating and sustaining hot plasmas long enough at fusion tempera-

tures was the new challenge. This led to the $2 X$ and $2 X I I$ experiments, followed by Baseball II with superconducting magnets. These machines used neutral ion beams to heat the plasma. Operation of this series of machines led to an understand-

ing of how to design the Magnetic Fusion Test Facility (MFTF) in 1981.

All this painful work led to great understanding of controlled fusion problems, but was unable to solve them. The popular approach in the world today is the Tokamak. At LLNL, 
controlled fusion has shifted from magnetic confinement to inertial confinement using lasers, which started in 1972.

The EE work for CTR was characterized by the need for very large amounts of power

("pulsed power") in very short periods of time. Since conventional vacuum tubes

...it is important to note
that Engineering...has been
viewed... as the 'flywheel of
the Laboratory.'
were inadequate and solid state devices were not yet developed, the components to generate this power were restricted to either ignitrons or thyratrons. Energy storage devices were primarily capacitor banks. Delivering the power to the fusion machines required cables that could carry thousands of amperes over long distances at a very low loss, so as to keep the pulse shape as pure as possible.

The CTR effort was about $10 \%$ of Engineering's work, causing some hardship for the CTR Program. When Weapons was gearing up for and conducting a field testing effort, large numbers of people were needed for months at a time. But when the test series was over, many employees needed other assignments. Some of these went to the CTR program. Then as soon as a new test series started again some of these same employees were recalled to their original assignment. CTR would try to phase the transition but on many occasions was unsuccessful.

The employee situation that existed for CTR also existed for other Laboratory programs and activities. On the plus side, it is important to note that Engineering for many years has been viewed by a large number of people at the Laboratory as the "flywheel of the Laboratory." It is seen as the organization that can most easily and effectively move employees from one program or activity to another, and thus be able to accommodate the everchanging requirements of Laboratory staffing.

\section{The Pluto Program}

Immediately after World War II ended, the US considered other uses for controlled atomic energy. By the early 50s, potential uses were identified. The principal original goal was the development of a nuclear powered aircraft. This goal received greater emphasis once the Russians had developed their hydrogen bomb.

The first attempt to use a nuclear reactor to power an aircraft was the installation of a test reactor on a B-36 bomber in 1955. Although the B-36 always used conventional engines for flight, tests were done to gather data relating 
to crew safety, and technical issues related to operation, maintenance, and safety.

The driving force to use nuclear power had been the establishment of the Strategic Air Command-its mission was to maintain an airborne fleet of nuclear armed bombers to counterattack a Russian nuclear strike on the US. This airborne fleet was refueled by air tankers, which could be eliminated by using nuclear powered bombers.

By 1955, the USAF broadened its interest to include a nuclear powered rocket for space use, an air-breathing ramjet to replace the airborne aircraft fleet, and nuclear power systems to replace batteries for space uses. These projects were named, respectively, Rover, Pluto and SNAP. LLNL and LANL were each assigned part of both Rover and Pluto. In January 1957, Rover was assigned to LANL and renamed NERVA, and the Pluto Program was assigned to Livermore.

Livermore's challenging goal was to develop a nuclear ramjet engine for a supersonic, low-altitude missile for the Air Force. The missile was to travel at Mach 3 and carry a payload of $5500 \mathrm{lb}$. This program required different types of engineers than were used by either the Weapons Program or CTR. What were required were nuclear reactor engineers who understood how reactors worked, how they were controlled, how measurements were made in hostile environments, how all of these things were controlled from a remote location-and all this on an experimental system.

Fortunately, there were two very capable engineers who filled the leadership positions: Henry (Hank) McDonald for EE and Blake Myers for ME. ME also had an extremely competent nuclear engineer, Carl Walter, who had a major role in the reactor development activities. The program leader, Ted Merkel, made McDonald and Myers equal partners with the scientific staff. In the weekly program staff meetings, issues such as the program direction, problems, and needs were on the table. Everyone had an equal say, leading to a unified and integrated program development staff.

This experience became very valuable for Hank in his later assignments as EE Department Head, and more so when he was appointed the first Associate Director (AD) for Engineering. It showed him the value of having engineering being a full participant with the program leadership in assuring the success of programmatic goals.

As the Pluto Program was increasing in its manpower needs, the Weapons Program was entering the three-year testing moratorium, from 1958 to 1961. The Russians broke it in 


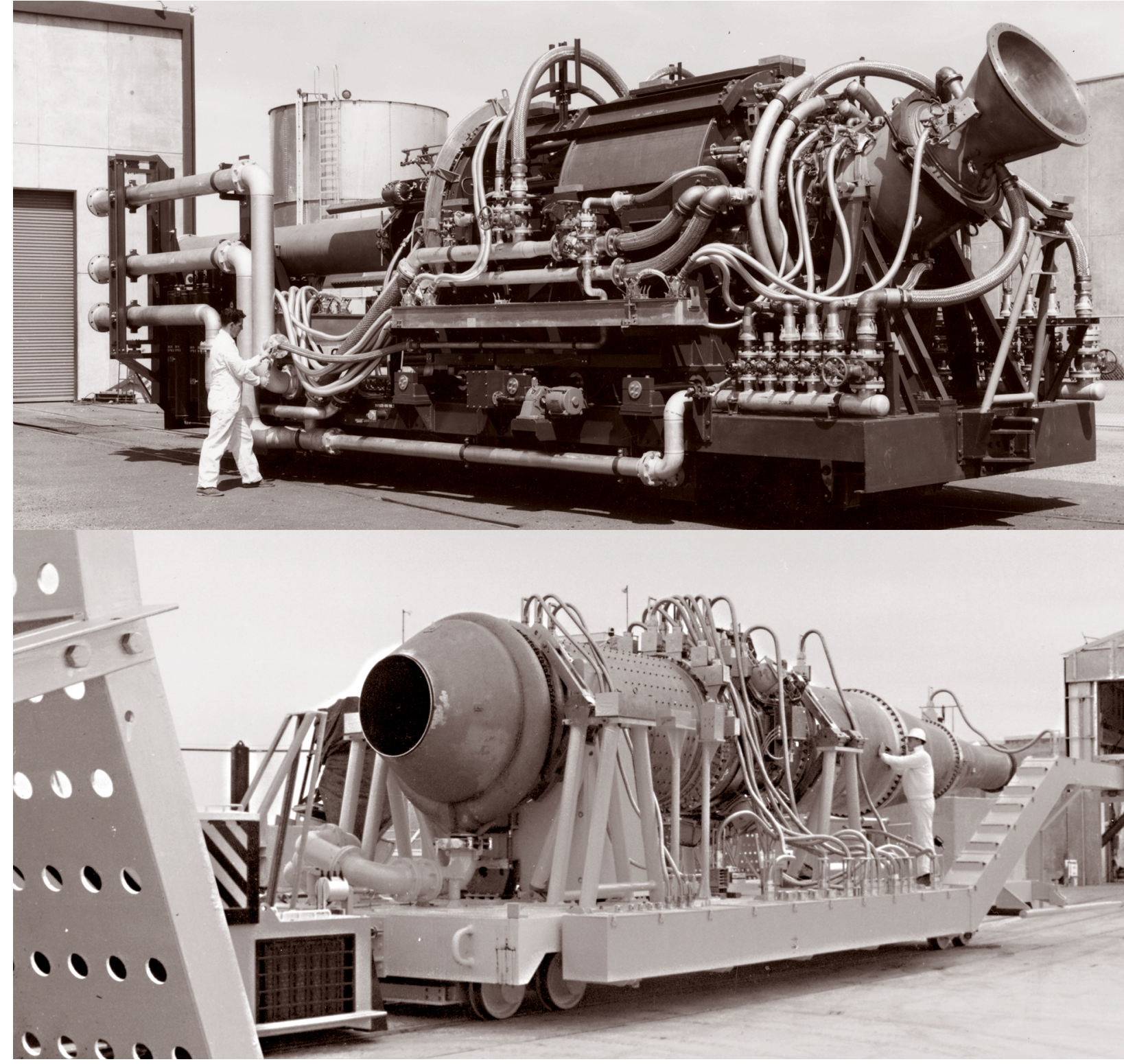

The Pluto Program's two experimental ramjet reactors are shown: (top) Tory II-A and (bottom) Tory II-C.
September 1961, and that led to a resumption of US testing in 1962 with the last overseas test series, Operation Dominic, at Christmas Island. In this same period, Pluto was building and testing two experimental ramjet reactors, Tory II-A and Tory II-C at Livermore, with the control building, test stand and disassembly buildings at NTS. Significant field effort was needed at NTS and, fortunately, Engineering had many employees with NTS experience available, due to the test moratorium.

The Pluto Program was phased out beginning in July 1964, after a very successful five-minute full power run by Tory II-C on May 14, 1964.

Mechanical Engineering for Pluto. The three major challenges were 1) neutronics inside the reactor core and how they changed with a change in temperature; 2) dynamics of air flow through the reactor at extremely high pressure and temperature; and 3) what materials to use for the reactor design.

The core of the first Pluto reactor, Tory II-A, was made of graphite and used a graphite reflector while that of the second reactor Tory II-C, was beryllium oxide (BeO) and had no reflector. The decision was to use uranium as the fuel and $\mathrm{BeO}$ as the moderator in Tory II-C. BeO was selected as the moderator because it is a low-Z ceramic-like material with good high temperature strength and good thermal conductivity, even though it is very toxic and must be handled very carefully. 
Uranium forms a volatile oxide when heated and exposed to air. The two components were successfully combined by Lab chemists into a single mixture, thus eliminating the need to separate the uranium from air, and greatly simplifying the reactor design. The operating conditions for the reactor were an inlet air temperature of $1050^{\circ} \mathrm{F}$, a core temperature of $2500^{\circ} \mathrm{F}$, and an exit air temperature of $2200^{\circ} \mathrm{F}$. At these temperatures material strength properties were critical. What shape to make the fuel elements, how to tie them together, and how to tie the total assembly together were all crucial if the ramjet was to operate successfully. The fuel elements were hexagonal rather than circular because they nested together better-as bees know so well-and they had a hole through the center to pass the air for heating.

The cores for II-A were fabricated and inspected for cracks by the Evandale plant of General Electric. The cores for II-C were different from the II-A cores: each II-A core had a hole through the center; the II-C cores used seven sections that dumped the air into a large single exit hole. These cores were made and inspected by Coors Ceramics in Golden, Colorado.

At NTS, the test stand was remote from the other two structures and was connected to the disassembly building by a railroad operated remotely from the control building. All connections to the test vehicle at the test stand had to be made remotely. A tank farm was built to supply the air at the required temperature. The

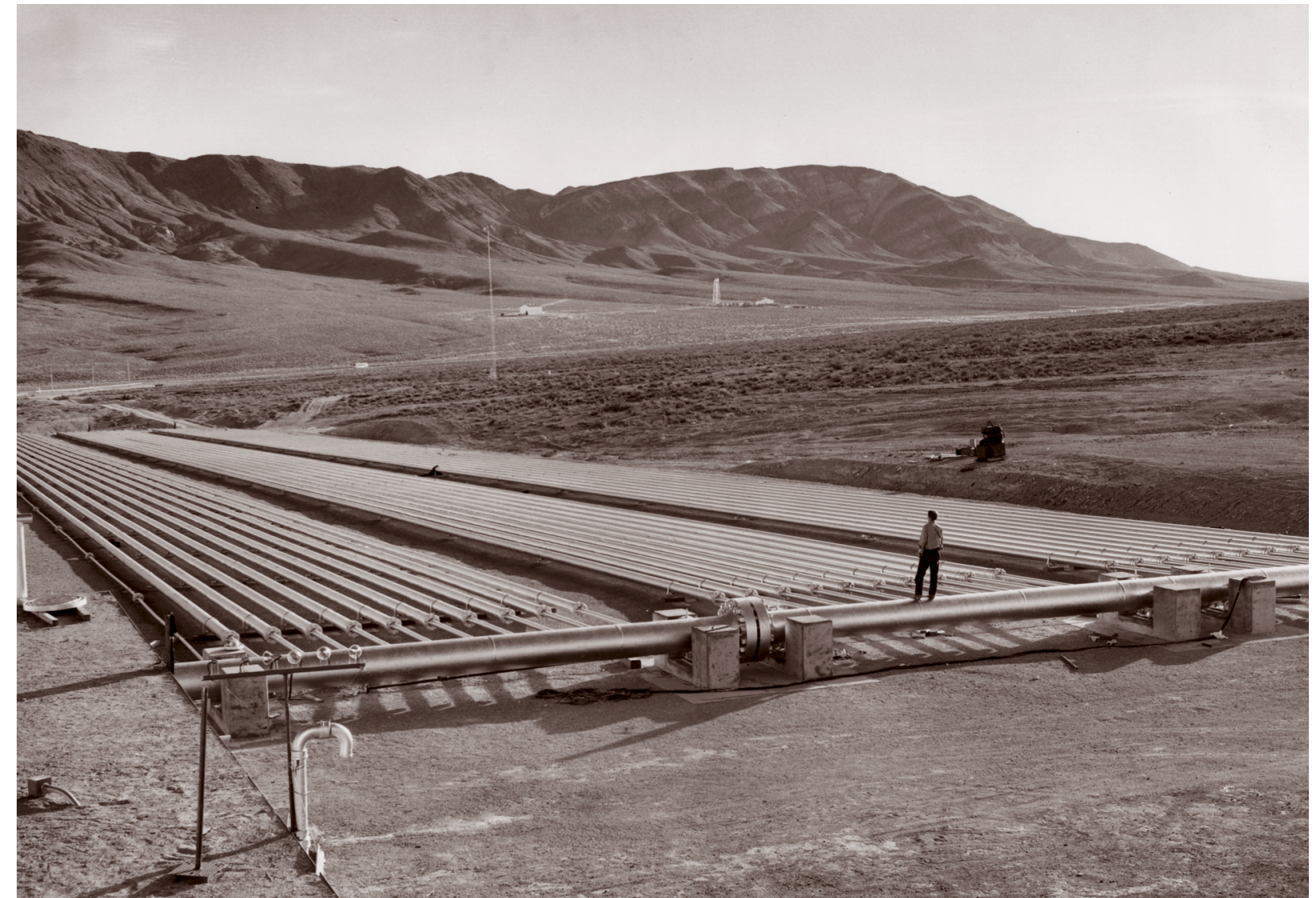

Pluto tank farm, Nevada Test Site.

tank farm was constructed from oil well drill pipe and stored $120,000 \mathrm{lb}$ of air at $320 \mathrm{psi}$ for the II-A runs. This air was passed through a heat sink (large tanks holding 1 -in. stainless steel balls heated to $1050^{\circ} \mathrm{F}$ ) prior to injection into the reactor. 


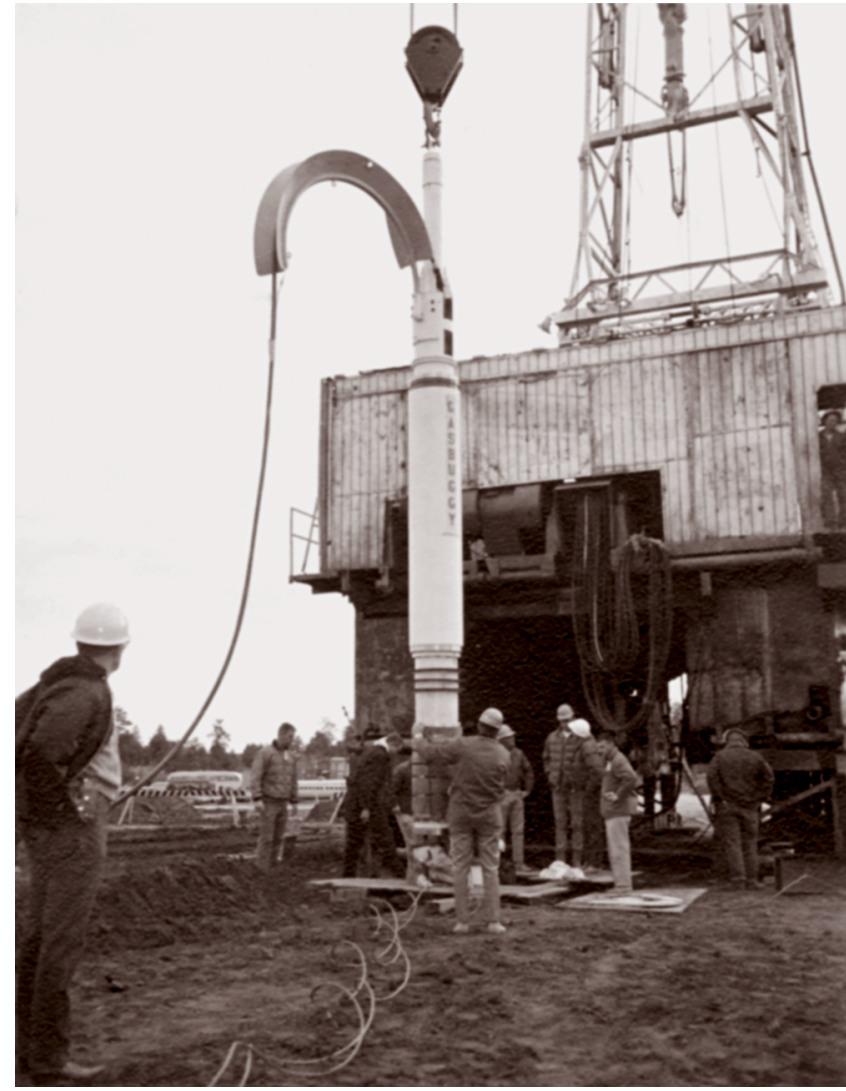

Gas Buggy gas stimulation experiment, circa 1967.
Tory II-A was a prototype system that was designed to operate at $50 \mathrm{MW}$, one-tenth of the design goal for II-C. It was successfully run on May 14, 1961, at $50 \mathrm{MW}$. There were four total runs of II-A.

In February 1964, the Tory II-C assembly, weighing 14,410 lb, was shipped from Livermore to Area 401 at NTS, where the core and the final assembly were made. To attain II-C operating conditions, the tank farm needed expansion to store sufficient air for a five-minute run at a 550 MW. On May 20, 1964, Tory II-C ran for five minutes at full power, achieving a base plate temperature of $2400^{\circ} \mathrm{F}$.

Electronics Engineering for Pluto. All the wire and connector insulation on the test reactor vehicle had to survive the expected high radiation dose accumulated during testing. Also, the wire insulation and the connectors had to withstand the predicted high temperatures (higher than the melting point of solder) produced by the radiation during each test. Insulation developed for the LANL Rover program by American Car and Foundry was not suitable because the soft insulation was easily penetrated by individual stray wire strands.

Special Remote TV camera windows were made of sapphire, to resist radiation damage. Also the thermal radiation probes were sapphire rods. The high-radiation-tolerant TV systems were developed by EG\&G.
The automatic control system was state-ofthe-art. The Tory II-C reactor had to be controlled over 12 decades of power with a fast ramp up to $550 \mathrm{MW}$. This control system required reliable and accurate logarithmic neutron detectors and amplifiers. The control signal used to set power was the log of power. Boron triflouride particle detectors covered the first six decades of power and ion chambers covered the final six decades of power.

The breakthrough was the development of very accurate logarithmic particle counters and power amplifiers that converted ion chamber current to the log of power. The control signal was derived combining three log power signals so that the middle signal would always be selected as the control signal. This allowed any one detector or power amplifier to fail in any manner without affecting the control signal. This simple analog twoout-of-three logic circuit was a key factor in the reliability of both the nuclear and the air supply control systems.

The pneumatic control rod system was beyond the state of the art in terms of pneumatic response and operating environment. The frequency response of the control rods was $10 \mathrm{~Hz}$ ("cycles" at that time). In addition, the control rods and their electromagnetic control valves had to operate red-hot at full reactor power (500 to $600 \mathrm{MW}$ ). This equipment was developed by Bendix Research Laboratory. 
The greatest Engineering challenge was to retain the Pluto team (about 600 FTE at its peak). After years of working together as a close knit team under the leadership of Ted Merkle, working on another Laboratory program would be a letdown. Many of the engineers went off to be very successful at other start-up companies. Mechanical Engineering, Physics, and Chemistry did the best at retention. Electronics Engineering lost most of its key people to other companies.

\section{The Plowshare Program}

The Plowshare Program was begun in 1957 as an implementation of the Eisenhower proposal to use nuclear explosives for peaceful purposes. The concept was to use nuclear weapons technology to move large volumes of earth matter to form harbors, canals, or the larger-scale civil engineering projects. Another Program goal was the production of oil shale for oil, and to stimulate the production of natural gas from tight formations of gas-bearing rock.

The most notable experiments were Gnome in 1961 and Sedan in 1962 as excavation experiments, and Gas Buggy in 1967 and Rio Blanco in 1973 as gas stimulation experiments.

For Engineering, these field experiments were extensions of and similar to the nuclear tests at the NTS. But, except for Sedan, which was conducted at NTS, each test was carried out at a unique site. This required the deployment of all

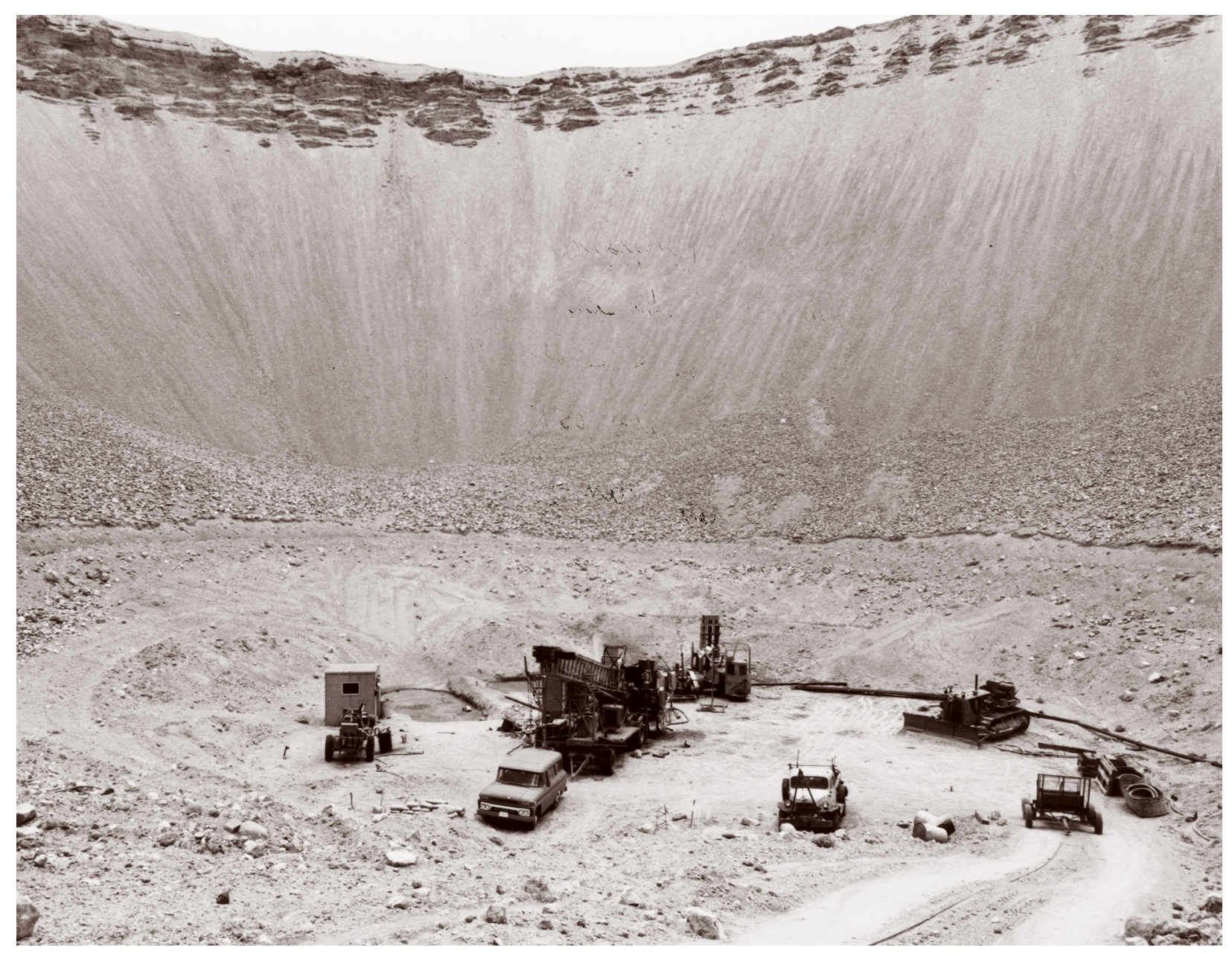

At the floor of Sedan Crater, Nevada Test Site. 
the support services normally found at NTS in addition to the usual engineering support required for an NTS test.

Due to increasing pressure from antinuclear activists, the program waned and was eventually stopped.

\section{Upgrading Engineering Education}

The important process of upgrading the educational level of engineers at the Laboratory was driven primarily by Ed Hulse and Wally Decker.

In 1963, for most engineers the BS was the terminal degree. EE began a two-fold upgrade program. First, the existing staff was enrolled in refresher and (then) new technology courses. Second, an effort was made to hire engineers with advanced degrees, prima-

\section{"In 1963, for most engineers the
BS was the terminal degree."} rily Masters degrees, and to a more limited extent, PhDs. The number of PhD degrees in Engineering in 1963 was less than one percent of the total.

This was a long-range effort that required changes at the university level to begin graduating more MS and PhD engineers. Some of this was already happening as a result of the United States Space Program.

In 1968, Wally Decker, who had become ME Department Head in 1962, began a similar upgrading program. It took until about 1973 to make the number of BS and MS engineers about equal. Five years later, by 1978, a degree mix of about $35 \%$ BS, $45 \%$ MS and $20 \%$ PhDs was achieved.

These changes had a profound effect on Engineering and on Laboratory Programs. Engineering was able to begin developing technologies that would be needed by the programs in the future-principally Quantum Electronics; Electromagnetics and Systems; Solid State Devices and Materials; Materials Testing (including Acoustic Emission); Structural Code Development; and Nondestructive Evaluation (which had been used for many years previously).

The emphasis on advanced degrees continved: more graduate level engineers were hired, and BS level engineers were expected to obtain an advanced degree while working full time. This process was enhanced by the use of Instructional Television from both the University of California at Davis and Stanford University.

What began as an effort to upgrade the quality of the engineering staff eventually created the now well-known process of 
"continuing education" for all employees. This occurred not only at the Laboratory but also throughout industry and across almost all disciplines. It further led to employees taking responsibility for their own career development and has led many people to make career changes into fields that they initially would not have considered.

On October 1, 1970 Decker joined with Chester Van Atta, AD for MFE, to conduct a comparative survey of LRL-L and industry employee policies. Decker never returned to active leadership of the ME Department.

Walter F. Arnold was appointed to replace Decker on September 14, 1971.

\section{The 60s to the Early 70s}

On November 1, 1963, EE made a major organizational change, the fundamental structure of which still serves LLNL.

The change was to a complete matrix system, a move from a functional division and project division structure to an almost total project structure with the new divisions dedicated to the direct support of specific programs. The new divisions are shown on the chart on this page.

Simultaneous with this organizational restructuring, Henry McDonald was named Assistant Department Head, in addition to his assignment as Physics Systems Division Head. All direct support was brought into single project groups headed by an engineer. Engineers, technicians, designers, and coordinators were now under the direct supervision of an engineer whose primary responsibility was to provide integrated support to a specific part of a major program.

This change provided direct contact between the scientist and the engineer, which led to a higher level of engineering influence and content in program hardware and direction.

Although there have been many changes in the EE organization regarding support responsibilities, the basic structure is the same as was instituted in 1963.

In 1963 Ed Hulse, at the suggestion of an engineer, began the EE Christmas Card Fund. The concept was that rather than exchange Christmas cards among employees who saw each other regularly, each person would contribute the money they would otherwise spend on cards to a fund operated by a group of EE employees. The money collected would be used to help less fortunate families in the Livermore area to have a better holiday season.

In the middle 70s the targeted group changed from families to senior citizens. The Livermore Senior Services Center personnel selected the recipients. In 1981, the donor group became all of Engineering and the practice continues to this day.
Electronics Engineering Divisions Effective November 1, 1963

> Physics Systems Division

Henry McDonald, Division Head

Provide support to P Division, R Division, N Division, $Q$ Division, and Equation of State

$>$ ABW Systems Division

Richard Epps, Division Head

Provide support to A Division, B Division, and W Division

$>$ Diagnostics Systems Division Allan Hyne, Division Head

Provide support to the Nuclear Test Program and the Space Program

$>$ Sherwood Systems Division Hugh Van Ness, Division Head

Provide support to the Sherwood (CTR and MFE) Program

$>$ Engineering Research Division R. Carol Maninger, Division Head

Development of an EE research program Electron Devices, Microwave Devices, and Electro-Optic Systems

> Special Program and Operations Division Alexander Stripeika, Division Head

Provide support to Chemistry Department Computation Division, $\vee$ Division, Counting Systems, Standards Laboratory, Fabrication, Systems, Standards Laboratory, Fabricatic
Installation, and Engineering Support including drafting and design, reliability specifications, components and standards, TV and communications, and clerical 
On October 29, 1971, Henry McDonald became EE Department Head. One of his first acts was to create the position of Electronics Engineering Project Engineer (EEPE) in the Test Program Support Division. He required that EEPEs conduct pre-mortems just as Mechanical Engineering was doing, to bring a more balanced engineering partnership to the Program.

Hank also began weekly meetings with all of the EE Division Leaders in a room outside of Building 131. His focus was to develop a synergy among the group and to have the DLs begin to understand that the role of $\mathrm{EE}$ did not begin and end in Building 131, but rather its role was to focus on program issues and needs. These meetings were a subtle way of moving the energy toward a different focus. He was very instrumental in encouraging the EEs to become members of and partners with the programs. This stemmed from his positive experience with Ted Merkel during the Pluto Program.

\section{The 70s and 80s: New Programs and Organization}

\section{Lasers}

In the early 70s, a major new program began to evolve: Inertial Confinement Fusion
(ICF) or perhaps better known as "the Laser Program" or "Y-Program."

Laser activities had been going on since the mid-60s, but the effort was small and spread among A-, B- and Q-Divisions, all part of the Weapons Program. In the very late 60s, there were several small research machines built: Long John and 4 pi.

In 1971, the Director asked Carl Haussmann to pull together the various activities and focus on a major effort in Lasers. In 1972, Carl recruited and hired John Emmett to lead this effort. Emmett brought with him or hired not only new people skilled in laser development, but new ideas of how Engineering should support Y-Program. Engineering was accustomed, in the Weapons Program, to not only being an almost equal partner, but to also having responsibility and authority to carry out the design and fabrication activities nearly independently from the program scientists.

\section{Emmett saw this differently.}

He envisioned that the engineering personnel assigned to Lasers should be integrated into the program and managed by the program. Not only should they receive the program goals and objectives from the scientific staff, but also the scientific staff should have veto power over engineering decisions. 
This form of engineering integration was used in the CTR Program, but to a more limited degree. Engineering in CTR maintained a more independent position than was desired by Emmett.

Although Emmett never acknowledged that the Engineering organization could or did make a contribution to the Laser Program, he was very supportive of the quality of the engineering people and of the ability of Engineering to move people in and out of Lasers. The challenges to Engineering Management and to the engineering personnel assigned was to develop a relationship with Lasers that was different than anywhere else at the Laboratory while maintaining sufficient discipline to carry out engineering functions in innovation, quality, safety, and reliability.

Eventually, the solution was to put a few senior engineers who Emmett trusted in places of major engineering responsibility and have them direct the engineering effort. Once Emmett had confidence in the senior engineer, he gave him authority to carry out the assigned responsibilities and budget authority as well.

Another major change was that Engineering needed to be very cost conscious in a different way than they were in the Weapons Program. As there were thousands of parts in a large laser system, holding individual component costs down had a big impact on final laser cost. For example, Nova had 10,000 capacitors as its flash lamp energy source, thousands of electrical connections, hundreds of optical components, thousands of parts machined from stainless steel, and thousands of nuts, bolts, seals, and washers. So even small changes in their unit cost resulted in big savings.

The majority of the Laser components were made by outside contractors. Therefore, major engineering effort was required to communicate with and follow each purchase. Accuracy, quality, cost, and schedule were always of prime concern.

Engineering was also challenged to provide personnel (engineers, designers, associates, coordinators, and technicians) and services in pulsed power, optics, electro-optics, computer control, clean room operations, precision fabrication of optical surfaces, optical alignment, and structural vibration specialists. Many of these disciplines were new or in very short supply within Engineering.

Emmett also wanted to bring in people with experience and not hire new graduates and then train them. Engineering's usual mode was to hire bright advanced degreed engineers fresh out of college and train them on the job. Engineering quickly adapted to Emmett's plan, but it required a change in recruiting efforts and applicant assessment methods. Hiring experienced engineering personnel also impacted employee evaluation and salary

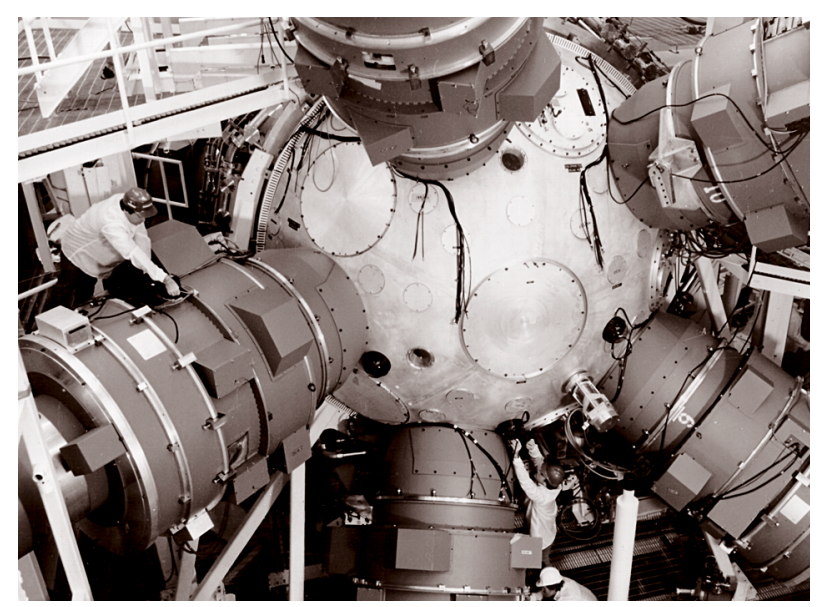

Nova target chamber. 
administration, especially with regard to senior engineering staff.

These were all problems that had to be worked in real time and coordinated with Laser management.

The major ME accomplishments in the Laser Program were the development of the process for grinding and polishing of optical surfaces; the design and fabrication of optical components; the development of seismically and thermally stable large optical benches by learning how to weld and prefabricate mechanical assemblies; and the development of a Class 100 cleanroom to assemble the laser amplifiers.

For the EEs, their major contributions were: the development of a very large distributed control system consisting of 74 computers used to control five different subsystems-a significant advance in machine control technology; the development of packaging techniques for pulsed power systems, including high density capacitors for energy storage; and the development of state-of-the-art diagnostic systems. These systems included streak cameras and detection components fabricated by the microelectronics facility. Some of these components were zone plates, pinhole arrays, laser targets, microchannel coolers, field emitters, and diffraction gratings.

\section{The AVLIS Program}

The AVLIS (Atomic Vapor Laser Isotope Separation) Program began in 1974 as a part of the Laser Program. By May 1975, LIS produced a small amount of reactor grade uranium, the first known use of lasers to enrich uranium on a larger than microscopic scale. The critical technologies in this program were the development of copper vapor and dye lasers used to separate isotopes of uranium, and the separator where the desired isotope was separated from the feed material.

The copper vapor lasers presented significant mechanical engineering problems. Heat transfer, optics, vacuum, material erosion, and mechanical assembly needed to be solved in a self-contained unit that was a subset of a series of identical units. The dye lasers presented problems in fluid flow and optics. The EE problems were the development of pulsed power units for the copper vapor laser and integrating them into the overall laser package. 


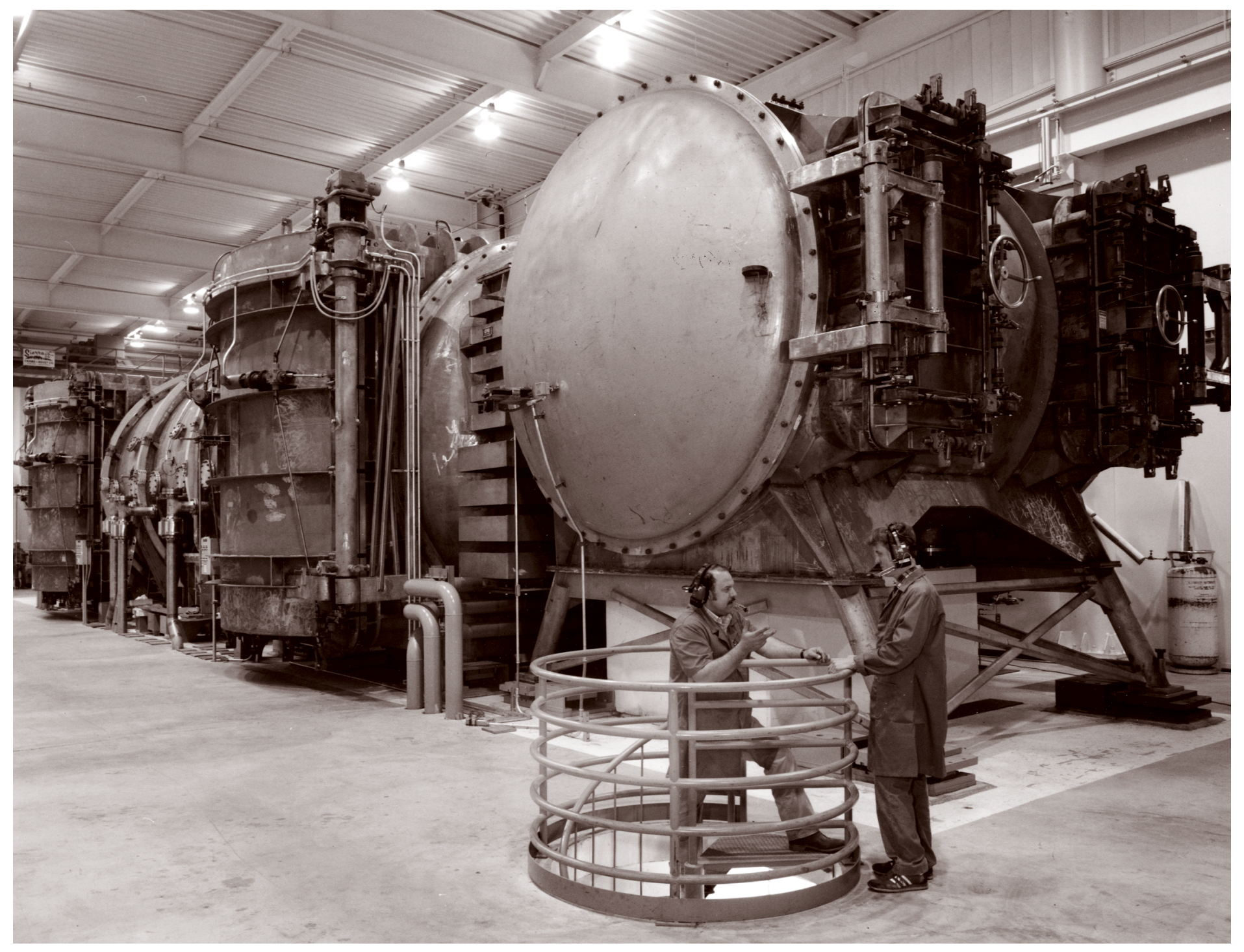

AVLIS separator, an early design, circa 1980. 


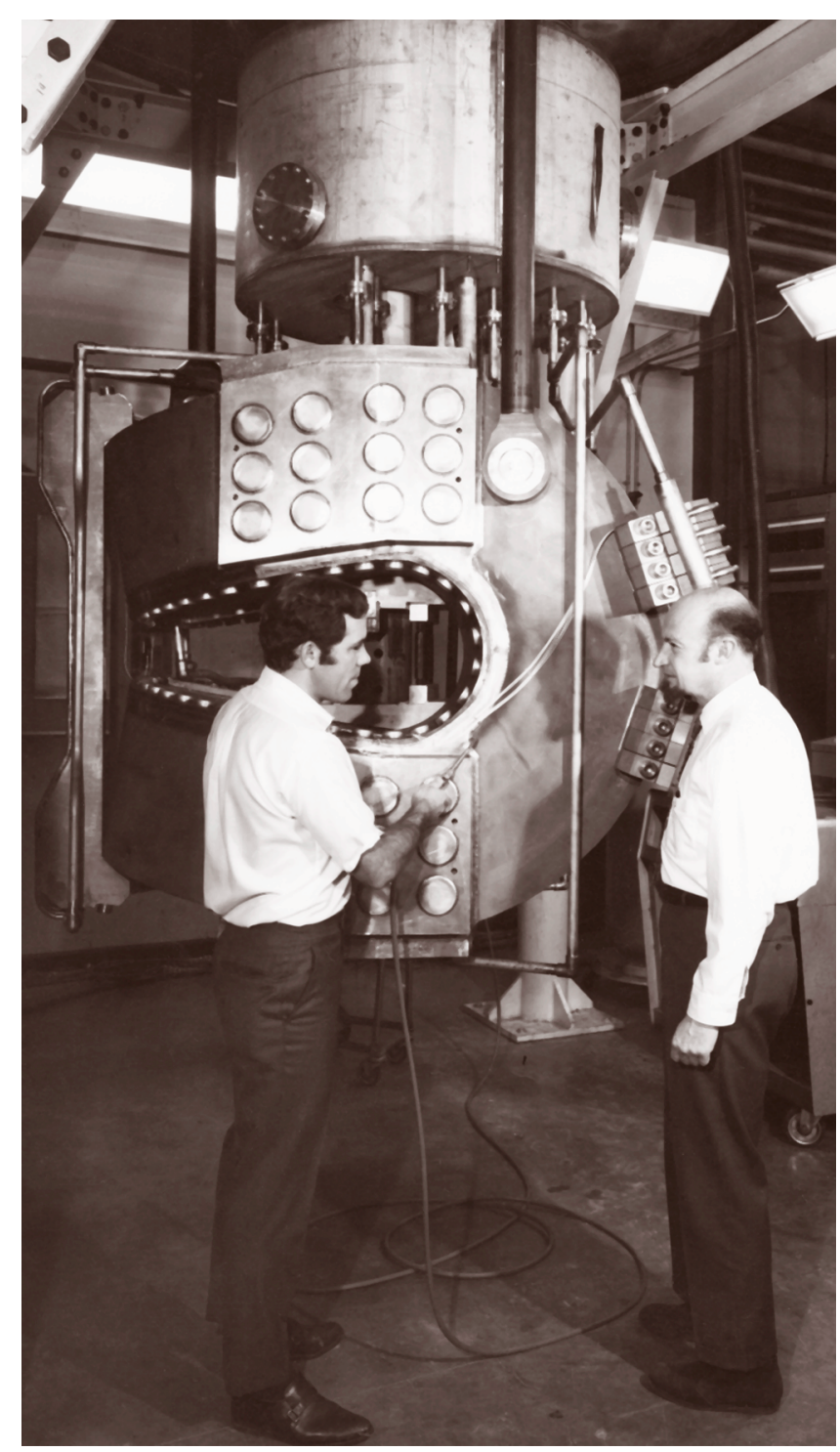

Carl Henning (I) and Charlie Damm (r), Baseball experiment, Magnetic Fusion Program.
The separators were a mechanical nightmare. Electron beam heating was used to melt the feed material. Special metals were needed to collect the product and to carry off the spent feed material.

Since AVLIS was intended to replace existing processes to produce reactor grade uranium, Engineering needed to design the system components toward commercial grade products that could eventually run for hours without failure and replacement. To help achieve commercialization of AVLIS, DOE brought in private contractors to work with the Laboratory personnel in the development and operation of the AVLIS equipment and testing. This was again another operating environment that Engineering needed to accommodate.

The AVLIS development and testing proved successful but other conditions, economics and politics, combined to cancel it.

\section{Magnetic Fusion Energy}

While Lasers was rapidly expanding, the Magnetic Fusion Program was also growing. Large new magnetic confinement machines were being built. The Princeton Plasma Physics Laboratory (PPPL) focused on the Tokamak method for plasma confinement, while LLNL was focused on the Magnetic Mirror method.
Carl Henning's method of using liquid nitrogen to cool the coils for the magnets on the Baseball experiment was the breakthrough technology that permitted the development of very high field magnets. The $2 \times 2-B$ machine was a single yin-yang magnet. TMX was two yin-yang magnets connected by a long solenoidal section, and was characterized by the addition of neutral beams to build plasma density and increase plasma temperature.

Neutral beams required high voltage, high current, fast switching, and rapid vacuum pumping. Tom Batzer, ME, developed the vacuum systems for TMX (Tandem Mirror Experiment) and Tony Chargin was the Project Manager. TMX also used LN cryo-panels and had internal gettering panels to enhance the pumping speed. The magnets on TMX were water cooled.

The next machine was to be the Magnetic Fusion Test Facility (MFTF), with Victor Karpenko as Project Manager. This was a larger version of a single yin-yang magnet system. However, early results from TMX indicated that the tandem was a promising design, so MFTF was re-funded to be a tandem machine and titled MFTF-B.

A major development on MFTF-B was the use of liquid helium cooled superconducting magnet coils. ME, led by Ray McClure, designed 
and built the magnets on site. Significant work went into the development of the superconducting wire and the associated refrigerant system needed to maintain superconductivity. Eventually two 400-ton magnets were built and installed.

The neutral beam sources were built in-house, designed to operate at $80 \mathrm{kV}$, which presented a very difficult design and fabrication job-it was necessary to maintain high voltage at high current, with large vacuum requirements and no sparking. The sources were a development project never before attempted on this scale and were a constant source of breakdown and redesign.

Meanwhile EE was involved with the procurement of the neutral beam power supplies and modulators-24 large pulsed power systems. After high level review, Engineering and $\mathrm{EE}$ Management recommended that a prototype be built in-house and the NB power supplies be procured on CPFF basis. However, Procurement required a fixed price contract, even though the NB power supplies were a development project in their own right. This was a major error. Not only were there significant cost overruns, but the supplies did not operate as required. Eventually they were made to work, and after the MFTF-B full power test, the supplies and modulators were transferred and used by other DOE contractors.

MFTF-B was operated at full magnet current, the magnets were quenched, a few of the neutral

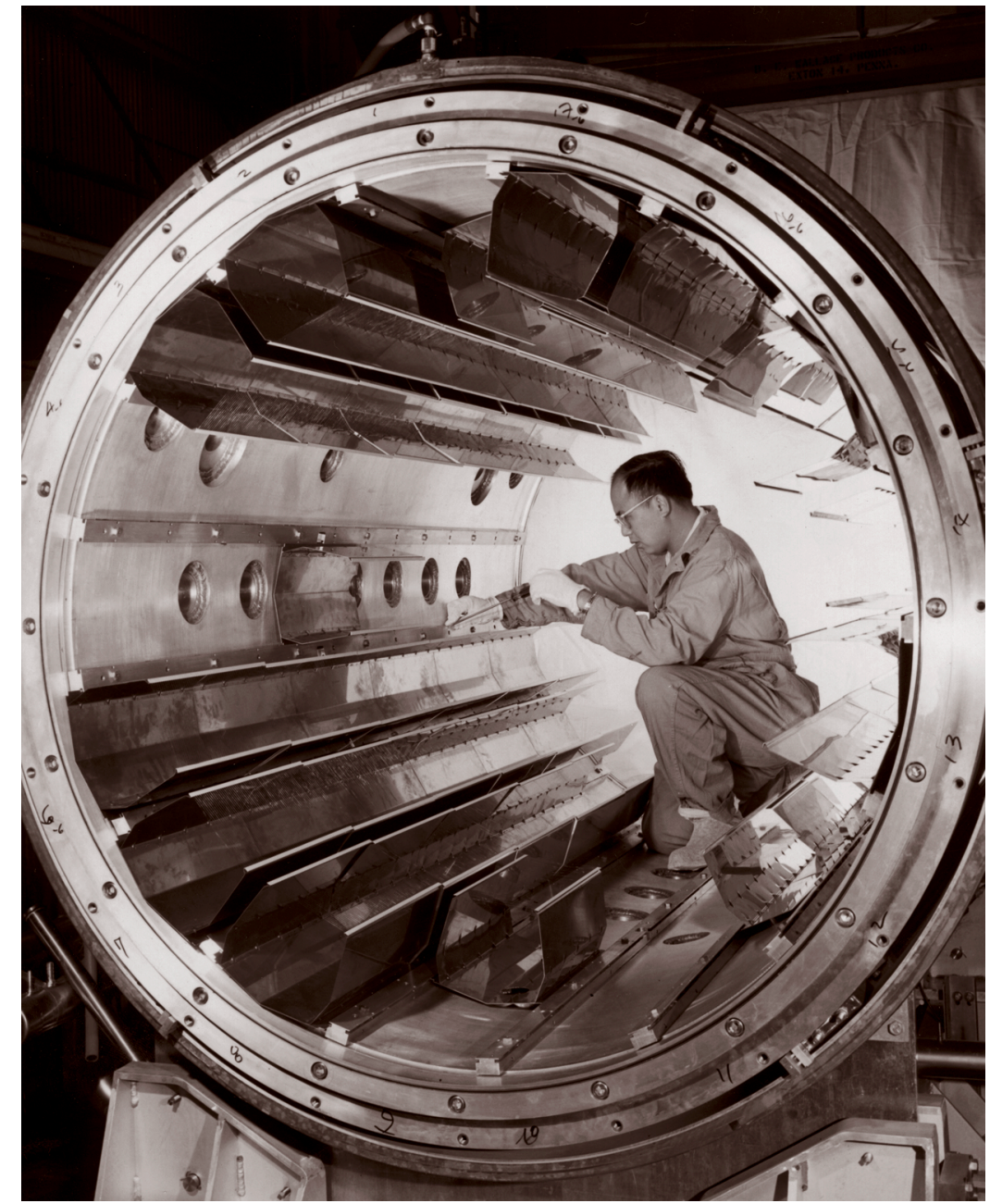

Tandem Mirror Experiment (TMX), Magnetic Fusion Test Facility. 
beam sources were operated at full power, and the entire system was remotely controlled from a state-of-the-art computer control system design built by EE and Computation. Additional results from TMX indicated that MFTF-B would not achieve physics expectations, so DOE decided to mothball it.

Concurrently with the MFTF work, Defense Advanced Research Projects Agency (DARPA) was funding work on large-scale induction accelerators. The goal was to generate very large particle beams, which could be directed at incoming missiles. Since the MFE Program had many years of experience in the development of induction accelerators, e.g., Astron, the work on the Experimental Test Accelerator (ETA) was done by some of the same people. This was primarily true of the EEs doing the pulse power design.

A follow-on machine, ATA, was designed, built, and operated at Site 300. Although its long-term mission was never accomplished, ATA was a very successful project. Major electromagnetic modeling work for the accelerator cavity was successfully done by EE.

When the free-electron laser became a candidate for an anti-missile weapon, the ATA was used as the injector. Wiggler magnets were first tested on the ETA in Livermore, and then a larger wiggler was designed, built, installed, and tested at the ATA at Site 300.

\section{Engineering's First Associate Director}

The mid-70s to the late 80s was a watershed period for Engineering.

On September 10, 1973 Henry McDonald was appointed the first Associate Director for Engineering. He had responsibility for both $\mathrm{EE}$ and $M E$, and reported to the Laboratory Director, Roger Batzel.

His first goal was to bring

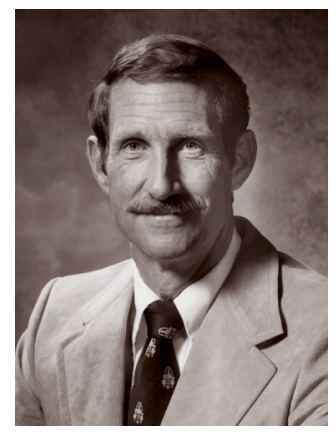
these two major labora-

tory organizations into a more unified position. He tried to accomplish this by establishing an executive committee consisting of the two Department Heads-Walt Arnold for ME and me, Ed Lafranchi, for EE-and the leaders of any program for which Engineering was responsible.

In addition he began weekly meetings of the Division Leaders of EE and ME-a way for 
him to pass information to everyone, and to encourage them to see themselves as a combined group. His vision was that Engineering could make a programmatic and institutional impact that was greater than the sum of its parts. Hank was able to influence the transfer of key people to assignments of major programmatic importance, and thus Engineering became a partner in the success or failure of large projects.

It was during Hank's years as AD that the Engineering Research and Development Program took shape. Lynn Cleland was a major contributor to this effort and was responsible for finding and hiring PhD engineers in EE. Ron Carr, who put together the ME Code Development Group, instituted a parallel effort in ME. The respective departments managed the R\&D programs, but Hank set their direction and funding. They were funded from a combination of Engineering research money that came through the Weapons Program, indirect money (a tax on Engineering technical personnel assigned to the programs, used to move the research through the development process), and overhead money from the Laboratory's general overhead, used for facility improvement, maintenance, and new functions.
This model proved to be very effective. Significant progress was made in Precision Engineering, principally with Diamond Turning Machines; Mechanical Engineering Code Development (with the modeling code DYNA); and Computational Electromagnetics to model EMP effects on power grids and aircraft and missile surfaces, especially antennas; Image and Signal Processing; and Solid State Electronics.

In the early 80s, the concept of Thrust Areas (TAS) for Engineering R\&D began in EE, through the efforts of Ed Miller, ERD Division Leader, and Gordon Longerbeam, Deputy Department Head. The five original EE TAs were Signal and Control Engineering, Engineering Modeling and Simulation, Diagnostics and Microelectronics, Microwave and Pulsed Power, and Computer-Aided Engineering. The six original ME TAs were Code Development, Computer-Aided Engineering, Fabrication Technology, Materials Test and Evaluation, Measurements Engineering, and Nondestructive Evaluation.

It was at this time that programs were embarking on major engineering-intensive projects. In Lasers, there was the succession of 


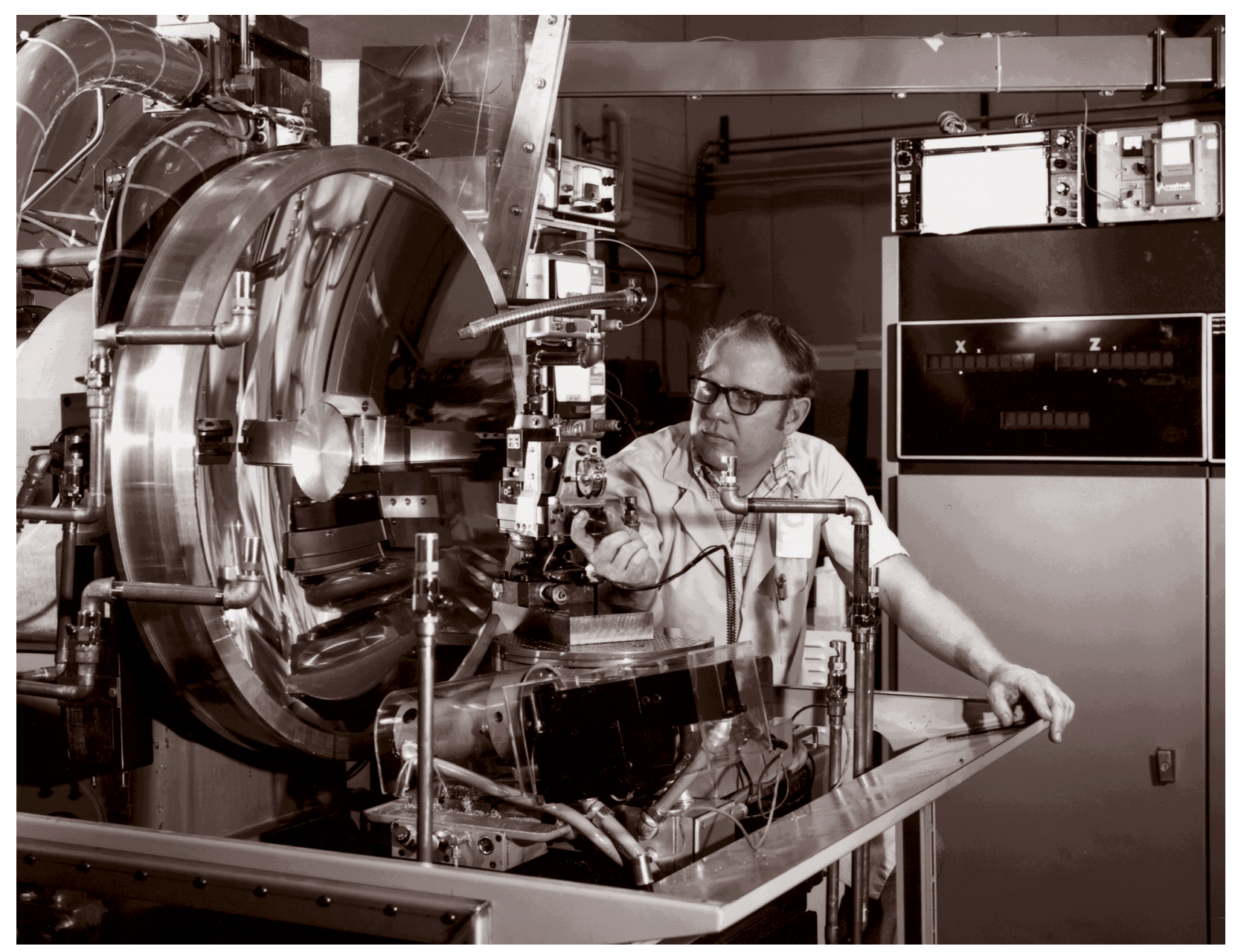

Diamond Turning Machine No. 2 (DTM-2) machining a mirror for the Laser Program, circa 1974. Moore Special Tool Co. later commercialized this machine and it was used to fabricate Forward Looking Infrared optics, to machine computer memory disks, and to machine molds for contact lenses. laser systems: Cyclops, Janus, Argus, Shiva, and Nova. In MFE, there were 2XII-B, TMX, MFTF-B, ETA, and ATA. In Weapons, there were FXR, the B-83, the W-84, and the W-87 warheads, the two-stage light gas gun, and the $x$ ray laser program. Each project had its unique requirements, but they all had in common the need for high quality, reliable, state-of-the-art engineering knowledge.

All the projects were engineering successes. By 1985, Engineering had grown to about 3000 people, 1200 EEs and 1800 MEs.

During this same time, Engineering was also building large, sophisticated machine tools: Diamond Turning Machine 3 (DTM-3) and Large Optics Diamond Turning Machine (LODTM). DTM-3, a horizontal axis machine, was under the direction of Jim Bryan, the father of diamond turning. Ray McClure directed LODTM, a vertical-axis machine, obtaining funds from ARPA for the machine construction and operation and a building to house it. LODTM was the only way to machine annular mirrors for the proposed Alpha space laser.

While the programs were embarking on these projects the Laboratory was moving rapidly with the expansion of its computational capabilities by adding the latest in large-scale computer systems and extending their reach 
to a broader user base through the time-sharing system. The Octopus system began in 1963 with the delivery of the CDC 6600, but it was limited to a few users. Bob Wyman, EE, built the hardware and Bob Abbot, Computation, developed the software.

As more computers were delivered and software developed, more hardware was designed, fabricated, and installed. Coaxial cables and telephone lines were extended from the Computer Center to the classified areas of the Laboratory. Data was sent via phone lines, while pictures were sent via coaxial cable. More and more users of the classified system went on-line using the new systems. Electronics Engineering was deeply involved in the evolution of this hardware and software. It wasn't until the early 1980s that any large amounts of appropriate commercial hardware became available. As a result, EE designed nearly all of the hardware needed to interface the computers with the input-output equipment.

In the late 60s, Digital Equipment Corporation brought out the PDP-8. The EEs saw how this small computer could be useful for experiment control, data collection, and limited calculations. At this time the Computation Division very tightly controlled all computer acquisition. Sid Fernbach

Computation Division Leader, was opposed to installing these machines throughout the Laboratory, as he believed that it was not as cost-effective as running calculations on the computers in the Computer Center. However, there was overwhelming interest and pressure by potential users. Consequently, Glenn Strahl and I from EE, and Ray Dessasure from

Computation began an effort to educate potential users and to review requests for new systems. This helped solve Sid's displeasure as we helped to assure him that the system requests were valid and the installation was not going to be used to bypass the Computer Center for major number crunching.

Another major activity was taking shape beginning in the early 70s. Intel Corporation had developed the 4-bit microprocessor, the 4004. This was followed by the Intel 8008, an 8bit integrated circuit. It was with great foresight that Gene Fisher and Gordon Jones saw the potential of these ICs and began teaching employees how they could be used in a laboratory environment. These ICs were also a way to bypass the formal requirements for the 
acquisition of computers imposed by the Congress, although by themselves they were not computers. However, as the IC capability expanded, they became the heart of the new wave of personal computers. Again, EE took the lead in introducing this new tool into the Laboratory by restricting the different manufacturers to a small number. This activity proved to have a major influence on how the Laboratory moved from no PCs to their current ubiquity.

Plant Engineering Transfers to

Engineering Directorate

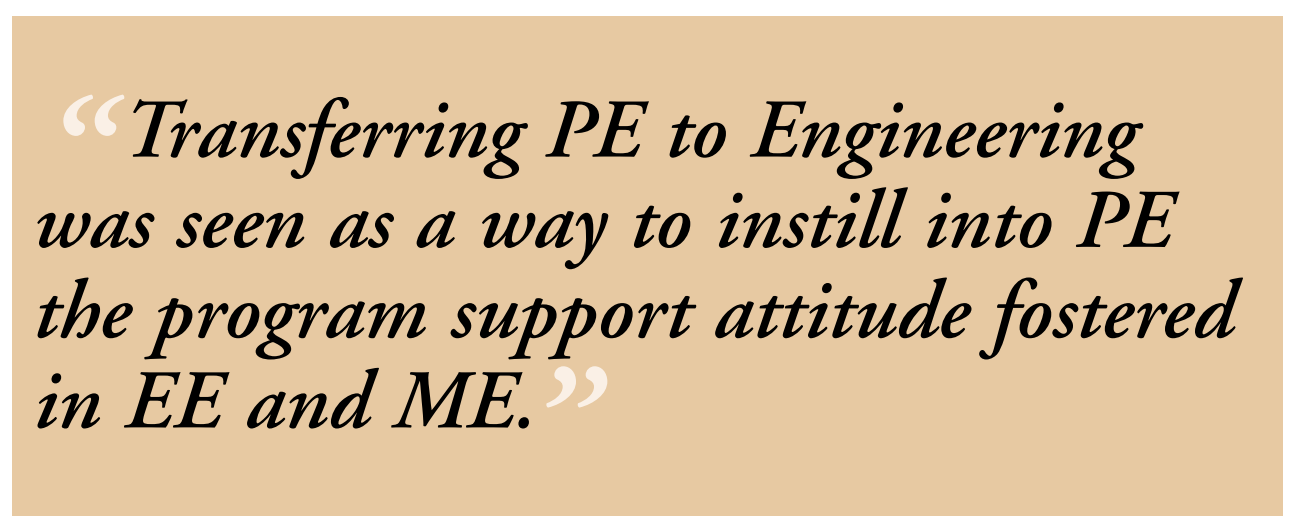

In 1978 the Plant

Engineering

Department was

transferred to the AD

for Engineering. Plant had the responsibility for the design, installation, operation, and maintenance of all Laboratory utilities except telecommunications. It was also responsible for building modifications and minor construction. Major construction projects were submitted for competitive bid.

Gene Broadman, a ME Division Leader, was named PE Department Head. At that time PED was viewed as not responsive to the needs of the programs. They were accused of being too costly, taking too long, overdesigning, not controlling costs, and having a bloated design, estimating and review system. In short, there was little good that was said about PE.

Transferring PE to Engineering was seen as a way to instill into PE the program support attitude fostered in EE and ME. In addition, this was an opportunity to transfer some leadership talent from the other two departments. Both EE and ME supplied senior engineers with supervisory and management experience to PE. Broadman made many organizational changes in an attempt to achieve the goal of improved program support and an enhanced image of professionalism.

The most visible change was the formation of program teams, assigned to support individual programs. These teams had a combination of engineers, designers, estimators, and crafts people under the direct supervision of an engineer. Some number of personnel in all disciplines were not assigned to teams, but made available for smaller programs or institutional activities that did not need dedicated effort.

Many of these changes improved the quality of the PE organization and the work. However, there remained the perception that 
PE was not getting the job done correctly, whatever that meant. It became obvious that $\mathrm{PE}$, because of the very nature of its work, could never achieve the same relationship with the programs that existed with EE and ME. The best that PE could do was "break even."

PE was transferred to the AD for Administration, Robert O. Godwin, in November 1985.

\section{A New Era Begins for Engineering}

Some months prior to his retirement, Hank proposed a major organizational change for Engineering: eliminate the $\mathrm{EE}$ and $\mathrm{ME}$ Departments and replace them with divisions containing both disciplines, each division aligned with a major program (Weapons, Lasers, MFE). His proposal also called for a single administrative function, a single research function, and a single manufacturing/fabrication function.

There were strong feelings both for and against his proposed changes. Unable to achieve consensus, the proposal was not implemented. Hank retired in June 1986. His successor, Dennis Fisher, was named AD on June 18, 1986.

One of Dennis's first objectives was to revisit Engineering

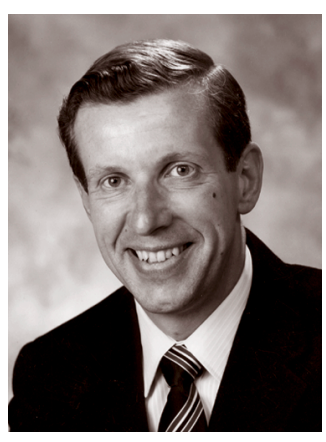

Dennis Fisher reorganization. He completed a review in November 1986 and made several changes. EE and ME were to remain as the major discipline organizations but some common functions were assigned to a new activity, Engineering Operations. EO was responsible for common administrative functions; personnel records, education and training, recruiting and hiring, salary administration; a unified Engineering Research program; ComputerAided Engineering and small computer support for the Laboratory.

Dennis appointed David Pehrson as Deputy Associate Director (DAD) for EE and Roger Werne as DAD for ME. I assumed the responsibility as the DAD for Engineering Operations.

Some of the major issues addressed by Fisher were as follows.

1) $\mathrm{EE} / \mathrm{ME}$ Integration. Fisher felt that the LLNL programs and cross-discipline technologies (e.g., laser engineering, precision engineering) required the ME and EE disciplines to work more closely together. To start this process, the ME and EE Department offices were colocated in the southeast corner of the first floor of Building 131. At the same time, a new DAD for Administration position was introduced, that sought to bring more coherence to Engineering's infrastructure and operations. 
Engineering Technology Centers

Effective March 2002

Center for Complex Distributed Systems David B. McCallen, Center Director

$>$ Center for Microtechnology Raymond P. Mariella, Jr., Center Director

$>$ Center for Precision Engineering Keith Carlisle, Center Director

$>$ Center for Computational Engineering Robert M. Sharpe, Acting Center Director

$>$ Center for Nondestructive Characterization Harry E. Martz, Jr. Center Director
2) Engineering Research. Engineering Research had been under attack by the rest of the Laboratory and needed to demonstrate its relevance to the programs. A lot of effort was put into restructuring the programs, gathering program input, subjecting proposals to high level external reviewers, managing the projects, and publishing results. As a result, the reputation of the Engineering Research Program was considerably enhanced and, in a Director's Program Review, declared to be a non-issue.

3) Microfabrication Facility. Microfabrication technology was beginning to take off and appeared to be a key technology for the future. EE's microfabrication facility in Building 131 had outgrown its space. Through a series of interactions with the Director's Office (Jack Kahn), various locations were explored.

However, none appeared satisfactory. Proposals were made and ultimately supported for capital funds to build a new dedicated building (Building 153, the Microfabrication Facility).

Director John Nuckolls appointed Fisher as Laboratory AD for Administration and Operations on September 7, 1988. I became

acting $A D$ for Engineering until the appointment of Roger Werne as AD for Engineering on January 18, 1989. Following the move of Werne from DAD/ME to AD, Tony Chargin became

DAD/ME on March 31, 1989

In the next decade Engineering was led by

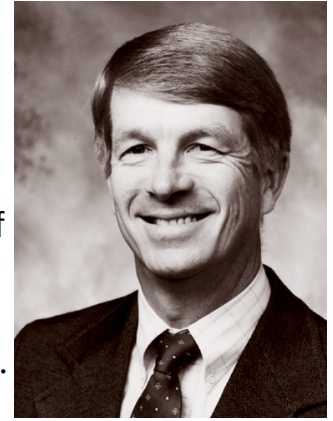

Roger Werne ADs Roger Werne (see the following section) and Spiros Dimolitsas, whose tenure ended in November 2001. Under Dimolitsas, Engineering focused on:

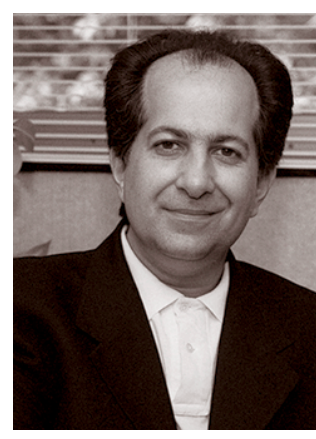

Spiros Dimolitsas
Centers of Excellence. The centers maintained expertise in areas such as communication technology, precision engineering computation and numerical simulation, complex systems and information technology, microtechnology, and nondestructive characterization.

National Outreach. Dimolitsas worked to have Engineering recognized in the national engineering community, as a premiere engineering 
organization, and the Laboratory as a more technically diverse organization, rather than a purely scientific research lab.

Extreme Engineering. Under the logo "X-treme Engineering," Dimolitsas emphasized the synergy between the very small and the very large in

$$
\text { engineering. Very }
$$

ENGINEERING large facilities, like

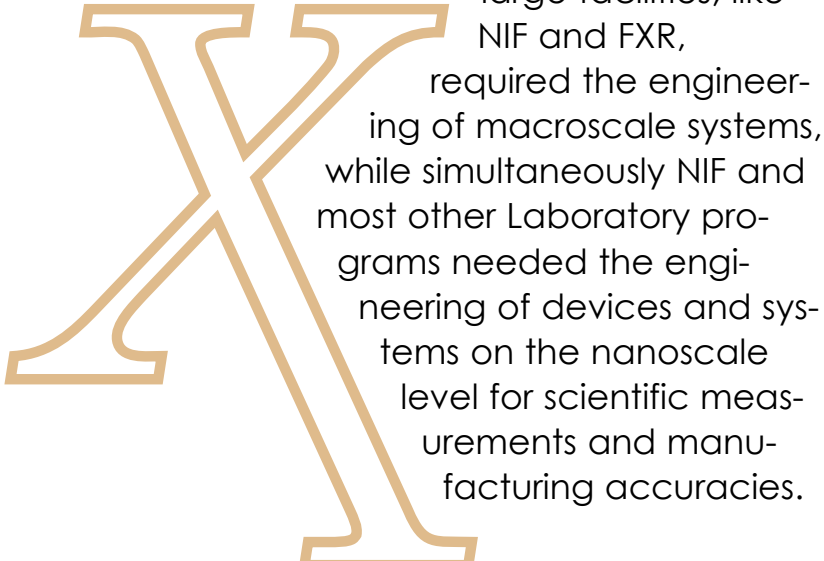

Pushing engineering science to the Xtreme
In January 2002, Glenn Mara was appointed AD for Engineering. Mara's mission is to assure Laboratory programs succeed by developing people and cutting-edge technologies.

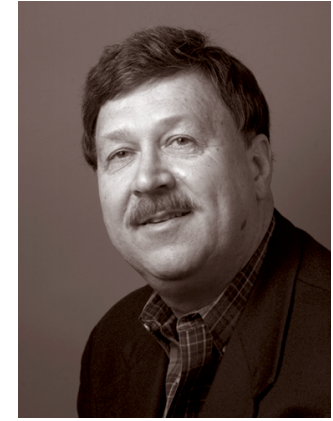

Glenn Mara
In the following pages, the contributions of Engineering to the Laboratory's history are presented by people who have had a great influence on its past, and its future. 
Engineering from 1989 to 1995 by Roger W. Werne

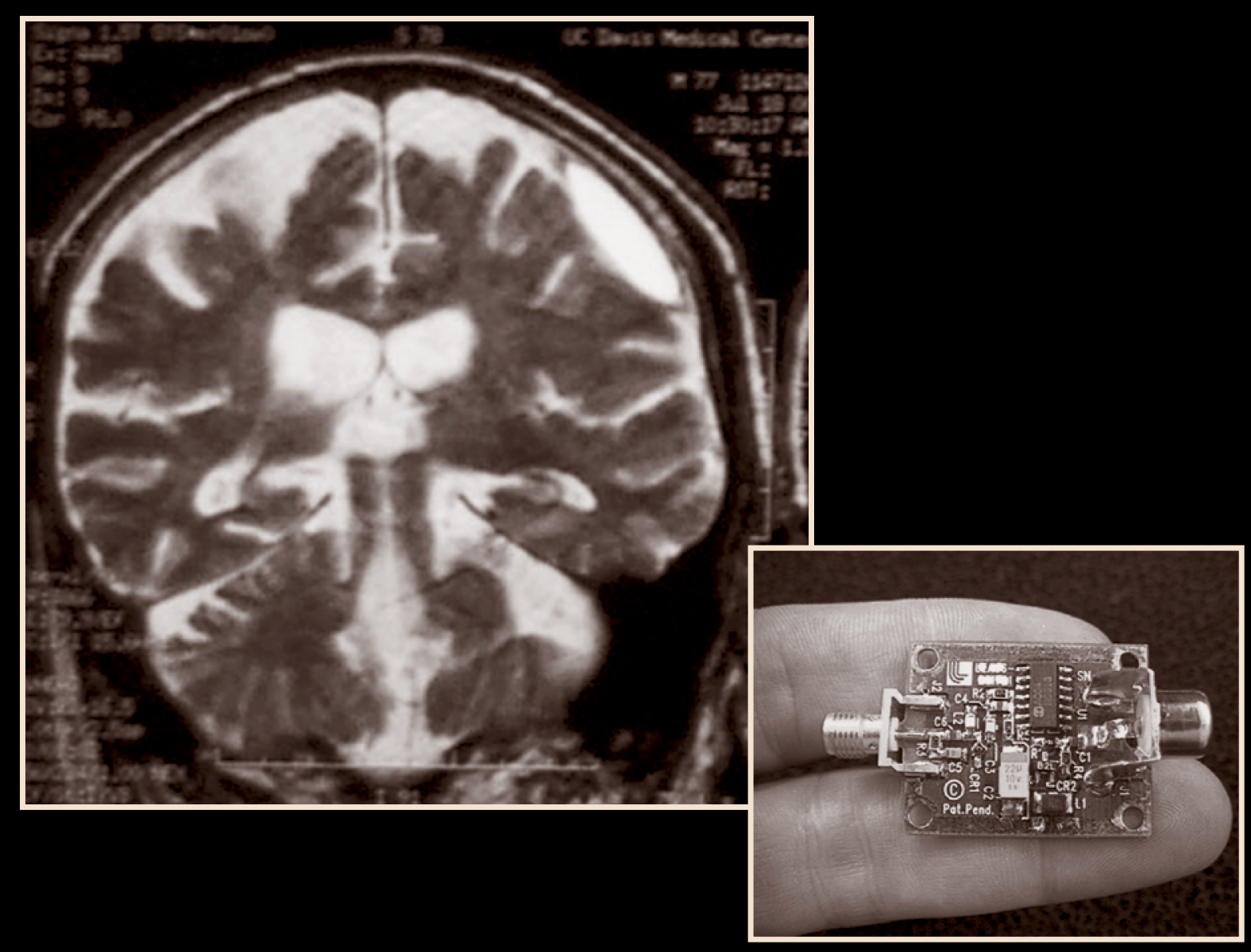


ittle did I realize in 1989 that the changes over the ensuing years would be so significant for the Laboratory and Engineering. The Soviet Union, our historic enemy and the Evil Empire, was collapsing under its own weight; Eastern Europe was opening up; the Berlin Wall had come down; and we as Laboratory employees could not believe what was happening.

Just months earlier, most of us believed that the Cold War would go on indefinitely and the Laboratory's mission of nuclear deterrence would always be an essential part of US national security strategy.

Another geopolitical process also emerged that would shape our future. During the mid 80s, Japan emerged as an economic and manufacturing superpower, challenging the economic preeminence of the US. Public anxiety about this was exacerbated by a sluggish US economy that was losing market share to Japan in virtually all manufacturing areas where they competed.

The election of George Bush to the Presidency in 1988 created another agent for change, in the form of Admiral Watkins, the Secretary of Energy. He came from Rickover's nuclear navy and had very strong opinions about how the national laboratories should be run with respect to environment, safety, and health regulation and operation; namely, the nuclear navy way. He was charismatic and didn't shy from the public eye, and was a close political ally of the President.

As it became clear that the Cold War was over and that we had prevailed, many began to talk of the "peace dividend" and downsizing

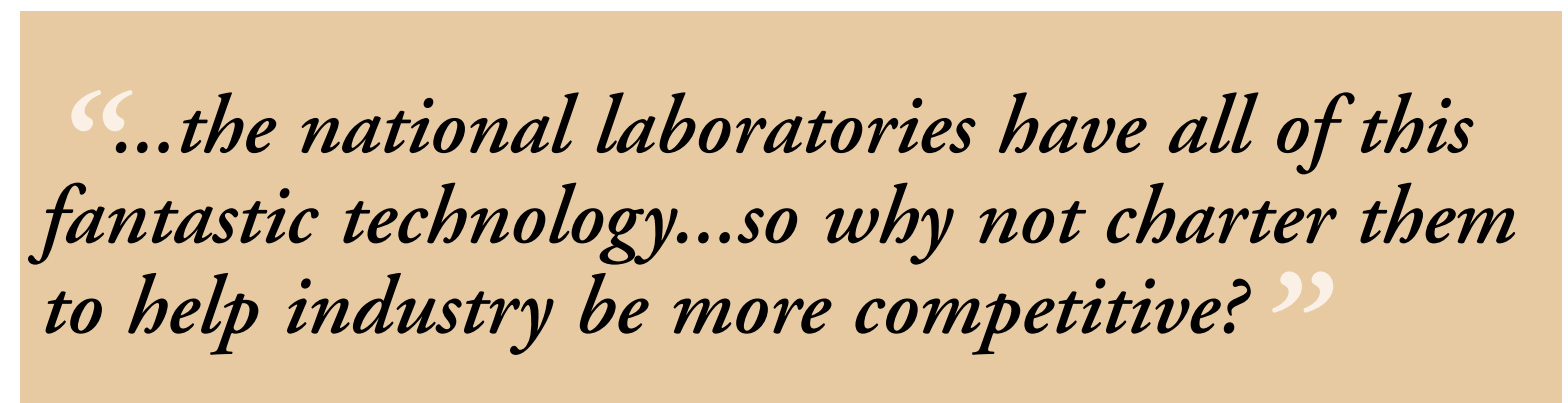

the Nuclear Weapons Program, or at least redirecting Laboratory efforts toward the problem of improving "US economic competitiveness."

The thinking in the Bush Administration was the following: US industry needs help retooling itself and modernizing its manufacturing infrastructure with new science and technology. And the national laboratories have all of this fantastic technology developed during the Cold War, so why not charter them to help industry be more competitive?
Left: Micropower Impulse Radar (MIR) allows noninvasive detection of hematomas following a stroke. 


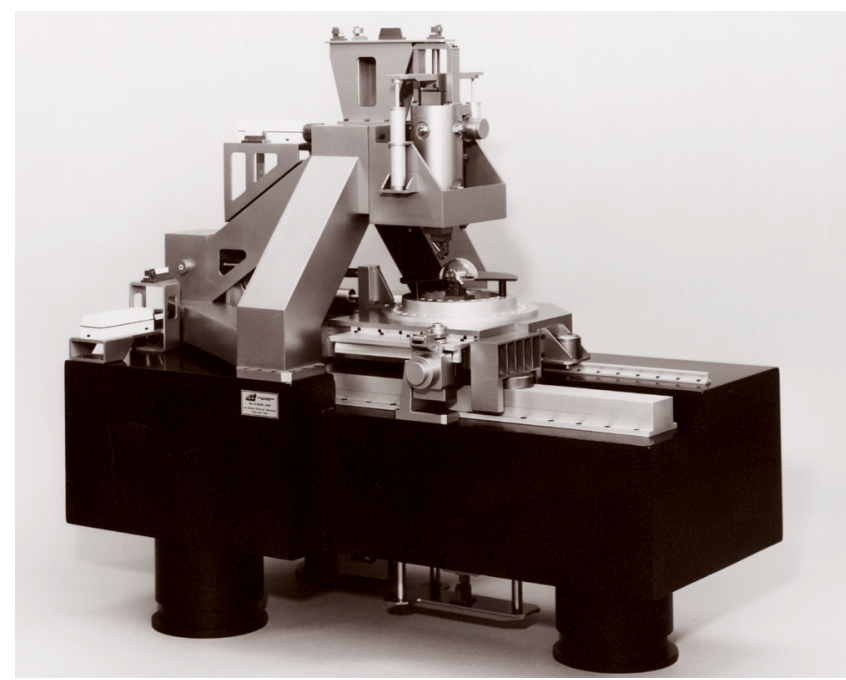

Certification of Process Gage (COP), circa 1988. A metrology instrument constructed to measure both the inside and outside of thin-walled shells and to serve as a measurement reference for other instruments. It was operated by an equally sophisticated computer control system.
Legislation passed by Congress in 1980, the Stevenson-Wydler Act, allowed the national laboratories to partner with industry on cooperative research and development and so, the technology transfer effort at the labs was born. Because there was some concern at DOE regarding the legality of the Laboratory engaging in this effort, subsequent legislation was passed in the late 80s clearly establishing the Laboratory's legal authority to enter into these arrangements. Between 1980 and 1989 the Laboratory was very active in technology transfer work.

The period of 1989 to 1992 was marked by the growth of the technology transfer programs at the national laboratories. Defense Program money was redirected from weaponization projects to technology transfer, to support efforts in joint R\&D with industry. The agreement was called a CRADA, i.e., a Cooperative Research And Development Agreement. However, there was some concern in some parts of the Weapons Program that DOE redirected too much money too fast which led to less than ideal CRADAs.
Then in 1991 the Bush Administration started a program called the National Technological Initiative, designed to help US industry regain manufacturing preeminence, with the aid of the national laboratories.

At LLNL, Engineering led the effort to develop relationships with industry, because most of the problems that industry wanted solved were engineering problems, and our people also had the most contacts. All of the strengths of engineering-including pulsed power, code development in electromagnetics, structures and heat transfer, microelectronics, precision engineering, optics, NDE, and materials - were marketed to industry, and industry loved what they saw.

By 1993 LLNL had about 60 CRADAs with industry, $\$ 155 \mathrm{M}$ in total value in various stages of negotiation ( $50 \%$ of the money from DOE and $50 \%$ from industry paying for its own effort). Half of these CRADAs were with Engineering teams.

During this same period, the Nuclear Weapons and Test Programs were still developing weapons and performing underground 
nuclear tests, albeit in an era of cooperation with the Soviet Union on such things as Joint

Verification Tests that were designed to develop an element of trust between the two sides.

Then in late 1992, the Bush Administration stopped all underground nuclear tests. The Test Program then began to go into a shutdown mode. Several weapons were in their final engineering development stage, but it soon became clear that without testing those would be the last new weapons to go into the stockpile.

In November of 1992, Bill Clinton was elected President and took office in January of 1993. The Clinton Administration embraced the concept of technology transfer and more money was put into the Technology Transfer Program. Technology transfer was talked about as a new mission for the Laboratory and in May of 1993, John Nuckolls officially changed my title to Associate Director for Engineering and Technology Transfer.

The Clinton administration further deemphasized the Weapons Program in terms of its need and value to the future of US national security, and the Weapons Program budget continued to decline. This decline affected Engineering in that programs such as Weapons Supporting Research and weapon Phase III development programs, which had long been the lifeblood of the Engineering technology base, were falling as well. The hope was that the funding from CRADAs would continue to keep Engineering's techbase strong and to some extent this proved true at least temporarily.

The years 1993 and 1994 were marked by the growth and enthusiasm of the Technology Transfer Program in particular, and the search for a new mission for the Laboratory in general. The Laboratory was somewhat rudderless, in the sense that its original purpose for existence was nuclear deterrence and the country now seemed to no longer need or want nuclear weapons.

Engineering was strongly and successfully interacting with industry and developing new programs. Engineering partnered with Lasers and Biology and Biotechnology Research Program (BBRP) to build the Medical

Technology Program, and with Energy to build the Transportation Program. The Fission Energy Systems Safety Program (FESSP), which had

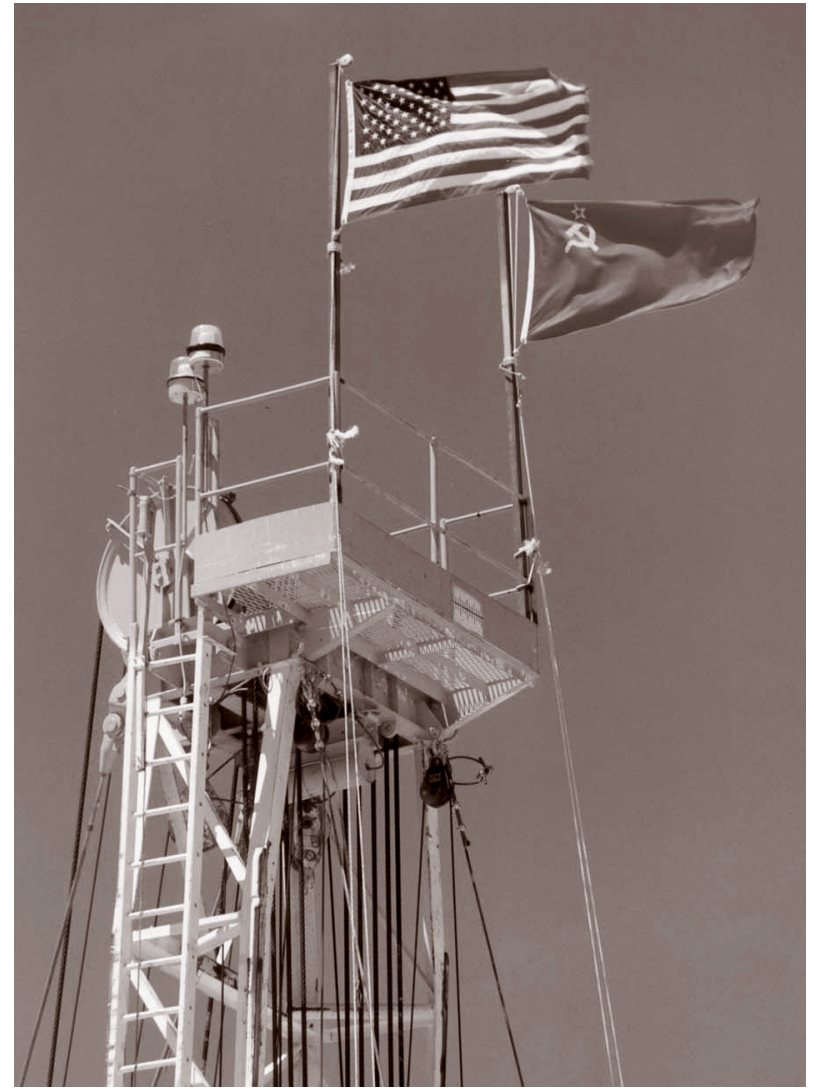

Joint Verification Tests were designed to develop an element of trust between the the US and the Soviet Union. 


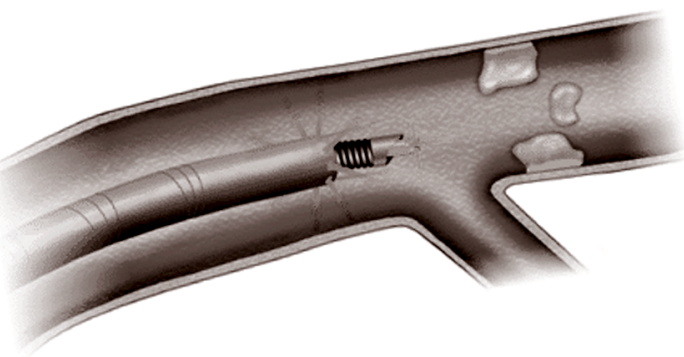

Artist's conception of an advanced imaging catheter inside an artery. The radial rays represent the infrared light emitted by fiber optics at the tip of the catheter. Extending from the catheter tip are optical fibers used to guide the catheter. been in Engineering from the outset, was also growing rapidly.

Engineering was so successful at program development that concern grew that we were becoming too large, and were in danger of being unable to do our primary job, to support Laboratory programs. At this point, I decided to shift several Engineering-developed programs over to other Directorates.

The Transportation, FESSP, and

Manufacturing Programs went to the Energy Program, and the Medical Device Program went to BBRP. These Programs were run by engineers who were transferred to the new AD's payroll group.

In 1994, a Republican Congress came to power and they were less than enthusiastic about Technology Transfer. They considered it "corporate welfare." The Republican Congress was also concerned about the state of the Nuclear Weapons Program and its seeming state of disarray. The Secretary of Energy named Vic Reis as the head of Defense Programs in DOE. Reis's marching orders from Congress, and presumably the Clinton Administration, were to refocus and rebuild the Nuclear Weapons Program. He started by deemphasizing technology transfer, and began moving money from technology transfer back into the Nuclear Weapons Program.

This trend of deemphasizing technology transfer and attempting to reinvigorate the Weapons Program was continuing when I left Engineering and the Laboratory to begin a start-up company in February of 1995. 


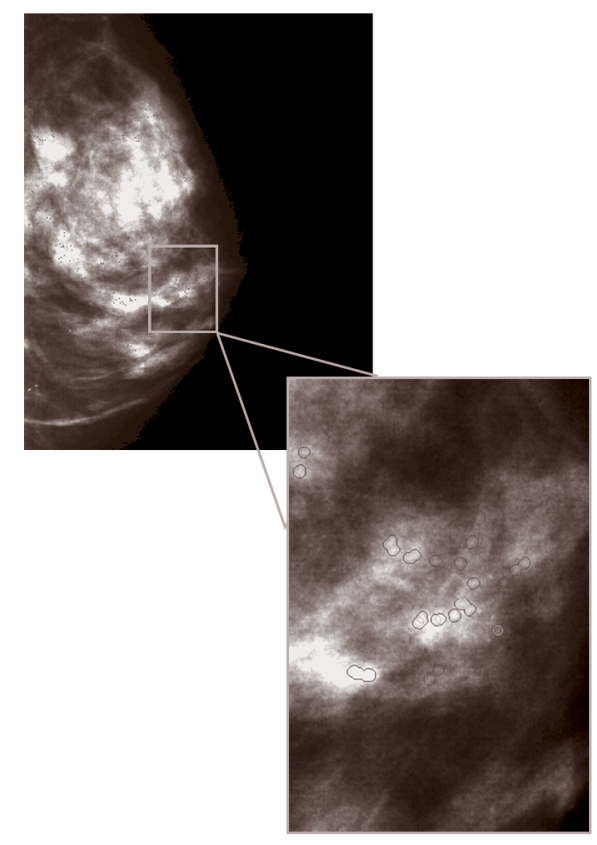

The full mammogram (top) is

inspected computationally and areas

of interest are highlighted. The inset is a

full-resolution view of the highlighted

area, showing calcifications found by

the computer. 
Engineering in the Test Program

by Gordon Longerbeam and Jim Page

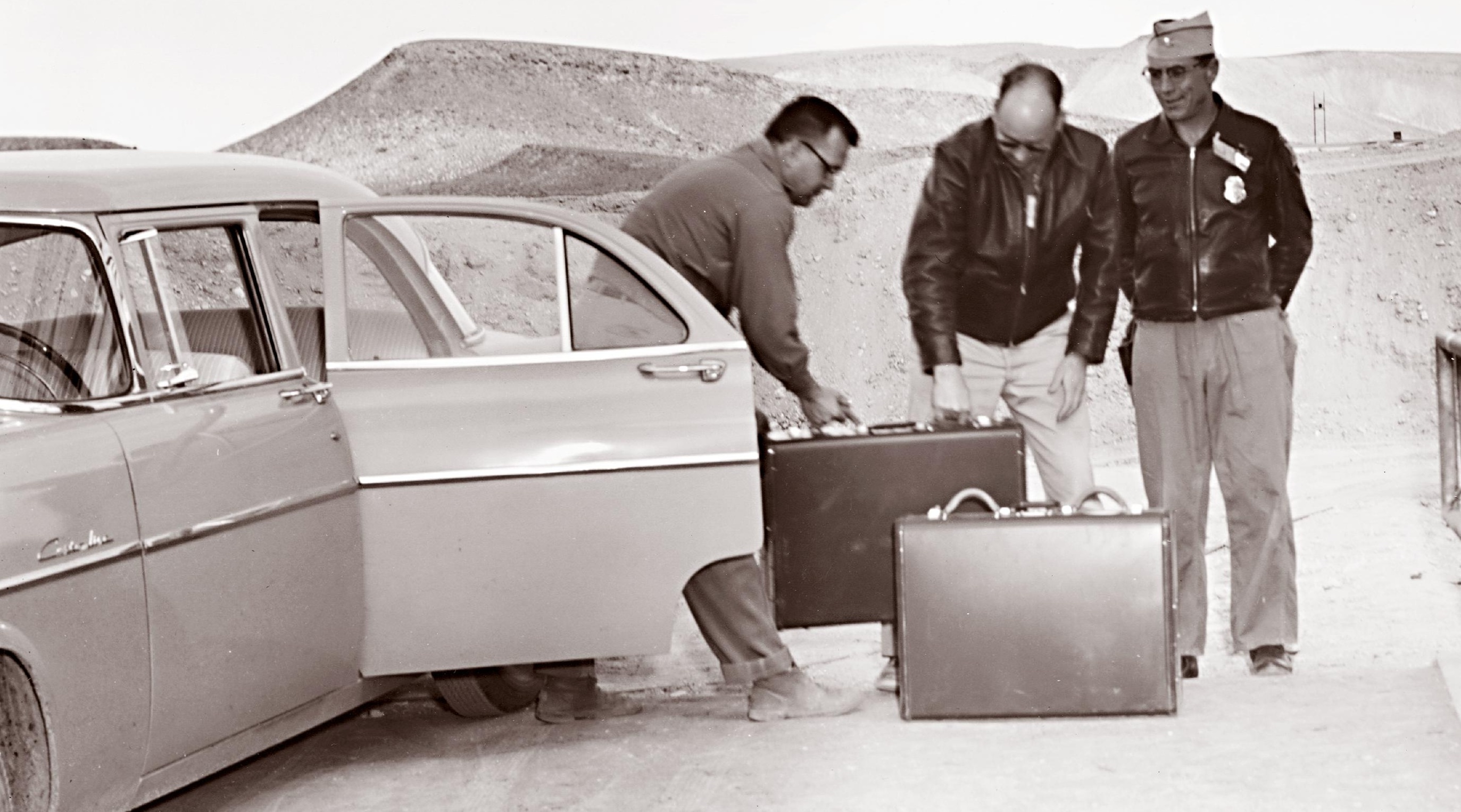




\section{The Culture of the LLNL Test Program and Engineering}

Ne've seen, earlier in this document, how 1 the matrix style of management came to characterize the newly formed Livermore Laboratory. Most agree that this organizational style decision was, and remains, one of the key factors of the success of Livermore programs, including the Test Program.

The culture of the Test Program itself, however, was at least as important as organizational style with respect to how engineering contributed to the successes of the Test Program, and later to the Plowshare Program.

The Test Program was organized around Physics (L Division), Engineering (Electronics and Mechanical), and Chemistry (Nuclear Chemistry), and a small permanent staff of Laboratory people at the Nevada Test Site (NTS).

The key element of the Test Program style was a tight project team, consisting of people assigned from each of the supporting organizations. The project team was responsible for the safe, timely, and successful fielding, detonation, and diagnostic measurement of each nuclear test, under the overall leadership of a Test Director. Each supporting organization was allowed and encouraged to have its own technology base and R\&D support using Test Program financial resources. People within each supporting organization tended to be moved back and forth between field assignments (project event teams), technology base development, and R\&D.

Direct experience in testing in the field was key in further technology development in the laboratory. Technology-base development and R\&D were also supported by Laboratory people not necessarily assigned full-time to the Test Program, but with important and relevant specialized skills. And very importantly, R\&D was also supported by EG\&G, Sandia, and others in US industry.

In the case of EG\&G and Sandia, they also provided key members of the event teams. The leveraging of industrial technologies and capabilities into the Test Program, by

Engineering, would lead to major advances in our abilities to successfully execute tests of increasing complexity over the years.

The role of the LLNL people, Engineering and others, permanently hired into the Nevada
Left: Walt Arnold, Art Werner and an unidentified guard delivering a small device at Nevada Test Site. 


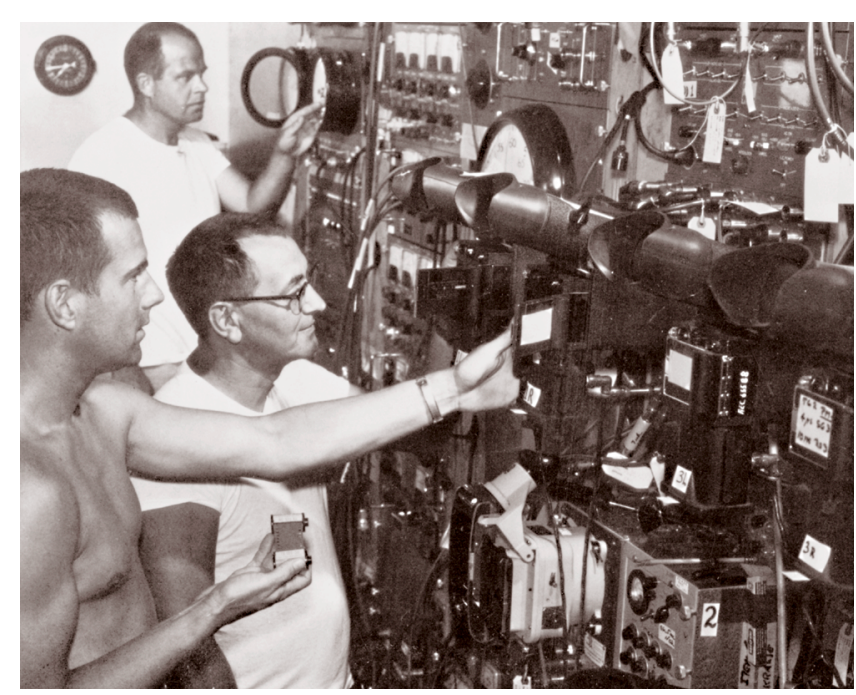

Ted Hamm, Hank Kuckenmeister, and Bob Boben making camera adjustments before Operation Dominic, circa 1962 organization deserves special mention. They included engineers and technicians assigned to support diagnostics measurements on the tests and to provide those functions akin to Plant engineering or Hazards Control. The electronics engineers and technicians were critical in making prompt diagnostic measurements on many events, and engineers such as Bill Geiri and Mike Ekstrom eventually moved to Livermore, taking on key leadership roles.

There was also a Mechanical Engineering Group to support the device and diagnostic effort at NTS. Also there was a Field Engineering Group that focused on construction, drilling, and field operations. While these groups were not administratively part of Mechanical Engineering, there was a relationship established that was critical to the successful execution of testing operations. Simply put, the Program assigned to ME the responsibility to ensure that the mechanical and civil/structural aspects of the tests were executed safely and consistent with accepted standards.

Several Livermore engineers, Larry Crooks, Cliff Bacigalupi, Larry Ferderber, and Lee Loquist, all experienced in the Test Program, would take on roles as Resident Manager of LLNL activities and people at NTS.

\section{The Early Days: 1952-1958}

With the establishment of the NTS in 1951, and Livermore in 1952, much was to change as we entered the era of underground testing and the beginnings of transistors and solid state electronics. (The general nature of diagnostic systems and arming systems for nuclear explosives testing was largely established and fairly well documented in reports such as NRL Report 4354, Analysis of Systems for the Recording of Exponential Signals, by R. V. Talbot et al., 1954, sometimes referred as the "diagnostics bible.")

Immediately after the establishment of the Livermore Lab, engineers went to work to build systems to support nuclear testing. Prior work at NRL (Naval Research Lab) and EG\&G led to the development of specialized oscilloscopes, streak cameras, and other specialized electronic systems to measure nuclear device performance. Much of this was not immediately available to Livermore, or was felt to be somewhat cumbersome or perhaps outdated by newer technology. Among the early engineers designing and fielding LLNL systems and equipment for testing were Jim Bell, Wally Decker, Otto Krause, Hank McDonald, Al Hyne,

Frank Inami, and Walt Arnold. Timing and countdown systems were provided by EG\&G, arming and firing systems by Sandia. But diagnostics measurements and systems, as well as 
the nuclear device itself, were to be the domain of Livermore engineers.

Early nuclear testing was in the atmosphere and diagnostic measurements of importance included reaction history, or the precise measurement of the exponential growth of neutrons (by measuring the attendant emission of gamma rays); the complete and accurate time history of the explosion over a period of approximately a few microseconds; and the overall yield of the explosion.

Yield measurement of the fireball and its growth were made optically, using electronic or mechanical streaking or framing cameras. Many other measurements were to become important, including temperatures, pressures, precise spectra of emissions from the explosion and effects of the explosion, but these were the basics.

The reaction history measurements were made by placing radiation detectors near the device, from several feet to several meters or tens of meters. The radiation detector converts the radiation signal to an electrical signal which is transported to the diagnostic system over coaxial cables a safe distance from the explosion, where it is recorded on fast oscilloscopes. (This system is described in a little more detail in an LLNL document, UCRL-7791, Electronic Instrumentation Systems for Nuclear Explosion Diagnostics, by McCraven and Longerbeam, 1964.)
The oscilloscopes were in a protected bunker, perhaps several hundred to several thousand feet from the explosion. An accurate measurement of the reaction history requires time precision of much less than a nanosecond, and amplitude accuracy of a percent or so. Commercial oscilloscopes were not capable of this accuracy, so Livermore engineers began to design our own oscilloscopes and supporting electronic equipment. Sub-nanosecond time precision was achieved by superimposing a precise sine wave frequency onto the horizontal sweep plates of the CRT. A single cycle of this frequency could be divided into subdivisions for increased accuracy.

This technique came to be known as the "Rossi display," named after an earlier scientist at Los Alamos. Recognizing that one had only one chance to make a successful test and measurement, two guidelines began to emerge as these systems were developed: a design philosophy and an operating philosophy. 
The design philosophy. First, it was important to find the very best components available from industry, and then test them to the limits of their specifications and beyond to get the highest performance that could be achieved. Thus, photomultiplier and photodiode tubes, for example, were tested to see how much output current could be achieved from the optical input before the signal would become a distorted version of the input (maximum linear output), and how fast an input optical signal could be accurately represented by the electrical output. Cathode ray tubes were tested to see how high a voltage could be put on the tube to accelerate the electrons to a high enough energy to create enough light at the phosphor so that fast signals could be recorded on the fastest film available.

American industry was very cooperative in providing their best products so that the most appropriate would be selected for development and incorporation into our specialized test measurement systems. As a consequence, a family of standard detectors was developed, and the Ll oscilloscope and all its supporting electronic equipment became the standard for Livermore test diagnostics, though some EG\&G oscilloscopes were used also.

Second, recognizing that electronic components sometimes fail, a philosophy of redundancy for reliability became routine. Systems of detectors and oscilloscopes were organized so that if one failed, an adjacent one would provide enough overlapping coverage to ensure essential data recovery. Basically, it was a philosophy of using belts plus suspenders for every critical function.

The Operating Philosophy. The total diagnostic system became somewhat complex, consisting of perhaps dozens of oscilloscopes, hundreds of electronic chassis, interconnecting cables and control systems, and thousands of components. Putting all this together required timing accuracies of less than 1 ns between oscilloscopes connected to detectors over perhaps thousands of feet of coaxial cable (thousands of nanoseconds transit time for the signal). It also required that each oscilloscope be set up with simulators to ensure that it would record the expected signal.

Dry run procedures were established to ensure that each element of a nuclear test was adequately tested prior to detonation. Standard dry runs for Livermore tests included bunker dry runs; timing signal dry runs; simultaneity dry runs; flashlamp (or simulated detector signal) dry runs; hot dry runs; fullpower, full-frequency dry runs; and final dry run. Standardized check-off sheets were used for each dry run to ensure that no mistakes were made in setting up the final system prior to a test. 
The dry run schedule was exacting:

- As many as 20 bunker dry runs might have been required for final set up.

- Timing signal dry runs were conducted many times over the several weeks leading up to a test.

- Simultaneity dry runs were conducted to ensure that each piece of data on an oscilloscope face could be accurately pieced together with all other data pieces to an accuracy of less than 1 ns.

- Flashlamp dry runs were conducted to ensure adequate operation of photomultiplier and photodiode tubes inside fluorescent radiation detectors, and resulting signals recorded on system oscilloscopes.

- The mechanical engineering device team conducted hot dry runs to ensure that highpressure systems were safe and reliable.

The mandatory full-power, full-frequency dry run was conducted by the test director. This dry run, with a full countdown, required that all test participants be on line, with all test equipment powered up as in the final test to ensure that no interference between experimenters would occur.
The final dry run is the last signal dry run, where all timing signals are sent out to experimenters, usually the day before detonation. Of course, the device has not yet been armed at this time, so signals associated with device detonation are simply simulated. Final arming of the device takes place a few hours prior to detonation. The arming party consists of a minimum of two people designated as "knowledgeable" regarding nuclear device and systems, and others to support them. After a nuclear device is assembled there must be two knowledgeable ("k list") people present with the device at all times. After all people have left the area at the end of the work day, two armed guards must be present outside the device structure at all times and "k list" people are on call for immediate recall to the area in case of any unusual occurrence.

Engineering people in the Test Program developed and operated these test systems successfully and safely from the first Livermore test in March of 1953 until the moratorium in 1958, and of course beyond into the 90s.

Prior to the moratorium in 1958, tests were primarily conducted in a campaign of several months' duration. Engineering people in the Test Program would typically stay in the Pacific area for three months, working an 


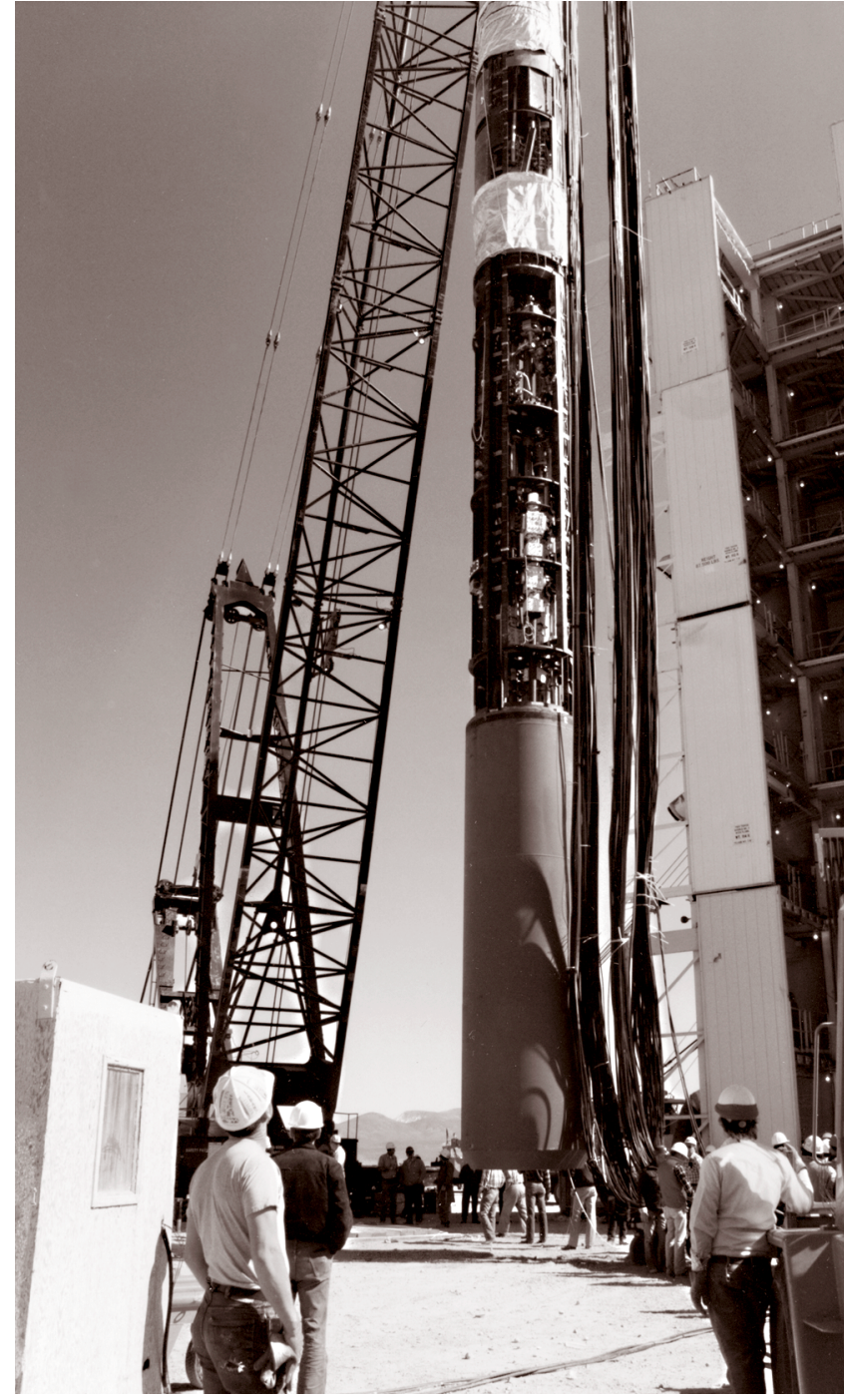

Canister going downhole at Nevada Test Site. extended workweek with extra pay. Actual workweeks were considerably longer than the official workweek of six days, nine hours per day. The work schedule at NTS was on a similar campaign basis.

The coming moratorium would give Test Program workers a respite from this hectic and demanding schedule.

\section{The Moratorium Years:}

\section{8-1961}

The US and the Soviet Union entered into a test moratorium in 1958. During this time, systems were kept in readiness to resume testing if necessary. This time also coincided with the beginning of a revolution in technology, moving from the era of vacuum tubes to transistor electronics.

Electronic systems for testing were turned on and run through a system of tests on a weekly basis-not very exciting work. Some components began to be redesigned, taking advantage of newer technology, which made the job a little more challenging. Quite a few of previous Test Program engineering people were reassigned to other areas during this period.

That was to change rapidly in September of 1961 when the Soviet Union resumed testing.

\section{Post Moratorium and Technology Revolutions}

The Soviet Union broke the moratorium on September 1, 1961. Within two weeks, LLNL engineers and scientists had prepared another test and conducted it in a tunnel in Nevada on September 15.

Thus began a hectic period of putting test systems back together, reassembling teams, procuring material from industry, and building new systems. Early testing was to be underground, in Nevada. At least one more campaign test series was to be held in the Pacific with atmospheric testing. Testing in Nevada was to move away from the campaign style, and move to a year-round continuous test program. Test resumption would again bring extended workweeks in both Nevada and the Pacific. Long days and three months in the Pacific and three weeks in Nevada would be the norm for the next few years.

Underground testing and the revolution in electronics would bring with it the evolution of whole new test systems. Rapid development of new systems and the requirement for greatly expanded systems to support several simultaneous tests in preparation would challenge Livermore engineers and require considerable help from US industry. 
The Mechanical Engineering technical challenges associated with the underground nuclear test (UGT) mission were formidable; the following is a partial list:

1) The downhole experiment packages had to be robust, in that they had to be compatible with the vertical emplacement process and survive the backfill/stemming process, while maintaining full experimental integrity. At the same time, a package couldn't weigh more than the capacity of the emplacement equipment that was to lower it into the vertical hole.

2) The integrity and reliability of the experimental equipment was critical. It was difficult (if not impossible) and very expensive to repair something after the stemming process had started.

3) The responsibility to ensure nuclear explosive safety influenced many design and operations decisions.

4) The engineered product had to be compatible with the science of the experiments. It was required that the materials, structures, and equipment of the experimental package support and enhance the scientific objectives without interfering with the results.
Canisters to contain the nuclear device and diagnostic systems had to be developed with several precisely aligned lines-of-sight. These canisters would be lowered into holes from a few feet to as much as ten feet in diameter, and a few hundred to several thousand feet in depth. The hole would then be backfilled to safely contain radioactive debris from the detonation.

"Containment" is the science/art of ensuring that the radioactive products of an underground nuclear explosion are prevented from reaching the surface. The depth of the hole was dictated by the requirement to contain the explosive force.

ME developed a variety of materials that were used to form solid or semi-solid plugs after the material was poured or pumped into the emplacement hole. These served as platforms to support the stemming column, and as solid barriers to resist the upward flow of material. Compositions included coal tar/epoxy and gravel, gypsum cement and sand, and epoxy blends and gravel.

They also developed features to "gas block" the cables that connected the downhole package to the diagnostics and control systems located on the surface. These included discrete gas blocks that could be

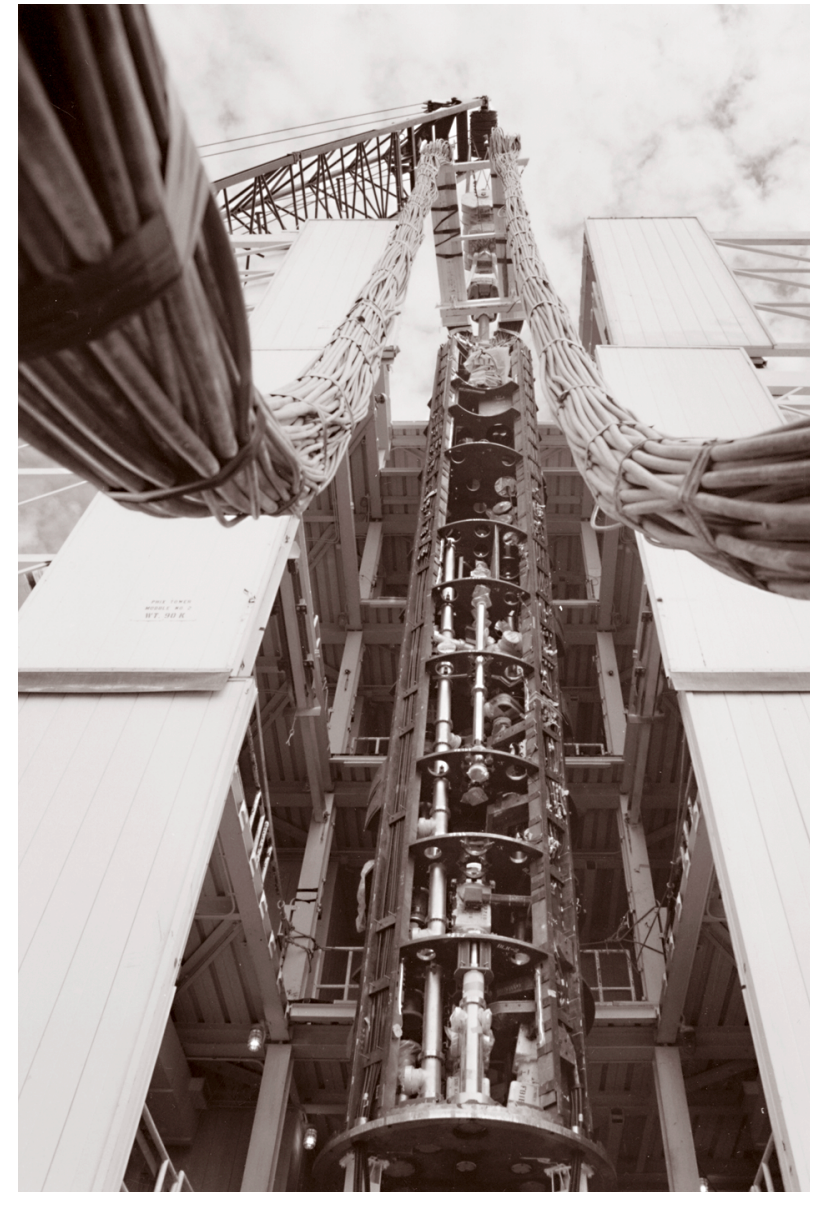

Diagnostic canister in tower at Nevada Test Site. 


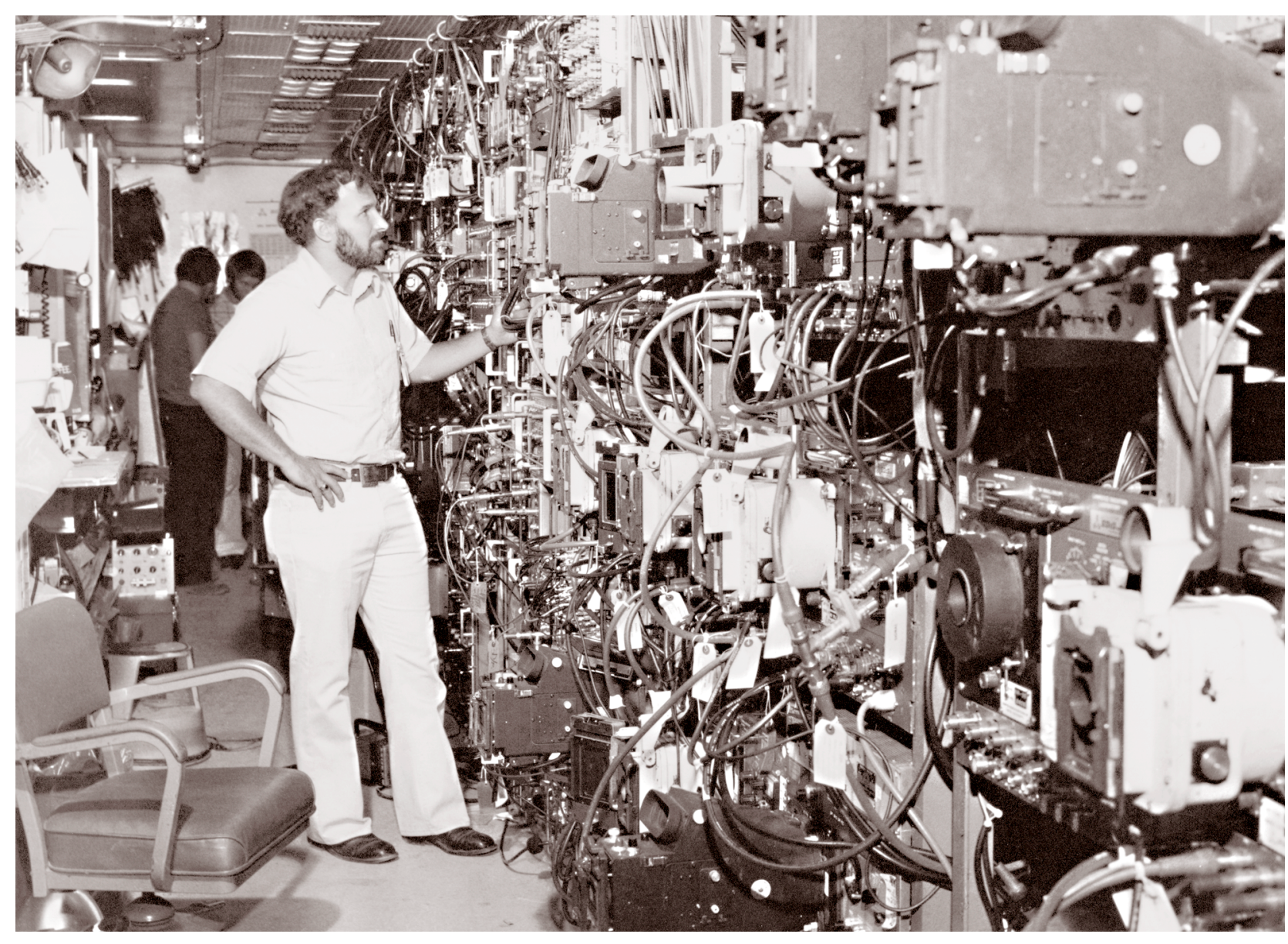

Willy Cooper in a diagnostic trailer at Nevada Test Site. built into the cable by the wiremen at NTS, and continuous gas blocks that were built into the cables at the factory. Gas blocking was successfully accomplished on both electrical and fiber-optic cables.

A great variety of closure devices were developed by ME that could quickly close lines of sight. These devices were explosively driven, and ranged in aperture size from less than 1 in. to 24 in. in diameter. Probably the most dramatic and challenging application of this technology was the "HE Machine," which was part of the containment system used to rapidly close the large vertical line-of-sight pipe to the surface that was the heart of the vertical "effects" type of underground testing.

The ME Structural Dynamics Group was the heart of the analytical capability of the engineering support to underground testing. A major area of interest was the response of large complex structures to the dramatic ground motion that resulted from an underground explosion. This work was related to (and was perhaps a forerunner of) the seismic response capability (analysis and prediction) that later developed within ME.

By the late 60s, ME had established a very competent analytical capability, with considerable expertise in systems analysis, dynamic 
response of complex structures, seismic engineering, risk assessment, thermodynamics, and thermo-fluids.

The detonation energy would melt and vaporize the surrounding earth to create a hot highpressure cavity with a diameter of about 50 times the cube root of yield. This cavity would cool and recondense within an hour or less with the pressure dropping to a point where the cavity could no longer support the weight of the soil above. It would then collapse, forming the now familiar craters at NTS. The diameter of this crater could be estimated from the previously calculated cavity. The combination of hole depth and crater radius would dictate the closest point at which diagnostic systems could be located in trailers, and thus the length of coaxial cables.

The trailers in many cases would have to be shock mounted by systems designed by Livermore mechanical engineers to survive the ground motion and acceleration from the explosion. The Mechanical Engineering Structural Dynamics capability was a major contributor to the successful implementation of trailer shock mounting. Data were largely recorded on film, taking pictures of oscilloscope faces. A reentry party would go in as soon as radiation sensors determined it was safe to do so, to recover the film.
The diagnostics systems that existed at the resumption of testing consisted largely of the old L1 oscilloscopes, a few EG\&G traveling wave oscilloscopes, and a few newer LLNLdesigned oscilloscopes known as the L2. All of these "scopes" and their supporting equipment were based on vacuum tube designs. Signal amplifiers for these oscilloscopes were not necessary as the radiation detectors produced from one ampere to several thousand amperes of linear current in response to the powerful gamma rays emitted from the exploding nuclear device.

Among the several EE groups supporting the Test Program, one was dedicated to fielding the diagnostic systems and another to design and development of the newer equipment required by an accelerating program. Equipment requirements were established by the fielding group based on the engineers' experience in the field and on physics requirements. Each new design was described in a "job authorization" (JA) or "job notification" (JN), written by one of the field engineers and submitted to the design group. If the requirement was to be submitted to industry for bid, a full formal specification was written and routed through the procurement organization to qualified bidders.

One of the difficulties we faced in the early days of resumed testing was that there were 


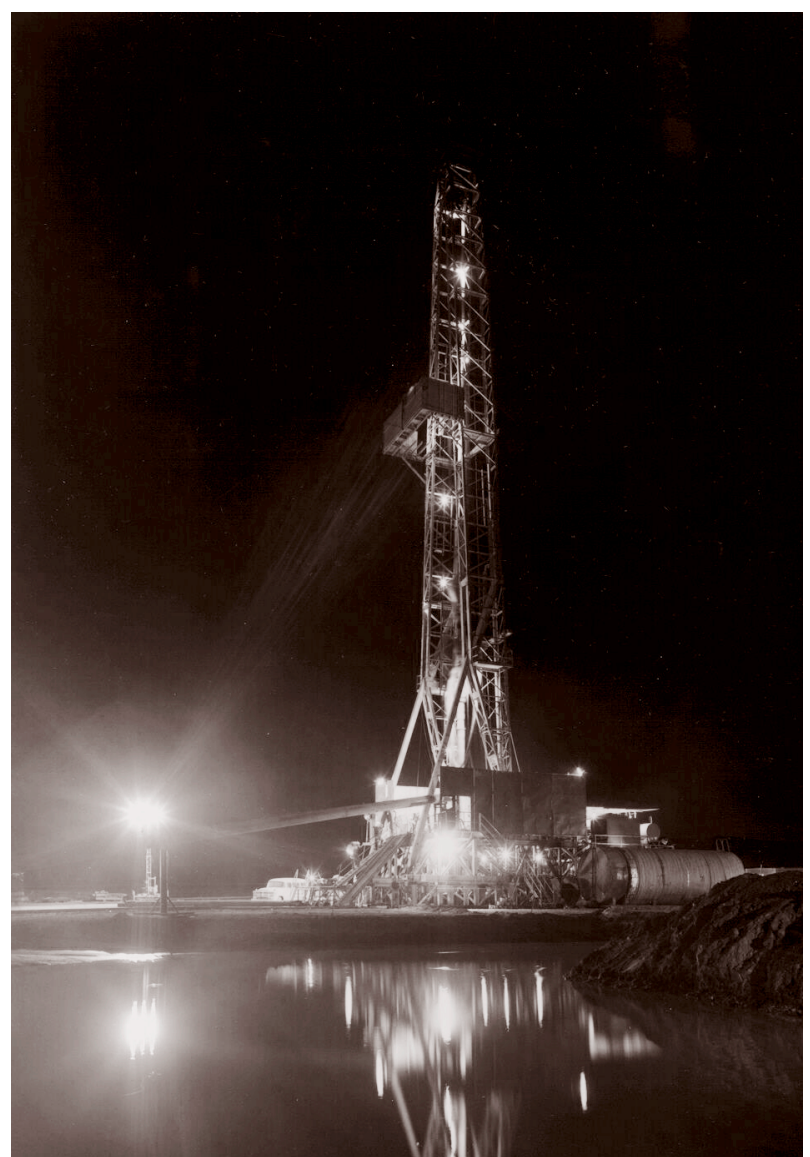

At the Nevada Test Site, hole drilling is a $24 \mathrm{~h} /$ day operation, circa 1980. significant differences in the equipment from EG\&G and that designed by LLNL. The EG\&G equipment was originally designed for Los Alamos. Los Alamos tended to use large, wide "skids" to house their diagnostic systems in Nevada, and there was sufficient room behind the equipment racks for engineers and technicians to work there. Livermore, on the other hand had focused on trailers, similar to those used for highway big rigs, to house systems for maximum portability, on wheels, at NTS and between Livermore and the test sites. These trailers were only eight to ten feet wide and there was insufficient room behind the racks to work there.

As a consequence, all Livermore equipment was cabled and tested from the front panel, while EG\& $G$ equipment was cabled and tested from the rear. Other differences existed as well, and a "Compatibility Committee" was established to standardize and make all systems more useful in the field. The committee was chaired by Ted Hamm and me, two LLNL engineers with field experience.

Engineers in the design group were tasked to redesign $E G \& G$ equipment, taking advantage of more modern solid state technology, and moving all required functions and controls to the front panel. After design acceptance, EG\&G in Boston was asked to fabricate the new equipment to our design and specifications. The design group was also asked to design an entire new generation of LLNL diagnostic equipment, including new oscilloscopes and all equipment required to run the oscilloscope systems. Dick Rufer, Don Campbell and Bill Karlotski made many important design contributions. The first dozen or so pieces of new equipment were built in EE's Fab Shop. Larger quantities were put out to bid to industry, largely in the Bay Area.

Even these dual efforts at Livermore and EG\&G were not quite sufficient to meet the growing and diversifying needs of the Test Program. Both Hewlett-Packard and Tektronix, the two major domestic suppliers of oscilloscopes, cooperated with Livermore engineers to build modified versions of their standard designs to meet the unique requirements of nuclear testing. Several dozen of these modified oscilloscopes were added to LLNL systems.

After the cancellation of the Pluto nuclear ramjet program, several engineers from that program also designed new equipment for nuclear testing. One of those designs was a very fast pulse generator that was used to measure the electrical length of coaxial cables by being retriggered by the reflected pulse from the open end of the coax. Thus the pulse generator became an oscillator whose 
frequency was determined by the length of the attached coax, and could be measured with a standard frequency meter. This little box

replaced an entire rack of equipment previously used to measure cable length, and reduced the time required to complete the previously men-

tioned simultaneity dry run from perhaps days, to an hour or so. A key discovery that enabled this new system was the avalanche transistor.

Ed Laine discovered the avalanche cable oscillator and Hank McDonald made the connection between that and the cable measurement. Bob Werner followed with the original design work for the first useable piece of equipment, which was later modified to a fully automated digital system that became a standard product.

As a consequence of these and other efforts, the Test Program had the ability to conduct as many as fifty nuclear tests in a single year at NTS. That number of tests would severely strain the ability of Livermore engineers and technicians to support that level of testing in the field.

Two other organizations would fill the gap. EG\&G, which already supplied people in Nevada to support Los Alamos testing, began to provide some of the same capability to LLNL. In addition, LLNL-Nevada hired more engineers and technicians to staff and run diagnostic systems. Ultimately, Livermore Test Program engineers were to concentrate on development of new and experimental systems for new requirements as opposed to operating standard systems in the field, greatly reducing the need for extended travel to Nevada.

More senior and experienced engineers were assigned to oversee all electronics and mechanical engineering efforts and systems on an event to reduce the probability of error or oversight. These event project engineers conducted "pre-mortems" where all engineering participants in the event would present descriptions of their efforts and plans to preclude unforeseen problems.

The ME Device Systems function was responsible for managing the "Ground Zero" (GZ) area operations, and operational and nuclear explosives safety. A Device Systems Engineer (DSE) was assigned to each event. The DSE had a broad range of responsibilities and authority, including preparing and controlling the arming and firing, and timing and control functions for the event. In the LLNL Test Program, the arming and firing function has always been strongly supported with personnel and equipment by Sandia.

Device Systems was a major element of what eventually became the Field Operations com- 


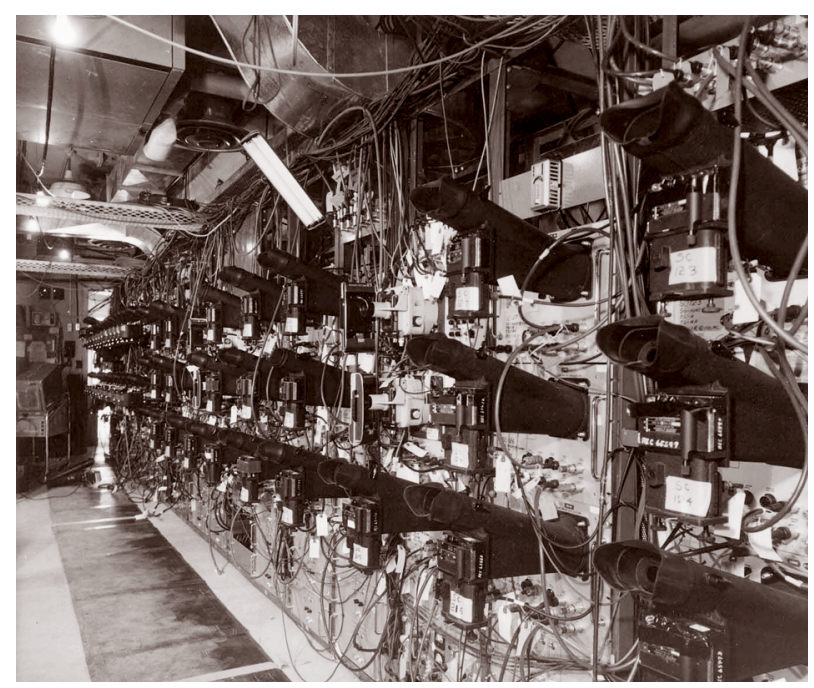

Bunker instrumentation room with 154 oscilloscopes for prompt diagnostics, Nevada Test Site, 1963. ponent of the LLNL Test Program. The other major component of Field Operations was the site construction and drilling effort, largely staffed by LLNL Nevada personnel. While the Device Systems Group was an ME organization, DSE positions were filled by both ME and EE personnel.

ME's Auxiliary Systems Group was responsible for high-pressure gas technology applications associated with nuclear testing. The work involved pressure systems design, fabrication, and field installation and operation. Significant accomplishments in the areas of flow control, instrumentation, vessel design and development, and explosive actuator development resulted from this work.

Senior engineers were assigned to review safety issues associated with nuclear testing. The pre-mortem would review any safety issues associated with the nuclear test, and in addition any new system with safety implications was to be reviewed by a higher level committee including representatives of LANL and Sandia. These reviews came to be known as "0560 Safety Committees," referring to the AEC (now DOE) regulations chapter relating to nuclear safety.

Special safety committees were sometimes established to review unique safety issues. For example, lightning safety was studied first by an LLNL committee, and later by a DOE committee appointed by the Nevada Operations Office of DOE, and staffed by LLNL, LANL, and Sandia.

I chaired both these committees. The committees examined the probability of a lightning strike at NTS detonating the high explosive charge in a nuclear explosive, and methods to isolate the explosive from the strike. As a consequence of these and other studies, many improvements were made in Nevada to reduce the vulnerability of systems to lightning.

And finally, senior engineers from both Electronics and Mechanical Engineering would evolve into roles as Test Directors, in charge of all aspects of the conduct of a nuclear test.

\section{Timing and Firing}

In addition to a shortage of modern diagnostic equipment, timing and firing systems limited our ability to escalate the level and intensity of nuclear testing. Timing and firing signals originated from the Control Point, CP1, in the central region of NTS. Connection to each event site was made through ground cables consisting of many pairs of wire, at least one for each required time signal in the 
countdown sequence. $\mathrm{CP} 1$ could be $20 \mathrm{mi}$ or more from the event site, and moving cable from site-to-site and connecting to experimental users was time-consuming and expensive.

The Test Program established the Timing and Firing Steering Committee to plan for a radiobased system to replace the cable network. An early system concept and design was done by Gerald St. Leger-Barter. The system that evolved and passed a safety review was a microwave point-to-point system with digitally encoded signals to prevent unauthorized intrusion. The actual firing signal was further encoded with two people entering half of the code during final arming of the device, and then later re-entering their half of the code at the CPI site to enable final detonation on the approval of the Test Director. System design, installation, and operation was done by EG\&G under guidance and review by Livermore engineers.

\section{The Digital Revolution}

As industrial electronics technology evolved from vacuum tubes to solid-state devices to integrated circuits, so, too, did the trend from analog systems to digital systems. In the mid-60s, as Livermore engineers shifted from fielding routine diagnostic systems to developing newer systems for new requirements, the focus on digital systems and small computers began to emerge.

For the traditional requirement to measure device performance by looking at the time history of gamma and neutron production, several innovative attempts were made to make this measurement with digital systems to replace oscilloscopes. This would ideally eliminate the need for time-consuming film, film-reading, and data reduction. Several of these early attempts are outlined in a series of papers presented at the 1969 Western Electronic Show and Convention (WESCON) by Livermore engineers and others. These sessions were titled "High Speed Oscilloscope Recording," and "Instrumentation for High speed Recording."

Examples of some techniques tried included high-speed analog-to-digital converters, scan converters, pulse stretchers, and bandwidth compressors. Although innovative, these techniques were only partially successful in digitally recording the very high-speed signals from the device. Later attempts were somewhat more successful as silicon technology improved, but newer nuclear device designs demanded even higher bandwidth recording, and high-speed oscilloscopes and film were to remain the principal tool to measure device performance.

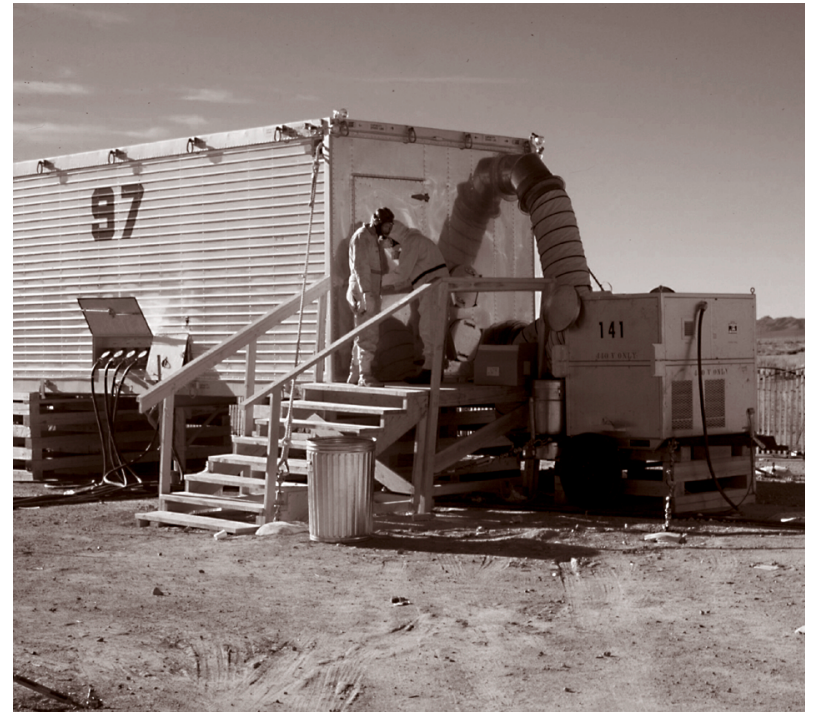

Oscilloscope film recovery after a shot, Nevada Test Site, circa 1969. 
New requirements in the Test Program would, however, take significant advantage of the revolution in digital electronics. Laboratory programs in vulnerability, lethality, and nuclear effects, particularly those due to $x$ rays, would result in measurement requirements with bandwidths of kilohertz to megahertz, as opposed to the hundreds of megahertz required to measure device reaction history.

At first these measurements were to be recorded using commercially available signa conditioning systems, modified for use in our nuclear test environment. They were multiplexed-frequency modulated signals recorded on high-speed tape recorders.

Livermore engineers worked with industry to get much higher bandwidth tape recorders with more channel capacity. Major effort at Livermore went into protecting these low-level signals (millivolts to volts) from the extremely noisy environment of a nuclear detonation. Grounding and shielding of cable from sensor to recorder were intensely modeled and studied before systems were successfully fielded. Frank Francis and Lee Loquist were instrumental in developing these early analog and digital systems for making low-level measurements in a very noisy environment.
As digital technology improved these measurements were made by digital techniques. Recording was made into memory systems in the diagnostic trailers, into small computers in the trailers, or telemetered to the CP over microwave links and recorded and analyzed by somewhat larger minicomputers. Small digital computers were soon to become ubiquitous in the field, and they were to take over many routine control, timing, and dry run functions in addition to recording or analyzing much of the lower bandwidth data.

\section{The Bandwidth Revolution}

By the mid-60s, physicists in the Nuclear Design Program had begun to call on L Division to provide ever more detailed diagnostic data from Nevada tests. More detailed information in turn required greater bandwidth and precision in the diagnostic systems. L Division turned to Electronics Engineering for help.

As mentioned earlier, the diagnostic system consisted of nuclear detectors, coaxial cables, and oscilloscopes to record the information. New, faster detectors were developed by L Division, principally vacuum Compton diodes. These detectors converted the gamma rays to electrons, which were col- 
lected at the anode, providing current into the coaxial cable. Compton diodes provided as much as $1000 \mathrm{~A}$ of linear current response, and thus as much as $50,000 \mathrm{~V}$ of signal in the $50-\Omega$ coax. They also had sub-ns response time.

These high-voltage signals required engineering to develop new connector and attenuator devices to prevent signal breakdown before recording the full signal. It also required the development of new high-voltage pulse generators to simulate the signals to test the system. Kris Aaland, an engineer borrowed from the Magnetic Fusion Program, was instrumental in developing these very high voltage systems.

The weak link in the detector-cable-oscilloscope chain, from a bandwidth perspective, was the coaxial cable. The high-frequency content of signals is attenuated more than low frequencies, and thus the signal is distorted. An R\&D program was started to determine the response characteristics of coaxial cable in much greater detail than had ever been published. Based on that data, two approaches were undertaken to remove cable distortion from the data. First, a series of cable equalizers were developed whose attenuation characteristics in both amplitude and phase was the exact opposite of the cable (i.e., low frequencies attenuated more than high). Second, mathematical and computer software techniques were developed, jointly with $\mathrm{L}$ Division, to remove distortion from the signals after initial film reading and data reduction (data deconvolution or unfolding). Mike Ekstrom made very valuable contributions to the development of equalizers and unfolding techniques.

Mechanical Engineering also developed innovative shock mounting techniques to allow trailers to be moved as close as possible to the predicted crater without damage, thus shortening cable lengths.

The oscilloscopes, though having better bandwidth than cables, still needed some improvement to record the fastest signals faithfully. Faster signals also required faster writing speed on the CRT face, that is, brighter traces. EG\&G was asked to make improvements to their traveling-wave CRTs in both bandwidth and writing speed. Over the next few years, several improvements were made including the use of fiber-optic and channel multiplier faceplates on the CRT to achieve greater brightness.

The combination of these and other Engineering efforts resulted in the ability of L Division to provide data of unprecedented quality to device designers, and in some cases 


\section{${ }^{C}$...engineers and physicists in the}

Test Program saw the potential for revolutionary applications in

nuclear testing. to make measurements not previously possible.

\section{The Optical and}

Imaging Revolution

By the late 70 s and into the 80 s, a revolution was going on in the US electronics industry. Fiber optic cable held out the promise of communication networks of immense capacity and bandwidth (later to be realized, of course). And the semiconductor industry began to produce solid state arrays of photosensitive devices, now commonplace in such devices as digital cameras.

At that time, engineers and physicists in the Test Program saw the potential for revolutionary applications in nuclear testing. The beginnings of the technology revolution coincided with the need for new kinds of data for nuclear device designers. Imaging had been done on nuclear tests even in the earliest days.

The desire for neutron and $\mathrm{x}$-ray pinhole imaging led to the development of the Pinex family of diagnostics. First came the mechanical (or "mud") Pinex, in which data recovery depended on the retrieval of an exposed film pack by winching it to the surface through the upper section of emplacement pipe. The work of L Division, ME, and EE collaborators to develop the electronic Pinex, or Elpinex, was a major accomplishment in that the image data was generated and transmitted to the surface electronically, thus eliminating the need for the recovery of film. This work was an early and significant contribution to the development of imaging technology as a major underground test diagnostics component.

Device designers developed a need for greatly increased data regarding the detailed time resolved spectra of different kinds of radiation emitted during a test. In some cases, this requirement was for hundreds, or even thousands of discrete channels of data. This would have been almost impossible if each channel required a coaxial cable to the recording system.

Engineers at LLNL developed downhole electronic imaging or spectral analysis systems using fiber optic cables coupled to electronic streaking tubes, image intensifiers, and solid state imaging arrays. In some cases, fiber optic cables were used to bring digitized data to the surface for recording. Overall system bandwidth with such systems could approach $20 \mathrm{GHz}$ as opposed to the perhaps $1 \mathrm{GHz}$ with traditional cable-equalized systems. Systems were originally developed by LLNL engineers, then routinely produced by EG\&G. By the 
cessation of testing in 1992, 400 to 500 of these electronic cameras had been fielded. A major contributor to this increased quantity and quality of data was the ME computer-aided-design expertise to design and build compact and complex mechanical assemblies to house the electronic systems.

\section{The Era of Treaties}

The Limited Test Ban Treaty (LTBT). The US and the (then) Soviet Union began a series of treaty negotiations related to nuclear weapons testing in the early 60s. Obviously, each of these was to have an impact on Engineering's support to the Test Program. The first treaty, the Limited Test Ban Treaty, banning testing in the atmosphere or outer space, was signed in August 1963 and ratified two months later.

Testing would end in the Pacific, but Congress insisted on safeguards in case atmospheric testing was to be resumed for any reason. A

"Readiness Program" was established with required instrumentation outfitted in specially modified KC135 jet aircraft. Other instrumentation was developed to be placed on rockets that could collect data during and after an atmospheric test. These systems were "dry-run" to ensure readiness, and Livermore engineers and technicians became members of the aircrew for such exercises.
Over time several scientific applications of these aircraft and systems became obvious, and the dry run exercises were augmented with pure scientific missions. In one case, the first detailed measurements of radiation in the Van Allen belts were made, determining that it consisted of protons. In another, the aircraft were flown through the trajectory of a solar eclipse taking measurements of outer solar ring phenomena. Some of the early work on $x$-ray astronomy was done through the

Readiness Program, including measurement of the x-ray spectra from stellar objects such as Cygnus.

In all cases, electronic systems for data collection and analysis were designed and fielded by engineering personnel supporting the Test Program. Where required, telemetry of data from rocket-based systems was provided by Sandia.

The Threshold Test Ban Treaty (TTBT). With the cessation of testing in the atmosphere more effort went into development of underground test technology. Before 1963, all high yield testing had been done in the Pacific. After the LTBT some high yield testing in the megaton range was still required, and safe locations to conduct such tests underground were sought. Deep drilling at the Pahute Mesa on the northern region of the Nevada Test Site provided one such location. It was far enough from 


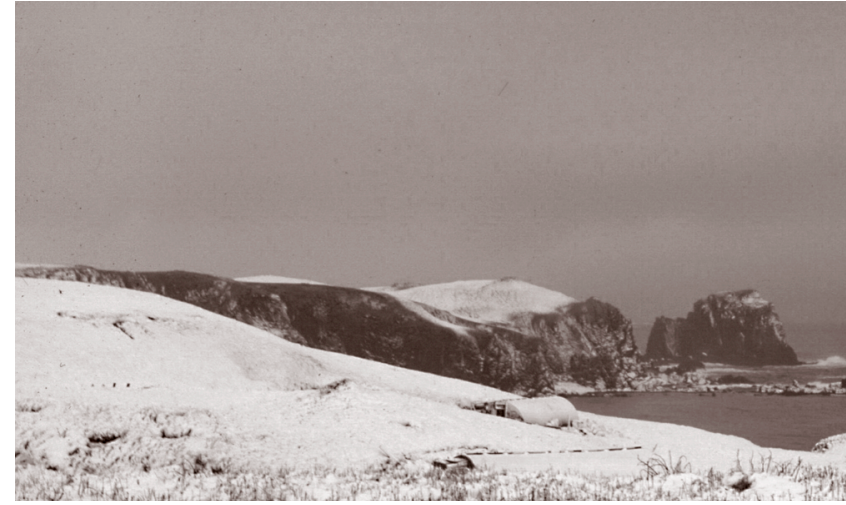

Cannikin Event, Amchitka Island, 1971.
Las Vegas for ground motion there (from high yield tests) to not be a significant problem. This distance also made for long work days and hours for Test Program people however.

Even Pahute Mesa was not an adequate site for required shots of even higher yield. The search for other sites included some LLNL engineering people on site surveys. Surveys and studies of sites on the North Slope of Alaska, Central Nevada, and Amchitka Island in the Aleutians were made. One seismic calibration shot was done in Central Nevada, and Amchitka Island was chosen as the site for the highest yield shot required. LLNL engineers and technicians were again called on in 1971, to spend several weeks at a time preparing for and conducting the Cannikin event, under difficult conditions.

The US and the Soviet Union had been searching for ways to further limit testing, but progress was slowed by concern over the inability to detect and verify clandestine tests. In July 1974 it was agreed that tests of $150 \mathrm{kt}$ or greater were easily verified, and the LTBT was signed. No testing above $150 \mathrm{kt}$ was to be allowed.

Further limits on testing were still pursued by both sides. Uncertainty existed over the degree to which both US and Soviet nuclear test sites could be seismically calibrated so that nuclear tests at either site could be reliably verified at remote seismic stations. As a consequence a seismic verification program was established. Each country would be allowed to make on-site yield measurements of a nuclear test by the other country. By comparing the on-site yield measurement to a remote seismic signal, the site could be seismically "calibrated," and greater confidence could be achieved for future detection of a nuclear test under treaty conditions.

Yield determination was made with an electronic system monitoring the rate at which a coaxial cable introduced into the shot hole was crushed and electrically shorted by the shock from the explosion, a standard measurement in Nevada. LLNL engineers and technicians were to travel to Russia to participate in a Russian nuclear test, a somewhat mind-blowing historical event. And in August 1988, Russian scientists and engineers would participate in the Kearsarge nuclear event at NTS alongside our scientists, engineers and technicians.

(Ted Hamm, perhaps the most traveled engineer in Test Program, participated in the high yield site surveys as well as the Amchitka,

Central Nevada, and yield verification test in the Soviet Union.) 
This kind of confidence-building measure, and other progress on relations with the Soviet Union, resulted in the signing of a comprehensive test ban treaty, and in September 1992, the last nuclear test was conducted at NTS. The Test Program and L Division would no longer exist as formal organizations, and the engineering divisions in Electronics and Mechanical Engineering supporting the Test Program would be reorganized, combined with other Divisions, renamed and given different missions in support of a very different Nuclear Weapons Program.

\section{Plowshare}

Even in the earliest days of the Nuclear Weapons Program it was recognized that the enormously high energy in a nuclear explosive held out the possibility of some peaceful applications. There were visions of large earth moving projects to economically create canals or deep water harbors. With the energy crisis of the 70s, nuclear explosives were felt to hold the possibility of stimulating natural gas from tight gas sands, or oil from oil shale, both in abundant supply in the US. To make this vision a reality, however, required a very different kind of nuclear explosive, and a very different kind of engineering support for the program.
For earth moving, the explosive would have to release a very small amount of residual radioactivity into the atmosphere, that is, be very "clean." For underground resource stimulation, gas or oil shale, the diameter of the explosive would need to be small to be placed in small drill holes. And perhaps, most importantly, the costs, and thus the manpower, to field experiments would have to be demonstrably smaller than that required typically at NTS. Engineering would be called on to demonstrate this latter point.

The requirement for detailed diagnostics on a nuclear test in Nevada, with each test being an experiment, required the presence of several trailers full of equipment and many people to support the test. Plowshare, to be successful, would have to rely on a standardized tested design and a small team of people to field an event. Mechanical Engineering developed a single transportainer to support the fielding and emplacement of a Plowshare nuclear device.

Electronics Engineering developed a single cable firing system to safely detonate the device, replacing a much more complicated, multi-cabled and manpower-intensive system that was required for Nevada tests. And K Division and Electronics Engineering

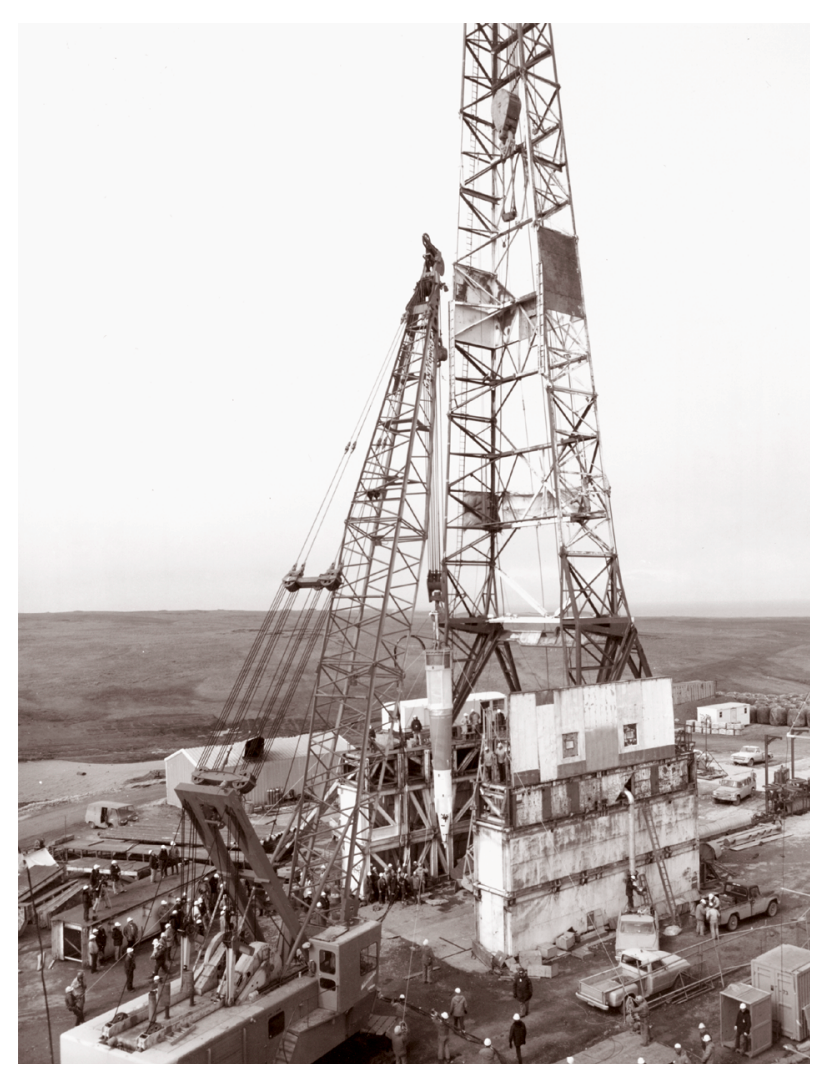

Cannikin device, 1971. 


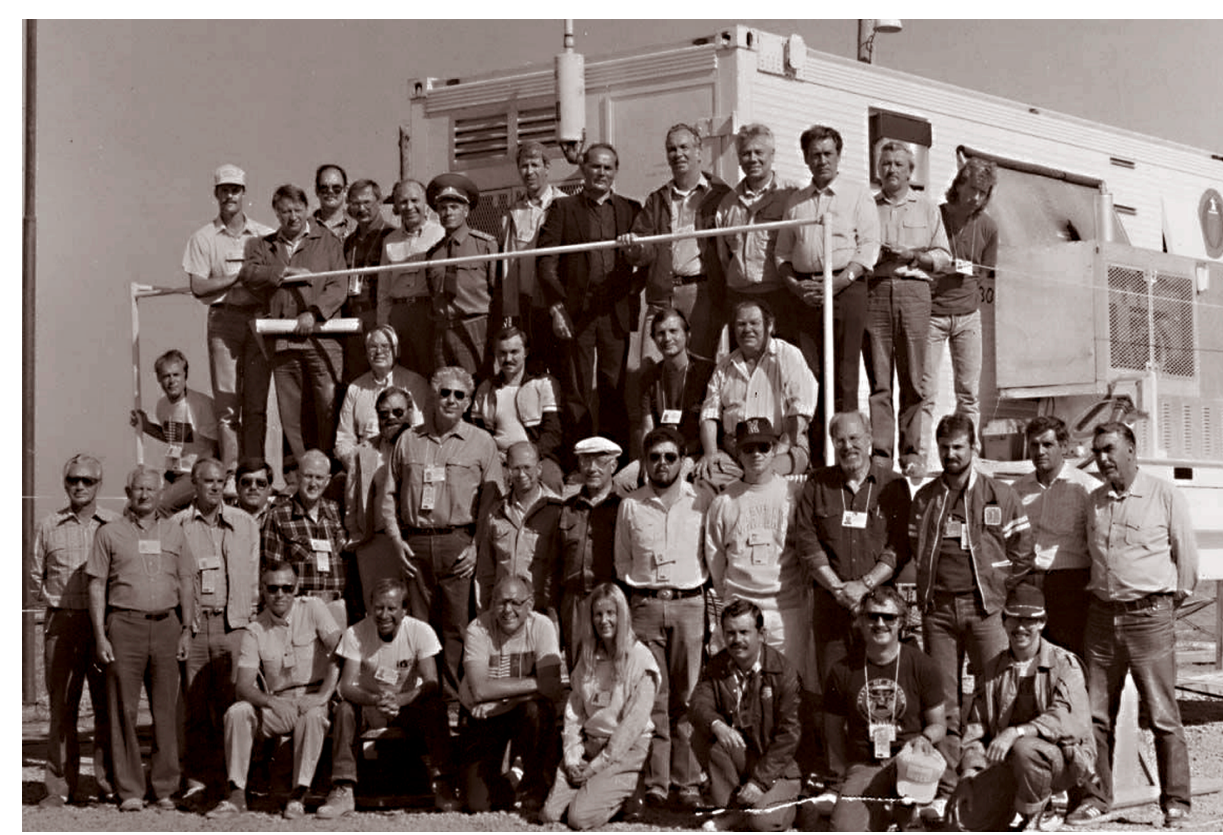

Under the Joint Verification Experiment Treaty, the Soviets invited us to ship one of our diagnostic trailers to their Semipalantinsk Nuclear Test Site to measure their nuclear device yield. Pictured are the US contingent with General Ilyenko (top row center), who was in charge of the Soviet Test Site, circa 1988. developed the SLIFER system to verify the yield of the device with a single cable. A version of the SLIFER system was later used in the US/Soviet Union Joint Verifications Experiments to seismically calibrate each country's test sites (described on page 68).

The single cable firing system (SCFS) successfully passed design reviews and nuclear safety reviews. It was used to simultaneously detonate three nuclear explosives separated by about 130 $m$ in a single vertical drill hole in the Rio Blanco event to stimulate natural gas from tight gas formations. This may be the only nuclear detonation ever conducted by LLNL that did not require large field crews from Sandia for arming and firing, or from $E G \& G$ for timing and firing.

\section{Test Program Epilogue}

Dick Neifert, a former leader of L Division, was asked his opinion of major Engineering contributions to the Test Program and the reasons for them. His response was not surprising. He talked about the importance of a tight test team with representatives from each of the supporting organizations, and with each organization having its own research and technology base.

Among the many engineering contributions he mentioned were major advances in highbandwidth recording; the digital and imaging revolutions that allowed significant growth 
in the amount of data that could be collected on underground tests; and significant improvements in fielding and downhole cable operations, which sped up shot preparation by days with significant cost savings.

Since the conduct of the final nuclear test in the US, in September 1992 LLNL has entered into an era with some similarity to the Readiness Program of the 60s. There is no longer a formal Test Program organization as existed before, but a limited number of subcritical tests are conducted at NTS with no nuclear explosion. These tests collect data important to science-based Stockpile Stewardship and also maintain some of the Engineering skills and capabilities that would be needed should testing ever need to be resumed. 


\section{The Biomedical Program}

by Paul Phelps

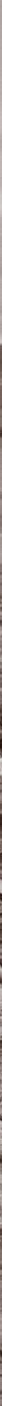




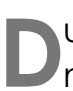
uring the tenure of John Foster, a decision was made to develop a competence in radiation safety and biomedical issues. This was motivated in part by work on the neutron bomb and projects like Plowshare, from which there were massive excavations of earth and natural gas stimulation.

The Atomic Energy Commission required that the Lab do research on the effects of fallout from past nuclear events. The projects described below are directly related to this mission.

In 1963, the Biomedical Program was started, under the direction of Dr. John Gofman, who had a distinguished record of work with Glenn Seaborg on U-235 and on the role of cholesterol in heart disease. Gofman assembled a team of physicists, biochemists, biologists, physical chemists, and other specialists, giving significant leadership responsibilities to his graduate students: Bernie Shore, Lynn Anspaugh, and Bill Roberson.

The purpose of the program was to study the effects of radiation and energy-related pollutants on plants, animals, and humans. EE work was directed by Glen Nish with me as deputy; ME work was led by Jeff Hodges.

From the first days, Gofman recognized the value of engineering support, placing a major emphasis on developing special instrumentation for quantifying complex low level mixtures of nuclides in biological samples.

The engineering work consisted primarily of the acquisition of samples in the field, preserving them for transport to Livermore, and building instrumentation systems for sample analysis. The work expanded to the development of sophisticated cell sorters and cell tagging, and eventually to technology for medical diagnostics and devices-initially for the early detection of beast cancer.

The breast cancer development was a followon to the work that had been done by Engineering in material assessment for the X-Ray Laser Program led by Clint Logan. Today all of this work is under the direction of the Medical Technology Program.

Early milestones include the following:

1) A ten-station radiotelemetry system for measuring open field gamma radiation and collecting radioactive particulates downwind from Plowshare events. Particles were collected in automated trays, with the opening of trays activated by radiation. The particles were later analyzed for size distribution and specific radionuclides and activity. Open field gamma was monitored in real time. This
Photo on the left shows the gamma radiation monitoring radio telemetry system for documenting radioactive fallout over long periods (2 to 3 weeks) from Plowshare cratering experiments using nuclear explosives. The system consisted of ten remote stations that fed open field gamma radiation data on command back to a central point. It was developed by the EE Biomedical Group and was successfully deployed on several Plowshare Events. Shown left to right is the early Biomedical field system crew: Gale Holladay, Jay Minkler, Glen Nish, Paul Phelps, Russ Niver, Don Grimes, and Charlie Pass. 
system proved to be very powerful in understanding environmental consequences of Plowshare experiments, and gave the first real hint of the significance of re-suspension (movement of radioactive particles back into the biosphere by wind action). Lynn Anspaugh did much of this work.

A prototype system was fielded on a Plowshare event, and subsequently on several follow-up Plowshare experiments. (Project Schooner was the last Plowshare cratering experiment conducted by the US.) For the first time, the history of radionuclide deposition and the collection of particulates as a function of time could be performed.

An important paper, "Gamma Radiation Monitoring Radio Telemetry System," by Nish, Phelps, and Holladay was presented at the National Telemetry Conference in April 1965.

2) $A \mathrm{Ge}(\mathrm{Li})$ gamma ray spectrometer of high sensitivity and resolution for biological and environmental counting.

This instrument was developed to analyze complex low-level mixtures of gamma-emitting radionuclides in biological and environmental samples.

It was fortuitous that at this time the Lab was engaged in the development of large Ge, Li-drifted detectors, led by Guy Armantrout, with Carol Maninger as Division Leader. There was very little of this technology available in the commercial market, especially in the sizes required for high sensitivity.

The primary detector was a planar Lidrifted $\mathrm{Ge}$ diode, contained within a plastic annulus. The configuration reduced Compton background, with an improvement resulting in weak spectral lines. The sensitivity permitted detection at levels below $0.05 \mathrm{pCi} / \mathrm{g}$; e.g., $10 \mathrm{pCi}$ of Cs- 137 could easily be detected in $2 \mathrm{~L}$ of cow's milk.

The system was used extensively for counting biological and environmental samples contaminated with worldwide fallout, such as debris from nuclear experiments and reactor effluent.

In April 1968, we delivered an important paper at a symposium sponsored by the 
American Chemical Society's Division of Nuclear Chemistry and Technology.

Gofman was convinced that even low levels of radiation could cause cancer. Many, including Edward Teller, held opposing views. Gofman also disliked the idea that the AEC was both regulator and promoter of nuclear energy, and felt that lower than safe thresholds resulted.

The success of these two projectstelemetry and gamma ray spectroscopywent a long way to earning the Lab great respect among the DOE staff in Washington and in NVOO.

An exciting and important application of our work was with pasture grass - using the gamma ray spectra generated from the $\mathrm{Ge}(\mathrm{Li})$ detector, we showed the distribution of radionuclides in lyophilized grass containing fallout from presumed Chinese nuclear testing. In a site visit by the AEC's Division of Biology and Medicine, which funded the program, a presentation of the $\mathrm{Ge}(\mathrm{Li})$ detectors for biological and whole body animal counting was received with great acclaim. The program got worldwide attention, with a large number of requests for copies of the paper and information on the system.

Up to this point, the program was strictly laboratory-based-samples came in from the field, and counting was done in the lab. The third milestone was the development of an in situ system.

3) A mobile counting system. This in situ Ge(Li) gamma ray spectroscopy system had wide use in many environmental programs. LLNL also worked with the Environmental Measurements Laboratory in New York. Our Lab's contribution was that we had the capability to fabricate large high-resolution detectors.

This system was completely portable, capable of quantifying gamma rayemitting radionuclides in the field. It proved to be more sensitive than lab analysis-demonstrated by obtaining the equivalent statistical accuracies for quantifying radioactivity from a $30-\mathrm{min}$ field count, compared to a 1400-min lab analysis.

The system could also be used for quantifying gaseous radionuclides,

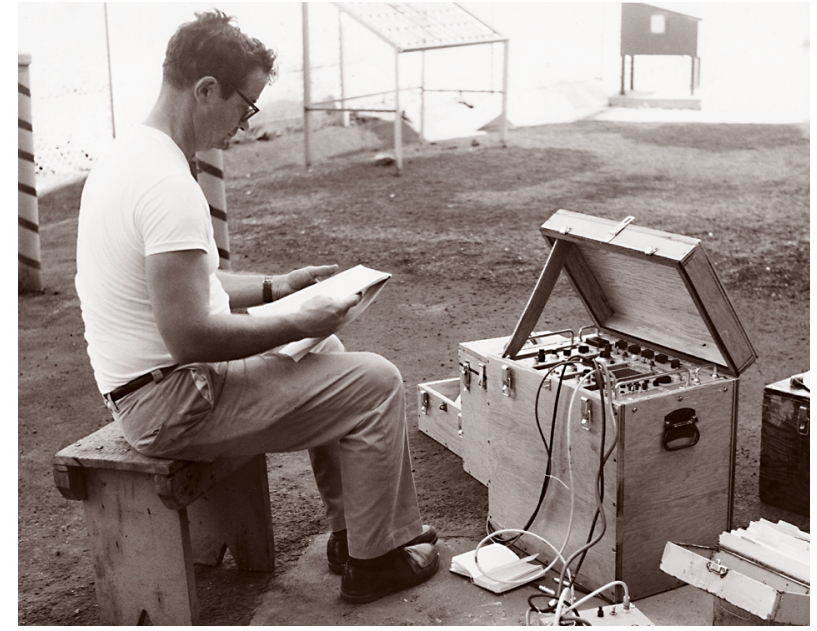

Gale Holladay making measurements for radioactive radon gas at the Geysers geothermal field in Northern California, the site of several electrical power plants. Steam, developed from water coming in contact with hot magma deep underground, is used to run the turbines. Radon gas is present in the steam and comes from natural radioactive deposits. The radiation measurement system was developed at LLNL. 


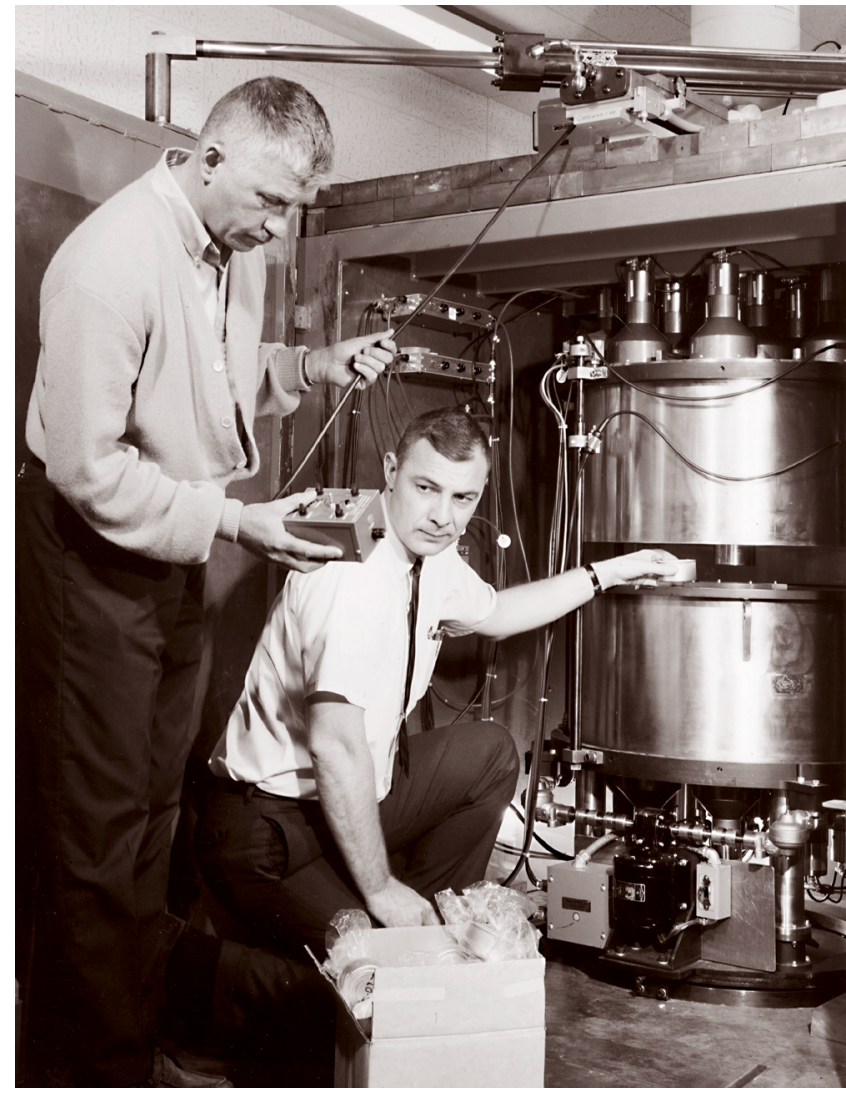

Keith Hamby (I) and Paul Phelps (r) next to a Ge(Li) Gamma-Ray Spectrometer of high sensitivity and resolution for biological and environmental counting. The spectrometer was developed to analyze complex, low level mixtures of gamma-emitting radionuclides in environmental and biological samples. This was one of the earliest low-level counters developed and was constructed before solid-state germanium, lithium-drifted detectors were commercially available. The solid state detector was grown by Guy Armantrout, EE Department. The design and construction was by the EE Biomedical Group. e.g., from reactor plumes, and found wide application in determining background signatures of gamma-emitting radionuclides, including the natural uranium and thorium series and radon. The information was useful, e.g., for utilities in reactor planning - they needed to know what they started with.

On this project, the program worked with utilities such as Pacific Gas \& Electric (PG\&E) and Sacramento Municipal Utility District (SMUD). For the now decommissioned Humboldt Bay reactor we characterized radionuclides in soil and in plumes. After Chernobyl, this technique was the major method of characterization for specific radionuclide contamination. Details are contained in the paper, "A Portable Ge(Li) Detector for Field Measurement of Radionuclides in the Environment," presented at the 1971 IEEE Nuclear Science Symposium (also UCRL-73561).

At that time LLNL was developing an interest in what ultimately happened to radionuclides that were deposited, then resuspended by forces like wind, especially as related to Plowshare shots. This was part of the dose assessment mission.
Professor James Sinclair, a key figure in the fourth milestone project described below, accepted an offer to spend a sabbatical year with our group. His abilities and interests were a good match with those of Anspaugh and other Biomedical Program staff.

4) Pu resuspension studies, including the building of instrumentation systems. Sinclair, a pilot, developed a one-seater airplane outfitted with sampling equipment and other instrumentation for $\mathrm{Pu}$ particle collection-the plane sat outside the building that housed the old Pratt and Whitney hot cells.

What a surprise to the LLNL guards when a truck would roll up with a light plane on the bed, and unload Biomed staff, EEs, and MEs at Building 412!

Anspaugh, project scientist, developed computer models that became used extensively by other labs, based on work done at NTS. The instrumentation included aerosol sampling, and computerized data systems for meteorological and airborne particulates. The old PD4 computer at NTS had such a small memory, it had to operate for several months to process data. 
Anspaugh later applied modeling developed on this project to Chernobyl, and to this day, the technique is used in following the movement of radioactivity from that accident.

The resuspension studies were especially important in the history of the Nevada Applied Ecology Group (NAEG), born out of the realization that a new age of environmental awareness was dawning. NAEG was established in July 1970 as part of the Office of Effects Evaluation, its purpose to coordinate the ecological, radiation monitoring, and other environmental programs necessary to support continued testing and comply with NEPA.

Lynn Anspaugh and I traveled extensively in central Nevada to measure the residual radioactive debris deposited by the Schooner event, which had far exceeded expectations-in fact, radioactive materials were detected in Canada, and even in Finland. The political ramifications of these results were complicated-coming at a time when DOE was preparing its first environmental impact statement for the NTS. They are reported in great detail in a special paper by Lynn Anspaugh.
A research program was established at the University of Utah, setting up a network of stations to collect aerosol samples as a function of time for NTS events.

\section{What a surprise to the LLNL guards when a truck would roll up with a light plane on the bed, and unload Biomed staff, EEs, and MEs at Building 412!}

5) Automated sampling stations, set up in Utah, downwind from NTS. This program included AEC/NVOO, DBM Washington, in cooperation with Professor Robert Pendleton, University of Utah. This network yielded good results.

An interesting sidelight: I was sitting next to Larry Germain on a flight to LV/NTS, talking about the network we had set up. He was on his way to NTS in connection 
with the BANEBERRY event, as I remember, in the position of Test Director. At the time LLNL's Biomed was cooperating with the Department of Radiological Health in studies throughout Utah on the distribution and movement of nuclides in agricultural and natural environments. EE had designed and fielded 17 stations, activated manually or by the presence of radiation, and sampled airborne radionuclides over a few hours.

Germain said we were wasting our time with such a system, because they had made calculations from geological conditions and shown that conditions were such that there could never be a venting.

Famous last words-shortly afterwards, I was home in bed with the flu and had a call from John Koranda, our Biomed environmental researcher, reporting that radioactive debris was being picked up in Utah. When the accidental venting, producing a cloud of radioactivity, moved into Utah, our system was in place, in a state of readiness and fully documented the event. A complete report was prepared, with detailed calculations and discussion,
"Radioecological Studies Related to the BANEBERRY Event," (UCRL-51027).

The bright side: measurements showed the possible doses through inhalation or cow milk pathways were very small and did not present safety issues.

Even more significant was this scenario: at the same time as the cloud passed, 1200 sheep died, and farmers concluded that NTS was the cause, stirring up the media. We were able to show the conclusion was baseless: the sheep died from a toxic poison, oxalate, from the range plant halogeton glomeratus, and not from NTS fallout. We had this information within a few hours.

6) The Humboldt Bay Project. This effort brought us into a cooperative venture with PG\&E. A group from LLNL approached PG\&E with the idea that we could use the Humboldt reactor as a field lab to better understand the behavior of radionuclides in marine organisms and sediments. We outlined our experimental program. There was some opposition, due to suspicions about Lab scientists and PG\&E's desire 
to keep things close to the vest, but in the end the project was approved.

Engineering developed specialized instrumentation and outfitted a Boston whaler for in situ measurements for monitoring gamma spectra in the discharge canal of the reactor, which emptied into Humboldt Bay. One of the leaders of this project was Gale Holladay.

In a project funded by PG\&E and LLNL to take care of problems with geysers, instrumentation was set up within the steam chambers of the power plant. We climbed inside, went below ground, climbed cooling towers, and made long-term measurements-whatever was required. We discovered that if they vented the steam chambers before maintenance, the dose was negligible and close to background.

We gave testimony to the California PUC commissioners. The result was that electricity could be produced from geothermal sources without concern about radionuclides.

This cooperative program with PG\&E led to broader association: the Imperial Valley
Project, a multi-station system of instrumentation for collecting long-term environmental and meteorological background data for geothermal development.

\section{C...measurements showed the possible doses through inhalation or cow milk pathways...did not present safety issues.}




\section{Engineering Technology Base}

by Ed Lafranchi
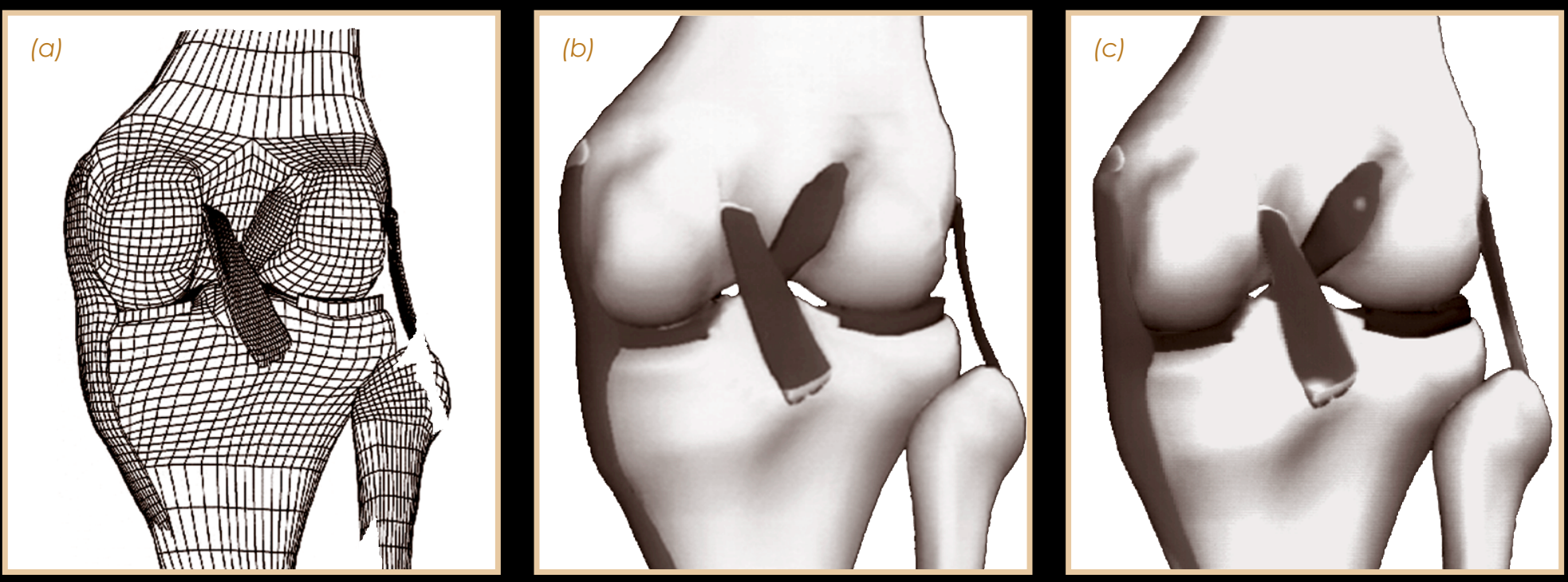
Engineering has always tried to anticipate program needs

Cand to be prepared with the engineering capability to meet them. Engineering technology base (techbase) is loosely defined as the research and development projects and facilities needed by the programs to carry out their missions.

Techbase began during the early days of the Laboratory, a small effort focused almost entirely on and funded by the Weapons Program. Over the years, as other programs either grew or came into being, Engineering broadened its techbase. A good example is the Precision Engineering Program,

described elsewhere in this publication. This section describes techbase development in Engineering. 


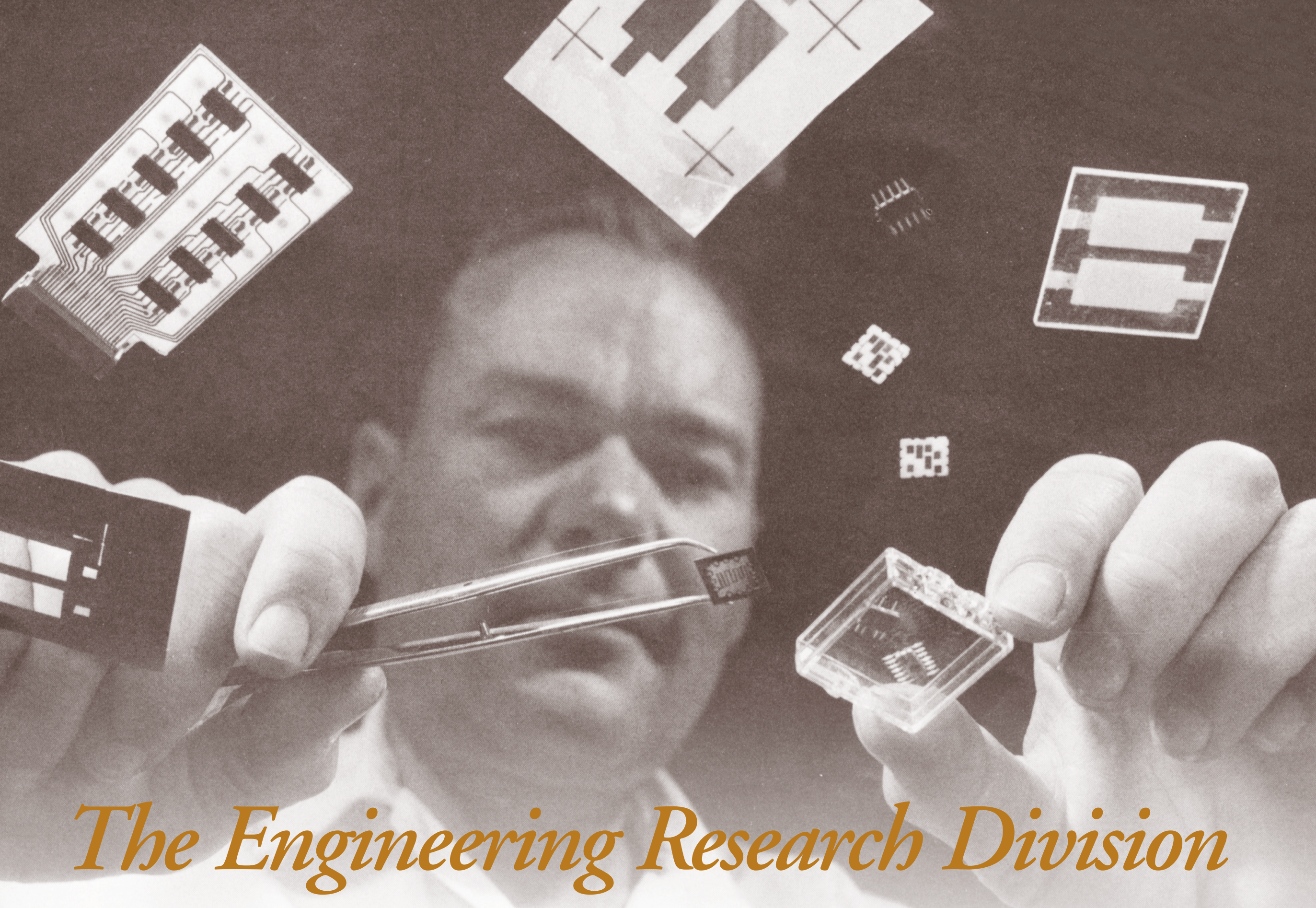

by L. Lynn Cleland 


\section{Introduction}

Erom late 1971 through 1978, I was the Division Leader of the Engineering Research Division. Funding for the ERD during that time was a combination of programmatic support from $X, Z, Q$, and $S$ Divisions, and later $Y$ (Laser) Program, and what was called Engineering Research (ER).

Y Program support grew to a level (> 50 staff) that was deemed appropriate for spinning out of ERD and into a Laser/Fusion Support Division. The Biomed Program support group was moved into ERD when Y Program moved out.

The ER funds, "skimmed" from the Weapons Program, for personnel and technology development, were adequate for about 18 people initially, and gradually declined to support approximately 10 people at the end of 1978.

When I took over the ERD, in addition to groups supporting direct programs, there were five technological areas with varying capabilities:

Electromagnetics (EM) Group, with approximately six people, whose approaches to problem solving were classical. There was not a lot of support or need for the kind of capability this group offered. Ed Miller had been hired, but was not yet on board.
Systems Group, also relatively small, with six or seven people, most of whom were generalists not trained in modern systems science theories and technologies. There was virtually no research activity associated with this group.

Quantum Electronics (QE) Group, an excellent group of about a dozen people who were generally quite creative and were providing good support to the Weapons, Test, and other programs. The general focus was on using lasers for diagnostics.

Electronic Devices Group, with nine or ten people, a mixture of talent with a general focus on vacuum tube-related technologies. Included were items such as streak cameras and special vacuum devices. Research activities were fair, but of limited use for the Laboratory. This group was eventually dissolved during my tenure, through a combination of retirements and transfers of some staff to the Mechanical Engineering Glass Shop.

Solid State Devices and Materials Group, of approximately 18 people with a variety of excellent talents. However, their support was quite limited. There was no thin film work, and almost all the activity was focused on bulk semiconductors. A substantial effort was focused on the development of high purity germanium detectors. What research was going on was excellent.
Left: Lloyd Graybeal surrounded by miniature electronics circuits, 1970s. 
It was from the above base that I started to work on a longer-term strategy.

\section{Strategy for the Long Term}

If Carol Maninger, my predecessor as ERD Division Leader, had a vision and strategy for ERD, it was not documented, to my knowledge. I recognized the need to forecast how ERD might best support the Laboratory's current and future programs.

At that time, a number of changes were taking place with regard to sponsors. Weapons and Testing were the base programs needing support; however, there was a massive push towards energy and other types of activities. For example, it was during that time that the Associate Directorate for Energy evolved.

I saw that we needed to establish critical mass core technologies if we were to be successful in developing a creative, exciting, and synergetic set of individuals for good R\&D. It was also clear that when good R\&D was available, the programs sought it out. This was best evidenced by the demand for the Quantum Electronics individuals already in the division.
As a base set, I used R\&D technologies commonly found in electrical engineering/ computer science departments at universities. Based on my knowledge of the Laboratory's current and predicted needs, I established which R\&D topics might have the best leverage for the future. I then set out to establish a process or marketing strategy to develop the critical mass core groups.

My first approach failed. I'd attempted to market directly to programs and to the $\mathrm{EE}$ Department Division Leaders. Programs were not interested in "betting on the come"-if there was a body to help them, they were interested, otherwise they were not. Other Division Leaders were sometimes interested in ideas where state-of-the-art technology could be applied in their supporting programmatic work, but they were very reluctant to provide allocations to ERD to expand existing capabilities or hire new staff.

After about a year, I realized that this strategy was not going to be successful. In addition, the R\&D groups were (historically) placed under three Associate Division Heads (ADHs). For various reasons, these individuals were not effective. They were also "in the chain" between the R\&D groups and myself. 
In 1972, I changed the reporting structure so the groups reported to me, and eventually eliminated the ADHs.

Fortunately, during that time-using ER fundsI started to identify and/or hire some key players that led to the second strategy. The second strategy, which proved to be successful, was to identify a key lead person who could attract other people with similar backgrounds. Guy Armantrout, Tom Burgess, and Ed Miller were already available, and Mike Ekstrom joined ERD after he got his PhD.

But somehow I had to establish a way to get excellent people from outside the Laboratory to join ERD. The process I used was as follows:

- I determined which universities were best known for the particular technical areas that we were pursuing, often seeking advice from my alma mater.

- I contacted the lead professors at the universities. I asked about students who would soon be receiving their $\mathrm{PhDs}$, or any recent graduates whom they thought might be outstanding leaders for the activity I was pursuing.
Generally, I found the professors to be extremely helpful. In one case, the professor himself became a Laboratory employee: Rob Smith.

- I contacted the individuals and explained to them what I was trying to do, that is to establish a critical mass core technology group that would be doing a combination of ER R\&D and direct programmatic support.

Throughout this process we interviewed a large number of people. I used ER funds to hire individuals who were conducting R\&D marketable either inside or outside the Laboratory. This was

important because of the need to leverage their R\&D to obtain more people. I was always very straight with these individuals, presenting my vision and expectations as well as potential risks.

Starting from one person, we developed a small core group using ER funds, then leveraged 


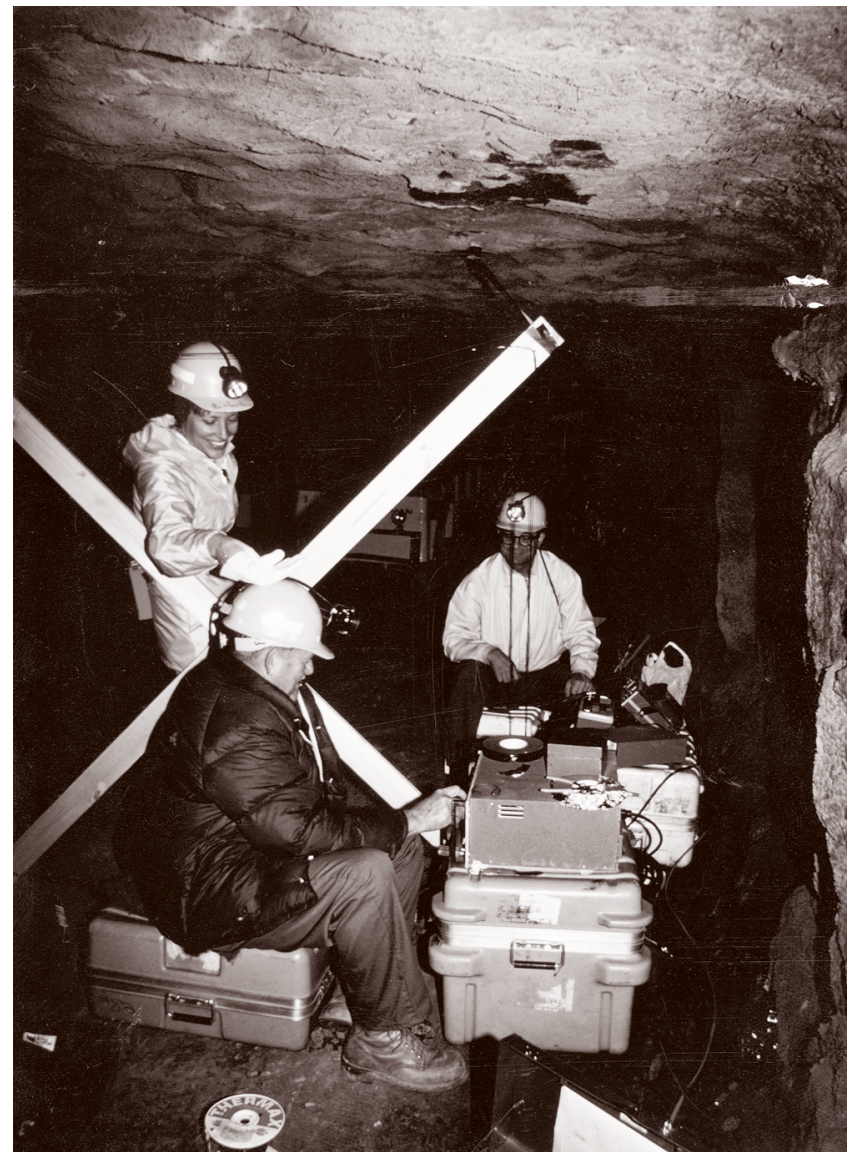

Edna Didwall instructs Ray Egbert in the finer points of field work at Pennsylvania in 1986. the small core group into a larger one by adding so-called "reimbursables" (now typically called Work for Others), and direct program support.

Once a core group was developed, I redeployed the ER funds into another area. When I became the Division Leader, a lot of ER funds were used for QE and bulk semiconductor device research because they had a successful track record. I had to "steal" ER funds from them to develop the other areas.

With the successful strategy now in place, I proceeded to strengthen existing and develop new core technologies in ERD.

The bottom line-I hired some excellent people. We hired over $50 \mathrm{PhDs}$, as well as many other talented staff in the approximately seven years I was ERD Division Leader.

\section{Applying the Strategy \\ Electromagnetics (EM) Group}

Ed Miller had been hired by Carol Maninger and me in 1971, just before I was named the Division Leader. I made him a Group Leader in 1972. Through Ed's experience and talents, we were able to substantially expand the number of quality and capable staff for this group, including Andy Poggio and

Hriar Cabayan. The primary difference, in addition to entrepreneurship, was the introduction of the "method of moments" technique applied to EM modeling. Indeed, many of the people hired were to support the theorists in the modeling effort. A significant portion of reimbursable funds was soon obtained, making the group continue to grow and to eventually receive direct programmatic support work as well.

Principal work for this group involved electromagnetic pulse modeling and antenna modeling, and a new technique developed by Jeff Lytle called geotomography.

Geotomography was a take-off from CAT (Computer Aided Tomography) - a set of convolution integral(s) defines how a particle moves through a medium and results in a detected signal at the other side. The ART (Algebraic Reconstruction Technique) algorithm is a technique to deconvolve a set of convolution integrals (converted to sums) to determine, e.g., densities of the media through which the signal passes. Geotomography replaces a particle source with an EM or acoustic source. 
There were a number of major challenges in developing geotomography. First, electromagnetic and acoustic waves are not the same as particles. Second, it was generally not possible to have a source and receiver that could be rotated symmetrically or the whole way around an object. This made the modeling problem very difficult. Nevertheless, successful algorithms were developed. There are a number of interesting applications, e.g., the study of permafrost in Alaska, finding tunnels in the demilitarized zone between North and South Korea, and 2D/3D geological imaging.

\section{Systems (Control Theory, Utility Theory,} Decision Theory, and Linear and NonLinear Systems) Group

While they were high quality people, none of the Systems Group was steeped in the modern teachings at universities. Therefore, this is an area I started more or less from scratch. Fortunately, in my marketing efforts, I came in contact with a person in Nuclear Regulatory Commission (NRC) Research who had genuine needs for system-related work, and I was able to convince him to let us start working some of his problems. My next challenge was to find a key person or persons to bring in with the appropriate knowledge.

The Guy Corynen Story. After contacting several of the better schools with strong systems background, and interviewing a large number of people, I met Guy Corynen from the University of Michigan. He had five degrees in music, mathematics, $\mathrm{EE}$, and systems science. Guy did not turn out to be as entrepreneurial as I had hoped, but he clearly was one of the strongest technical people one could obtain to develop systems expertise. Not only did Guy understand linear and non-linear systems, he also had knowledge of decision theory, utility theory, and control theory. He had a strong mathematical background including a clear understanding of Lebesque Measure Theory. I immediately recognized that Guy would be able to attract other theoretically based individuals, and hired him in, I believe, late 1974.

With Guy Corynen's theoretical base and NRC Research and ER as funding sources, we quickly expanded our overall systems capability. We hired Jim Candy, who has a very strong control theory background; Stein Weissenberger, Rokaya Al-Ayat and others with a decision theory background; and John Lathrop, a utility theory expert.

For those unfamiliar with utility theory: it is based on axioms developed by Von Neumann in the late 30 s and early 40 s, and further defined by Raffeia and Kenney in the 60s. It is a formal way to handle extremely complex and often conflicting problems. 


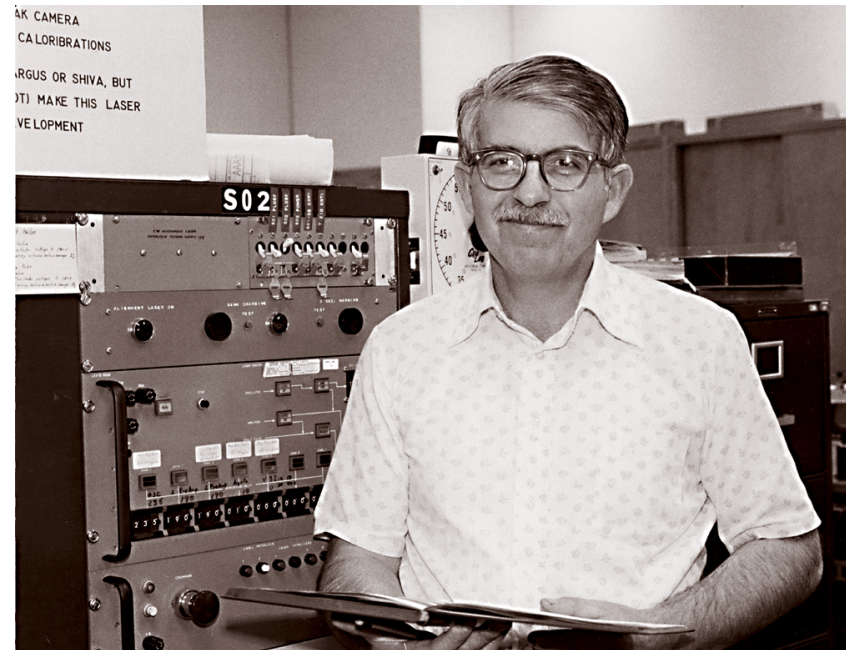

Ralph Kalibjian, an early developer of thin-film capability.

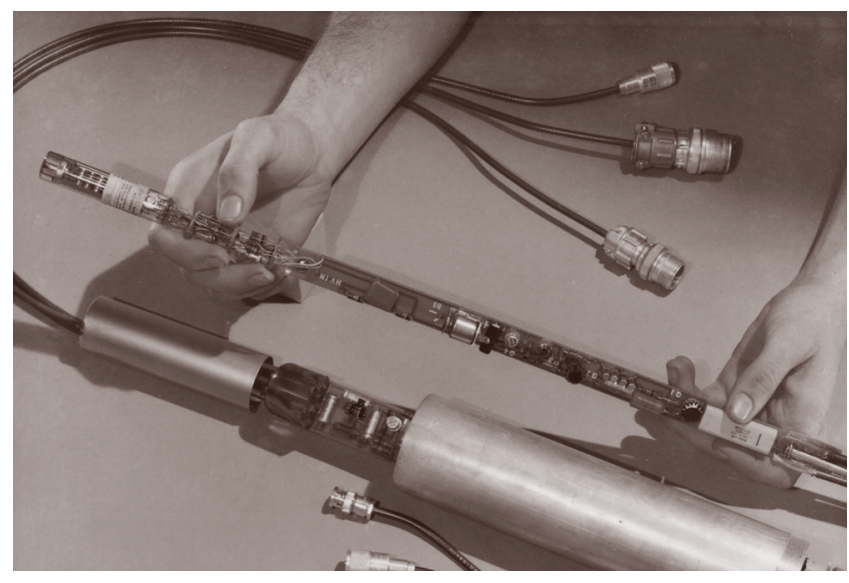

Photomultiplier tube with electronics developed by the EE Tube Lab, 1960s.

\section{Quantum Electronics (QE) Group}

The QE Group in 1971 was led by Tom Burgess, with other key researchers such as Gill Lippelmeier and Rich Schriever. It was expanded considerably with the start of the Laser Program. We were able to hire some outstanding staff. Later, many of the original staff, including Gil Lippelmeier, Rich Schriever, Bill Simmons, and Don Davis were absorbed, reluctantly, by the program.

While much of the core QE Group eventually moved out of ERD to the EE Laser Division, there were a number of positives. Rich Schriever went on to head the whole DOE Laser Program in Washington, DC; Bill Simmons played a key role in the Laser Program large laser system development; Don Davis was the first to develop an ultra short pulse laser system; and a young upstart I promoted to Group Leader eventually became the Laboratory Controller, Phil Schultz.

\section{Materials, Effects and Solid State Devices Groups}

Guy Armantrout had a small group of very good staff. When I became Division Leader, much of the group's effort was focused on high purity germanium detector systems. There was great interest in developing large crystals for cancer patient use. A good relationship had been established with University of California San Francisco, New York University Medical School, and the University of Chicago Medical School. In about 1972, we added a focus on modeling, led by Jick Yee. He is an excellent theoretician and he and others added much to the total efforts of these two groups.

Also, in about 1972 the value of having a thinfilm capability became apparent, driven by special devices for fast diagnostics and special circuits, i.e., PALs. Working with Ralph Kalibjian and Guy, we set out to develop this capability. Somewhat later (1975), the Tube Lab was being phased out, so space was available for an ion implant machine and other thin film equipment in Building 131. All existing staff, for example Ralph, Dino Ciarlo, and others, were very good, but the early addition of Joe Balch and Steve Swierkowski was a big help in the overall process.

These groups were very successful in developing fast silicon devices, including CCDs, which were designed for fast "parallel writing" of down-hole event information, followed by a slower "serial read" for recording. In about 1975 Mike Pocha, Dale Miller, Asher Blum, and others joined Guy's and Ralph's groups. 
Some of the other devices developed included fast gallium arsenide transistors and ICs, mercuric iodide detectors, magnetic thin film devices, and later, in the early 80s, silicon optical gradients, and special devices (e.g., microvalves and a micro "tube" for a miniature gas chromatograph).

Although I have not tracked these groups for several years, I believe it is a safe assumption that their present activities evolved from this beginning.

\section{Image Processing and Information Technologies Group}

The quality of this early research, led by Mike Ekstrom and, later, Rick Twogood, is highlighted by the fact that ERD got National Science Foundation and National Institute of Health grants. Others joined as the work continved to expand, e.g., Jim Sherman and Ivan Sacks. Unfortunately, Mike Ekstrom went through some personal rethinking in the mid-70s, which led to his departure from the Laboratory, and Jim Sherman became Group Leader. Many interesting internal and external problem applications were worked by this group, many of which are well known today.

\section{Design Automation Group}

EE was heavily involved in the uses of integrated circuits and special devices on printed circuit boards. Many of these were one of a kind or small quantities. Design automation, specifically automated circuit board layout, was a fairly hot research area, and Waldo Magneson, a long-time

employee of the Laboratory, had been pursuing it without great success. In the 1974-75 timeframe I contacted key universities doing good research in design automation and talked with a number of companies that were doing similar research.

One of the leaders at the time was Professor Rob Smith of the University of Texas. A week or two after I had already contacted one of his students, I received a phone call from Rob, asking if I would be interested in him, that he had been thinking about leaving the University and going to a different environment. We interviewed and eventually hired him. He worked well with Waldo and others, and did some excellent research leading to a fairly decent system for automated layout. Eventually, however, the private sector and university research caught up with us-I don't recall the reasons, but Rob eventually left the Laboratory.

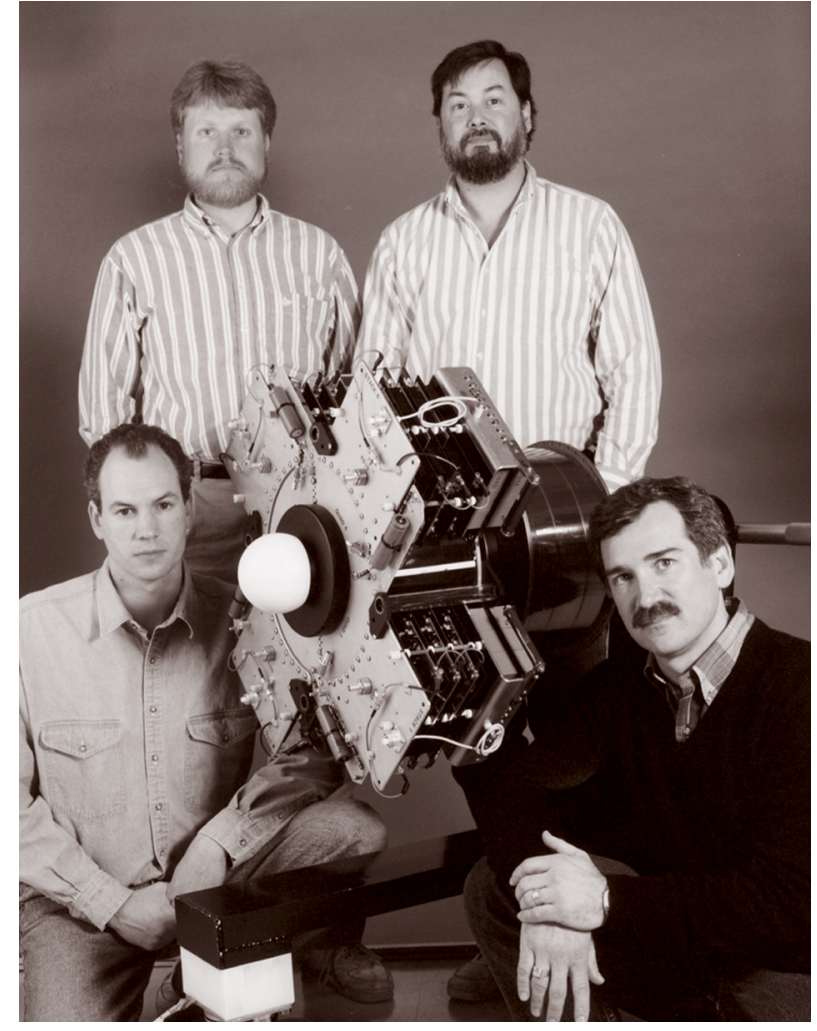

Back row: Ray Cravey and Craig Ollis. Front row: Steve Hawkins and Hugh Kirby with MOSFET Modulator. 


\section{Computer Applications and}

Research Group

Common in EE and EE/Computer Science Departments at universities were various aspects of computer research. In 1976,

Bob Wyman was asked to lead such a group in ERD. One of the consultants to that group was Chip Hatfield, who, I believe, was a professor at UCD at the time. At a later date, he joined the Laboratory and became the Group Leader for this technology area.

\section{Medical Technologies}

The total description of ERD would not be complete without talking about a decision I made in the mid-70s to try to break into medical technologies. As alluded to above,

Guy Armantrout had close ties with university research hospitals with the high purity germanium detector work. Mike Ekstrom had $\mathrm{NIH}$ grant money, the Bio-environmental EE sup-

\section{C...none of us realized the difficulty of obtaining funds when you are not a part of a university hospital structure.}

port group had joined ERD, and we had ideas for electromagnetic and thin film techniques that could be used for medical applications.

All the ERD groups were quite enthused about the prospects. We worked closely with UC Davis Medical School and had some support from UCSF, both of which helped to train us in some of the issues where they thought technology could make a contribution. While we were all enthusiastic and, indeed, had a number of good ideas that would have contributed to the medical technologies field none of us realized the difficulty of obtaining funds when you are not a part of a university hospital structure. The bottom line: we worked hard, we had good ideas, but we could not sell any of them to the extent necessary to develop a core capability. After many months of trying, I pulled the plug on this particular activity as I could see it was not going anywhere.

\section{Keys to a Successful Expansion}

There are several reasons why I was successful in expanding the capability of ERD.

First and foremost, I had ER funds that were totally under my control without being reviewed extensively by my managers. With the freedom to make quick decisions, and 
sometimes not popular ones as perceived by those who had been receiving the ER funds, I had unusual opportunities that are not readily available in today's world. My management also allowed me to develop and implement my strategies. I was allowed to make mistakes, but still I was held accountable. I believe they recognized that, overall, my activities and the results, i.e., the quality of ERD in support of the Laboratory's programs, was a net positive.

I don't want to understate the wisdom and graciousness of the management that allowed me to pursue the strategies. I was impulsive, aggressive, and relatively intolerant of management. Nevertheless, the managers-Ed Hulse, Carol Maninger, Hank McDonald, and Ed Lafranchi-had the foresight to look at the bigger picture.

\section{Budgets and Marketing}

Reimbursables. During the seven years that I led ERD, the Laboratory's budget went up and down several times. When the budget went up, ERD was criticized for all the "reimbursable" work that they were doing rather than supporting the programs. On the other hand, when the budget went down, we were criticized for not being more aggressive in getting reimbursables. At one point then-Director Roger Batzel became concerned about the reimbursable work being done in ERD and asked Mike May to review it. The total reim-

bursable funding was about $\$ 10 \mathrm{M}$ per year by then.

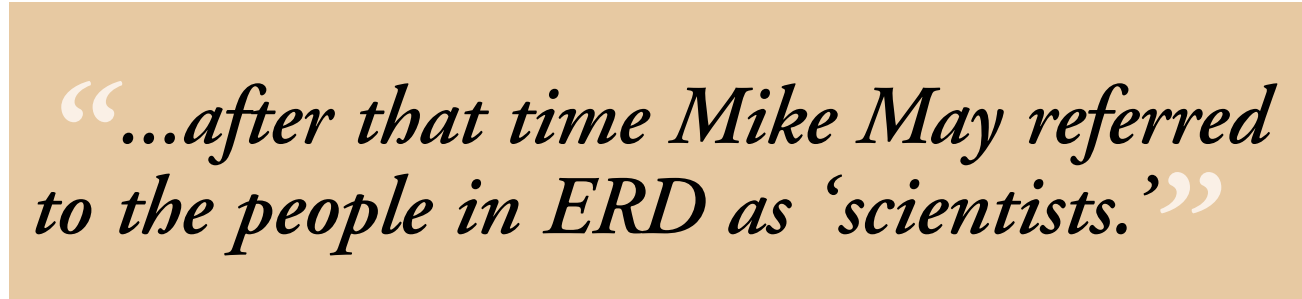

I knew that Mike May was a physicist but that his PhD was in EM. Thus, we led off with a very powerful group of people headed by Ed Miller, and covered the many aspects of EM that we had under way. Mike immediately recognized the quality of the work and the capability of the people. As we went through the various groups presenting their material over several days, Mike May went away very impressed.

An interesting side note: after that time Mike May referred to the people in ERD as "scientists." Before we were viewed as engineers. We joked about this "promotion."

On the road. I spent a lot of time on the road, as did many of our lead individuals. I also spent a lot of time teaching (on-the-job style) how to market. The purpose for this was to market our capabilities and receive reimbursable funding as required for developing and, in some cases, sustaining a sizeable core group of technologists. Our sources of reimbursable funds included the following organizations: 


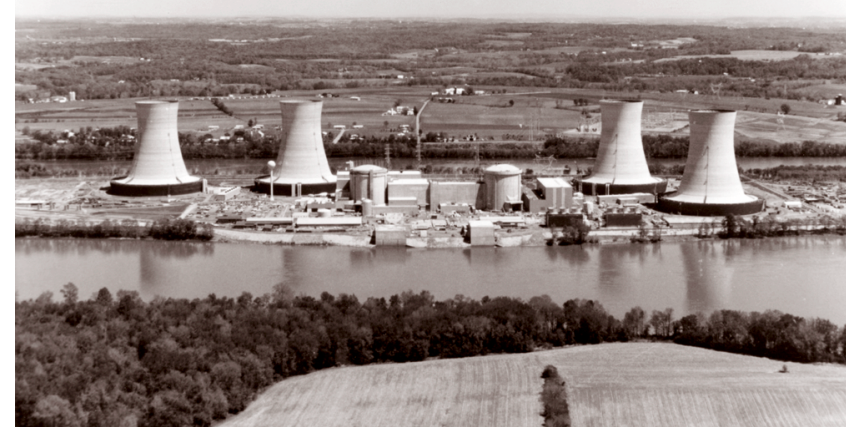

A typical nuclear reactor power generating complex in the 1970s.
- The Nuclear Regulatory Commission

- National Institute of Health

- Advanced Research Projects Agency

- US Air Force

- US Navy

- US Army

- National Science Foundation

- Defense Nuclear Agency

- Department of Energy and its predecessors

When I stepped down as the Division Leader for ERD, we were receiving over \$12 M a year in reimbursable funds. In 1978 dollars, that was a substantial amount. It is also likely the reason Roger Batzel felt it was appropriate for Mike May to review what we were doing.

Whereas each of the sources of funding generally covered more than one of our technology areas, the NRC was a fairly broadbased target and was a primary source for work that attracted people to all aspects of systems, including decision theory, utility theory, modern control theory, and non-linear systems. In 1979 (I believe that is the correct date) Roger Batzel, recognizing that both EE and ME were doing a lot of work for NRC, asked me to form a program that led to the formation of the Nuclear Systems Safety Program (NSSP), now the Fission Energy Systems Safety Program (FESSP).

\section{Some Firsts}

In closing, let me mention a few firsts that come to mind. In 1963, I believe I was the first person to build a laser at the Laboratory. The Laboratory had a lot of lasers used in a lot of different applications at that time, most of which had been purchased from Spectra Physicsthey were quite expensive. What was needed was a laser that could be blown up at the test site, i.e., a fairly inexpensive device that we could build in-house and would be adequate for our diagnostic purposes. Working with the Tube Shop, I designed and had built a helium neon laser. As it turns out, the power supply I had available was not of high enough potential to break down the gas, so I used a Tesla coil to initiate the laser. It worked fine the first try.

A funny anecdote: A number of the managers came out to see the newly developed 
laser. I fired it up and it worked fine, except it gradually started to change color. The gas went from its usual red-orange to a bit of a purple color, clearly indicating that something was happening. As it turned out, I had touched the Tesla coil to a region where the glass tube had been sealed off, and I had created a pinhole. My helium neon laser now had air in it, and eventually stopped lasing while the managers looked on.

I believe I was also the first to develop a bangbang control system for a real application at the Laboratory. The Astron machine, Nick Christofilos's idea for how to make a fusion machine, needed a very high current control and "topping" system for a mine-sweep generator that was used to power some of the magnets. The original approach planned was to use a sizeable IVR, i.e., a motor driven primary/secondary transformer. The motor was to be driven by a linear tube amplifier. I saw that there was an up and down button, i.e., a forward and reverse button, on the motor and volunteered to develop a bang-bang control system.

I developed a suitable control system by putting appropriate damping on the motor and developing a variable hysteresis limit control. With a few adjustments and some testing to be sure the system did not limit cycle and the motor would not get too hot, the system worked within the total limits required.

The first thin film laboratory for both silicon and gallium arsenide was developed in ERD. We developed very high speed "parallel write/serial read" CCDs for weapon test diagnostics, magnetic field sensing thin films, and mercuric iodide detectors. There are, no doubt, a lot of other firsts, but these are ones that come to mind.

In closing: there were great challenges and difficulties in developing and running ERD. I

worked very long hours, but it was fun too. The true successes of ERD were the great and dedicated men and women who also worked very hard. I was fortunate to have the opportunity to work with them. 
From Lingineering Research Division to the N(Fcrotechnolog'y Centern by Dino R. Ciarlo

目
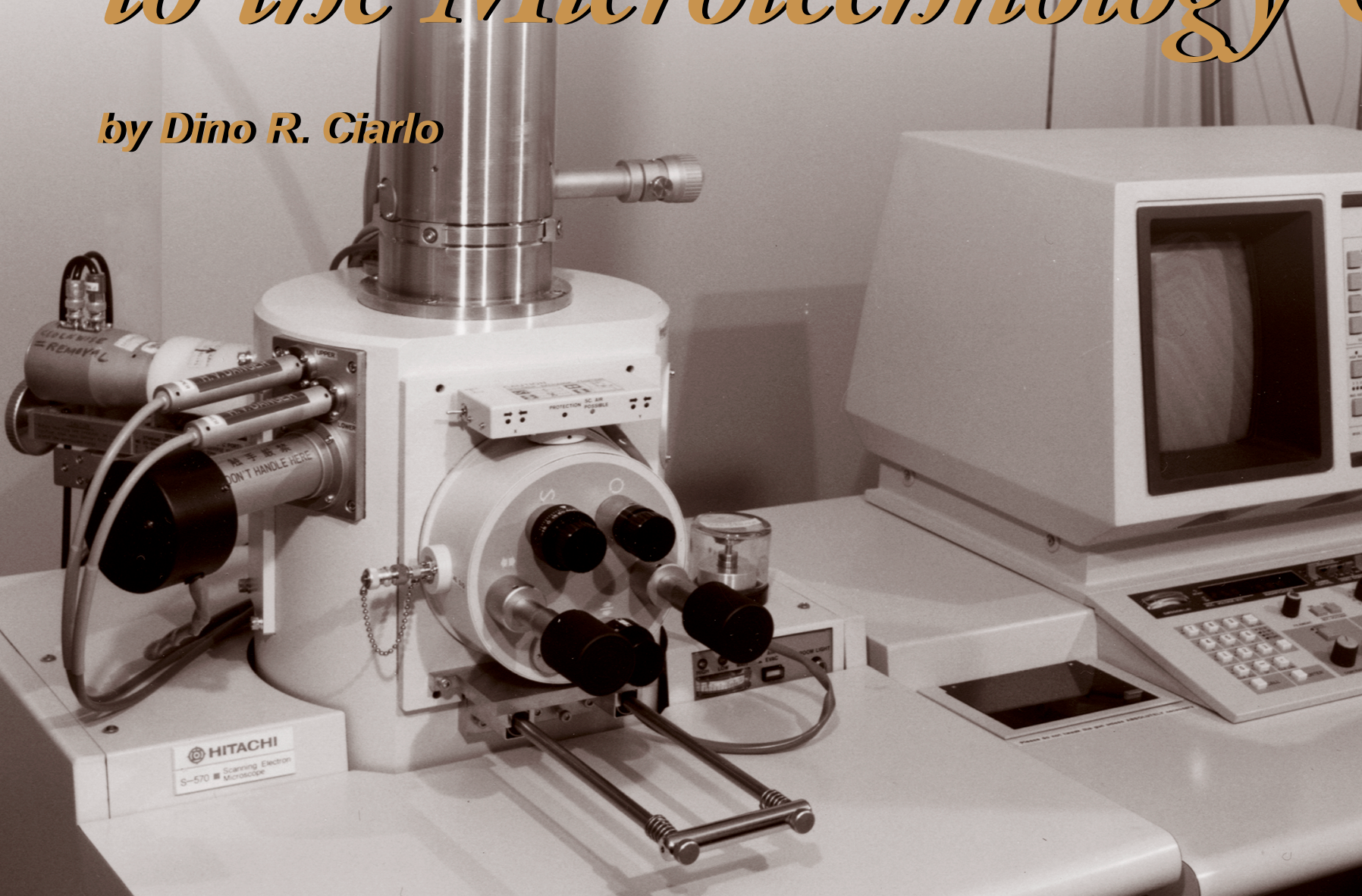
$M$ first assignment was to work on thin film circuits for radiation hard environments in the Test Program.

I'd been hired in June of 1965 by Lou Zevanove, Alex Stripeka, and EE Department Head Ed Hulse, first as summer employee and then as an FTE.

Early on, the EE Department decided to establish a Research Division to anticipate program needs. Carol Maninger was the first Division Leader.

One of the first projects having real impact was the Lithium Drifted Germanium radiation detector. Guy Armantrout was instrumental in developing this technology. I remember being Guy's officemate when he was writing his PhD thesis (for Purdue University) on this subject. Word processors were unknown at this time and Guy would write page after page, long hand.

I was always impressed at how he could write the final version without any need for corrections, modifications, or editing.

Dan Okubo was Guy's technician during those days and together they delivered many detector systems. Eventually, the technology was picked up by commercial companies like Ortec.

My work (under Ralph Kalibjian) eventually led to the development of Metal Oxide
Semiconductor (MOS) radiation detectors for the Test Program. We fielded many experimental systems for physicist Tom Boster. Others in our Group worked on high speed diagnostic systems for the same application.

In the late 60s, ERD decided to make a major investment in radiation hard thin film circuits. They hired Eric Schwartz and

Erwin Fischer-Colbrie to lead the effort. Ed Hsieh was one of the first young engineers to get hired to do the actual work. Ed's first assignment was to develop a thin film metaloxide metal transistor similar to what

Carver Mead had done at Cal Tech. This work eventually led to magnetic thin films for data recording. All this was motivated by the needs of the Test Program.

Hand-held calculators were still unknown at that time, and I remember a room devoted to large Singer calculators. If you divided two large numbers with these things they would make a lot of noise, vibrate and just about walk off the table. Eventually HP came out with their hand-held calculator. Initially, each one of these calculators was stamped with a 9-digit DOE number. I remember AI Schiff going to an Intel seminar and bringing back news of a 4004 microprocessor. We sat around trying to figure out what this might be useful for and couldn't come up with any good ideas. When Ed Miller was Division

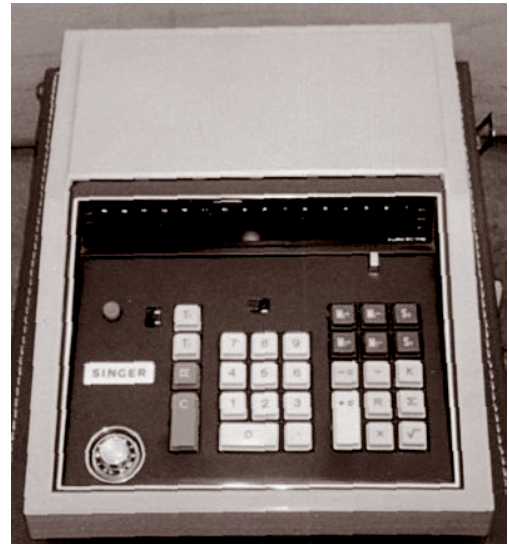

Singer calculator, early 1970s.

Left: Dino Ciarlo uses a Scanning Electron Microscope to inspect miniature solid state devices. This system was purchased by the EE Department in the late 1970s and was an example of many capital equipment purchases made throughout the years to maintain state-of-the-art capability in solid state electronics. 
Leader, he promoted the use of small computers and I remember checking out PETs for the weekend to learn how to use them.

In the early 70s, the test schedule slowed down and a number of us worked on solar energy projects. We investigated silicon cells, GaAs, CdTe among others. Jick Yee guided the work with his theoretical calculations.

A significant event for my work was the hiring of physicist Nat Ceglio in the mid-70s from MIT by the Laser Program. Nat had just completed his thesis on the use of microfabrication to build x-ray diagnostic devices, and he wanted to continue this work. He promoted the idea that the technology and equipment used by the computer chip industry could be used to fabricate advanced diagnostic devices and laser targets. By this time, it was becoming obvious that in no way could we compete with industry to design and build computer chips. So we began building zone plates, pinhole arrays, thin windows, laser targets, microchannel coolers, field emitters, and diffraction gratings. Most were used by the Laser Program but other physics divisions also requested them.
During the 80s, there was more and more pressure to get us out of Building 131 because of the need for clean room space and because of the toxic gases we used. By this time, Joe Balch had become our Associate Division Leader and he actively looked for better space. Somehow, he managed to get the required funds with the help of visionaries like Hank McDonald, Dennis Fisher, Ed Lafranchi, and Dave Pehrson, and with the design help of Ken Harmon and Mike Atkinson, Joe was able to build Building 153, and we moved in, in November 1992.

The Microtechnology Center has since evolved into a very versatile, quick response facility that supports programs throughout LLNL. We do not compete with industry, but work on problems for which there are no commercial solutions readily available. Management expects us to plant the early seeds for projects that could eventually lead to major programs. A couple of our most notable efforts now are detectors for chemical and biological warfare and high speed optical interconnects for advanced computers. We continue to search for ways to help the stockpile stewardship effort and to apply our capability toward the fabrication of NIF targets. 


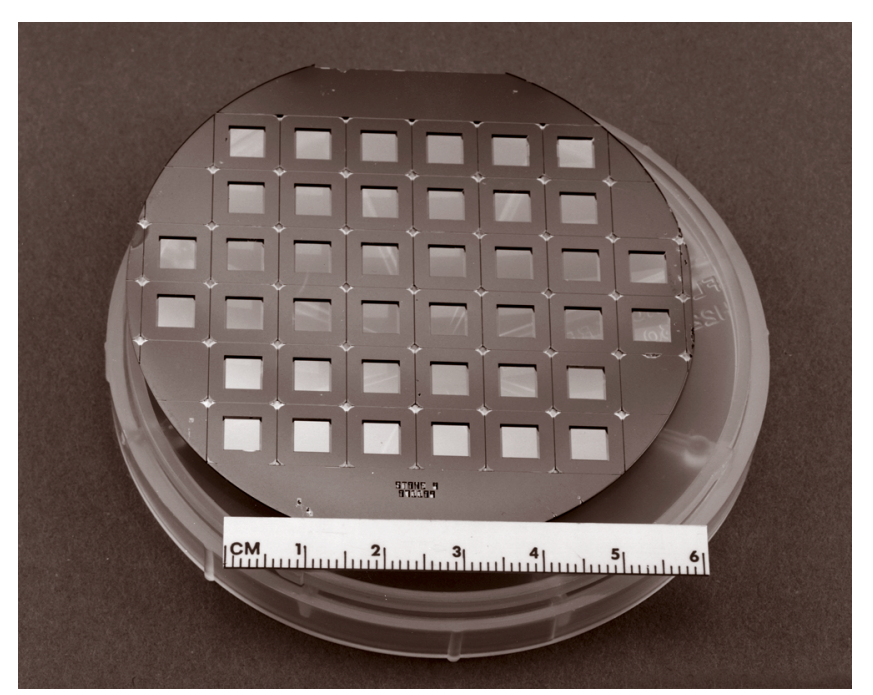

A 3-in. diameter silicon wafer with an array of very

thin ( 1000 A) silicon nitride windows. This is an

example of a device made by micromachining,

which was started in the early 1970s. Eventually the

effort grew to support many physics experiments,

especially those involving x-ray diagnostics. 


\section{The Solid State Devices Group}

by Steve Swierkowski
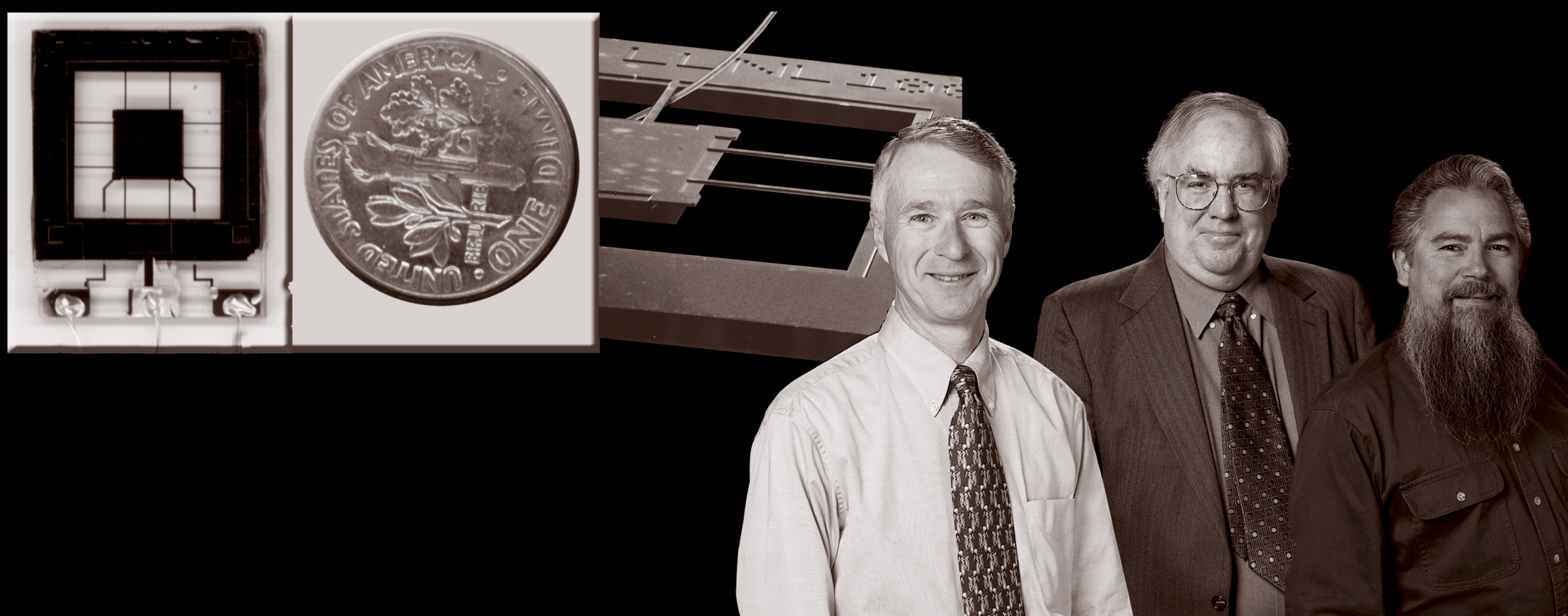
came to LLNL on August 1, 1972 and it was hotter than hell.

The all time record of $116^{\circ} \mathrm{F}$ was set shortly after I started. I was wondering what kind of hellhole I had signed up for; my wife used the phrase "cultural Siberia."

I was hired by Ralph Kalibjian, Guy Armantrout and Lynn Cleland into EE/ERD (Engineering Research Division), into the brand new Solid State Devices Group, which was split off from Ralph's group.

I divide my exposure at LLNL/EE into three main phases or eras:

The physical electronics phase, roughly pre1970: pulse power, HV, circuits, scopes, PC boards, high vacuum tube R\&D, streak cameras, and the like. Mainly weapons support; some MFE; some national security (Z Division).

When I arrived, the Lab population was about 3600 , having just survived its first, but small, layoff. Joe Balch and I had just signed on, and there was some bitter resentment from some of the layoff survivors. This early phase centered around the "Tube Lab," i.e., vacuum tubes. The start of the solid state groups and Microtechnology Center goes back, I think, to Ralph Kalibjian making some MOS radiation detectors out of silicon. The radiation dose (charge) was stored in the MOS capacitor gate oxide, and it was read out after a suitable (but short) time delay near the underground device. This very successful simple sensor led to more sophistication, arrays of devices, and the need for better readout electronics, and our first solid state device processing capability started-and started to squeeze out the tube lab stuff and the glass blower.

The ERD solid state groups phase, roughly 1970 to 1990: growing the solid state device groups of ERD, and the thriving and spin-off of the Quantum Electronics and Lasers groups; the introduction of other Engineering Operations activities into ERD-mostly weapons support, Y Program support, some Z Division work; VERIP era-(somewhat depressing, approximately two years before the end of weapons testing).

I started work on Ge radiation detectors in 1972 (DARPA support), and Balch started work on silicon sensors and readout CCDs (weapons support). The work went very well and we grew the engineering staff from about 10 to 30 . There was very good funding from ER, now called techbase, in the beginning, but in the end, this discretionary, flexible, growth creating money started to wither badly, and almost dried up.

Computer systems came in, with computer modeling in a big way. There was a huge

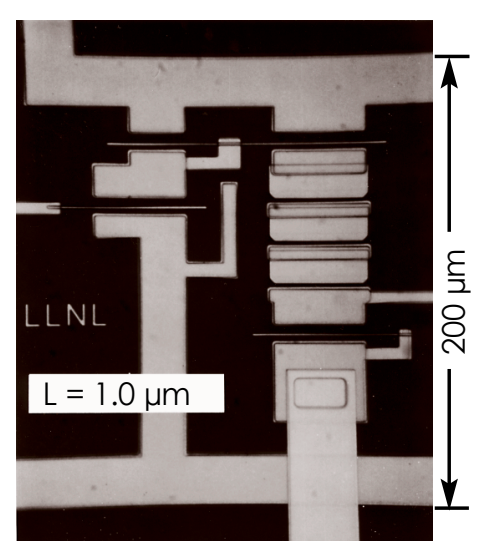

Integrated circuit.
Left: In 2001, Steve Swierkowski, Chuck McConaghy and Jimmy Trevino (I to r) developed a microelectromechanical system (MEMS) accelerometer that has a $10 \mu \mathrm{g}$ sensitivity in the $1 \mathrm{~Hz}$ to $10 \mathrm{~Hz}$ range. Applications include national security and environmental monitoring needs for intelligent networks of small-sized, low-power sensors. Uses range from monitoring ground signatures in surveillance applications to movement in massive structures such as bridges and buildings. 


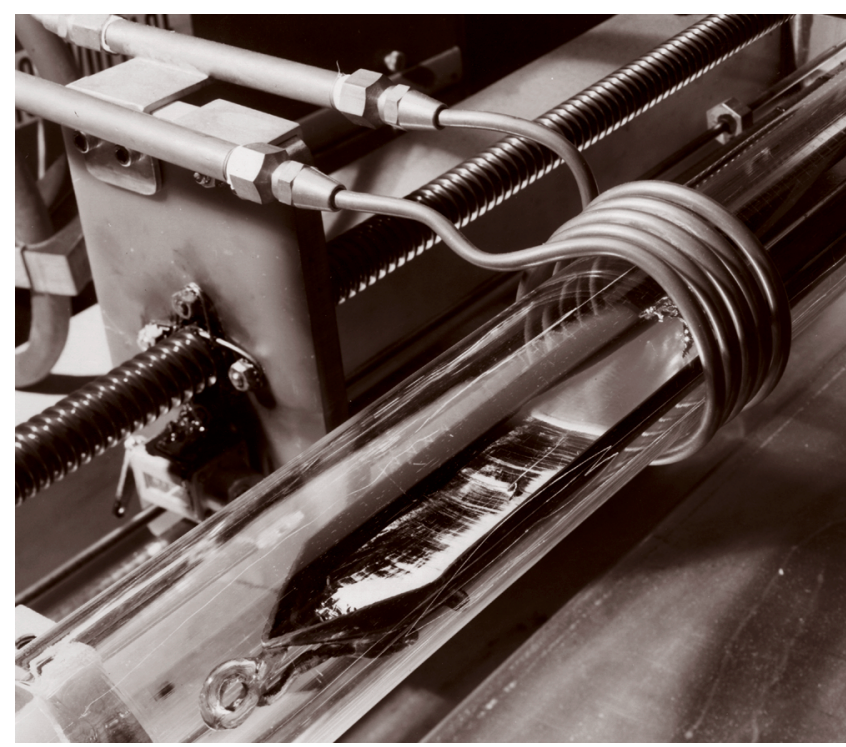

Growing our first semiconductors at LLNL 1972-74. We grew large ingots of ultra-high purity germanium for radiation detectors.
DEC VAX network down the hall that never impressed me as being used effectivelybut they were probably thinking the same about us!

Shortly before the depressing VERIP era, our Division Leader (enamored of computer modeling) said at one ERD review, "Well, you've seen one chip, you've seen 'em all!" He was commenting on one of our most sophisticated solid state achievements at the time-a medium scale integration Si IC (for the soon to be withering Weapons Program). Not much support! He actually floated the idea of disbanding the solid state device groups at this point, but we were not quitters.

In fact, I was madder than hell. We enlisted the support of all our many, and very diverse, programmatic customers, and it was just overwhelming in our favor. We struggled on through tough funding times.

I remember a very pivotal meeting with Joe Balch, Mike Pocha, and myself one or two years before the last nuclear test. We (the three solid state leaders) had an informal meeting once a week. We plotted the money and number of nuclear tests roughly versus time, and it didn't take a genius to figure out that the solid state efforts (money sources) had to diversify to survive.

Mike and I concentrated mainly on surviving and coping, and Joe Balch went off and did a study and we decided that the BBRP program was ripe for assistance: old-fashioned instrumentation technology, scientists far removed from our type of high tech, good cross-cutting opportunities, lots of very difficult measurement problems, and a whole new area of microfluidics that we felt we could contribute to.

We knew the electronics, the physics, the microfabrication; we had to learn about working with fluids and microdrops and biologists. And it seemed that we wouldn't have much competition for a while if we had something good to contribute to this niche area. We were very careful not to embark on competing with big private industry (e.g., high bandwidth interconnects would be THE domain of companies like ATT and NTT).

We were already starting to support Y Program with devices, laser diodes, microchannel coolers, gratings, and laser targets, so this was one good new growth 
direction. The origin of all the EO work goes back to when I convinced the department to get an MBE (Molecular Beam Epitaxy) machine (initially for GaAs ICs) if we wanted to stay state-of-theart in electronics. It was expensive $(\$ 750 \mathrm{~K})$, but turned out to be a great investment.

In this era, Dino Ciarlo was willing to make small stuff for just about anyone, and the best part was he did it on a shoestring-and still does. So lots of experimenters came to Dino to get special optical targets, gratings, microwells, pinhole arrays, thin film windows, and on and on, a few of a kind. And THIS really was the beginning of MEMS, except that acronym hadn't been invented yet.

Everyone-all the labs and universities-has a MEMS facility now and we were 15 to 20 years ahead. I think the reasons Sandia has such a terrific MEMS program now are: 1) they were desperate to find something to do with this enormous, new, underutilized, rad hard MOS IC facility; 2) they picked our brains on several visits, on how to set up a MEMS facility (with the blessings of LLNL's upper management); and 3) the corporate leaders behind Sandia threw a lot of support for them to get into the business. Better late than never. They've done a good job.
The Microtechnology Center (MTC) phase or MEMS phase, roughly 1990 (i.e., approximately two years before the end of weapons testing) to present: planning for Building 153 building it, moving in, acquiring new equipment; diversity of applications (away from weapons support); hiring lots of new staff; the demise of weapons testing (and much of our funding); large growth of lasers; expansion into MEMS.

One of the Weapons Program's early dying gasps was essential to our rebirth: the system convinced DOE to spend major dollars on a "weapons restoration program." There were many antiquated facilities and so we con-

vinced the EE and LLNL management to consider Building 153. We were starting to grow again after the lean period, and Building 131 just was not suitable for us. We hated it: too much vibration, toxic gases near big office crowds, never enough space, and no real possibility of sensible clean rooms that were really clean. We had to work under negative atmospheric pressure because of the toxic hazards, which meant we sucked in dirt from everywhere in spite of our best attempts to keep it off the wafers and chips. 


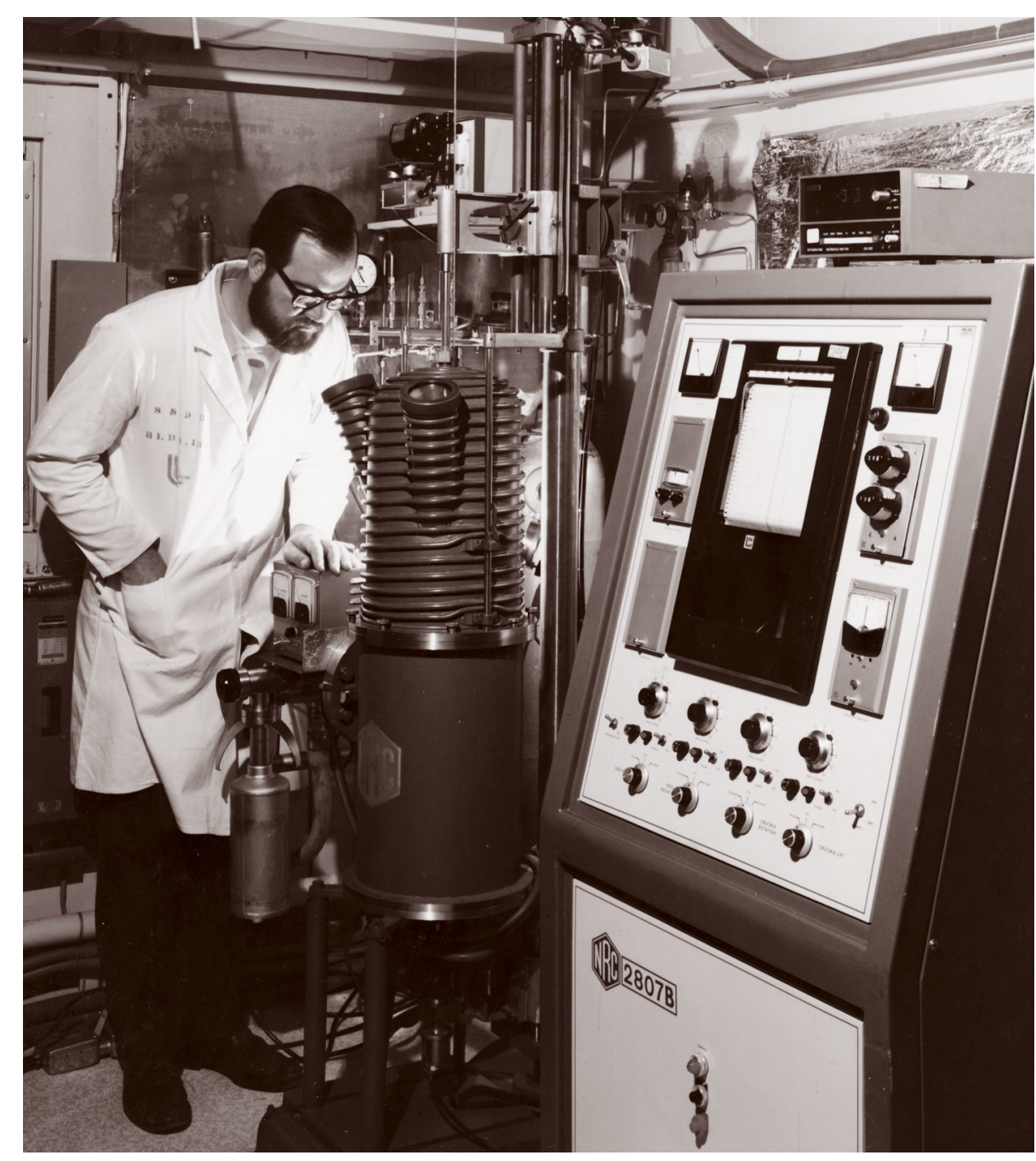

I will always be grateful to AD Hank McDonald for getting behind us to make Building 153 happen, and to his successor, AD Dennis Fisher, to continue and not drop the ball and help us through the end of this transition. Roger Werne said more than once, something to the effect that the MTC was one of the "crown jewels of LLNL engineering." I think that was true then, and still is. It was a very broad team effort and we are very proud of what we all accomplished.

After we got the ball rolling with MEMs microfluidics, I was just thrilled when the NAI Directorate came into being. It was clear that there are many national security needs that MTC could contribute to.

Much of our early effort to support BBRP now folded over and overlapped with new efforts coming through NAl. Microfluidics is just a major new killer technology and we were pioneers in the game. We had very good ongoing activities with BBRP, DARPA, and NAI in this area. Calling this shot right has meant our survival-I think the alternative might have been withering on the vine. 
My summary: We (MTC) started with about 12 people (out of 3600 total) and are now about 60 (out of 7000 total). We survived and grew through three main technological eras and various institutional stresses. ("That which doesn't kill you, makes you stronger.")

My advice for the future: We must always remain very flexible and be willing to adapt and to learn new things and ways of doing business. LLNL should increase its effort to fund small discretionary types of R\&D research, i.e., not high overhead LDRD, because this type of effort is by far the key to our success. Without the "techbase" R\&D managed at the division level, one is burning the seed crop for the future. Multiple programs and disciplines at LLNL are our biggest assets-we should not become too dependent on any one program. 
Electromagnetics in the Engineering Directorate

by Andrew J. Poggio

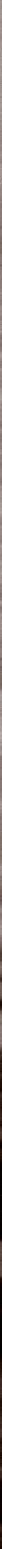




\section{Introduction}

The following is an abridged history of electromagnetics in the Engineering Directorate. It deals primarily with the activities in computational electromagnetics and only briefly describes work in experimental transient electromagnetics. It stops short of a description of extensive experimental work in electromagnetics in the 80s and early 90s dealing with High Power Microwaves (HPM) that was funded primarily by the DoD. It also does not delve into the electromagnetic regime of Pulse Power. Fortunately, some snippets of this work are included in the following section by Wayne Hofer.

\section{Infancy and Evolution}

Since its founding, LLNL had always had a keen interest in computing systems. By the 1960s LLNL had demonstrated the value of computers in computational physics and was at the forefront in this discipline. Modeling, which had heretofore been either crude or the realm of mathematical physics with special functions and orthogonal expansions, was taking its role alongside experimentation as a tool in the hands of scientists and engineers.
During the 60s, the importance of predicting nuclear effects such as those associated with Electromagnetic Pulse (EMP) was becoming acute in the national weapons community. Coincidentally, some major steps had been made in computational electromagnetics (CEM) to service the antenna and radar cross-section communities. It was not surprising then that the application of integral equation techniques for solving Maxwell's Equations in the frequency (or spectral) domain to EMP effects modeling was becoming common. And, since the EMP problem was inherently transient, innovative steps for numerically solving Maxwell's equations in the time domain were also being explored.

In the latter case, Kane Yee of LLNL's $D$ Division made seminal contributions and, in 1966, published an algorithm for solving the time-dependent equations that presently bears his name and is a cornerstone in finitedifference methods. The full impact of this work was realized in the following decade, when computing power increased to enable full advantage of the algorithm. Over the years many careers, papers and textbooks evolved out of the Yee Algorithm.
Left: Jeff Lytle and crew dropping probes into snowpacked ground in Alaska, circa 1970. 


\section{The 1970s}

At the turn of the decade, Electronics Engineering (EE) was poised to enter the EM arena as it was being called upon to support diverse activities in weapons effects and remote sensing. Novel experimental and computational methods were in development across the nation and their applicability to LLNL interests did not go unnoticed.

\section{NEC became synonymous with
EM/wire structure analysis.}

Ed Miller, already a renowned mathematical modeler in EM, was invited to join LLNL in 1971 by Lynn Cleland. Ed organized an EM team in EE to solve problems dealing with EMP that had been posed by Lou Wouters of $L$ Division. He entered an environment created to support research in several engineering disciplines and to develop leading edge tools for existing and anticipated needs in the programs. Lynn Cleland, as leader of ERD, had motivated and nurtured this culture and took the initial steps that would ultimately lead to profound capabilities in several key technology areas.

Within three years the team had grown to include Bob Latorre, Leroy Martin,

Bob Bevensee, Jeff Lytle, Darrel Lager,
Fred Deadrick, Bob Anderson, Leo Spogen, Jerry Landt, Jerry Burke, and me,

Andy Poggio. Many of these team members had performed research in universities and industry during the CEM infancy of the 60s or had worked in the R\&D on methods for assessing EM effects and remote sensing. They were known on the national scene because of books, articles in the peer-reviewed literature, and industrial and programmatic reports.

The motivation and support at that time came primarily from L Division (EMP effects), Z Division (theory, techniques, and systems for remote sensing), and Work for Others. The latter included the Coast Guard, Navy, Air Force, and Army (numerical methods for antennas), the Air Force Weapons Lab (CEM techniques development for EMP), and the Defense Nuclear Agency (EMP Protection Methodologies). The impacts were profound as the methods and techniques that we developed were immediately applied to the prediction of electromagnetic effects and system performance.

The mid-70s brought LLNL to prominence in the antenna and scattering community where its NEC (Numerical Electromagnetics Code), already acclaimed for innovation and usefulness, quickly became the most widely used code for wire structure analysis. Initiated at MBAssociates near the turn of the decade 
and refined at LLNL in the early 70 s by developers Jerry Burke, Ed Miller, and me, NEC became synonymous with EM/wire structure analysis. As a result of continuing upgrades it could, by the 90s, boast of three thousand users worldwide with user news groups on the Internet, international aficionados, a national conference originally dedicated to its use, numerous commercial firms that provide "wrappers" to facilitate the user interface, and implementations on all popular computing platforms including Macs and PCs. Jerry Burke, a constant element and dominant contributor throughout NEC's entire history, ushered it through four major versions containing innumerable improvements and, in the process, established an international reputation.

The computational engineering community was exposed to thinking in terms of transients or the time domain in the late 60s after publications by Kane Yee, Sperry Research, MBAssociates, and the University of Pennsylvania. Following the trend, Jerry Burke, Ed Miller and I initiated the development of time-domain codes for electromagnetic interactions with surfaces and wires at MBAssociates. We ultimately migrated the algorithms to LLNL and the TWTD (Thin Wire Time Domain) code was developed. The response in the peer-reviewed literature was substantial, especially to the expository papers in the Journal of Computational Physics. In the early years, TWTD provided many of the physical insights that are now plentiful in the time domain with widespread use during the EMP and High Power Microwave (HPM) era. TWTD allowed us to follow electrical currents and charges on structures and see how they "flowed, radiated, and coupled." We even created an integral hologram that was mounted on a transparent cylinder and rotated around an incandescent light so that we could display the time-dependent currents due to pulses driving a simple dipole. The display was consistent with the physics we had learned and the laws of nature. The "movie" and the subtleties that were evident were discussion topics for days. Some of the early applications of TWTD were directed towards providing insight and guidance for use in a Defense Nuclear Agency program at LLNL that was developing an EMP Protection Methodology.

By the mid-70s LLNL was an acknowledged international leader in CEM with computational tools that were having significant impacts at the Lab and across the DoD. But that wasn't all. Transient measurement capabilities were another strength possessed by EE that was recognized on a worldwide scale. Bob Anderson and Fred Deadrick were key in the development of early versions of the transient electromagnetic facility, EMPEROR. This experimental tool used a cone driven against a large conducting plane to generate predictable waves. They performed experiments and collected data that were at once unique and revealing

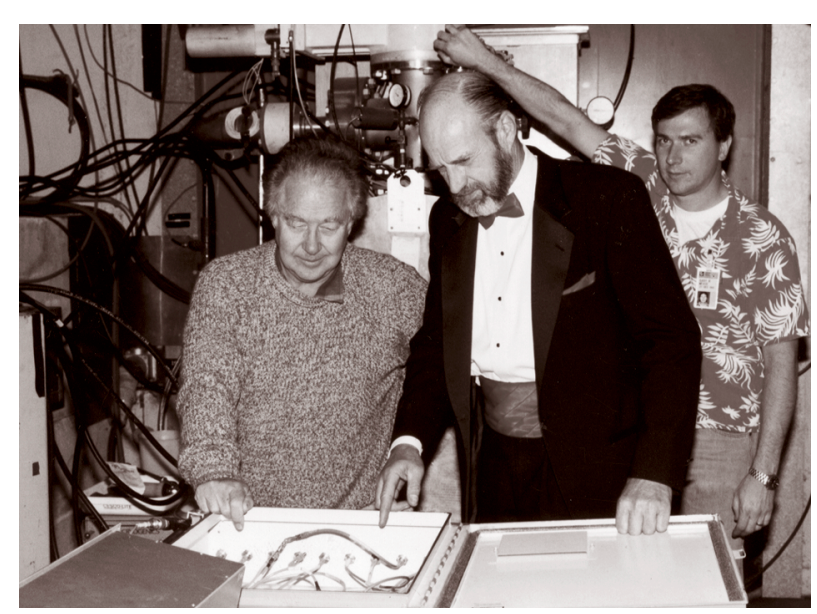

Left to right: Ken Leighton, Bob Anderson, and Gary Mease checking diagnostics for the Backward Wave Oscillator, early 1990s. 
to the national EM community. The facility, even in its early days, produced transient data resulting from quasi-impulsive sources that revolutionized thinking in terms of impulse responses for electromagnetic structures.

The problems in EMP effects that had originally spawned the movement of EE into electromagnetic modeling and measurements also provided impetus for the development of systems analysis capabilities. Original team members involved in systems analysis, such as Leroy Martin, Leo Spogen, and Bob Latorre, and motivators such as Lynn Cleland and Ed Miller, pointed out the need for formal systems analysis support. For some details of the growth of this technology area, see the comments by Lynn Cleland in his description of the Engineering Research Division.

Concurrently, the remote sensing portion of the team produced some outstanding tools for underground probing and characterization. Starting with experimental and analytical studies to predict propagation in the ground for national security applications, they progressed under the leadership of Jeff Lytle to develop experimental and modeling tools for creating maps of underground structures. Their cross-borehole EM techniques, which employed homegrown computer-based inversion methods, were executed worldwide and the results were used for science-based decision making in international security and energy programs. Subsurface communications, subterranean tunnel detection, and oil, water and mineral deposit mapping were all in the application space of their tools.

Just prior to the onset of the 1980s, a brainchild of Ed Miller and Stein Weissenberger evolved into the thrust area construct. They had observed an increasing diversity of $E E$ activities and programmatic responsibilities. They had also noted the need for a strategy to decide which technological areas should be targeted as well as a structure in which to cultivate these technologies. Ed and Stein felt that a thrust area should additionally provide a needed technology base that 1) was the responsibility of engineers and not available in a timely or cost-effective fashion from external sources; 2) made engineers more effective in executing their jobs and therefore had an indirect programmatic contribution; and/or 3) could have a direct payoff for the programs. They appreciated the need for a certain amount of technology forecasting to anticipate technology trends and future programmatic needs.

One of these thrust areas, originally called Modeling and Simulation, but ultimately referred to as Computational Electromagnetics, 


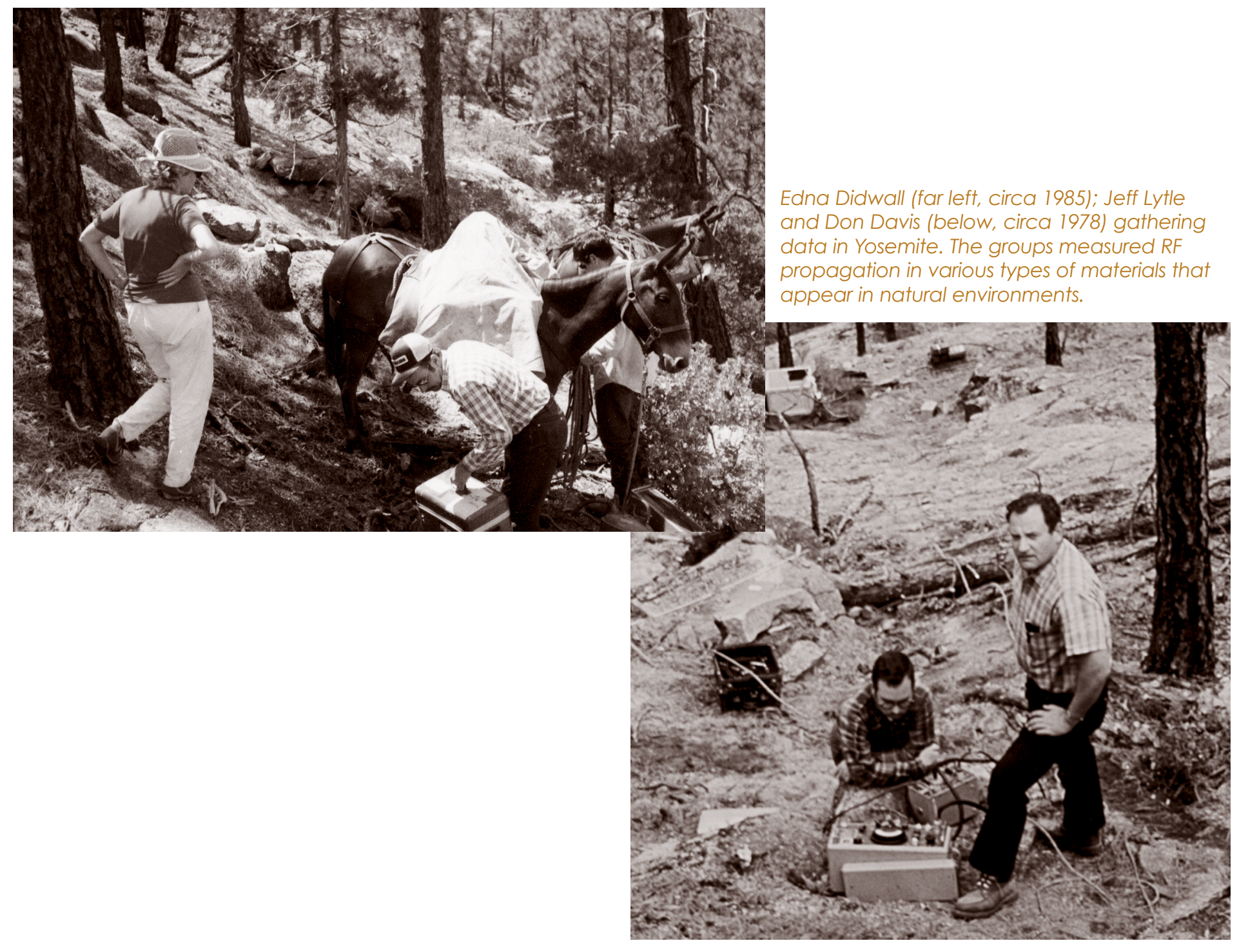




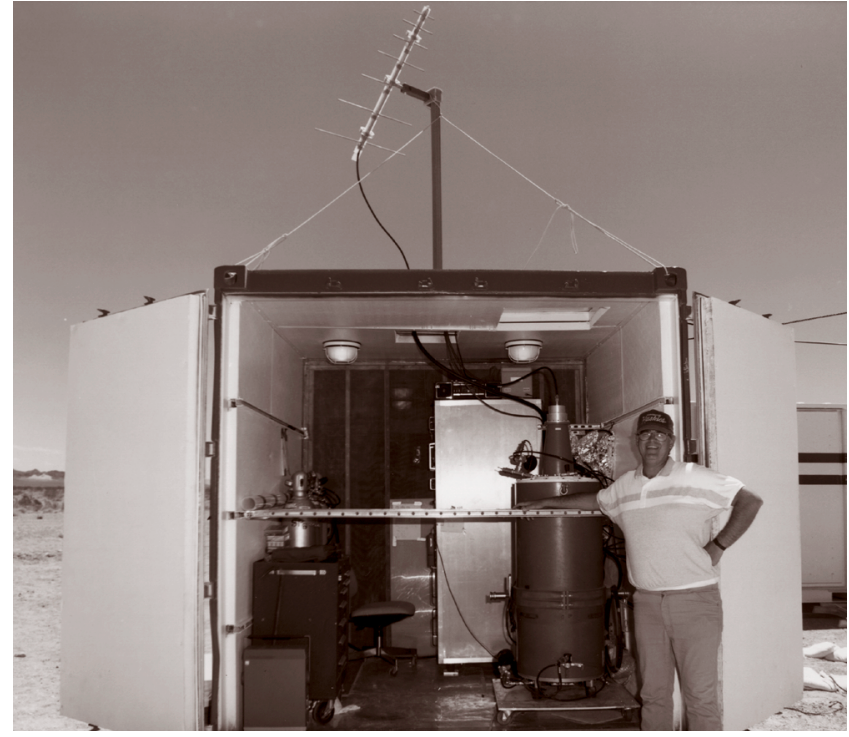

Karl Freytag in front of mobile Pulse Power Laboratory, circa 1990 was led by Hriar Cabayan who had joined in the mid-70s and became a renowned nationallevel contributor in EM effects. The thrust area formalized the core competency in EE while providing centralized oversight and nurturing of the technology. Likewise, a thrust area in Microwave and Pulse Power was formed under Wayne Hofer (see following article) to look after activities in EM measurements, diagnostics, and pulsed power sources. Other EE thrust areas evolved in signal and image processing (under Rick Twogood), and in microelectronics (under Joe Balch).

Don Dudley, a professor at the University of Arizona, head of its Electromagnetics Laboratory and oft-times summer member of our team, captured the essence of the evolving EM thrust at LLNL: "The 70s, particularly the latter portion of the decade, were halcyon days for EM in Engineering with the leadership, team members, and sponsors focused on substantial and truly remarkable innovation, productivity and recognition."

\section{The 1980s}

The growth of EM activities continued in the 80 s with growing interest in High Powered Microwave (HPM) combined with the existing interest in EMP effects. A continuing burst of intellectual contributions in theoretical and computational electromagnetics added to the national visibility. Stalwarts who had joined the Electronics Engineering electromagnetics team in the late 70 s and early 80 s added to the LLNL national and international reputation. Included in this eclectic group were Jim Brittingham, Ray King, Karl Kunz,

Rick Ziolkowski, Kendall Casey, Niel Madsen, Bill Johnson, and Gerry Hudson.

Jim Brittingham, who had been pursuing new solutions to Maxwell's Equations that permitted globular or packet-like propagation of energy for many years as a hobby (or obsession), continued his unfunded research on Focused Wave Modes. I fondly remember our morning meetings-every morning for 20 minutes-when Jim would relate his discoveries of the night before. Ultimately, with support from Engineering, he published peer-reviewed papers on the subject that began inspiring and controversial debate among electromagnetic theoreticians that continues to this day.

Ray King, a former professor from the University of Wisconsin, became leader of efforts in EMP and HPM phenomenology prediction and characterization. He conceived and developed technology, methods, and experiments that enabled the prediction of effects of the electromagnetic radiation on systems-a capability of great value to the military. He was supported in these efforts by the numerical modeling team, systems analysts, 
and electromagnetic experimentalists such as Gerry Hudson. Gerry's picture ultimately appeared on the cover of the IEEE Spectrum magazine with the Emperor measurement facility-a true endorsement of our position at the leading edge.

The programmatic thrusts revolved around HPM and EMP coupling and phenomenology with LLNL a prime participant and leader in nationally renowned programs. Ray King and Hriar Cabayan, with the very capable support of Kendall Casey and Karl Kunz, left their imprints on the national programs and promoted the relationships with A Division, D Division, L Division, the other Defense Program national laboratories, and the DoD service laboratories.

To support these programs with competent computational capabilities it was necessary to initiate several development activities. At the start of the decade Niel Madsen, a computational mathematician with substantial engineering and physics background, began an intense investigation of finite element methods (FEM) and adaptive methods for EM. Concurrently Karl Kunz, an early pioneer in FDTD, assembled a concept development team composed of nationally renowned researchers (such as Professor Alan Taflove) from universities that laid out a theoretical framework upon which to build a state-ofthe-art computational tool. By the time they "finished" the tool called TSAR (Transient Scattering

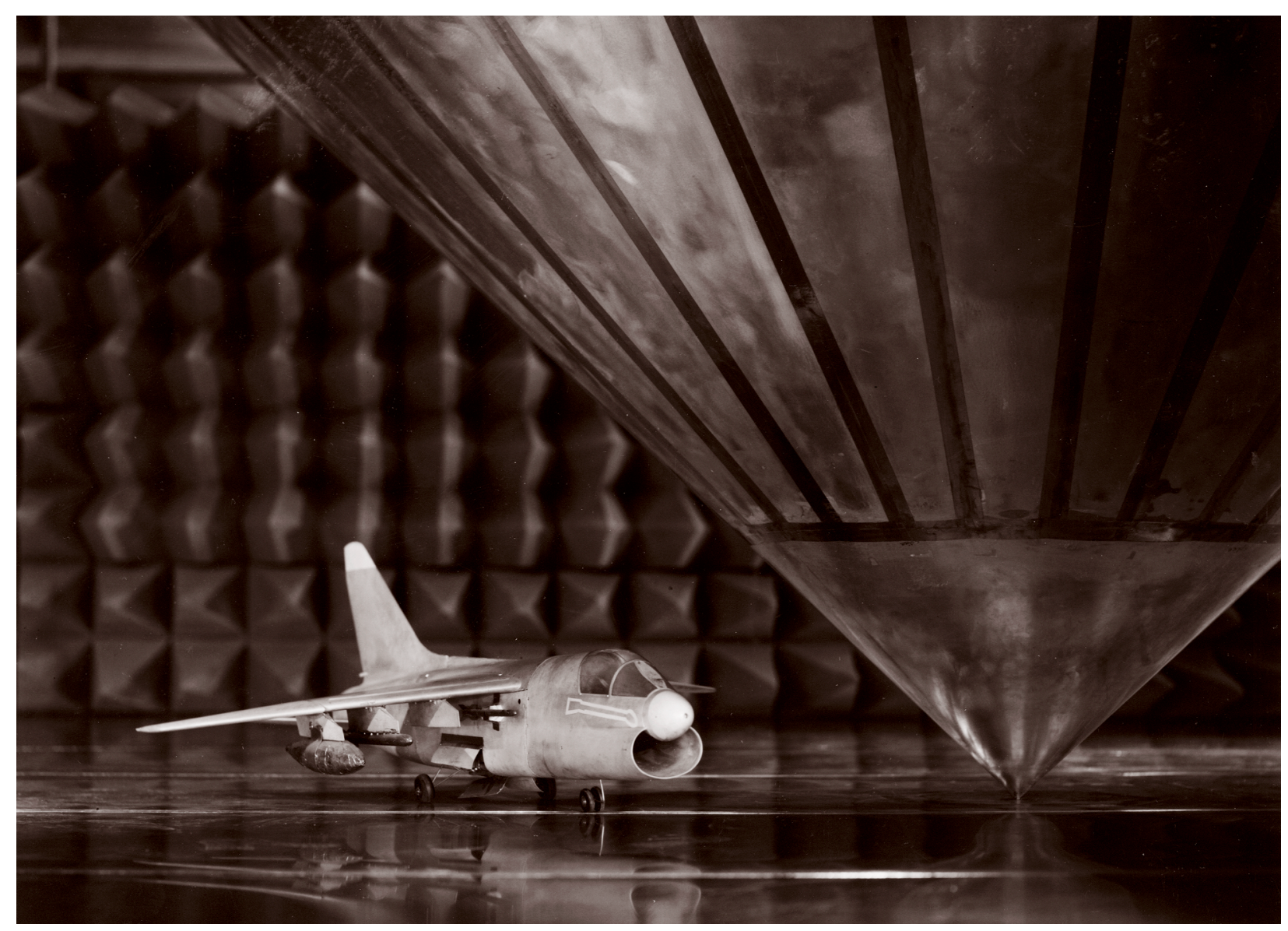

The photo shows a late 1980s version of the EMPEROR facility being used to test the electromagnetic responses of systems in an aircraft. A picture of this facility even found its way onto the cover of Spectrum, the flagship magazine of the IEEE. 
and Radiation) in the late 80s, Bob McLeod, Scott Ray, Gary Laguna, and Steve Pennock had introduced the most advanced state-ofthe-art FDTD package in the world. It included not only the physics kernel but a complete package with pre- and post-processors for solids modeling, grid generation, mesh viewing, and data presentation.

In concert with the major steps being taken in the time domain, the need for robust and highly capable frequency domain tools that were capable of dealing with structures composed of arbitrary materials was apparent. Bill Johnson undertook the creation of that tool, called PATCH, which was based on the work of Professor Don Wilton and his students and was ultimately co-authored with Wilton, and Rob Sharpe - then a graduate student. This development delivered a capability for full wave modeling of electromagnetic interactions with arbitrarily shaped surfaces and wire appendages.

Throughout this time, the Computer Systems Research Group under the leadership of Chip Hatfield had been providing cuttingedge guidance and consultation on the computer science and computer operations issues associated with computer modeling. Already, the subjects of graphical user interfaces (GUIs) menu-driven applications, advanced comput- ing platforms, and visualization were being given detailed attention. It is not surprising that in the latter part of the 80s Brian Cabral could make some key contributions to the computermodeling arena with his visualization work. The ability to view 3-D results in dynamic 2-D displays (the workstation screen) made understanding of the results far less demanding. Likewise, viewing of the subject geometries or the computational grid prior to invoking the physics engines was a great effort saver and confidence builder.

\section{The 1990s}

The 90s dawned with a healthy EM R\&D environment at LLNL. Rick Ziolkowski, thrust area leader during the pivotal years of the late 1980s, left for academia and was replaced by John DeFord. In the late 80s John had developed a code called AMOS for accelerator modeling as a member of George Caporaso's team. It was used in several accelerator element design campaigns but was ultimately hampered by several difficulties that led to plans for implementing a FEM version.

Programmatic applications continued in Weapons and Accelerators. WFO activities for DoD in EM effects, and for NASA in RF effects on commercial aircraft highlighted LLNL capabilities. The latter had been motivated by the work of Rick Ziolkowski, Bill Johnson, Brian Grant, 
and Kendall Casey that had demonstrated field enhancement in enclosures and had captured the attention of NASA and FAA personnel worried about RF coupling in fly-by-wire airplanes. This served as a catalyst for a NASA-sponsored, FAAbenefiting program in the 90 s to provide a validated computational capability to predict the RF coupling into sensitive wiring and systems in fly-bywire aircraft that were being planned for the civil fleet. LLNL not only provided computational tools and expertise but directed an extensive experimental program wherein a Boeing 757 was subjected to a diverse electromagnetic environment. Ultimately these experimental results were used in the validation of the tools.

The early 90 s also had thrusts focused on accelerator modeling and photonics. In the former, improvements were made to modeling codes and analyses were carried out for high average power components and accelerator modules. Modeling was carried out for fusion plasma heating components, gyrotron windows, and amplifier sever structures. Prominent in these activities was Cliff Shang who became thrust area leader when John DeFord left LLNL for the private sector in 1994. We can also identify several junctures where LLNL's computational capabilities included computational photonics. Important in this regard was the demonstration that TSAR, the FDTD code for EM applications, could predict the behavior of integrated optical devices. Led by Ray Hawkins, the tool was applied to photonic device design at LLNL with followers at Bellcore and Hughes. Also developed were BEEMER (using pseudospectral methods) and TSARLITE, a 2-D FDTD code with a fully integrated GUI, both prepared by Jeff Kallman. A natural extension of this R\&D was a framework entitled MELD (Multiscale ElectroDynamics) which provided a framework for integrating multiple modeling tools. This effort, led by Rick Ratowski, won an R\&D100 award in 1997.

In 1994, a new era in EM modeling codes had manifested itself. Large complex codes had been written, but rarely were they sufficiently modularized or structured to permit easy modification or extension. Rather simple modifications to the physics kernels of NEC or TSAR would require massive rewrites because of the interwoven nature of the coding structure. Modern software engineering paradigms were needed to create codes that could be easily modified or ported to diverse computing platforms. Enter EIGER (Electromagnetic

Interactions Generalized)-a new generation of computational electromagnetics tools.

Teaming with the University of Houston, Sandia National Laboratories, and the Navy Command and Control Ocean Surveillance Center, LLNL began to lay the framework and develop a truly extensible, portable, and modular multi-purpose EM code.

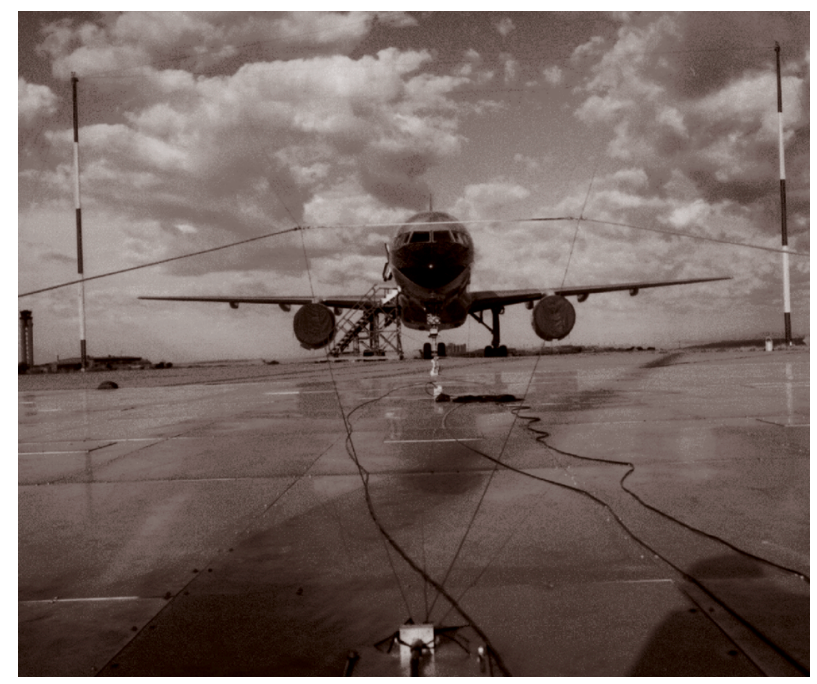

Boeing 757 in the LESLI Facility at Kirkland Air Force Base. 
New software engineering methods, specifically object-oriented design concepts, were used to abstract key components of spectral analysis methods so that the tools could be easily modified and extended to treat new classes of problems. With the support of LLNL in the formative stages and the Office of Secretary of Defense, the intelligence community, and the US Navy during the formative and coding stages, significant progress was made and EIGER was applied to several key problems of national importance. EIGER has been validated with major modeling successes in MEMS, frequency selective surfaces, phased arrays and full-scale ships. The major LLNL participants in this breakthrough endeavor in EM were Rob Sharpe, Brian Grant, and Nathan Champagne.

\section{A New Thrust Area}

In 1998, the Computational Electronics and Electromagnetics Thrust Area and the Computational Mechanics Thrust Area were combined to form the Center for

Computational Engineering. The role of the center, one of five that form the Engineering Science and Technology Program, is to vigorously grow the core technologies that can enable long term growth of new programs. In the particular case at hand, Engineering created a strong multidisciplinary center to cover the application of advanced computing methods and computer science to all aspects of engineering. One of the main institutional goals of the new Center for Computational Engineering is the development of tools that facilitate research in engineering computing. Kim Mish joined LLNL as the new leader for the Center and brought with him an extensive background in computational mechanics, computational mathematics, and modern software engineering philosophy.

\section{Epilogue}

After three decades in Engineering and almost as many years of following (and often leading) computational and experimental electromagnetics in $\mathrm{EE}$, I can honestly say that the preparation of this abridged history has reminded me of what I have been part of and what I have seen. We were motivated by giants with a vision like Ed Miller and Lynn Cleland, we have had teams whose members had national, often international, reputations for extraordinary experimental and computational accomplishments, and we have always had a "can-do" attitude. At the beginning I noted that we never thought anything was impossible and many of my conversations with Ed started with "I may be crazy but I think we can...." I'm glad to report that the electromagnetic teams are "still crazy after all these years." It's important to keep this feeling alive throughout our entire organization. 


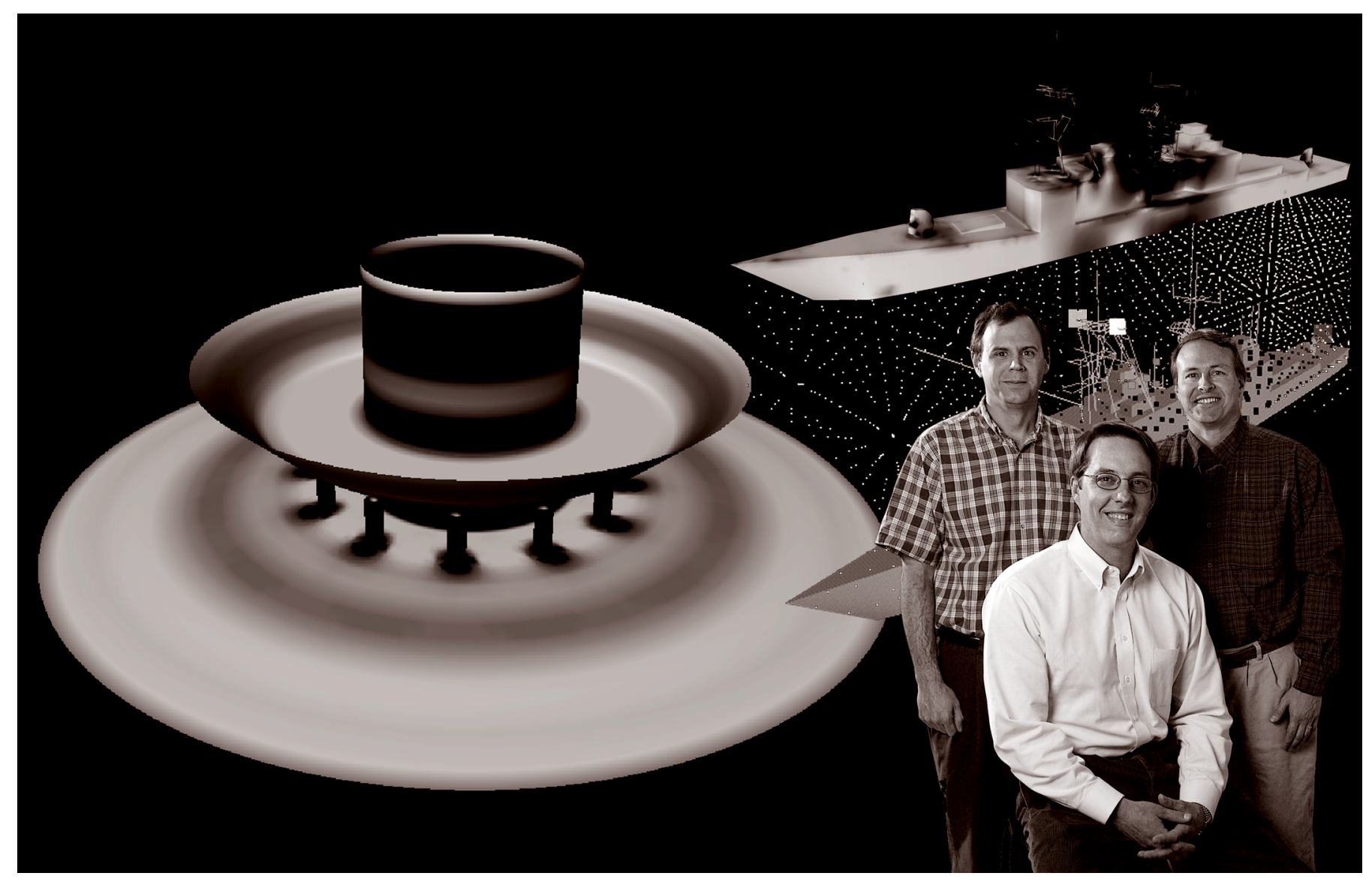

Rob Sharpe, Nathan Champagne, and Dan White (of Computation) form LLNL's present-day core CEM development team. Shown above are applications of EIGER to DoD problems, specifically the currents on a GPS antenna system and those on a destroyer that are induced by an on-board transmitting antenna. 
- ulsed power, the storage of electrical energy and then its rapid release in single or multiple bursts of high power, has been and continues to be a critical technology at LLNL. Its history abounds with accomplishments with the most notable beginning in the 60 s and continuing through today.

A chronicle of pulse power at LLNL would warrant a tome of its own, so I have chosen to focus on a small sliver of this history. The portion I'll focus on highlights Engineering's Microwave and Pulse Power Thrust Area and reflects the prominent role of pulse power in Engineering's technology base.

In the early 1980s, Engineering became acutely aware of the need to recruit and train pulsed power engineers and technicians to support the rapid expansion of pulsed power intensive technologies at LLNL. Intensive recruiting programs were begun, targeting primarily Texas Tech University (TTU) and the University of Texas. TTU in particular, due to an extensive and unique pulsed program led by Dr. Kris Kristiansen, was a source of several top-notch pulsed power engineers at LLNL. These included Hugh Kirbie, Lloyd Gordon, Mark Newton, Bob Druce, and Ray Cravey.

In 1982, Engineering established the Microwave and Pulse Power Thrust Area under my leadership. The purpose of the Thrust Area was to:
- Help recruit pulsed power engineering talent to the Laboratory

- Identify and develop important technologies that supported Laboratory programs in Weapons, Lasers, and Magnetic Fusion Energy

- Establish engineering pulsed power R\&D facilities

- Provide a synergistic link with other Engineering technologies.

Due to the large Laboratory Weapons Program effort in high power microwave generation and vulnerability studies, the early focus (1983) by the newly founded Thrust Area was the development and construction of a high power pulsed microwave generator, MGX. The MGX was housed in a Weapons Program facility, and was largely funded by the Weapons Program. Ray Scarpetti headed the design and development of the pulsed source and microwave source. Scott Burkhart, a new and talented engineer from Cal Tech, developed a suite of high power microwave detectors and diagnostic systems.

The microwave source was a virtual cathode oscillator (VIRCATOR), a relatively new
Left: The Flash X-Ray machine (FXR), that is the flag ship of B Program's hydrodynamic testing efforts, is under the watchful eye of Engineering's mechanical technologist Mike McGregor. 


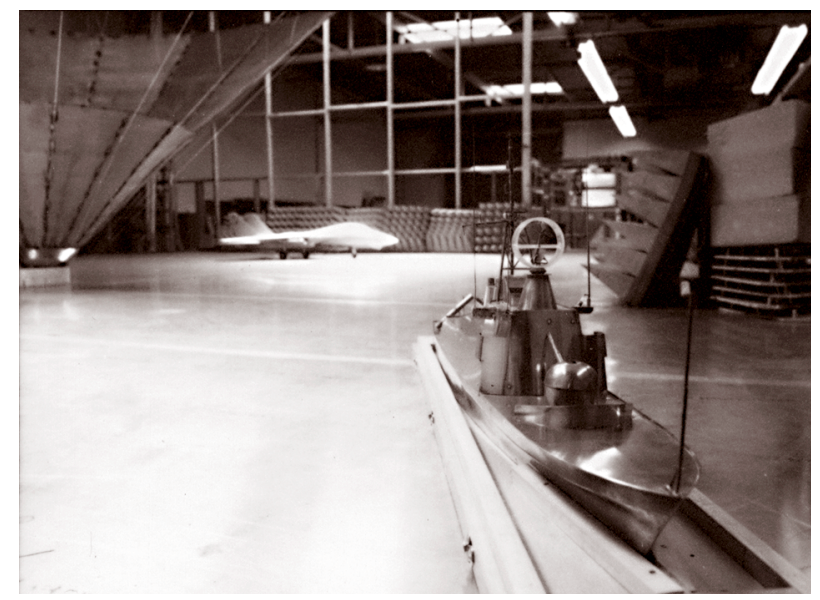

The Electromagnetic Transient Facility in Building 141. concept developed by Don Sullivan at MRC. The VIRCATOR was carefully modeled and designed using particle-in-cell codes recently developed by A Division. The MGX worked nearly as predicted and by 1985 , it was producing nearly $1 \mathrm{GW}$ at about $8 \mathrm{GHz}$. Then, using a newly developed 2-MV accelerator, the VIRCATOR produced about $4 \mathrm{GW}$ at $7 \mathrm{GHz}$. The MGX was used to develop and test HPM components and diagnostic systems until the high power microwave program at LLNL was terminated in the late 1980s.

In 1983 the Thrust Area added two major pulsed power and microwave facilities, a large (8500 ft2) Pulsed Power Laboratory (PPL) and the Electromagnetic Transient Facility both in Building 141. The PPL initially consisted of two test bays, a screen room for diagnostics, and work and assembly areas.

Diagnostics included a high-speed electrooptical camera, a computer-based data acquisition system for high-speed diagnostics, and a host of high voltage power supplies, trigger systems, and controls. The facility was used extensively for high voltage component testing, material studies, lightning simulation for weapons components, probe calibration for weapons high voltage experiments, and testing the breakdown of various dielectrics and interfaces.
In 1984, Dr. Lloyd Gordon, a new hire from TTU, collaborated with Dr. Chat Cooke at MIT to develop a dielectric testing and failure prediction capability based on the technique of Partial Discharge Analysis. The technique and associated instrumentation proved useful during the ensuing years and was used to predict the voltage breakdown limits of high voltage detonator cable assemblies and other components for weapons and other Laboratory dielectric systems. Mike Wilson, then an excellent pulsed power and high voltage technician, was largely responsible for setting up and operating many of the capabilities in the PPL.

In addition to the PPL, a large microwave anechoic chamber was constructed. It featured a 12-ft diameter by 6-ft high test zone for a quieting of $-30 \mathrm{~dB}$. It was fully instrumented with an array of low power microwave sources and instrumentation. This facility has proven a very useful Engineering facility and continues to be used by the Engineering and Laboratory programs.

In about 1985, a Thrust Area project under the excellent technical leadership of Hugh Kirbie and Ron Kihara developed an alternator-driven, high average power magnetic modulator. The average output power of the modulator was $\sim 10 \mathrm{~kW}$ at $10 \mathrm{kHz}$ with 
a $500-n s$ output pulse. It achieved over $70 \%$ efficiency wall plug to output. This effort was initiated in anticipation of the need for compact, efficient, low-cost modulators to drive emerging LLNL programs in pulsed lasers and highbrightness particle accelerators.

In 1984 and 1985, the Thrust Area funded the design and installation of a 2-MeV, 200-kA, electron beam accelerator in the PPL. Karl Freytag led this effort. The accelerator and accompanying facility was established using a combination of Engineering techbase and program funds. The accelerator used a 50-kV first-stage Marx generator that charged a $6-\Omega, 60$-ns water-dielectric pulse-forming line driving a low impedance vacuum electron beam diode.

The experimental area on the diode end of the accelerator was fully shielded by concrete blocks. The diagnostics were enclosed in a screen room and great precautions were taken to ensure low noise levels on the diagnostic channels. The accelerator proved extremely useful for the development, evaluation, and testing of components used by the Weapons and Laser Programs.

Two high power microwave concepts were tried on the new accelerator. In 1985 and 1986, LLNL researchers, Dr. Marco Di Capua (a new
LLNL engineer from Physics International), Dr. Don Meeker (NESD), and Dr. Rick Ziolkowski (ERD) collaborated with Dr. John DeGroot at UC Davis to develop a microwave generation concept based on the interaction of a high power relativistic electron beam and a background plasma.

The project included extensive theoretical and experimental elements. A second HPM source development, the relativistic beam driven backward-wave oscillator (BWO), was begun in 1989. This effort headed by Frank Camacho, Brian Poole, Tom Rosenbury, and Mark Rhodes continued for about two years. Although the BWO produced a few hundred megawatts of microwave energy, it did not achieve the predicted efficiency. Both efforts were eventually discontinved as the LLNL emphasis on high power relativistic beam driven HPM generation declined.

In the 1990 timeframe, there was an increased emphasis on the high power solid state switching. Two LLNL approaches were photo-triggered high power switching in GaAs and self-breakdown avalanche switching in an inexpensive commercial silicon transistor. The motivation for the first approach was the desire in DoD for low-cost, ultra wideband radar systems for detection, secure

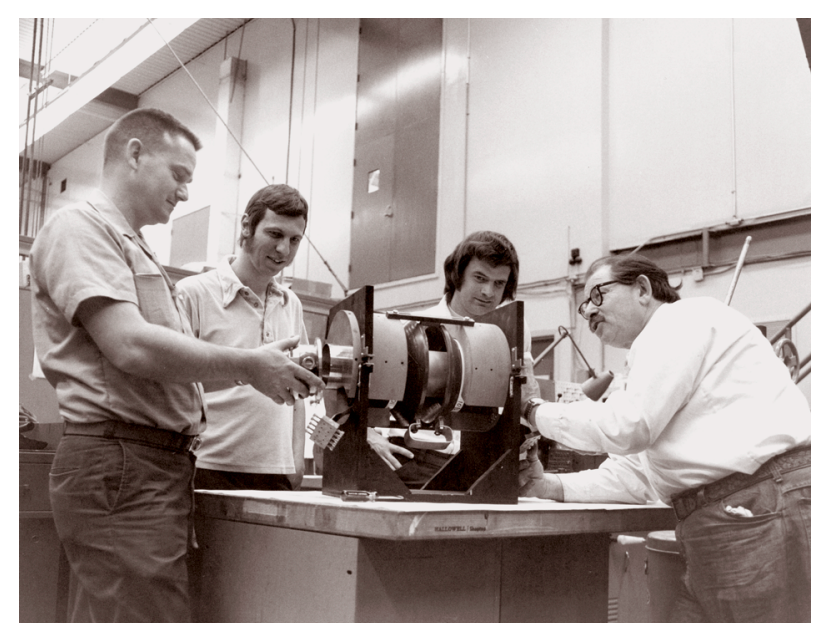

Ron Hawke, second from left, and team members with early railgun, a pulse power driven projectile used for extremely high pressure impact studies, late 1970s. 
communications, and system upset. The Thrust Area partnered with Rockwell International to develop a microwave antenna array capable of generating up to $10 \mathrm{GW}$ peak power at a modest repetition rate. Bob Druce (NESD) and Mike Pocha (ERD) led this effort.

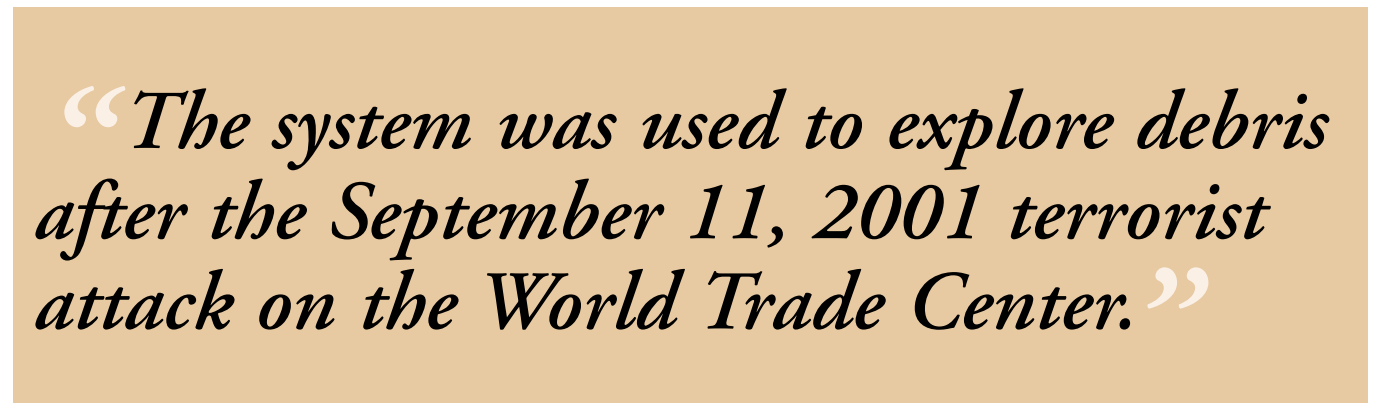

In this concept, a laserdriven GaAs switch holding off a few kilovolts drove each element of the array. The project was success-

ful in that it achieved megawatt broadband output. However for the system to be viable it needed to be interfaced with a high repetition rate solid-state laser trigger system. Also, additional work was required to increase switch lifetime. There was not sufficient internal funding or priority in Engineering to continue this work when it became clear that the DoD was not going to contract with the Laboratory for continued development of the microwave source. DoD had decided to fund a similar effort at Sandia National Laboratory, where work was being conducted and significantly more progress was being made. However this work on UWB radar spawned a larger joint effort in Engineering and the Laser Program to develop the Micropower Impulse Radar (MIR) under the leadership of Tom McEwan in the Laser Program.

The transmitter and receiver circuits were spin-offs of work done by Tom for the NOVA laser diagnostic system. The Engineering Thrust Area partnered with McEwan to develop a compact low-cost impulse radar system for a variety of commercial and government applications. They include roadbed and bridgedeck inspection, land mine and buried ordnance detection, detection of underground utility lines, ocean imaging, wall thickness and composition, nondestructive evaluation, and through-wall detection of people. The system was used to explore beneath debris after the September 11, 2001 terrorist attack on the World Trade Center.

In 1992, Karl Freytag was appointed leader of the Microwave and Pulsed Power Thrust Area. In 1993, the Thrust Area was renamed Power Conversion Technologies and was led by Mark Newton. With increased national emphasis on the clean environment and the potential for Laboratory contribution, the Engineering funded efforts using pulsed power and plasmas to treat the effluents for solid-waste processing and testing of potentially environmentally safe refrigerants. The Advanced Test 
Accelerator (ATA) was still an important Laboratory effort and upgrades to the Weapons Program Flash X-Ray unit were anticipated. This motivated Engineering techbase efforts to develop compact power supplies and high performance insulators and to improve the electron emission of cathodes. There was increased linkage between the Engineering techbase and Laboratory Programs. Engineers embedded in Laser and Weapons Programs included Hugh Kirbie, Mark Newton, John Warhus, Stephen Azevedo, David Goerz, and Stephen Sampayan. They were principal investigators on most Engineering techbase projects.

In 1997, Ronald Haigh served as the leader for Power Conversion Technologies and led an effort on the development of high-density photovoltaics. Nineteen ninety-eight was a transition year for Engineering. Traditional focus on thrust

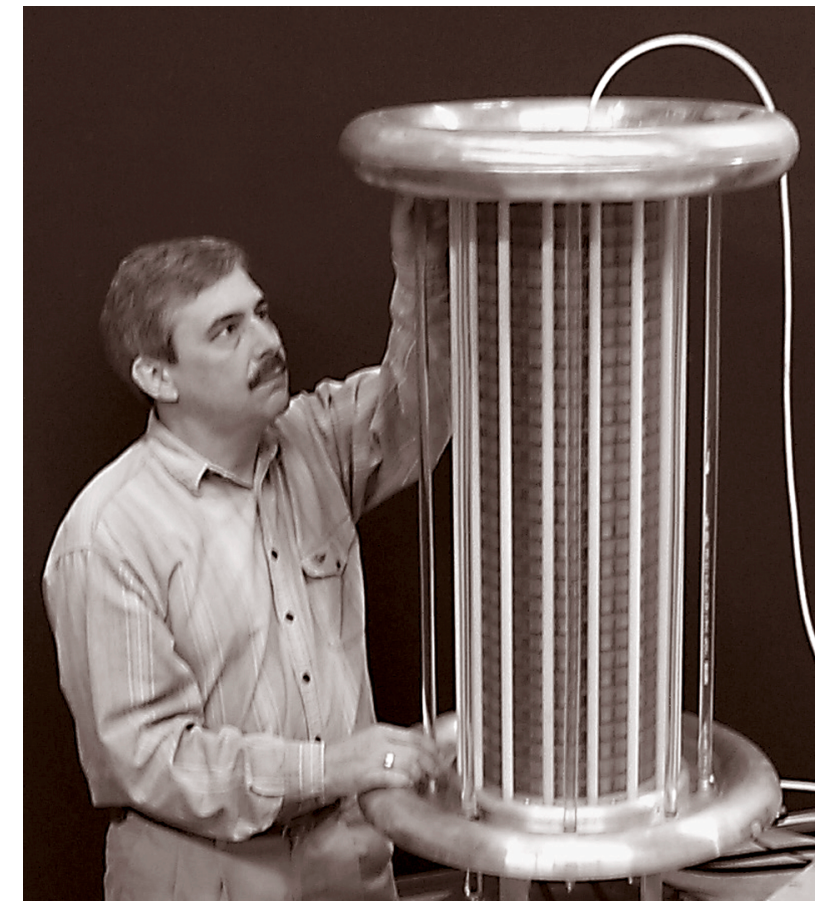

Dave Goerz with the Compact Max Generator developed around the turn of the 21 st Century.

areas was moved to a more focused approach with research centers. Five new centers of excellence were established and constituted Engineering's Science and Technology program. Ongoing efforts in the Power Conversion Thrust Area were incorporated into the Center for Microtechnology and the Center for Nondestructive Characterization. 


\section{Earthquake Engineering}

by David B. McCallen

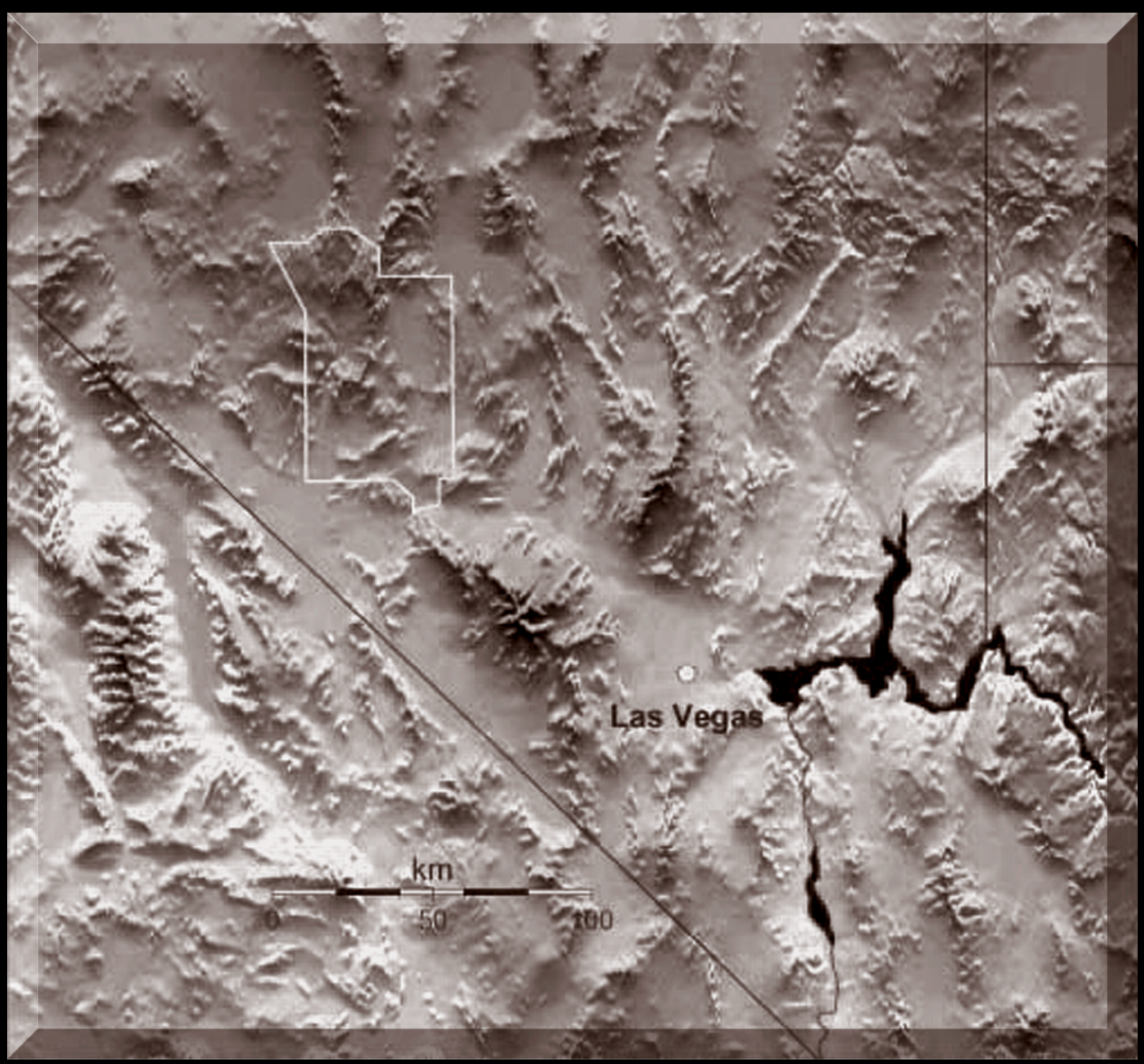


W hen the AEC went to underground nuclear testing in 1963, the seismic motion generated by each test caused buildings in Las Vegas to sway. Since Las Vegas sits on an alluvial plane surrounded by mountains, the seismic energy from the underground test is funneled from the NTS to Las Vegas and can cause large seismic motions.

While it appeared that the buildings were not going to collapse from the test, Howard Hughes, who was then living in the penthouse of the Desert Inn which he owned, did not like his buildings acting like they were experiencing an earthquake. He was an important and influential enough person that the AEC became interested in the situation. LLNL was very interested in finding a solution and had its own seismic expert in the person of Don Bernreuter.

Bernreuter hired James Bloom, a recognized earthquake expert from San Francisco, to assist with developing a better understanding of the impact of underground testing on seismic motion in the Las Vegas area. Bloom, since he was not an LLNL employee, became the primary contact to Howard Hughes and the Las Vegas political establishment. He would set up seismic detectors on top of Las Vegas buildings and record building motions in an attempt to satisfy residents that the buildings were indeed safe and were not going to collapse due to the nuclear test.
Meanwhile, Bernreuter began developing models of how the test energy was coupling to the surrounding environment, was being transmitted over long distances, and then coupled into building structures. His primary effort was to estimate the magnitude of ground motions in Las Vegas from a given nuclear test at NTS.

In the 1970s Bernreuter et al. moved into developing methods to analyze the seismic integrity of nuclear power reactors and eventually they developed nuclear reactor seismic design criteria for the Nuclear Regulatory Commission. These design standards in the 1980s were enhanced and used to evaluate the seismic integrity of all nuclear facilities of the DOE complex. Fortunately, these standards pointed out building deficiencies that could be corrected before any accidents occurred. The effort is now focused on assisting CalTrans to analyze the safety of bridges and the Bureau of Reclamation to analyze dams.

During these 40 years, significant effort has gone into moving from using almost exclusively empirical data to the development of complex modeling and analysis codes, primarily NIKE.

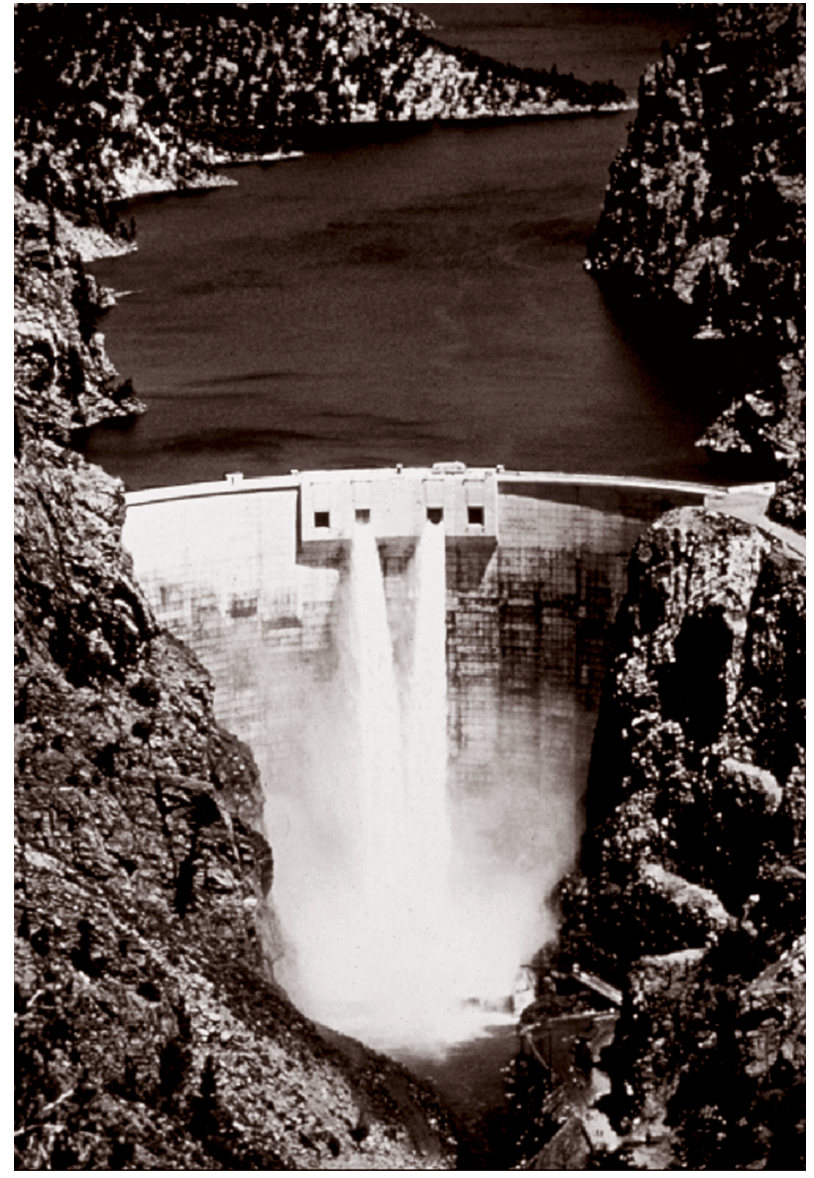

Lawrence Livermore National Laboratory investigated the effects of extreme events on thin-doublecurvature arch dams and radial gate structures.

Left: The Nevada Test Site is highlighted on the topographic map of the Las Vegas area. 
The Methods Development Group

by Art Shapiro
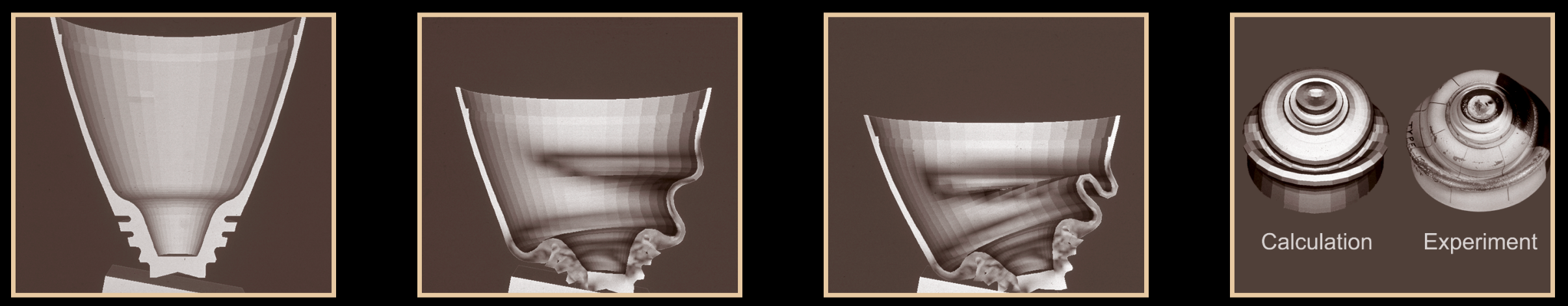
$V^{\prime}$ irtually all the major programs at LLNL rely heavily on Mechanical Engineering. In turn, mechanical engineering is becoming increasingly dependent upon computer simulations. Modeling and computers are now indispensable to the entire engineering process, from the initial refinement of an idea with computer-aided engineering tools (CAE), to its implementation with computer-aided design/drafting (CADD) and manufacturing (CAM) tools.

Computer models assist the design engineer to unravel the basic physical phenomena in a real process, whether it be the interaction between a high-energy laser beam and the optics it passes through, the shock deformation of a warhead penetrating the earth, or the thermal response of a nuclear fuel shipping container in a fire accident.

The special research and development work at LLNL imposes modeling requirements that are more complex and of a larger scale than those faced in the broader engineering community. We are asked to model high-energy laser events occurring in picoseconds and, on the other hand, model low-energy nuclear waste storage issues at Yucca Mountain on time scales of centuries. The unique Lab modeling need for engineering at extremes was the driver for the creation of the Methods Development Group (MDG).

\section{The Early Years (1975-1995)}

MDG was formed in 1975. Jerry Goudreau managed the group from its inception until 1995, providing a sandbox for the code developers to play in. He told me once that he placed a filter on the information coming down from above so we wouldn't be burdened by it.

The years from 1975 to 1987 were the John Halquist era. John's awesome programming productivity resulted in a suite of codes (e.g., DYNA, NIKE, MAZE, ORION, TAURUS) that are still being maintained at LLNL. John was your classic LLNL "hero code developer," with incredible drive and focus.

The DYNA code was first released in 1976. DYNA is used to model the rapid nonlinear response of solids to an applied force. While LLNL applied DYNA to study the high-velocity impact of nose cones, Detroit used DYNA to model car crashes, and Coors to model the manufacturing of beer cans.

NIKE is an implicit computational mechanics code that is used for long (greater than $1 \mathrm{~s}$ ) duration deformation modeling, to model weapon deformation response.

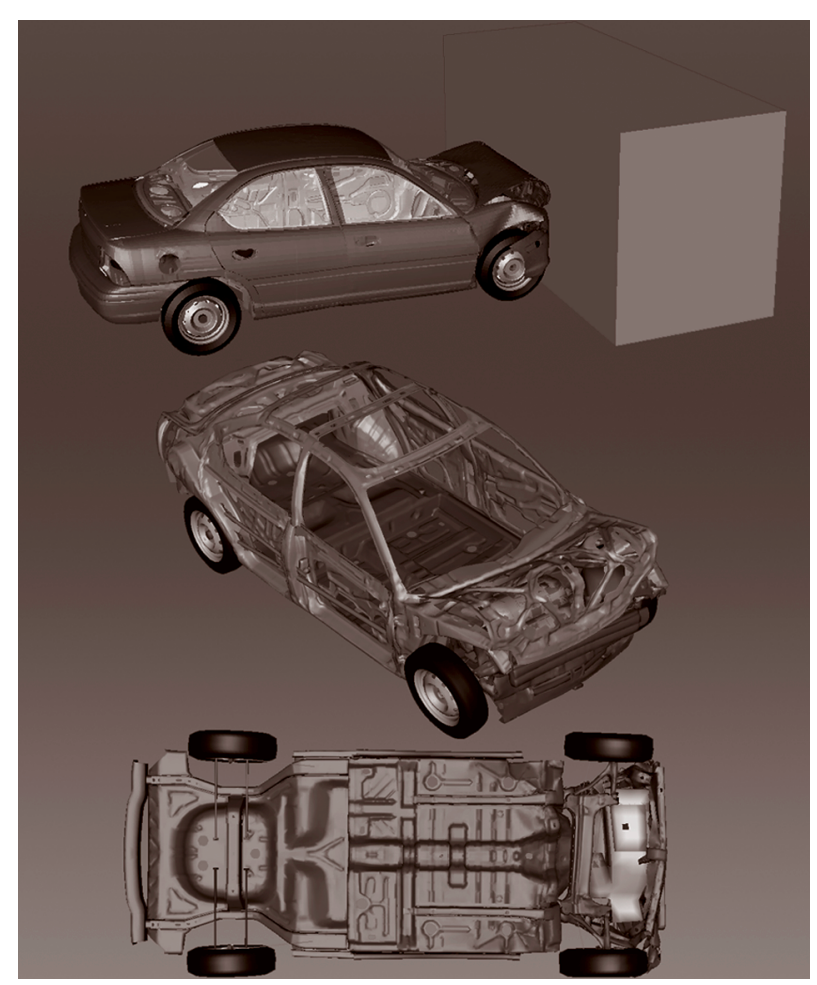

Courtesy of Federal Highway Administration/ National Highway Traffic Safety Administration (FHWA/NHTSA) National Crash Analysis Center. 
The source code to DYNA was freely circulated. John's opinion was that by the time others figured out what was coded, he would be so far ahead that they couldn't catch up. You could step through thousands of lines of code and never encounter a comment statement. There was just too much exciting numerical physics to code, and therefore why waste time with comments? John's codes were soon found in universities and government and industrial laboratories throughout the world.

\section{You could step through thou- sands of lines of code and never encounter a comment statement.} cessful company has con-
In 1987, John left LLNL and founded Livermore Software Technology Corporation. This very suctinued DYNA development for the worldwide industrial marketplace.

Many others contributed to the success of the MDG code suite, as noted below.

Steve Sackett (1977-1979) developed MDGLIB, with many subroutines written in assembly code for the linear equation solver and $\mathrm{IO}$ subroutines. Although re-coded several times over the years (the assembly code was dropped), the fundamental architecture of familied IO files is still used. Steve also developed the structural mechanics code SAP4, which was subsequently transformed into GEMINI by Bob Murray.

Bill Mason developed the TACO heat transfer code. In 1979 Bill joined Sandia and began naming his codes after Italian food (PASTA). Pat Burns (1979-1980) continued development, and then I, Art Shapiro, took over the code in 1981. I re-wrote the code using Halquist's vectorized style of coding in NIKE for the CRAY computer architecture. I continued the development of TOPAZ to the present time, and TOPAZ is used extensively throughout the Lab for heat transfer analysis. A particularly important application is distortion calculations for NIF final optic assembly. Since Mason was naming his codes after food, Hallquist after constellations (ORION, TAURUS), I chose gem stones (TOPAZ, FACET).

Dave Benson (1984-1987) developed ALE (Arbitrary Lagrangian Eulerian) methods and implemented them in DYNA2D. This allowed a new class of problems to be solved in which a deformable material could flow through an Eulerian mesh, preventing mesh entanglement due to large deformation. Dave also implemented single surface contact in DYNA3D. This allowed us to model the deforming surface folding in on itself (e.g., the nose cone on page 124). 
Bob Ferencz (1984-1990) worked on elementby-element preconditioned conjugate gradien iterative solution strategies as part of his $\mathrm{PhD}$ work at Stanford, and implemented them in NIKE3D. Bob left the Lab in 1990 and was one of the founders of Centric, Inc.

Brad Maker (1990-1995) picked up NIKE3D development and added rigid bodies which significantly increased code execution for this class of problems.

Robert Whirley and Bruce Engelman (1988-1993) developed a coupled thermalmechanical code called PALM by coupling NIKE and TOPAZ. They also developed an automatic solution driver, called ISLAND, that helped NIKE reach a solution in computationally difficult regions due to nonlinearities.

Along with the development of modeling codes came the need for mesh generation. The first finite-element mesh generator with TMDS graphics (remember that TMDS was really before its time) was ZONE (1975) by Mike Burger. ZONE had the infamous "switch" command that sometimes worked. This command would rotate the 2-D axisymetric mesh into a hexahedral 3-D mesh. However, computer power and memory limited the model to less than 2500 elements. Mike also developed our first attempt at interactive mesh generation. He implemented software to read engineering drawing line coordinates through a digitizer tablet and display the results on the TMDS.

Fully 3-D mesh code development can be traced to the INGEN code at LANL as the starting point. Two development paths evolved. In one, Mike Gerhard transformed INGEN into OASIS (something providing relief from a dull or dreary routine), and finally to SLIC (structural language with interactive commands). In the other path, Doug Stillman transformed INGEN into INGRID. Doug developed the idea of "index space" which greatly reduced (by about a factor of 100) the number of lines of input required to describe a 3-D mesh.

Bob Rainsberger took the next step by making INGRID interactive using a Graphical User Interface. Bob added features that made INGRID usable by engineers. Bob founded XYZ Scientific Corporation in

1991, and markets a significantly improved version of INGRID called TrueGrid, which is used throughout LLNL. 


\section{Transition Years (1995-2000)}

Peter Raboin became the MDG Group Leader in 1995. During these years the developers made many incremental, but significant, improvements to the suite of codes. Peter joined the group after several years as an engineering analyst. He brought a knowledge base of desired code features that would make the analysts' job easier, and proceeded to implement them in code. Also, during this time, Ed Zywicz developed automatic 3-D contact in DYNA3D and constitutive models for composite materials. Jerry Lin implemented rigid body switching in DYNA3D by which the part could automatically switch between being modeled as a deformable object or as a rigid body.

Mike Puso focused on element technology and mathematical consistency of the various algorithms in NIKE3D. Mike's work greatly improved the convergence of NIKE3D in obtaining a solution to highly nonlinear problems.

\section{The Age of ASCI}

Carol Hoover is the current Group Leader of MDG. The code development focus has shifted from discipline-oriented codes to multidiscipline codes and to parallel computer architecture. The LLNL massively-parallel ASC computers and high-speed workstation clusters have provided the opportunity to extend this suite of codes, DYNA, NIKE, and TOPAZ, with a new generation of computer programs.

The new software incorporates multidisciplinary coupling of solid and fluid mechanics, thermodynamics with chemical kinetics, and transport algorithms. Carol Hoover and Tony DeGroot are developing PARADYN, a parallel version of DYNA. Bob Ferencz and Mark Havstad are developing a new implicit multi-discipline code called DIABLO. 


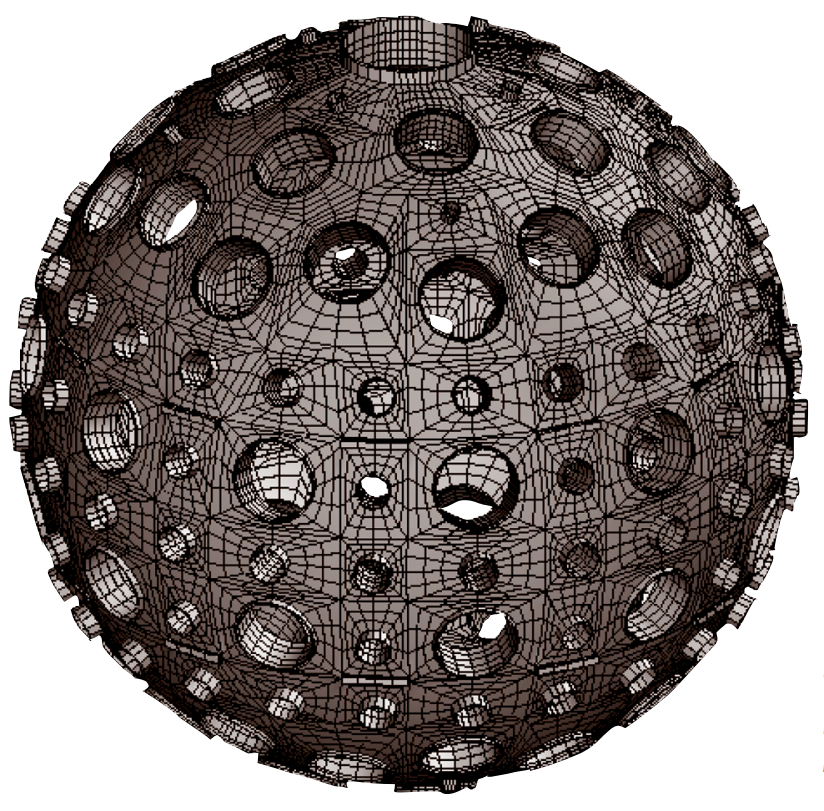

The finite element model of the National Ignition

Facility target chamber shows laser beam entry locations and diagnostic instrumentation ports. 


\section{Nondestructive Evaluation}

by Harry E. Martz, Jr.

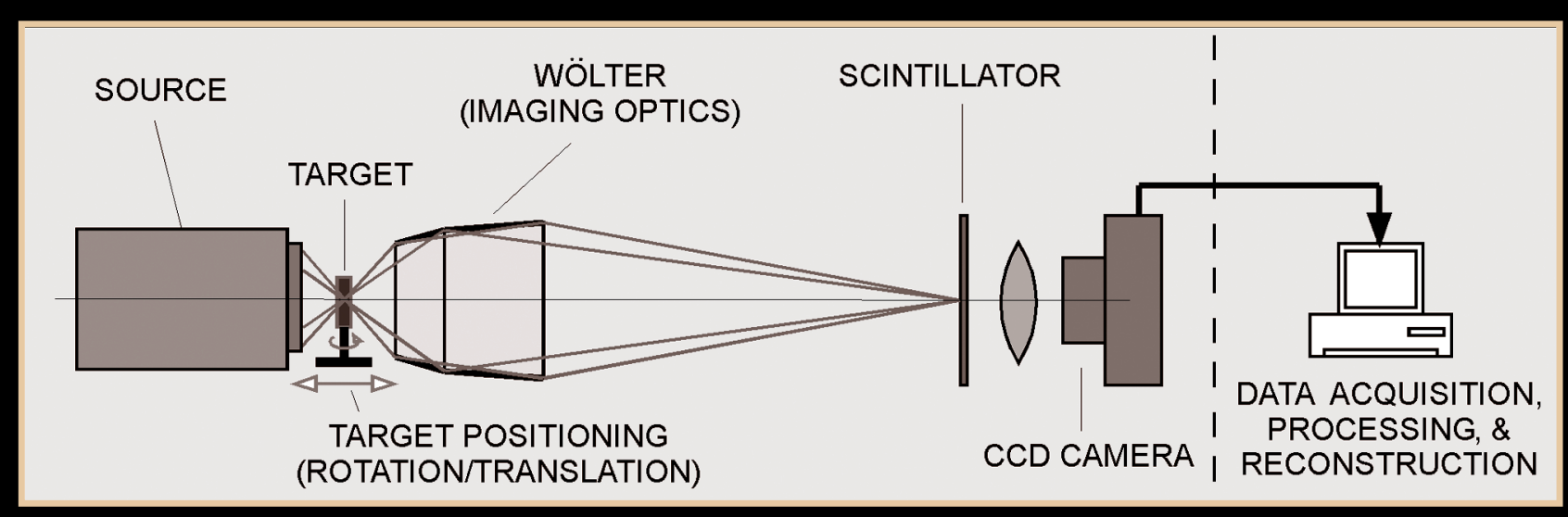




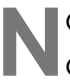
ondestructive Evaluation (NDE), originally called nondestructive testing, began in the earliest days of the Laboratory. The group transferred from ME in Berkeley, headed by Jack Hum and staffed by Ellen Placas and Dick Nickerson. These three were in the Berkeley metallurgy group, and Brobeck told them that there was not going to be metallurgy in both Berkeley and Livermore. Ellen was given the option of changing assignments and remaining in Berkeley or transferring to Livermore. She elected to move.

Over the years Placas became very active in the American Society for Nondestructive Testing (ASNT). She held leadership positions in the local sections and, through the sponsorship of Walt Arnold, became a Director in the National ASNT, a position she held for three years. While a Director, Ellen proposed that the name NDT be changed to NDE but the male dominated Board said it would cost too much.

The original technique for NDT was the use of a cobalt-60 source for x-ray radiography. There was a portable PIG* available for field radiography. Ultrasonics was added later to complement the available x-ray methods. These two techniques were used to detect flaws, welds, uniformity and fit in beryllium, foams, machined parts, and final assemblies. The NDT group always radiographed weapons assemblies on the firing tables at Site 300 to ascertain the exact center of the assembly about to undergo the test. The NDT group was responsible not only for acquiring the film radiograph but also for the development and reading of the x-ray film.

Acoustic Emission was developed in the early 60s to predict failure of pressure vessels under pressure but without taking them to failure. Ultrasonic testing, although useful, had the serious drawback that it required the test object to be immersed in a liquid. Some parts could not be immersed in a liquid so this method was precluded from use. It was a very useful method for determining the quality of the bonds in bonded weapons parts.

Eventually electronics technology came to be a major force and improvement in NDE. For example, the development of CCD cameras and flat panel amorphous silicon and amorphous selenium arrays provided a quantum leap in the available digital radiographic imaging technology. The addition of computers led to Computed Tomography (developed primarily for medical imaging) and the addition of processing algorithms such as VIEW and RECON added yet a further dimension to the technology base. Future directions include nanoscale imaging (including x-ray Wölter microscope/tomoscope and photothermal microscopy) and NDE to physics understanding through asbuilt meshes.

\footnotetext{
*A PIG is typically a leaded and shuttered container for transporta-
} tion and safe use of $x$-ray or gamma-ray radiation.

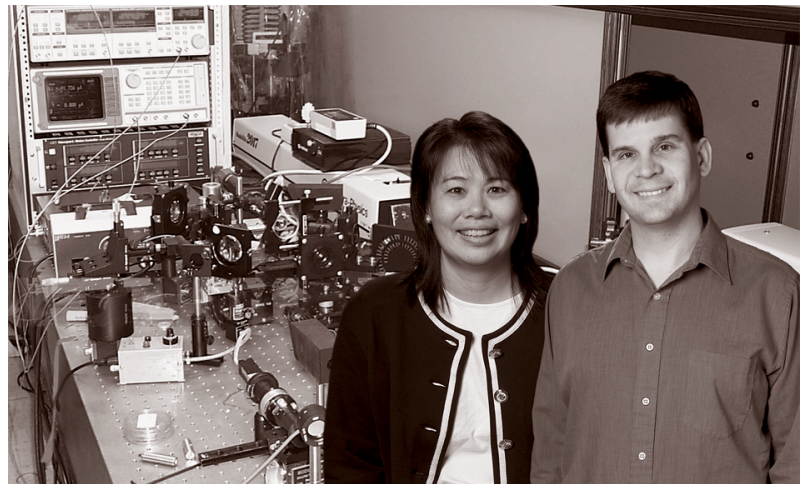

Diane Chinn and Chris Stolz are developing tools to advance the state of photothermal microscopy (PTM) to nanoscale spatial resolution.
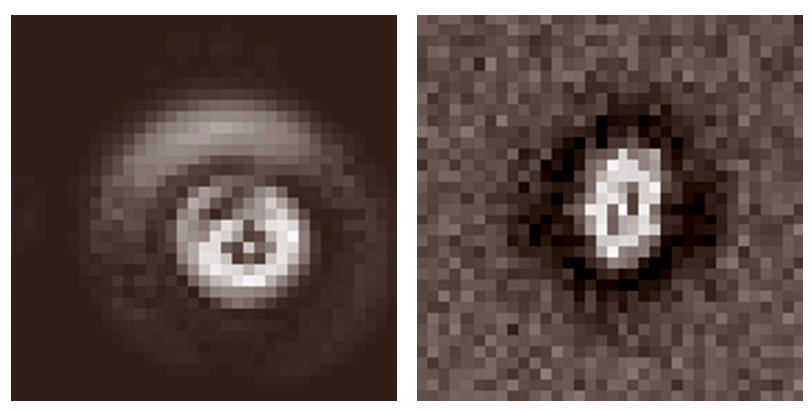

Photothermal imaging speeds up thermal flaw detection in National Ignition Facility optics. Left: Photothermal scanning microscopy (PTSM) scan time took 35 min. Right: Photothermal imaging microscopy (PTIM) image time took $40 \mathrm{~s}$.

Left: High-accuracy tomography of meso-scale targets. 


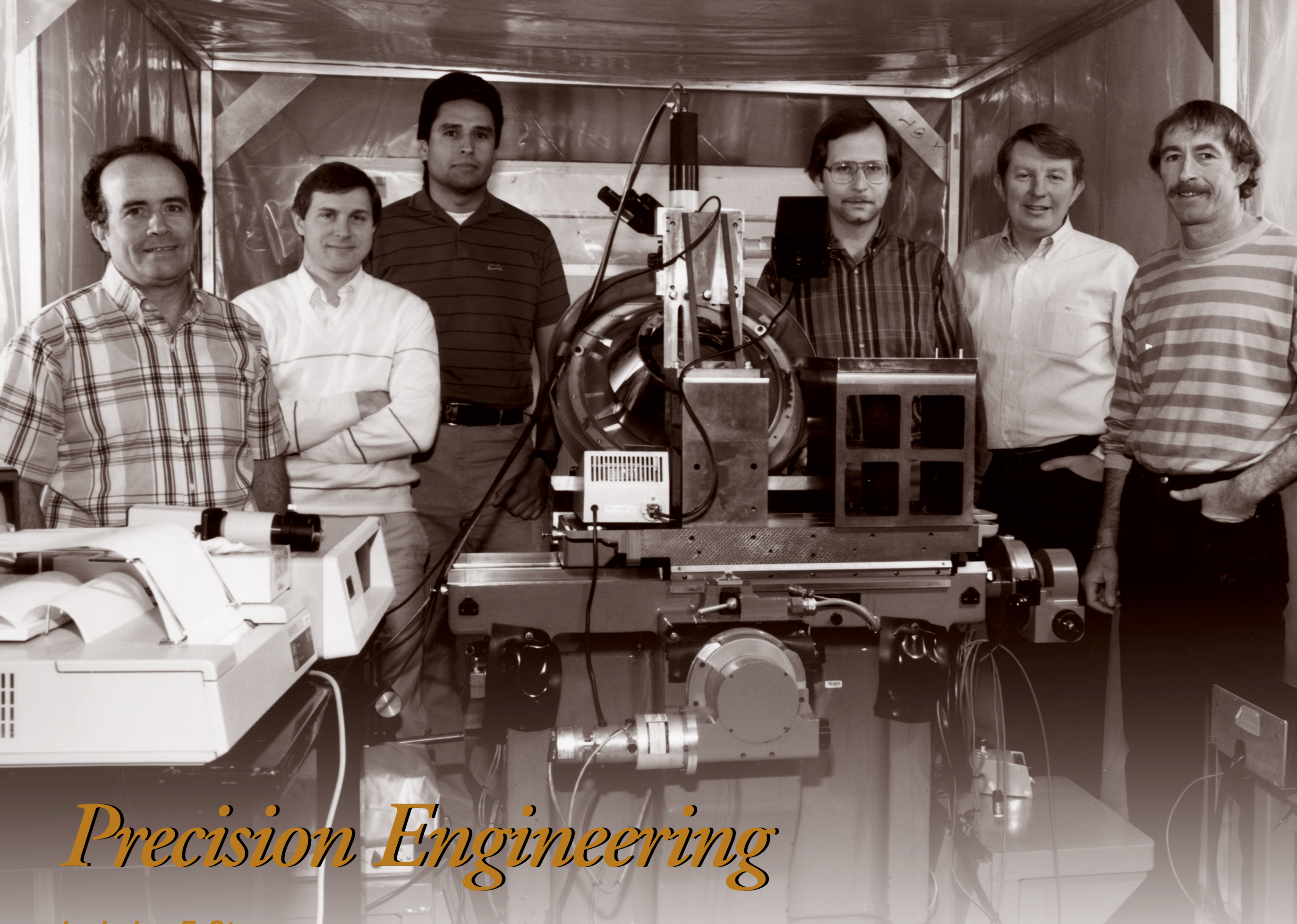

by Irving F. Stowers 


\section{The Early Years: 1955-1965}

A $\mathrm{n}$ interest in achieving precision contours in Ametals began at LLNL with the Nuclear Weapons Program. James Bryan, the Laboratory's chief metrologist until his retirement in 1987, was most responsible for instilling precision concepts into engineers and technicians.

Jim was hired in 1955 by Bill Brobeck, the Laboratory's first mechanical engineer to work for Jim Bell in Livermore. He was assigned to a new group organized by Jim Bell, to design and build gages to measure components used in the Nuclear Weapons Program. It was called the "Gaging Group." The group produced a series of gages with various names (e.g., one ball gage, three ball gage, Mare Island Gage), and eventually wrote the specifications and developed the operating procedures for the Sheffield Rotary Contour Gages still in use today.

The group also developed the Template Filing and Measuring Machine used to fabricate by hand "point-defined" tracer lathe templates to a tolerance of $+/-200 \mu \mathrm{in}$. Next, they moved on to the task of upgrading the accuracy of the tracer lathes. After three years of work they succeeded in achieving the same kind of tolerances on test parts as they had achieved on templates. The technology was then transferred to other organizations in the Weapons Complex. About this time the name of the group was changed from the Gaging Group to the Metrology Group.

When numerically controlled lathes became available, the group was actively involved in writing specifications and upgrading the accuracy of these machines to the +/-200$\mu$ in. level previously achieved on the tracer lathes. The numerically controlled machines were, however, much more efficient and did not require templates.

One of Bryan's key contributions was recognition of the deterministic behavior of measuring machines and machine tools. His philosophy: "There is nothing random or probabilistic about the performance of these machines. They obey Newton's laws. All errors happen for a reason, and the list of reasons is small enough to manage economically."

First on the list are thermal effects that have proven to be the largest single source of error. Thermal effects can be economically controlled using temperature-controlled liquid or air showers.

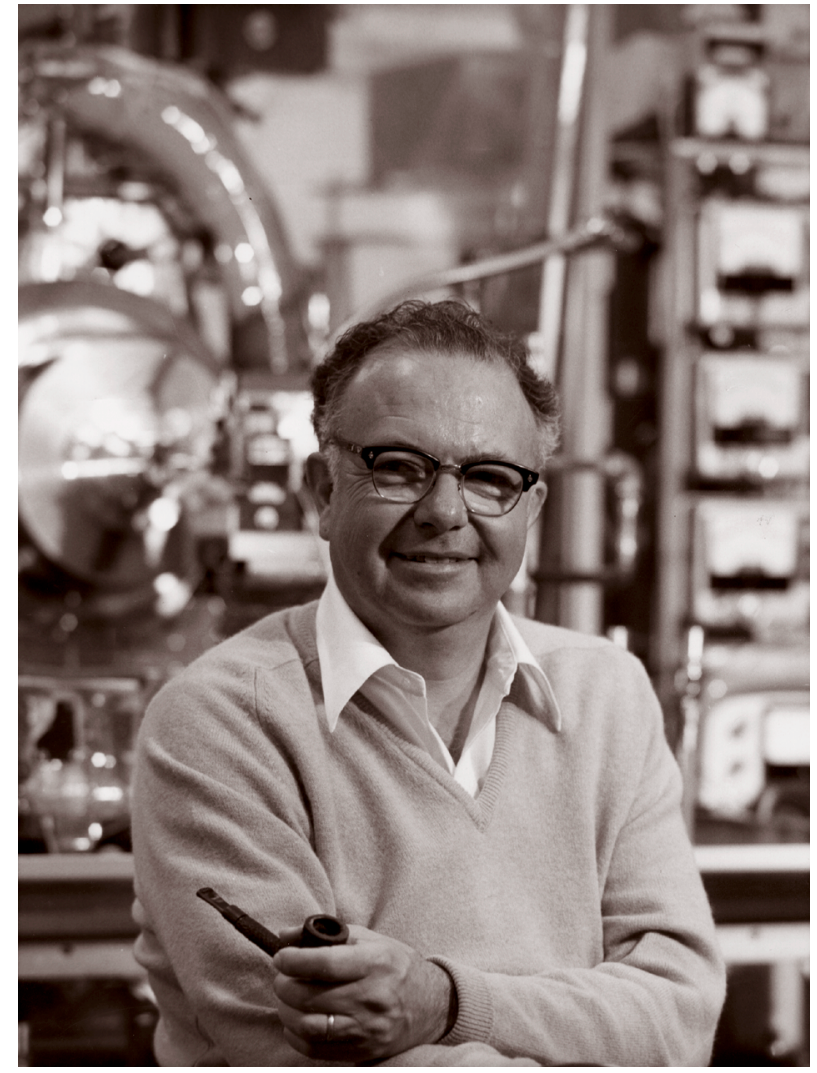

James Bryan in front of DTM-2, circa 1977. Jim was named one of a handful of Heroes of US

Manufacturing by Fortune Magazine in 2000 for his pioneering work in defining and correcting the errors in the motion of machine tools.

Left: The successful completion of the EUVL imaging system required advances in the state of the art in optical design, optics fabrication, interferometry multilayer coating, precision engineering, and alignment. This EUV imaging system is regarded as the most accurate optical system ever constructed. 


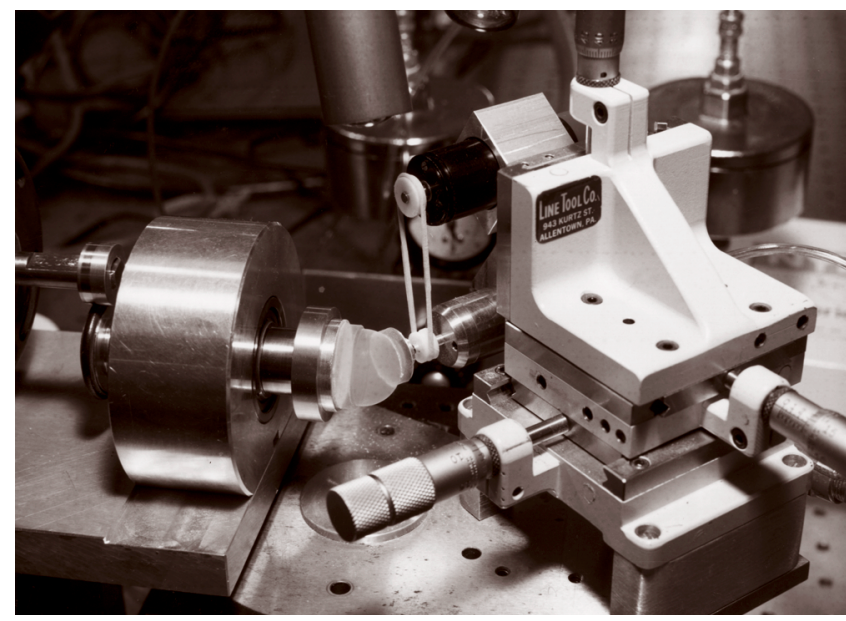

Aerogel being precision ground. The operators expressed concern with having to grind a part that they had difficulty seeing and even more difficulty measuring, circa 1987

\section{Diamond Turning History:} 1968-1977

The Metrology Group went on to develop the world's first numerically-controlled diamond turning machine (DTM-1). Because of its $40-$ gallon $/ \mathrm{min},+/-0.1^{\circ} \mathrm{F}$ oil shower temperature control, this machine had a repeatability of $40 \mu \mathrm{in}$. $(1 \mu)$. It was followed by DTM-2 in 1975. These machines were assembled from commercially available measuring machine components, but were not available as a complete machine tool. The DTM-2 design eventually became available from the Moore Special Tool Company of Bridgeport

Connecticut as the M-18 Aspheric Generator.

DTM-3 was designed and built from scratch by the Metrology Group and is the largest diamond turning machine in the world. It has a 96-in.-diameter swing and weighs 120 tons. It was completed in 1985, and incorporated all of the current thinking on the design of precision machine tools at that time: a separate metrology base, a horizontal hydrostatic bearing spindle capable of supporting a $2000-\mathrm{lb}$ workpiece at $20 \mathrm{in}$. from the spindle face, traction drives for the slideways, and 400 galIon/min, $+/-0.001^{\circ} \mathrm{F}$ oil shower temperature control. It uses laser interferometers operating in helium to give a resolution of $0.5 \mu \mathrm{in}$.
The layout of the interferometers is in strict accordance with the Generalized Abbe Principle. The DTM series of machines were used to fabricate many components for the Laser Program and for outside agencies and private organizations which viewed LLNL as the vendor of last resort when a component with a beyond-the-state-of-the-art accuracy was needed.

One of these customers was Professor Stuart Bowyer, of the Astronomy Department at UC Berkeley. Bowyer and his students designed a series of EUV telescopes that were diamond turned over a period of fifteen years, on DTM-1, DTM-2, and DTM-3. In testimony before the UC Regents, Bowyer made the statement that his research "could not have been performed without the support of LLNL."

In 1968 Professor John Loxham, of Cranfield University in England and father of the "Deterministic Theory" began to use the term "Precision Engineering" instead of

"Metrology" in recognition of the fact that metrologists were now developing machine tools as well as measuring machines. With a grant from the British Government, he established the Cranfield Unit for Precision Engineering (CUPE). 
The original Metrology Group at Livermore never bothered to change its name, but agreed that Precision Engineering is a much more descriptive term. One definition is that "precision engineering skills are needed whenever geometric tolerances are perceived as being impossible, too difficult, or too expensive to achieve."

\section{The Precision Engineering Program Era at LLNL:}

\section{$1978-1988$}

While precision engineering took hold as a direct result of substantial programmatic need, it was supported by Materials Fabrication Division/Engineering discretionary funds (a tax on program funds) to maintain the core competencies. In 1978, Ray McClure observed a cultural change at LLNL and further observed that these discretionary funds were beginning to disappear. He proposed the formation of the Precision Engineering Program (PEP) within Engineering.

The PEP was to preserve and grow specific core competencies and to form a self-sustaining organization to establish partnerships with government agencies and private industry.

PEP accomplished these goals and, through the Machine Tool Task Force (MTTF) and Precision Machining Commercialization (PMC) projects, was able to assist in the establishment of an American industrial sector that now offers diamond turning machines as catalog selections rather than custom-built, oneof-a-kind precision instruments.

These commercially available machine tools have enabled the mass production of hard memory disks, VCR components, and diamond turned optics for use in military and consumer goods. The PEP was also instrumental in the creation of the American Society for Precision Engineering (ASPE), which now hosts two technical meetings each year and has more than 600 active members.

By far the most significant accomplishment of PEP was the design and construction of the Large Optics Diamond Turning Machine (LODTM) for the Strategic Defense Initiative/ Ballistic Missile Defense Organization (SDI/ BMDO) Program. The LODTM is a vertical axis turning machine capable of turning a 64-in.diameter part weighing $3000 \mathrm{lb}$ to a contour accuracy of $4 \mu \mathrm{in}$. Its single-point diamond cutting tool is positioned by seven Michelson-type laser interferometers operating in vacuum and attached to a temperature-controlled kinematically-mounted metrology frame to ensure its stability during long cutting cycles. The entire machine tool is isolated from ground vibrations by pneumatic cylinders, and enclosed within three walls of thermal and acoustic isolation.

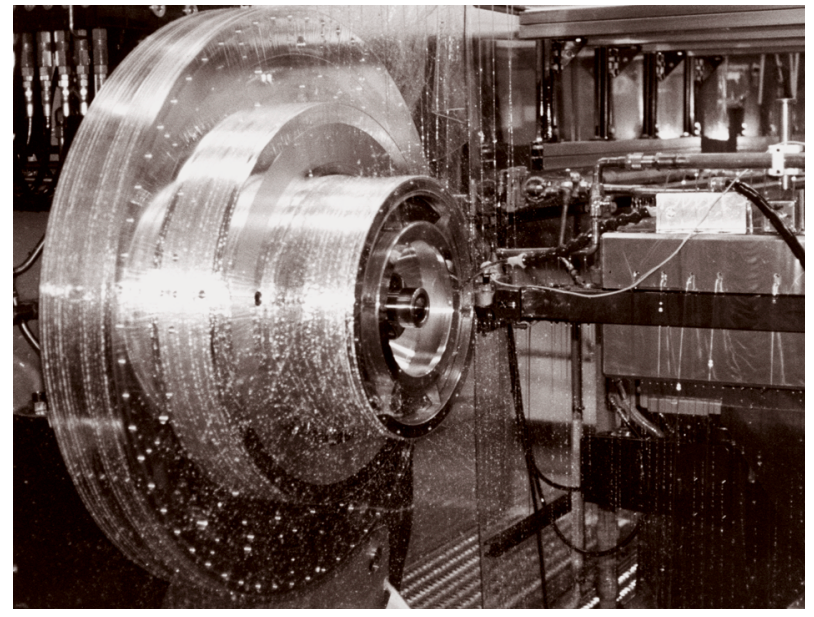

DTM-3 shown machining an astronomical telescope with the oil shower running to maintain temperature control, circa 1985.

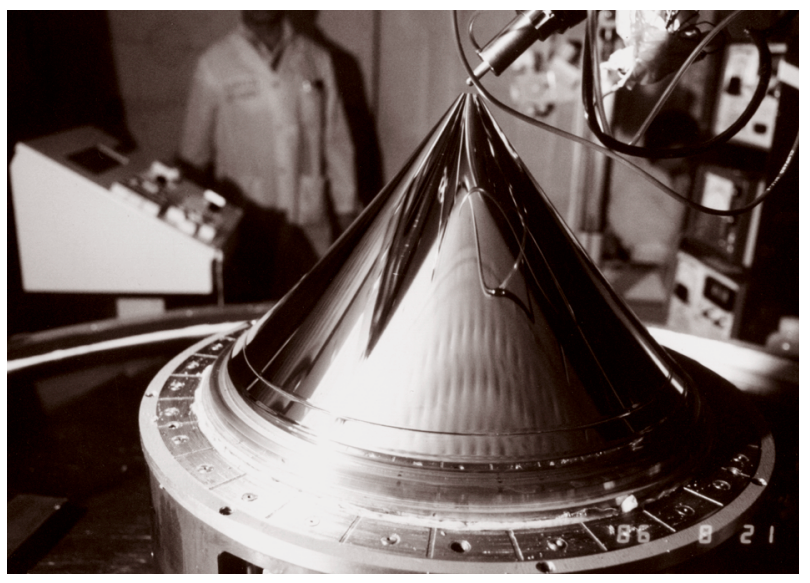

Aspheric cone machined for SDI by the Large Optics Diamond Turning Machine (LODTM), circa 1986. 


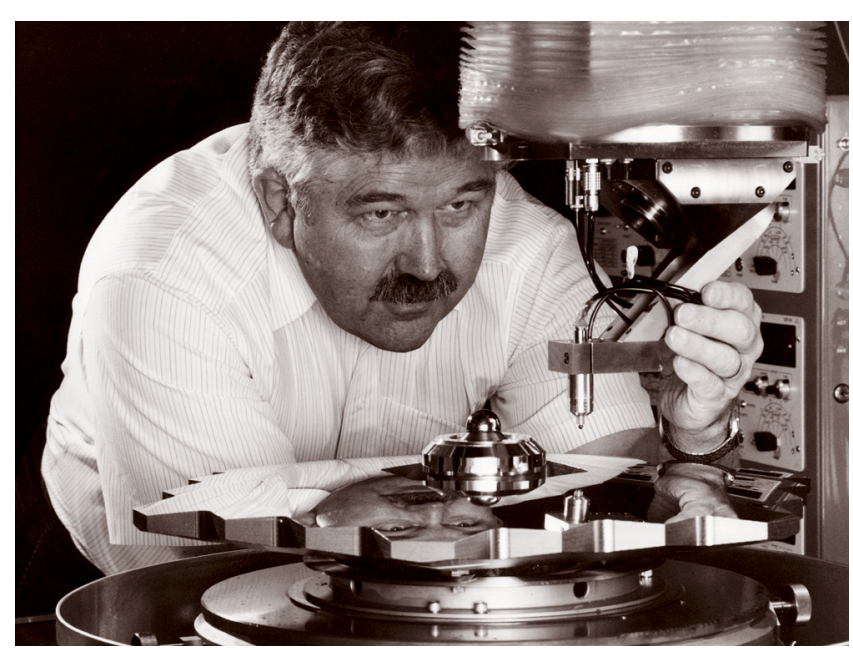

Bob Donaldson examines the metrology set-up to confirm the contour accuracy of a secondary mirror for the Keck Observatory in Hawaii, circa 1991. In 1995 Bob received the Leonardo da Vinci Award from ASME for his work on the Large Optics Diamond Turning Machine.

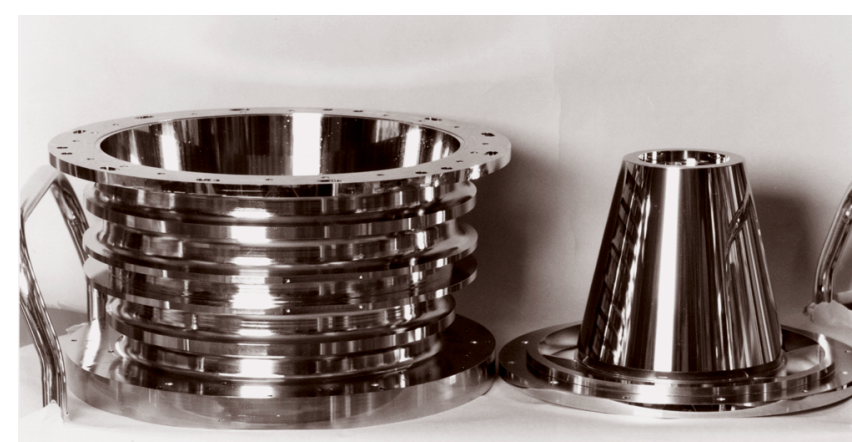

Inner and outer cone of EUVE astronomical telescope optics that was machined on DTM-3 in 1985 and launched as part of the EUV Explorer optical package in 1992.
LODTM is still acknowledged as the world's most accurate large machine tool and has been used to machine precision optics for the Keck Astronomical Observatory in Hawaii. Most recently, LODTM demonstrated the ability to directly machine large single crystal silicon optics to $\mu$ in. accuracy for the BMDO Program.

Simultaneous with the growth of the PEP to perform Work For Others, was a significant growth in programmatic work, including the construction of the Precision Engineering Research Lathes (PERL), capable of diamond turning small metal optics to a surface finish of $0.040 \mu \mathrm{in} .(1 \mathrm{~nm})$; the Baby Optics Diamond Turning Machine used for beryllium machining to $\mu$ in. accuracy; and precision grinding of aerogel components for the Laser Program.

\section{After the Cold War:}

\section{9-2002}

The end of the Cold War was a high-water mark for precision engineering, bringing a slow demise in funding for PEP and LODTM. As Defense Programs terminated underground testing and moved to the use of computers as simulation tools, the need for in-house precision machine tools significantly declined.
Currently, the majority of precision engineering work is being done within Laboratory Programs using many of the same engineers, optical designers, and technicians who previously designed and built precision metrology instruments and precision machine tools. The engineering matrix system is working as intended, and those highly skilled precision engineers who received their apprenticeship during the construction of the DTM machines, LODTM, PERL, and COP are now fully employed in the direct support of Programs whose technology is dependent on the precision engineering core competencies.

For example, PEP and the initial X-ray Lithography Program worked together with LDRD and Engineering Research funds to understand how to construct and measure normal incidence $x$-ray optics.

PEP has had a long history working with the Laser program, beginning with the diamond turning of grazing incidence diagnostic optics and later the diamond flycutting of KDP crystals for laser frequency conversion. Machines designed and built by the Precision Machine Tools Group at LLNL were able to achieve the necessary ultra smooth surfaces of $<2 \mathrm{~nm}$ rms and flatness of $<2 \mu \mathrm{m}$ for the full $42 \mathrm{~cm}$ aperture, while maintaining the crystallographic orientation necessary for high frequency conversion efficiency. 
Recent PEP history includes its merging into the Energy, Manufacturing and Transportation Technologies Program (EMATT), the transfer of PEP to the Energy Directorate in 1993, and its transfer back to Engineering in 2001. The association of PEP with the Energy Directorate emphasized its role as a technology transfer organization and during this time the core competencies were maintained within MMED and the major laboratory programs.

The fundamental need for precision is based upon a need to construct machines or mechanical devices with predictable motions smaller than the wavelength of light, despite the large physical size of the device. It is not uncommon for precision devices to be capable of delivering reliable and repeatable 10-nm motion over a working distance of 1-m (a dynamic range of 108:1).

There is no reason to believe that the Laboratory's need for precision will lessen in the future and every reason to believe that technical progress will be determined by an ability to achieve increased precision.

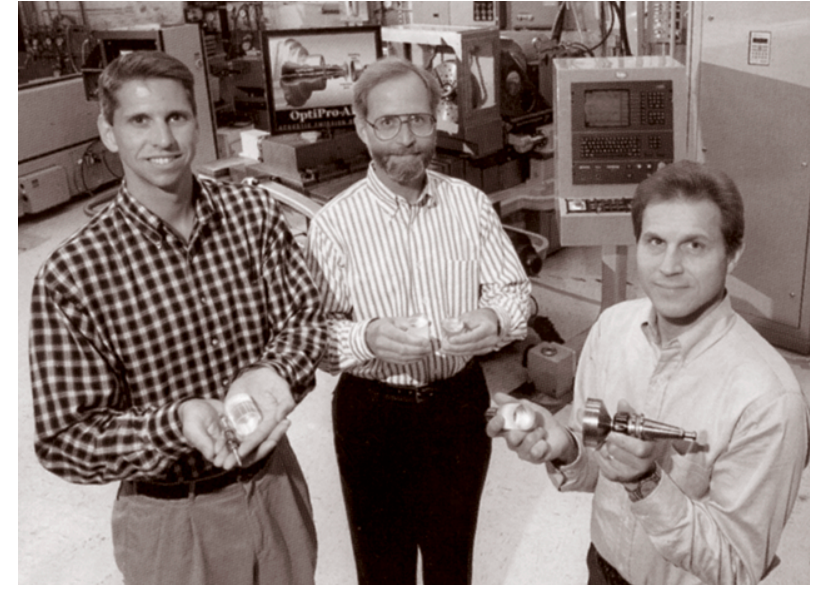

Mark Piscotty, John S. Taylor, and Kenneth Blaedel hold precision ground optics and the acoustic emission proximity sensor that won an R\&D100 award in 1998

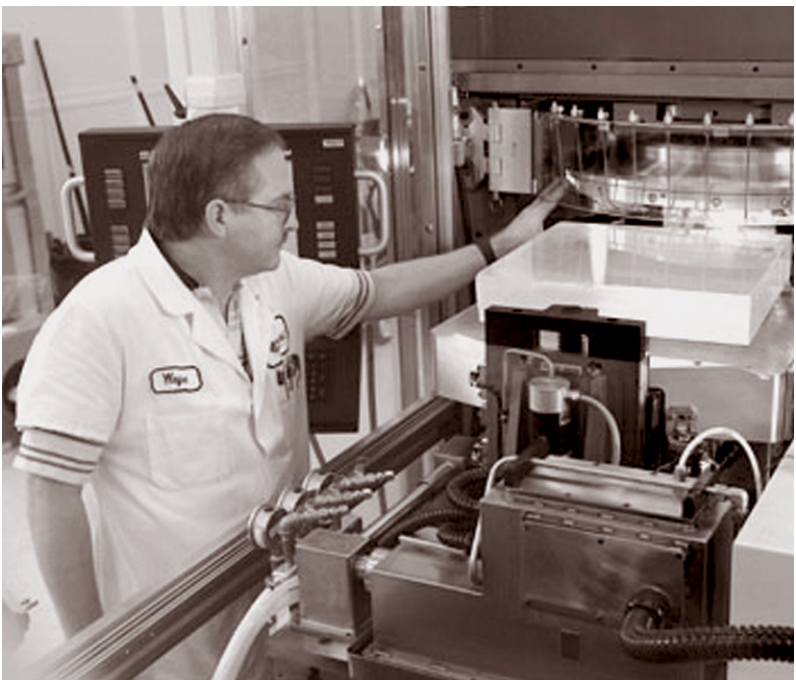

Wayne Brocious cutting a KDP crystal on a fly-cutting machine.

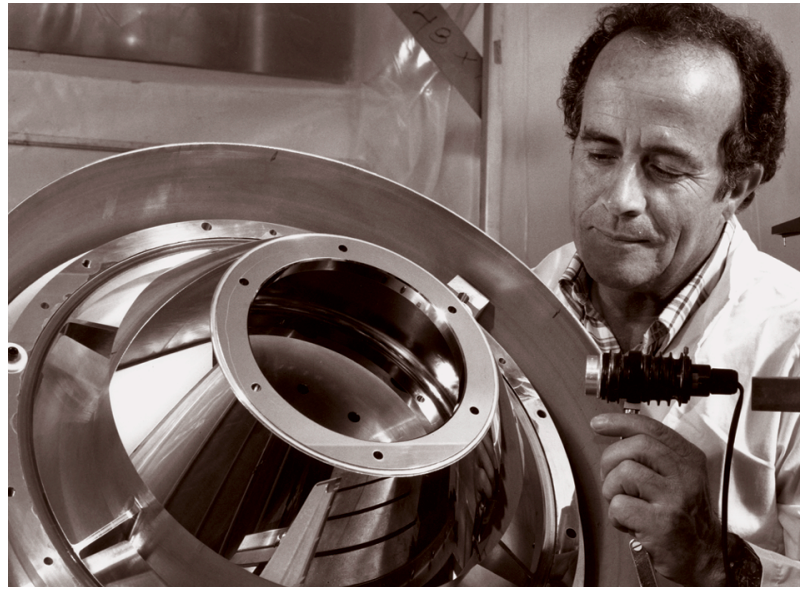

Tony Demiris examines the polished surface of one of three EUVE astronomical telescopes that had been machined and polished by LLNL and then assem bled by the Space Science Lab at UC Berkeley, launched by NASA in 1992, and reentered the atmosphere in February 2002. 
Engineering Coniributions to Mlougnetic I'usion Linergy Research by Carl Henning

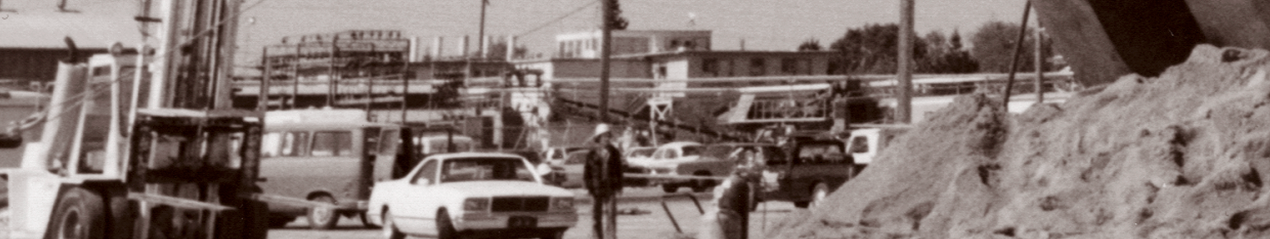


rom the earliest days of Magnetic Fusion Energy Research there have been many enabling developments made by engineers at LLNL. Without these advances in engineering technology it would not have been possible to advance the research so dramatically.

While magnetic fusion energy has not yet been achieved in the Laboratory after 40 years of work, confinement of the hydrogen plasmas has been improved by six orders of magnitude.

Ultra-High Vacuum was one of the first technologies to make a contribution. The high-temperature hydrogen plasmas could not be sustained in the presence of other energy-robbing neutral gases. Thus, all-metal enclosures with aluminum foil vacuum flanges were developed to replace more leaky rubber O-rings. Baking methods were devised to clean residual gases from the container surfaces and metal walls. Together with liquid helium-cooled cryo-pumps operating as low as $2^{\circ} \mathrm{K}$, it became possible to condense unwanted gases to produce vacuum conditions better than one-billionth of a Torr (about onetrillionth of atmospheric pressure).

Finite-element codes, such as FORCE and EFFI, were developed by Livermore engineers to help design the magnets that were needed to insulate the fusion plasmas from the cooling walls of the vacuum chambers. As modern computers were developed, the capabilities of these magnetic field codes were combined with stress

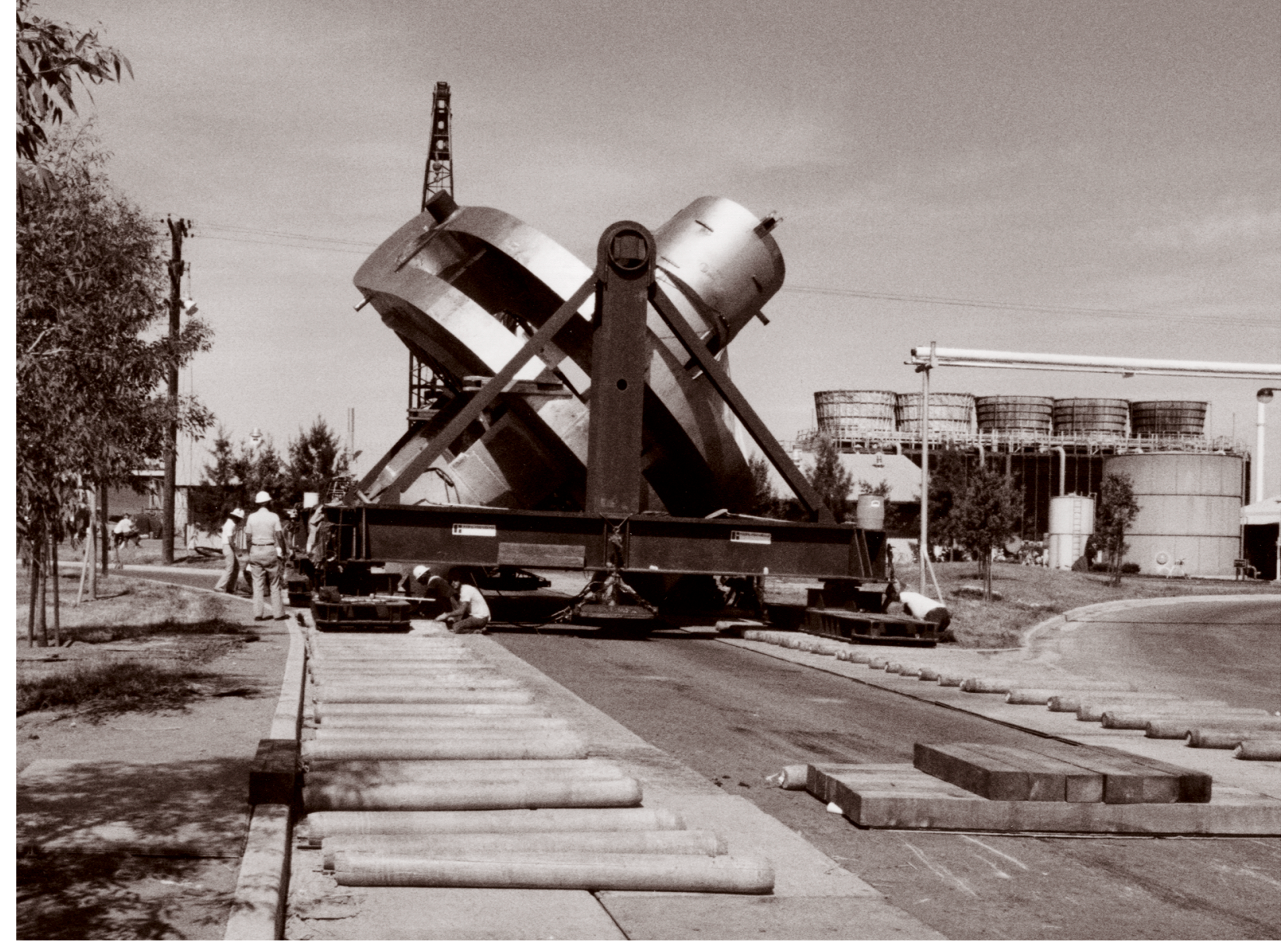

Mirror Fusion Test Facility's yin-yang magnet being transported on wood rollers.

Left: The yin-yang magnet prior to being moved onto its transporter. 


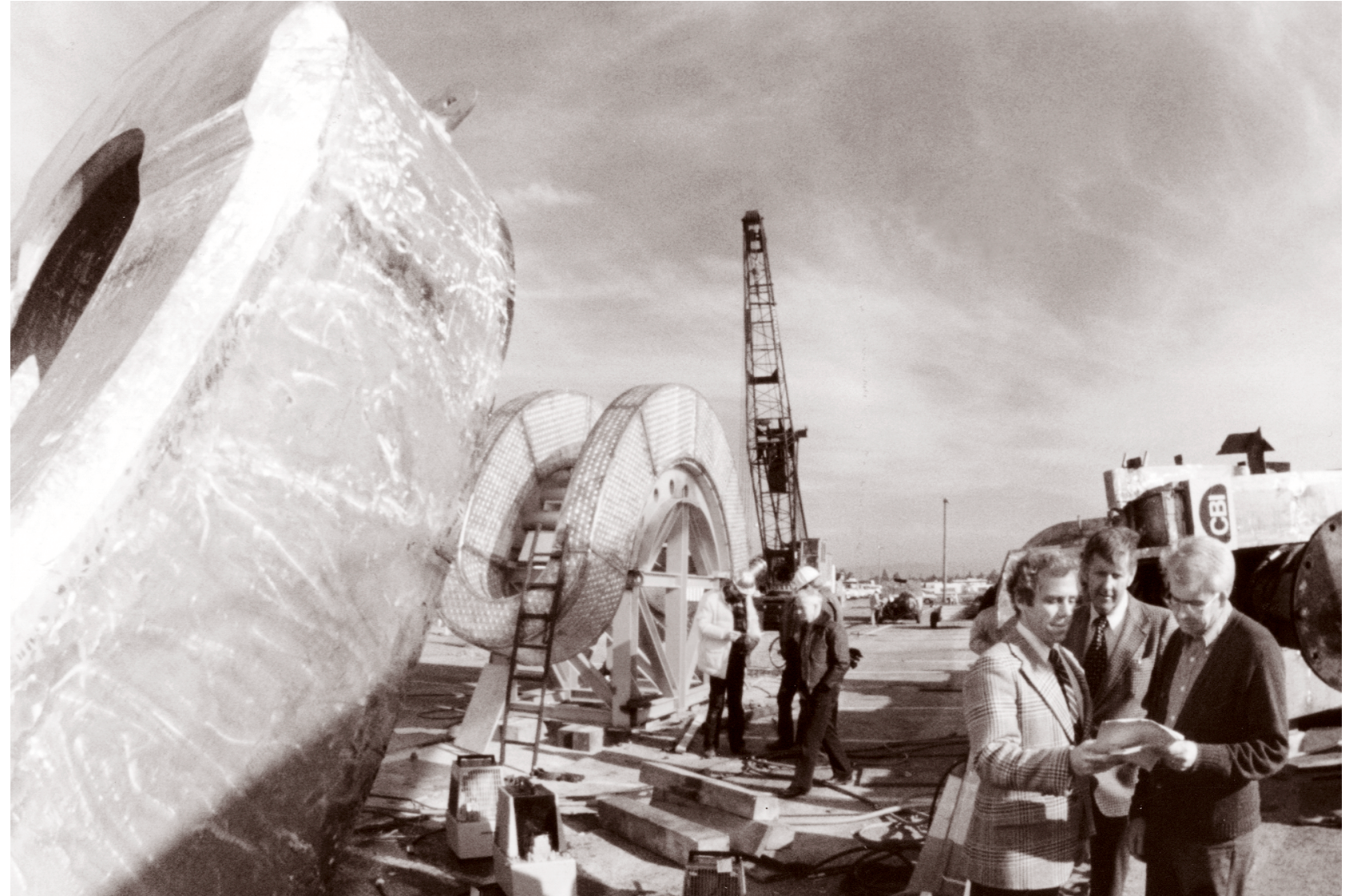

Carl Henning (Deputy Project Manager), Jeff Hodges (Engineer), and Ken Fowler (Fusion Energy Associate Director) reviewing plans for the placement of the yin-yang magnet, Mirror Fusion Test Facility. finite-element codes such as DYNA to design and build electromagnets of unprecedented size and strength.

Cryogenic magnets (such as Baseball) cooled with liquid nitrogen at $77^{\circ} \mathrm{K}$ were constructed to produce magnetic fields (at the winding) up to 4 T. Then, larger superconducting magnets (such as Baseball II) immersed in liquid helium at $4^{\circ} \mathrm{K}$ were developed with magnetic fields up to $6 \mathrm{~T}$. Soon whole buildings were filled with 400-ton magnets, such as MFTF, that achieved $8 \mathrm{~T}, 12 \mathrm{~T}$ in the smaller choke coils made of niobium tin.

Special cryogenic structural materials were needed to withstand the magnetic-induced stresses up to $100 \mathrm{ksi}$. A low ferrite nitronic steel (21-6-9) developed for Baseball II was given the Lincoln Welding Award by Inconel for the methods to join it. Further advances in cryogenic structural development were achieved with the MFTF. A low ferrite $304 \mathrm{LN}$ stainless steel was joined with 316 stainless steel electrodes with carefully controlled ferrite for strength and fracture toughness. This structure received the first prize in the national Lincoln Welding competition.

Many of these fusion engineers and their developments have subsequently contributed to other areas of energy research and to industry. 


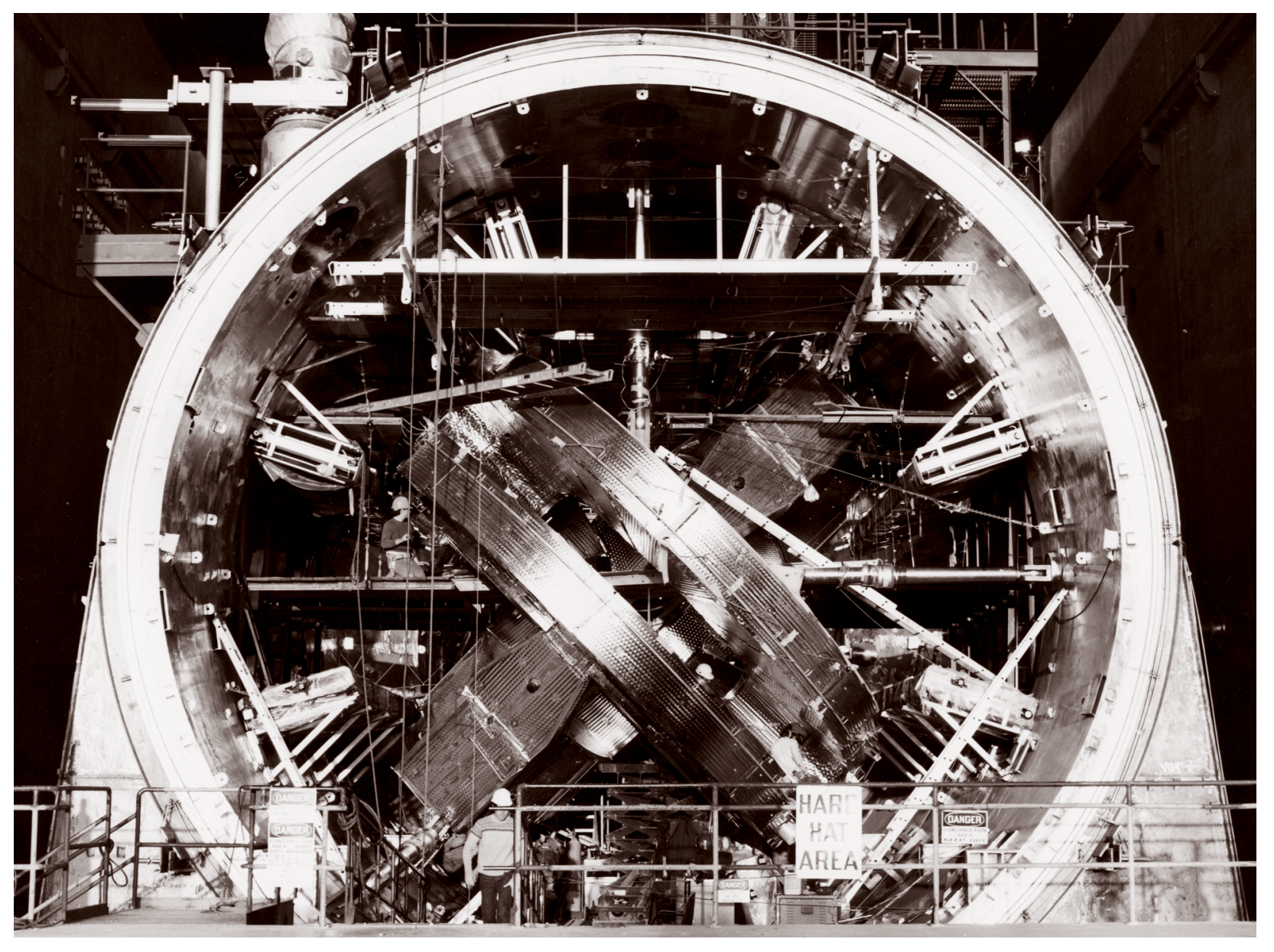

For after all is said and done, Engineering's primary assets were and are its people. 

Technical Editor Ed Lafranchi

Editor

Camille Minichino

Graphic Designer Lucy Dobson

Art Staff

Jeff Bonivert

Irene Chan

JUNE 2002

ENG-02-0076-AD 


\section{ENGINEERING}

University of California

Lawrence Livermore National

Laboratory
P.O. Box 808, L-15

Livermore, CA 9455

www-eng.IInl.gov 